\title{
WestVirginiaUniversity
}

THE RESEARCH REPOSITORY @ WVU

Graduate Theses, Dissertations, and Problem Reports

2000

\section{Carbon products from coal liquefaction fractions}

\author{
Lizbeth Laureano-Perez \\ West Virginia University
}

Follow this and additional works at: https://researchrepository.wvu.edu/etd

\section{Recommended Citation}

Laureano-Perez, Lizbeth, "Carbon products from coal liquefaction fractions" (2000). Graduate Theses, Dissertations, and Problem Reports. 1081.

https://researchrepository.wvu.edu/etd/1081

This Thesis is protected by copyright and/or related rights. It has been brought to you by the The Research Repository @ WVU with permission from the rights-holder(s). You are free to use this Thesis in any way that is permitted by the copyright and related rights legislation that applies to your use. For other uses you must obtain permission from the rights-holder(s) directly, unless additional rights are indicated by a Creative Commons license in the record and/ or on the work itself. This Thesis has been accepted for inclusion in WVU Graduate Theses, Dissertations, and Problem Reports collection by an authorized administrator of The Research Repository @ WVU. For more information, please contact researchrepository@mail.wvu.edu. 


\title{
Carbon Products from Coal Liquefaction Fractions
}

\author{
Lizbeth Laureano-Perez
}

Thesis submitted to the College of Engineering and Mineral Resources

at West Virginia University in partial fulfillment of the requirements

for the degree of

\author{
Master of Science \\ in \\ Chemical Engineering \\ John W. Zondlo, Ph.D., Chair \\ Peter G. Stansberry, Ph.D. \\ Alfred H. Stiller, Ph. D. \\ Anthony V. Cugini, Ph.D. \\ Department of Chemical Engineering \\ Morgantown, WV \\ 2000
}

Keywords: Coal, Carbon Products, Coal Liquefaction

Copyright 2000 Lizbeth Laureano-Perez 


\section{ABSTRACT \\ Carbon Products from Coal Liquefaction Fractions}

\section{Lizbeth Laureano-Perez}

Processes for coal conversion are being evaluated for the development of carbonproduct precursors. It is known that through suitable reaction conditions many carbon products, such as coke, activated carbons, and specialty carbon materials can be produced from coal. In the present work, coal hydrogenation is being considered as a procedure for tailoring the properties of the precursors for specific carbon products. The object of this project is to assess and evaluate such coal-derived materials for use as precursors for the production of carbon products. The work is a joint program between the Department of Energy/ National Energy Technology Laboratory (DOE/NETL) and The West Virginia University Chemical Engineering Department. Coal liquefaction samples are made at NETL under various processing conditions, e.g. temperature, pressure, solvent. Softening points, ash content and coking values of the samples are determined at WVU by ASTM methods. These samples were also examined for coke microstructure and mesophase formation under the optical microscope at WVU. It was found that the asphaltene fraction is an especially attractive precursor and its properties can be tailored by varying the hydrogenation conditions. In general, there is a difference in behavior between products derived exclusively from coal (coal and coal-derived solvent) and those generated from a combination of coal and petroleum oil when materials are produced and compared at the same conditions. The optical texture for the cokes of the asphaltene fraction showed larger anisotropic domains as the reaction temperature was increased for the coal-derived solvent. The use of petroleum-derived solvent produced isotropic cokes with little or no optical activity. The most favorable liquefaction conditions for the production of an acceptable coal-tar binder pitch are the use of V-1074 (coal-derived) solvent at $390^{\circ} \mathrm{C}$ and $1000 \mathrm{psig}$. These conditions produce an asphaltene fraction with low ash $(0.02 \%)$, a proper softening point $\left(114.7^{\circ} \mathrm{C}\right)$ but with a low coking value $(32 \%)$. Coal-derived (using coal and coal-derived solvent) anisotropic coke is another promising material that could be obtained from this asphaltene fraction. 


\section{ACKNOWLEDGEMENTS}

Financial support is acknowledged by DOE contract DE-FC26-98FT40143 through the University of Pittsburgh. Thanks to R. Hirsh, J Brannen, and R. Rokicki of Parsons Project Services, Inc. who performed the semi-batch unit operation and preliminary solvent extraction work at DOE/NETL.

I would also like to recognize my advisor John W. Zondlo for his help and support along during the duration of my research. Thanks to Dr. Cugini for his efforts in obtaining the samples. Finally, thanks to Dr. Stiller and Dr. Stansberry for their continuous support.

I give special thanks to my best and unconditional friend Alexei, for his patience and encouragement during hard times. I would also like to acknowledge my mom for her love and support. 


\section{Table of Contents}

Content Page

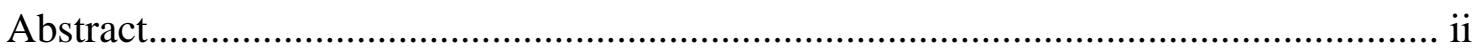

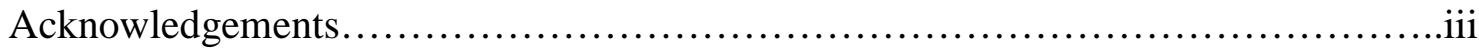

Table of Contents............................................................................................ iv

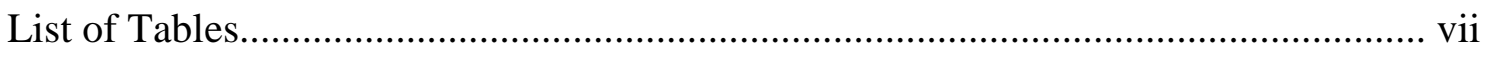

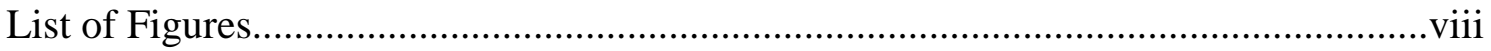

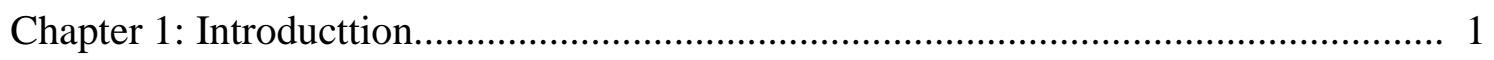

1.1 Carbon Products........................................................................... 1

1.1.1 Uses of Coke..................................................................... 2

1.1.2 Uses of Pitch ............................................................... 2

1.2 Important Characteristics of Carbon Products....................................... 3

1.3 Research Objectives........................................................................ 4

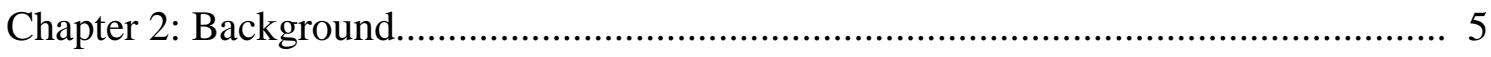

2.1 History of Coal Utilization............................................................... 5

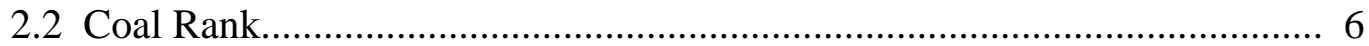

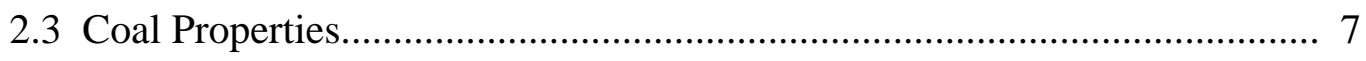

2.4 Coal and Coal-derived Products............................................................. 8

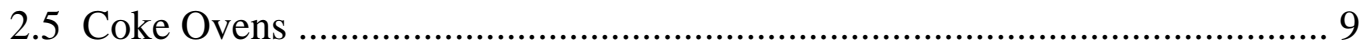

2.5.1 The Future of Coke Ovens.......................................................10

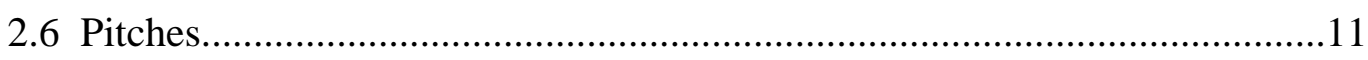

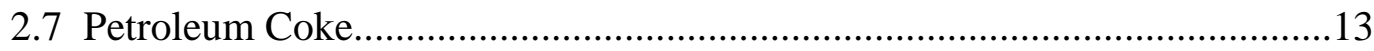

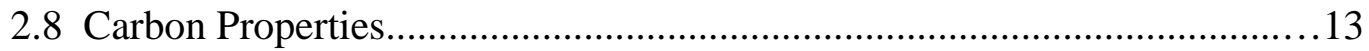

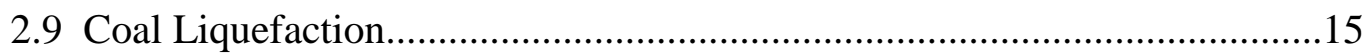

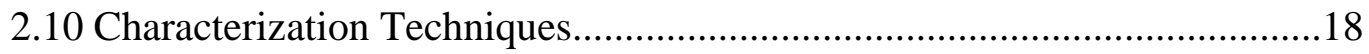

2.10.1 Solvent Extraction............................................................19

2.10.2 Softening Point................................................................... 19

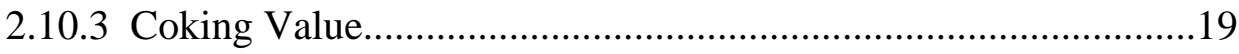

2.10.4 Optical Texture................................................................19

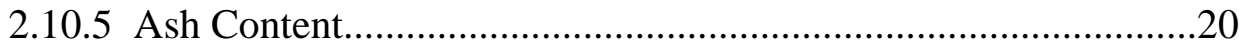


2.10.6 Nuclear Magnetic Resonance and Ultimate Analysis.................20

2.11 Summary Background Remarks................................22

Chapter 3: Experimental Procedure.....................................................................23

3.1 Production Reaction.........................................................................23

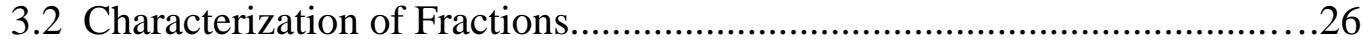

3.2.1 Solvent Fractionation........................................................26

3.2.2 Softening Points.................................................................29

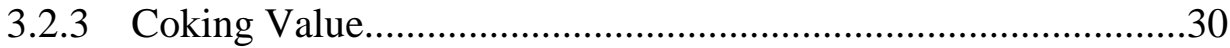

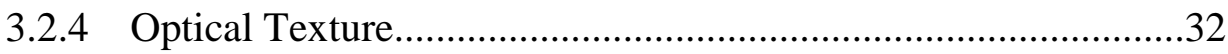

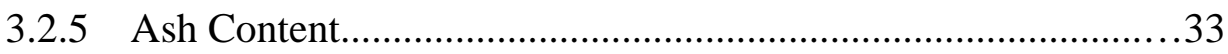

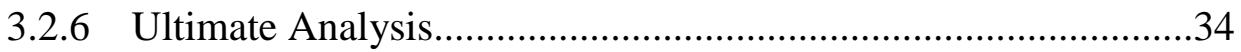

3.2.7 Nuclear Magnetic Resonance....................................................35

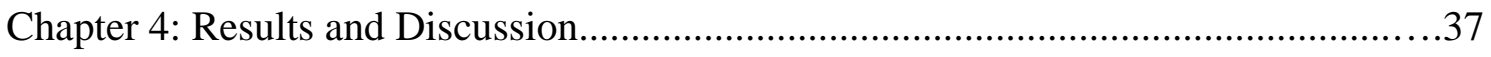

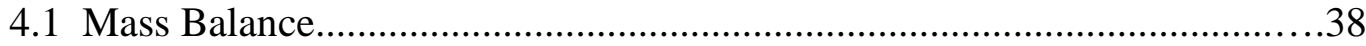

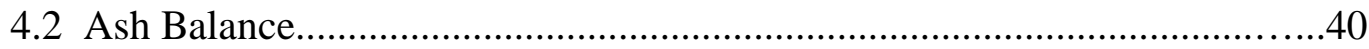

4.3 Parameter Evaluation..........................................43

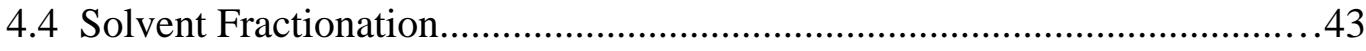

4.4.1 THF Extraction................................................................43

4.4.2 Heptane Extraction............................................................49

4.4.3 Toluene Extraction............................................................53

4.4.4 NMP Extraction.............................................................56

4.5 Liquefaction Fractions Yield.............................................................60

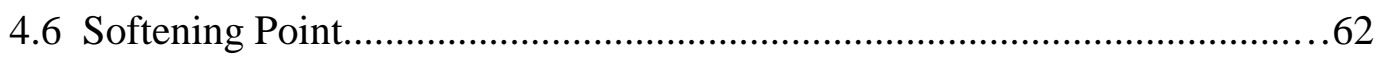

4.7 Coking Value Determination................................................................ 70

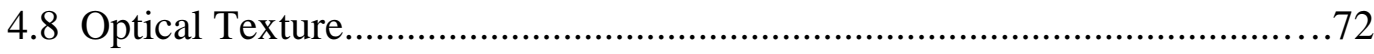

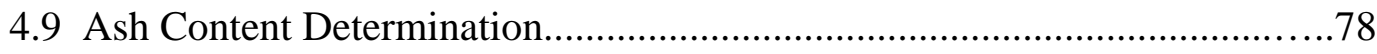

4.10 Ultimate Analysis and NMR Studies............................................... 81

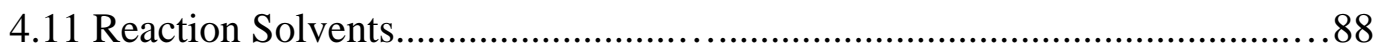

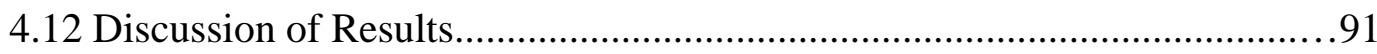

Chapter 5: Conclusions and Recommendations................................................95

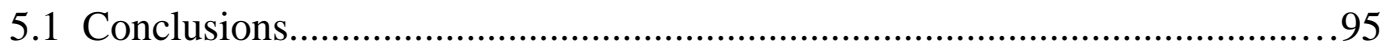


5.2 Recommendations for Future Work..................................................97

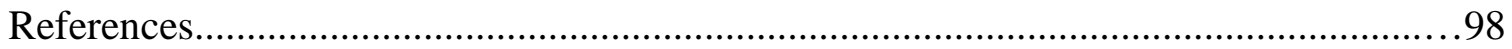

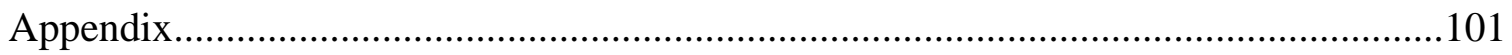

Appendix A: Safety Requirements and Supplies ...........................................102

Appendix B: Micrographs of cokes.............................................................105

Appendix C: Raw Data............................................ 144

Appendix D: Gas Products..........................................150

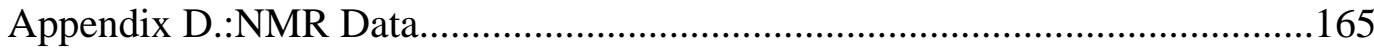

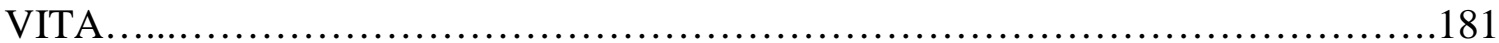




\section{List of Tables}

Page

Table 2.1: The ASTM system for classifying coals by rank........................................ 7

Table 2.2: Characterization tests for coal liquefaction fractions...................................18

Table 3.1: Experimental conditions for liquefaction runs performed at NETL/DOE, Pittsburgh, PA..............................................................24

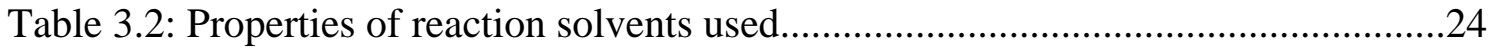

Table 3.3: Ultimate and proximate analysis of Pittsburgh \#8 coal................................25

Table 3.4: Amounts of fractions produced at DOE/NETL for various reaction

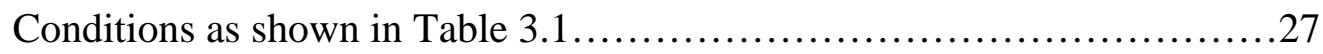

Table 4.1: Overall mass balance of the coal liquefaction reactions..............................39

Table 4.2: Ash balance of the coal liquefaction fraction at all the reaction conditions.

Table 4.3:Optical texture present in the Asphaltene Fraction.....................................76

Table 4.4: Effect of reaction solvent, pressure and temperature on the ash content for reaction with pure $\mathrm{H}_{2}$ gas.

Table 4.5: Effect of $3 \% \mathrm{H}_{2} \mathrm{~S} / 97 \% \mathrm{H}_{2}$ mixture and pressure on ash content using reaction solvent $\mathrm{V}-1074$ and $390^{\circ} \mathrm{C}$.

Table 4.6: Effect of reaction temperature on ash content using reaction solvent $\mathrm{V}-1074$ and $3 \% \mathrm{H}_{2} \mathrm{~S} / 97 \% \mathrm{H}_{2}$ gas phase....................................81

Table 4.7: $\mathrm{H} / \mathrm{C}$ for the asphaltene fractions at 1000 psig of $\mathrm{H}_{2}$ using $\mathrm{V}-1074 \ldots \ldots \ldots \ldots . . . .85$

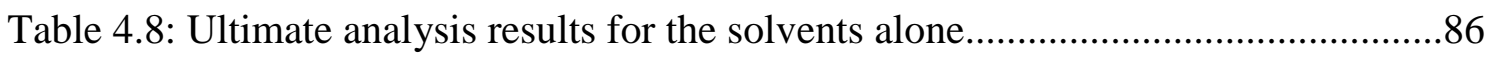

Table C.1: Raw Data..................................................... 145

Table D.1: Gas Products.................................................. 151 


\section{List of Figures}

Page

Figure 2.1: Cross-sectional representation of a battery a modern recovery coke oven. .10

Figure 2.2 Schematic diagram of growth and association of mesophase.......................12

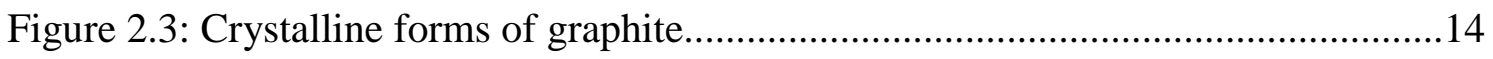

Figure 2.4: Representation of A) isotropic and, B)anisotropic carbon cokes..................15

Figure 2.5: Schematic diagram of a typical direct Coal Liquefaction process................16

Figure 3.1: Rotary evaporator used for solvent removal..........................................27

Figure 3.2: Soxhlet extraction system for the preasphaltene

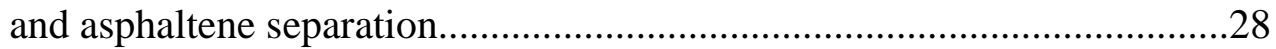

Figure 3.3: Solvent fractionation scheme followed by DOE/NETL and WVU.............29

Figure 3.4: Mettler Softening Point Apparatus...........................................................30

Figure 3.5: Apparatus for determining Conradson Carbon Residue (Coking Value) via ASTM D-189

Figure 3.6: Mesophase in the oil fraction from liquefaction run at $390^{\circ} \mathrm{C}$ and 1500 psig $\mathrm{H}_{2}$ using $\mathrm{V}-1074$ as a solvent

Figure 4.1: Effect of reaction temperature, pressure and solvent on the product solubility in THF for liquefaction in the presence of $\mathrm{H}_{2}$ gas.

Figure 4.2: Effect of pressure on the product solubility in THF with solvent $\mathrm{V}-1074$ and $\mathrm{H}_{2}$ at $425^{\circ} \mathrm{C}$ .46

Figure 4.3: Effect of $3 \% \mathrm{H}_{2} \mathrm{~S} / 97 \% \mathrm{H}_{2}$ mixture at various pressures on the THF solubility at $390^{\circ} \mathrm{C}$ and reaction solvent V-1074.

Figure 4.4: Effect of reaction temperature and pressure on THF solubility with reaction solvent $\mathrm{V}-1074$ and $3 \% \mathrm{H}_{2} \mathrm{~S} / 97 \% \mathrm{H}_{2}$.

Figure 4.5: Effect of temperature on heptane solubility of THF-soluble fraction at various reaction conditions in $\mathrm{H}_{2}$. .50

Figure 4.6: Effect of reaction pressure on heptane solubility at $425^{\circ} \mathrm{C}$ of THFsoluble fraction and using reaction solvent V-1074 and gaseous $\mathrm{H}_{2}$.

Figure 4.7: Effect of $\mathrm{H}_{2} \mathrm{~S} / \mathrm{H}_{2}$ mixture on heptane solubility of THF-soluble fraction with reaction solvent $\mathrm{V}-1074$ and $390^{\circ} \mathrm{C}$ 
Figure 4.8: Effect of temperature and pressure on heptane solubility of THFsoluble fraction with $\mathrm{V}-1074$ and $3 \% \mathrm{H}_{2} \mathrm{~S} / \mathrm{H}_{2}$ mixture. .54

Figure 4.9: Effect of reaction temperature, $\mathrm{H}_{2}$ pressure and solvent on toluene solubility of heptane-insoluble fraction and the production of asphaltene fraction.....55

Figure 4.10: Effect of reaction pressure on toluene solubility of heptane-insoluble fraction with solvent $\mathrm{V}-1074$ and $425^{\circ} \mathrm{C}$

Figure 4.11: Effect of the $\mathrm{H}_{2} \mathrm{~S}$ gas mixture on the Toluene Solubility of heptaneinsoluble fraction and for the production of asphaltene fraction with V-1074 at $390^{\circ} \mathrm{C}$. .58

Figure 4.12: Effect of Reaction Pressure on Toluene Solubility of the heptane-insoluble fraction using the reaction solvent $\mathrm{V}-1074$ and the $\mathrm{H}_{2} \mathrm{~S}$ mixture. .59

Figure 4.13: Effect of reaction temperature and pressure on liquefaction fraction yields at various reaction conditions with pure $\mathrm{H}_{2}$ gas based on the total mass (coal and solvent ) fed to the reactor.

Figure 4.14: Effect of $3 \% \mathrm{H}_{2} \mathrm{~S} / \mathrm{H}_{2}$ mixture on the liquefaction fraction yields with $\mathrm{V}-1074$ and $390^{\circ} \mathrm{C}$ based on the total mass (coal and solvent) fed to the reactor.

Figure 4.15: Effect of reaction temperature and pressure on liquefaction fraction yields with $\mathrm{V}-1074$ and the $3 \% \mathrm{H}_{2} \mathrm{~S}$ mixture based on the total mass (coal and solvent) fed to the reactor.

Figure 4.16: Effect of reaction temperature, pressure and solvent on softening point using pure $\mathrm{H}_{2}$ gas

Figure 4.17: Effect of reaction temperature on softening point with reaction solvent $\mathrm{V}-1074$ and $1000 \mathrm{psig}_{2}$ .67

Figure 4.18: Effect of $3 \% \mathrm{H}_{2} \mathrm{~S} / \mathrm{H} 2$ gas mixture at 1000 psig on the softening point using the reaction solvent $\mathrm{V}-1074$ and $390{ }^{\circ} \mathrm{C}$ .68

Figure 4.19: Variation of softening point with reaction temperature and pressure using solvent V-1074 and the mixture of $3 \% \mathrm{H}_{2} \mathrm{~S} / \mathrm{H}_{2}$ gas

Figure 4.20: Variation of the coking value with reaction temperature, pressure and solvent using pure $\mathrm{H}_{2}$ in the gas phase 
Figure 4.21: Effect of $\mathrm{H}_{2} \mathrm{~S}$ mixture and reaction pressure on coking value using reaction solvent $\mathrm{V}-1074$ and $390^{\circ} \mathrm{C}$.

Figure 4.22: Effect of reaction temperature and pressure on coking value of the various fractions using solvent V-1074 and the gas mixture of $3 \% \mathrm{H}_{2} \mathrm{~S} / \mathrm{H}_{2}$ .74

Figure 4.23: Micrographs of cokes made from the asphaltene fraction with reaction conditions of 1500 psig: a)Hondo and $350^{\circ} \mathrm{C}$; b) $\mathrm{V}-1074$ and $350^{\circ} \mathrm{C}$;

c) Hondo and $390^{\circ} \mathrm{C}$; d) $\mathrm{V}-1074$ and $390^{\circ} \mathrm{C}$; e) Hondo and $425^{\circ} \mathrm{C}$; f) $\mathrm{V}-1074$ and $425^{\circ} \mathrm{C}$

Figure 4.24: Effect of reaction temperature on carbon content in the asphaltene fraction using solvent V-1074 and 1000 psig of $\mathrm{H}_{2}$

Figure 4.25: Effect of temperature on the content of sulfur, nitrogen, oxygen and hydrogen in the asphaltene fraction using solvent V-1074 and 1000 psig of $\mathrm{H}_{2}$ 84

Figure 4.26: Comparison of the protonated and alkyl substituted aromatic carbons present in the asphaltene fraction as a function of reaction temperature. Reaction solvent is V-1074 and the gas phase is pure $\mathrm{H}_{2}$. .87

Figure 4.27: Graph of $\mathrm{sp}^{2}$ to $\mathrm{sp}^{3}$ carbon ratio in the asphaltene fraction as a function of reaction temperature using the reaction solvent V-1074, 1000 psig and $\mathrm{H}_{2}$ in the gas phase.

Figure 4.28: Effect of reaction temperature on solid and liquid state aromaticity determination for the asphaltene fraction. $13 \mathrm{C}$ and $1 \mathrm{H}$ are analysis performed in the liquid-state sample and $\mathrm{CP}$ and SP are done in the the fraction solid-state. .90

Figure B.1: BCP- 393, THF Insolubles with reaction conditions of:

Solvent: V-1074; $390{ }^{\circ} \mathrm{C} 1500$ psig $\mathrm{H}_{2}$ .106

Figure B.2: BCP- 393, Heptane Insolubles with reaction conditions of:

Solvent: V-1074; $390{ }^{\circ} \mathrm{C} ; 1500$ psig $\mathrm{H}_{2}$ .106

Figure B.3: BCP- 393, Heptane Solubles with reaction conditions of:

Solvent: V-1074; $390{ }^{\circ} \mathrm{C} ; 1500$ psig $\mathrm{H}_{2}$ .106 
Figure B.4: BCP- 393, Heptane Insoluble and Toluene Insoluble with reaction conditions of: Solvent: V-1074; $390{ }^{\circ} \mathrm{C} ; 1500$ psig $\mathrm{H}_{2}$ 107

Figure B.5: BCP- 393, Heptane Insoluble and Toluene Soluble with reaction conditions of: Solvent: V-1074; $390^{\circ} \mathrm{C} ; 1500$ psig $\mathrm{H}_{2}$. 107

Figure B.6: BCP- 394, THF Insolubles with reaction conditions of:

Solvent: Hondo; $390{ }^{\circ} \mathrm{C} ; 1500$ psig $\mathrm{H}_{2}$ 108

Figure B.7: BCP- 394, Heptane Insolubles with reaction conditions of:

Solvent: Hondo; $390{ }^{\circ} \mathrm{C}$; 1500 psig $\mathrm{H}_{2}$ 108

Figure B.8: BCP- 394, Heptane Solubles with reaction conditions of:

Solvent: Hondo; $390^{\circ} \mathrm{C} ; 1500$ psig $\mathrm{H}_{2}$ 108

Figure B.9: BCP- 394, Heptane Insoluble and Toluene Insoluble with reaction conditions of: Solvent: Hondo; $390{ }^{\circ} \mathrm{C} ; 1500$ psig $\mathrm{H}_{2}$.

Figure B.10: BCP- 394, Heptane Insoluble and Toluene Soluble with reaction conditions of: Solvent: Hondo; $390^{\circ} \mathrm{C} ; 1500$ psig $\mathrm{H}_{2}$

Figure B.11: BCP- 395, THF Insolubles with reaction conditions of:

Solvent: V-1074; $350{ }^{\circ} \mathrm{C} ; 1500$ psig $\mathrm{H}_{2}$

Figure B.12: BCP- 395, Heptane Insolubles with reaction conditions of:

Solvent: V-1074; $350{ }^{\circ} \mathrm{C} ; 1500$ psig $\mathrm{H}_{2}$

Figure B.13: BCP- 395, Heptane Solubles with reaction conditions of:

Solvent: V-1074; $350{ }^{\circ} \mathrm{C} ; 1500$ psig $\mathrm{H}_{2}$

Figure B.14: BCP- 395, Heptane Insoluble and Toluene Insoluble with reaction conditions of: Solvent: V-1074; $350^{\circ} \mathrm{C} ; 1500$ psig $\mathrm{H}_{2}$

Figure B.15: BCP- 395, Heptane Insoluble and Toluene Soluble with reaction conditions of: Solvent: V-1074; $350^{\circ} \mathrm{C} ; 1500$ psig $\mathrm{H}_{2}$

Figure B.16: BCP- 396, THF Insolubles with reaction conditions of:

Solvent: Hondo; $350^{\circ} \mathrm{C} ; 1500$ psig $\mathrm{H}_{2}$

Figure B.17: BCP- 396, Heptane Insolubles with reaction conditions of:

Solvent: Hondo; $350^{\circ} \mathrm{C} ; 1500$ psig $\mathrm{H}_{2}$

Figure B.18: BCP- 396, Heptane Solubles with reaction conditions of:

Solvent: Hondo; $350{ }^{\circ} \mathrm{C} ; 1500$ psig $\mathrm{H}_{2}$ 
Figure B.19: BCP- 396, Heptane Insoluble and Toluene Insoluble with reaction conditions of: Solvent: Hondo; $350^{\circ} \mathrm{C} ; 1500$ psig $\mathrm{H}_{2}$

Figure B.20: BCP- 396, Heptane Insoluble and Toluene Soluble with reaction conditions of: Solvent: Hondo; $350^{\circ} \mathrm{C} ; 1500$ psig $\mathrm{H}_{2}$

Figure B.21: BCP- 397, THF Insolubles with reaction conditions of:

Solvent: V-1074; $350{ }^{\circ} \mathrm{C} ; 1000$ psig $\mathrm{H}_{2}$

Figure B.22: BCP- 397, Heptane Insolubles with reaction conditions of:

Solvent: V-1074; $350{ }^{\circ} \mathrm{C} ; 1000$ psig $\mathrm{H}_{2}$

Figure B.23: BCP- 397, Heptane Soluble with reaction conditions of:

Solvent: V-1074; $350{ }^{\circ} \mathrm{C} ; 1000$ psig $\mathrm{H}_{2}$

Figure B.24: BCP- 397, Heptane Insoluble and Toluene Insoluble with reaction

conditions of: Solvent: V-1074; $350^{\circ} \mathrm{C} ; 1000$ psig $\mathrm{H}_{2}$

Figure B.25: BCP- 397, Heptane Insoluble and Toluene Soluble with reaction conditions of: Solvent: V-1074; $350^{\circ} \mathrm{C} ; 1000$ psig $\mathrm{H}_{2}$

Figure B.26: BCP-398, THF Insolubles with reaction conditions of:

Solvent: Hondo; $350^{\circ} \mathrm{C} ; 1000$ psig $\mathrm{H}_{2}$

Figure B.27: BCP-398, Heptane Insoluble with reaction conditions of:

Solvent: Hondo; $350^{\circ} \mathrm{C} ; 1000$ psig $\mathrm{H}_{2}$

Figure B.28: BCP-398, Heptane Soluble with reaction conditions of:

Solvent: Hondo; $350{ }^{\circ} \mathrm{C} ; 1000$ psig $\mathrm{H}_{2}$

Figure B.29: BCP-398, Heptane Insoluble and Toluene Soluble with reaction conditions of: Solvent: Hondo; $350^{\circ} \mathrm{C} ; 1000$ psig $\mathrm{H}_{2}$

Figure B.30: BCP-399, THF Insoluble with reaction conditions of:

Solvent: V-174; $390{ }^{\circ} \mathrm{C} ; 1000$ psig $\mathrm{H}_{2}$

Figure B.31: BCP-399, Heptane Insoluble with reaction conditions of:

Solvent: V-1074; $390{ }^{\circ} \mathrm{C} ; 1000$ psig $\mathrm{H}_{2}$.

Figure B.32: BCP-399, Heptane Soluble with reaction conditions of:

Solvent: V-1074; $390{ }^{\circ} \mathrm{C} ; 1000$ psig $\mathrm{H}_{2}$. .118

Figure B.33: BCP-399, Heptane Insoluble and Toluene Insoluble with reaction conditions of: Solvent: V-1074; $390^{\circ} \mathrm{C} ; 1000$ psig $\mathrm{H}_{2}$ 
Figure B.34: BCP-399, Heptane Insoluble and Toluene Soluble with reaction conditions of: Solvent: V-1074; $390^{\circ} \mathrm{C} ; 1000$ psig $\mathrm{H}_{2}$

Figure B.35: BCP-400, THF Insoluble with reaction conditions of:

Solvent: V-1074; $425^{\circ} \mathrm{C} ; 1000$ psig $\mathrm{H}_{2}$.

Figure B.36: BCP-400, Heptane Insoluble with reaction conditions of

Solvent: V-1074; $425^{\circ} \mathrm{C} ; 1000$ psig $\mathrm{H}_{2}$.....

Figure B.37: BCP-400, Heptane Soluble with reaction conditions of:

Solvent: V-1074; $425^{\circ} \mathrm{C} ; 1000$ psig $\mathrm{H}_{2}$.

Figure B.38: BCP-400, Heptane Insoluble and Toluene Insoluble with reaction conditions of: Solvent: V-1074; $425^{\circ} \mathrm{C} ; 1000$ psig $\mathrm{H}_{2}$

Figure B.39: BCP-400, Heptane Insoluble and Toluene Soluble with reaction conditions of: Solvent: V-1074; $425^{\circ} \mathrm{C} ; 1000$ psig $\mathrm{H}_{2}$

Figure B.40: BCP-401, THF Insoluble with reaction conditions of:

Solvent: V-1074; $425^{\circ} \mathrm{C} ; 1500$ psig $\mathrm{H}_{2}$.

Figure B.41: BCP-401, Heptane Insoluble with reaction conditions of:

Solvent: V-1074; $425^{\circ} \mathrm{C} ; 1500$ psig $\mathrm{H}_{2}$.

Figure B.42: BCP-401, Heptane Soluble with reaction conditions of:

Solvent: V-1074; $425^{\circ} \mathrm{C} ; 1500$ psig $\mathrm{H}_{2}$.

Figure B.43: BCP-401, Heptane Insoluble and Toluene Insoluble with reaction

conditions of: Solvent: V-1074; $425^{\circ} \mathrm{C} ; 1500$ psig $\mathrm{H}_{2}$

Figure B.44: BCP-401, Heptane Insoluble and Toluene Soluble with reaction conditions of: Solvent: V-1074; $425^{\circ} \mathrm{C} ; 1500$ psig $\mathrm{H}_{2}$

Figure B.45: BCP-403, THF Insoluble with reaction conditions of:

Solvent: V-1074; $425^{\circ} \mathrm{C} ; 1500$ psig $\mathrm{H}_{2}$

Figure B.46: BCP-403, Heptane Insoluble with reaction conditions of:

Solvent: V-1074; $425^{\circ} \mathrm{C} ; 1000$ psig $\mathrm{H}_{2}$.

Figure B.47: BCP-403, Heptane Soluble with reaction conditions of:

Solvent: V-1074; $425^{\circ} \mathrm{C} ; 1000$ psig $\mathrm{H}_{2}$.

Figure B.48: BCP-403, Heptane Insoluble and Toluene Insoluble with reaction conditions of: Solvent: V-1074; $425^{\circ} \mathrm{C} ; 1000$ psig $\mathrm{H}_{2}$ 
Figure B.49: BCP-403, Heptane Insoluble and Toluene Soluble with reaction conditions of: Solvent: V-1074; $425^{\circ} \mathrm{C} ; 1000$ psig $\mathrm{H}_{2}$ 125

Fig ure B.50: BCP-404, THF Insoluble with reaction conditions of:

Solvent: V-1074, $425^{\circ} \mathrm{C} 500 \mathrm{psig}_{2}$.......

Figure B.51: BCP-404, Heptane Insoluble with reaction conditions of:

Solvent: V-1074, $425^{\circ} \mathrm{C} 500$ psig $\mathrm{H}_{2}$

Figure B.52: BCP-404, Heptane Soluble with reaction conditions of:

Solvent: V-1074, $425^{\circ} \mathrm{C} 500$ psig $\mathrm{H}_{2}$

Figure B.53: BCP-404, Heptane Insoluble and Toluene Insoluble with reaction conditions of: Solvent: V-1074, $425^{\circ} \mathrm{C} 500$ psig $\mathrm{H}_{2}$.

Figure B.54: BCP-404, Heptane Insoluble and Toluene Soluble with reaction conditions of: Solvent: V-1074, $425^{\circ} \mathrm{C} 500$ psig $\mathrm{H}_{2}$

Figure B.55: BCP-405, THF Insoluble with reaction conditions of:

Solvent: Hondo, $425^{\circ} \mathrm{C} 1500$ psig $\mathrm{H}_{2}$ .128

Figure B.56: BCP-405, Heptane Insoluble with reaction conditions of:

Solvent: Hondo, $425^{\circ} \mathrm{C} 1500$ psig $\mathrm{H}_{2}$

Figure B.57: BCP-405, Heptane Soluble with reaction conditions of:

Solvent: Hondo, $425^{\circ} \mathrm{C} 1500$ psig $\mathrm{H}_{2}$ 128

Figure B.58: BCP-405, Heptane Insoluble and Toluene Insoluble with reaction conditions of: Solvent: Hondo, $425^{\circ} \mathrm{C} 1500$ psig $\mathrm{H}_{2}$

Figure B.59: BCP-405, Heptane Insoluble and Toluene Soluble with reaction conditions of: Solvent: Hondo, $425^{\circ} \mathrm{C} 1500$ psig $\mathrm{H}_{2}$

Figure B.60: BCP-406, THF Insoluble with reaction conditions of:

Solvent: V-1074, $390{ }^{\circ} \mathrm{C} 1500$ psig $97 \% \mathrm{H}_{2} / 3 \% \mathrm{H}_{2} \mathrm{~S}$

Figure B.61: BCP-406, Heptane Insoluble with reaction conditions of:

Solvent: V-1074, $390{ }^{\circ} \mathrm{C} 1500$ psig $97 \% \mathrm{H}_{2} / 3 \% \mathrm{H}_{2} \mathrm{~S}$

Figure B.62: BCP-406, Heptane Soluble with reaction conditions of

Solvent: V-1074, $390{ }^{\circ} \mathrm{C} 1500$ psig $97 \% \mathrm{H}_{2} / 3 \% \mathrm{H}_{2} \mathrm{~S}$ 130

Figure B.63: BCP-406, Heptane Insoluble and Toluene Insoluble with reaction conditions of: Solvent: V-1074, $390{ }^{\circ} \mathrm{C} 1500$ psig $97 \% \mathrm{H}_{2} / 3 \% \mathrm{H}_{2} \mathrm{~S}$. 
Figure B.64: BCP-406, Heptane Insoluble and Toluene Soluble with reaction conditions of: Solvent: V-1074, $390{ }^{\circ} \mathrm{C} 1500$ psig $97 \% \mathrm{H}_{2} / 3 \% \mathrm{H}_{2} \mathrm{~S}$ 131

Figure B.65: BCP-407, THF Insoluble with reaction conditions of:

Solvent: V-1074, $410{ }^{\circ} \mathrm{C} 1500$ psig $97 \% \mathrm{H}_{2} / 3 \% \mathrm{H}_{2} \mathrm{~S}$

Figure B.66: BCP-407, Heptane Insoluble with reaction conditions of:

Solvent: V-1074, $410{ }^{\circ} \mathrm{C} 1500$ psig $97 \% \mathrm{H}_{2} / 3 \% \mathrm{H}_{2} \mathrm{~S}$

Figure B.67: BCP-407, Heptane Soluble with reaction conditions of:

Solvent: V-1074, $410{ }^{\circ} \mathrm{C} 1500$ psig $97 \% \mathrm{H}_{2} / 3 \% \mathrm{H}_{2} \mathrm{~S}$

Figure B.68: BCP-407, Heptane Insoluble and Toluene Insoluble with reaction conditions of: Solvent: V-1074, $410{ }^{\circ} \mathrm{C} 1500$ psig $97 \% \mathrm{H}_{2} / 3 \% \mathrm{H}_{2} \mathrm{~S}$.

Figure B.69: BCP-407, Heptane Insoluble and Toluene Soluble with reaction conditions of: Solvent: V-1074, $410{ }^{\circ} \mathrm{C} 1500$ psig $97 \% \mathrm{H}_{2} / 3 \% \mathrm{H}_{2} \mathrm{~S}$

Figure B.70: BCP-408, THF Insoluble with reaction conditions of:

Solvent: V-1074, $410{ }^{\circ} \mathrm{C} 1000$ psig $97 \% \mathrm{H}_{2} / 3 \% \mathrm{H}_{2} \mathrm{~S}$

Figure B.71: BCP-408, Heptane Insoluble with reaction conditions of:

Solvent: V-1074, $410{ }^{\circ} \mathrm{C} 1000$ psig $97 \% \mathrm{H}_{2} / 3 \% \mathrm{H}_{2} \mathrm{~S}$

Figure B.72: BCP-408, Heptane Soluble with reaction conditions of:

Solvent: V-1074, $410{ }^{\circ} \mathrm{C} 1000$ psig $97 \% \mathrm{H}_{2} / 3 \% \mathrm{H}_{2} \mathrm{~S}$

Figure B.73: BCP-408, Heptane Insoluble and Toluene Insoluble with reaction conditions of: Solvent: V-1074, $410{ }^{\circ} \mathrm{C} 1000$ psig $97 \% \mathrm{H}_{2} / 3 \% \mathrm{H}_{2} \mathrm{~S}$. 135

Figure B.74: BCP-408, Heptane Insoluble and Toluene Soluble with reaction conditions of: Solvent: V-1074, $410{ }^{\circ} \mathrm{C} 1000$ psig $97 \% \mathrm{H}_{2} / 3 \% \mathrm{H}_{2} \mathrm{~S}$ .135

Figure B.75: BCP-409, THF Insoluble with reaction conditions of:

Solvent: V-1074, $410{ }^{\circ} \mathrm{C} 500$ psig $97 \% \mathrm{H}_{2} / 3 \% \mathrm{H}_{2} \mathrm{~S}$

Figure B.76: BCP-409, Heptane Insoluble with reaction conditions of:

Solvent: V-1074, $410{ }^{\circ} \mathrm{C} 500$ psig $97 \% \mathrm{H}_{2} / 3 \% \mathrm{H}_{2} \mathrm{~S}$ 136

Figure B.77: BCP-409, Heptane Soluble with reaction conditions of:

Solvent: V-1074, $410{ }^{\circ} \mathrm{C} 500$ psig $97 \% \mathrm{H}_{2} / 3 \% \mathrm{H}_{2} \mathrm{~S}$ 136

Figure B.78: BCP-409, Heptane Insoluble and Toluene Insoluble with reaction conditions of: Solvent: V-1074, $410{ }^{\circ} \mathrm{C} 500$ psig $97 \% \mathrm{H}_{2} / 3 \% \mathrm{H}_{2} \mathrm{~S}$. 
Figure B.79: BCP-409, Heptane Insoluble and Toluene Soluble with reaction conditions of: Solvent: V-1074, $410{ }^{\circ} \mathrm{C} 500$ psig $97 \% \mathrm{H}_{2} / 3 \% \mathrm{H}_{2} \mathrm{~S}$ 137

Figure B.80: BCP-410, THF Insoluble with reaction conditions of:

Solvent: V-1074, $390{ }^{\circ} \mathrm{C} 1000$ psig $97 \% \mathrm{H}_{2} / 3 \% \mathrm{H}_{2} \mathrm{~S}$

Figure B.81: BCP-410, Heptane Insoluble with reaction conditions of:

Solvent: V-1074, $390{ }^{\circ} \mathrm{C} 1000$ psig $97 \% \mathrm{H}_{2} / 3 \% \mathrm{H}_{2} \mathrm{~S}$

Figure B.82: BCP-410, Heptane Soluble with reaction conditions of:

Solvent: V-1074, $390{ }^{\circ} \mathrm{C} 1000$ psig $97 \% \mathrm{H}_{2} / 3 \% \mathrm{H}_{2} \mathrm{~S}$

Figure B.83: BCP-410, Heptane Insoluble and Toluene Insoluble with reaction conditions of: Solvent: V-1074, $390{ }^{\circ} \mathrm{C} 1000$ psig $97 \% \mathrm{H}_{2} / 3 \% \mathrm{H}_{2} \mathrm{~S}$.

Figure B.84: BCP-410, Heptane Insoluble and Toluene Soluble with reaction conditions of: Solvent: V-1074, $390{ }^{\circ} \mathrm{C} 1000$ psig $97 \% \mathrm{H}_{2} / 3 \% \mathrm{H}_{2} \mathrm{~S}$.

Figure B.85: BCP-411, THF Insoluble with reaction conditions of:

Solvent: V-1074 only, $410{ }^{\circ} \mathrm{C} 1000$ psig $97 \% \mathrm{H}_{2} / 3 \% \mathrm{H}_{2} \mathrm{~S}$

Figure B.86: BCP-411, Heptane Insoluble with reaction conditions of:

Solvent: V-1074 only, $410{ }^{\circ} \mathrm{C} 1000$ psig $97 \% \mathrm{H}_{2} / 3 \% \mathrm{H}_{2} \mathrm{~S}$

Figure B.87: BCP-411, Heptane Soluble with reaction conditions of:

Solvent: V-1074 only, $410{ }^{\circ} \mathrm{C} 1000$ psig $97 \% \mathrm{H}_{2} / 3 \% \mathrm{H}_{2} \mathrm{~S}$

Figure B.88: BCP-411, Heptane Insoluble and Toluene Insoluble with

reaction conditions of: Solvent: V-1074 only, $410{ }^{\circ} \mathrm{C} 1000 \mathrm{psig}$

$97 \% \mathrm{H}_{2} / 3 \% \mathrm{H}_{2} \mathrm{~S}$.

Figure B.89: BCP-411, Heptane Insoluble and Toluene Soluble with reaction conditions of: Solvent: V-1074 only, $410^{\circ} \mathrm{C} 1000$ psig $97 \% \mathrm{H}_{2} / 3 \% \mathrm{H}_{2} \mathrm{~S}$ 141

Figure B.90: Coal-derived reaction solvent V-1074 142

Figure B.91: Coal-derived reaction solvent V-1074 toluene soluble 142

Figure B.92: Petroleum derived reaction solvent Hondo 143

Figure B.93: Petroleum derived reaction solvent Hondo toluene soluble 143 


\section{Chapter 1:}

\section{Introduction}

Coal is one of the most abundant natural resources in United States. Due to its vast supply, it could serve as a raw material that may have many advantages in the future by replacing petroleum-based fuels and carbon-product feedstocks. Coal-based carbon feedstocks such as pitch and cokes are currently derived from by-product coke ovens. Unfortunately, the U.S. supply of coal tar pitch is declining at 3-4\% per year due to increased imports, reduction in blast furnace steel making, decreasing coke demand and environmental constraints placed on coke ovens [6]. On the other hand, the reserves of petroleum, which supply the world demand for fuel, are dwindling. One disadvantage of petroleum coke is that its availability in the United States depends upon imported crude oil sources. Also, since it is a by-product, the possibility of uncontrolled variability is ever present. Furthermore, crude oil is tending to increase in impurities, such as sulfur, vanadium and nickel which are detrimental to coke utilization.

Currently other processes for coal conversion are being evaluated as an alternative to coke ovens. These ovens produce coke and by-products such as coal-tar, light oil, ammonia liquor and gas. It is known that with suitable treatment, many carbon products, such as coke, activated carbons, carbon blacks and specialty coal-derived materials can be produced from coal. The precursors for each of these products need specific characteristics and properties. Direct coal liquefaction is being considered as an option for the production of precursors for these carbon products. Moreover, the coal liquefaction products can be separated and their properties tailored by means of solvent extraction to obtain fractions with the most desirable characteristics.

\subsection{Carbon Products}

The production of carbon materials from coal would bring new technology and industrial growth to the United States. It could also bring an international level of competition in the area of materials research. Many of these carbon-based materials have 
high commercial value. In the future, coal could be the basis of a secure supply of feedstock while eliminating the need for dependence on foreign petroleum. In addition, the currently-used petroleum-based feedstocks are exhibiting higher levels of impurities, which are either detrimental for use in carbon products or harmful to the environment. The carbon materials that can be produced from coal could be divided in two main material types: cokes and pitches. These two raw materials can be produced from coal using hydrogenation, solvent extraction and heat treatment to produce high - value carbon products.

\subsubsection{Uses of Coke}

One material that is in great demand is high-grade coke, which is used extensively in the aluminum industry for the reduction of aluminum oxide to aluminum. Another consumer of coke is the production of graphite electrodes and some carbon-carbon composites. Two kinds of cokes can be produced: anisotropic and isotropic. Isotropic coke is mainly used in the manufacture of nuclear-grade graphite. Anisotropic coke, on the other hand, is used primarily for electrode and anode production. The difference between these two cokes stems from the domain size of the mesophase present in the sample.

\subsubsection{Uses of Pitch}

In addition to coke, pitch has several important uses. It is employed as a binder or "glue" which holds coke particles together during manufacture of carbon materials. It also can be used as an impregnation pitch for densyfying graphite by filling voids left after calcination prior to graphitization. Another suitable use for pitch is as the precursor of graphite fibers. Graphite fiber manufacture requires a highly oriented (mesophase) pitch and low softening point to allow spinning. Non-mesophase pitch can be used for isotropic fibers. These pitches are thus precursors of high-value products such as carbon anodes for aluminum industry, graphite electrodes for electric furnaces, specialty graphites such as nuclear graphite. In addition, the final product uses of graphite include 
heaters for semiconductor processing, molds for the aerospace industry, crucibles for metal refining, and graphite powders for batteries and fuel cells. They can also be the precursors of activated carbon adsorbents, low cost carbon fibers, high performance carbon fibers, and carbon-carbon composites.

Binder pitch is currently refined from coal tar, which is a by-product of metallurgical coke making. It is subject to variation in quality and its supply is declining in the U.S. as recovery coke ovens close and environmental regulations become stricter. Due to the closure of these by-products ovens, the domestic production of coal tar will decline at 3-4\% annually over the next five (5) years [6].

Some other applications for graphite and composites are in the automotive industry. Truck brakes, clutches and even parts for internal combustion engines are all candidates for carbon materials. Carbon fiber composites could be applied as molecular sieves and adsorbents for such areas as air and water purification, gas separation and hydrogen absorption for heavy oil and residuum upgrading.

\subsection{Important Characteristics of Carbon Products}

The characteristics of a particular carbon product vary according to its use. Binder pitch requires an assurance of uniform quality and supply. It should have low sulfur and metals, acceptable rheology and adequate coke yield. An acceptable impregnating pitch should have a good impregnation rate, no mesophase and less than one poise viscosity at the required temperature [6]. In order to perform effectively as an impregnation pitch, certain parameters have to be established such as, temperature, assurance of uniform quality supply, low sulfur and metals concentration, adequate density, porosity, coefficient of thermal expansion and electrical resistivity, high grain stability and very importantly low air and $\mathrm{CO}_{2}$ reactivity [6]. Pitches that are either too reactive or viscous restrict the development of mesophase and no amount of heat treatment will transform the material to graphite under ordinary circumstance [5]. 


\subsection{Research Objectives}

This research is focused on the characterization of precursors specifically derived from coal liquefaction. The fundamental material considered as a potential pitch substitute is the asphaltene fraction, which is obtained from the coal liquefaction products. Such asphaltene fractions, the coal liquefaction product insoluble in heptane and soluble in toluene, were obtained in conjunction with the National Energy Technology Laboratory/ Department of Energy (NETL/DOE) in Pittsburgh, PA. The coal conversion is performed with different liquefaction processing parameters e.g. temperature, pressure, catalyst, etc. The different fractions are characterized and carbonized and their properties are related to the liquefaction conditions. In order to determine the possible uses of these asphaltenes, the following parameters are determined: softening point, coking value, ash content, solubility, optical texture and mesophase formation. All these, together with the ultimate and NMR analyses, allowed an assessment of the production of high-value carbon products from coal liquefaction fractions. The results are evaluated and a recommendation made for the possible uses of these parent asphaltenes and the improvement of process conditions to obtain premium precursors. 


\section{Chapter 2:}

\section{Background}

Over the centuries, different definitions have been assigned to coal, according to many diverse perspectives. For example, coal is a vital resource that could replace imported energy supplies. Coal is an obsolete fuel whose predominance as an energy source passed decades ago. Coal is a dirty fuel; its mining and use have caused environmental damage as well as human suffering. Presently, coal may be viewed as the key to a smooth transition from the present petroleum-based energy economy to renewable, nonpolluting energy sources in the $21^{\text {st }}$ century [26].

\subsection{History of Coal Utilization}

Coal has been used as a source of heat for thousands of years. Several civilizations have depended on it through the centuries. Coal was used in China about 2500 years ago; the Greeks and Romans also knew of it. When coal was first used, it was only in the vicinity of the primitive mines. In the $13^{\text {th }}$ century, the development of methods of transportation, particularly the boat, made it available throughout Europe. Eventually coal technology was brought to America shortly after colonization in the $17^{\text {th }}$ century. It first was employed for heating homes, small factories and commercial buildings. It continued to be used until the pollution produced by burning coal made it unbearable. This caused various governments around the world to create laws to restrict its use. Presently, coal has been replaced by natural gas and fuel oil mostly because of the ease of transportation and convenience afforded by the latter two fuels. The use of coal in homes also presents the problem of poor thermal efficiency and the serious pollution from smoke and fumes resulting from incomplete combustion.

Even though coal has been replaced for domestic heating, coal still satisfies the needs of a modern society. Indeed such basic requirements as electricity, transportation fuels, metals, chemicals and process heat are all based to some extent on coal [26]. At 
present over $50 \%$ of the electricity in the United States comes from coal-fired power plants, which is the principle use of coal in the United States.

Metallurgical coke production is the second most important use of coal. Coke is an important raw material for the iron and steel industry, where it is employed as a reductant in metallurgical processing. The by-products from the metallurgical coke ovens are a source of a variety of chemicals, including solvents, ammonia, chemicals and fertilizers. Most of the modern organic chemical industry is based on petroleum today but when the sources of petroleum decrease, a new chemical industry derived from coal could take its place.

\subsection{Coal Rank}

Coal is classified by rank. It is ranked as brown coal, lignite, subbituminous coal, bitmuninous coal and anthracite. This classification is based upon the degree of coalification, i.e., the continuous evolution of the parent plant material towards a pure carbon structure (i.e, graphite).

The classification of coal by rank is presented in Table 2.1. Brown coal has a very high moisture content, is easy to ignite but has low heating value. This kind of coal is not normally found in the United States. Lignite is the lowest rank of coal found in U.S. and contains less than $75 \%$ carbon on a moisture- and ash-free basis. It also has high moisture content (about 40-42\%) and is high in volatile matter. Its heating value is low, about one-half that of bituminous coal. Subbituminous coal contains enough volatile matter to be easily ignited. It is generally very low in sulfur and offers a reasonably high heating value. Its carbon content is intermediate between lignite and bituminous coals. The moisture and volatile contents in bituminous coal are low and it has a high fixed carbon content and high heating value. Anthracite is the highest rank coal with greater than about $90 \%$ carbon. It contains low ash and has a high heating value. Metallurgical coke is formed from bituminous coal when heat is applied in the absence of oxygen and volatile matter is driven off. 
Table 2.1: The ASTM system for classifying coals by rank

\begin{tabular}{|c|c|c|c|c|}
\hline Class & Group & $\begin{array}{c}\text { Fixed } \\
\text { Carbon }^{\text {a }}\end{array}$ & $\begin{array}{l}\text { Volatile } \\
\text { Matter }^{\mathrm{a}}\end{array}$ & $\begin{array}{l}\text { Heating } \\
\text { Value }^{\mathrm{b}}\end{array}$ \\
\hline \multirow[t]{3}{*}{ Anthracite } & Metaanthracite & $>98$ & $<2$ & \\
\hline & Anthracite & $92-98$ & $2-8$ & \\
\hline & Semianthracite & $86-92$ & $8-14$ & \\
\hline \multirow[t]{5}{*}{ Bituminous } & Low-volatile & $78-86$ & $14-22$ & \\
\hline & Medium-volatile & $69-78$ & $22-31$ & \\
\hline & High-volatile A & $<69$ & $>31$ & $>14,000$ \\
\hline & High volatile B & & & $13,000-14,000$ \\
\hline & High-volatile C & & & $10,500-13,000$ \\
\hline \multirow[t]{3}{*}{ Subbituminous } & Subbituminous A & & & $10,500-11,500$ \\
\hline & Subbituminous B & & & $9,500-10,500$ \\
\hline & Subbituminous C & & & $8,300-9,500$ \\
\hline \multirow[t]{2}{*}{ Lignitic } & lignite $\mathrm{A}$ & & & $6,300-8,300$ \\
\hline & lignite B & & & $<6,300$ \\
\hline $\begin{array}{l}\text { Note: This classification } \\
\text { standards. a The fixed c } \\
\text { matter is calculated from } \\
\text { value, reported in Briti } \\
\text { moisture or equilibrium } \\
\text { occurs in the heating-val } \\
\text { are classified as high vol }\end{array}$ & $\begin{array}{l}\text { tem is based on ASTM } \\
\text { on and volatile matter, r } \\
\text { e ash content by the Parr }\end{array}$ & $\begin{array}{l}\text { D 388-66, v } \\
\text { s percentag }\end{array}$ & $\begin{array}{l}\text { ed annually } \\
\text { led on a dry, } \\
\text { ent ash }+0.5 \\
\text { free basis. } \\
\text { relative hum } \\
\text { vith heating }\end{array}$ & $\begin{array}{l}M \text { in their compilation o } \\
\text { free basis. The minera } \\
\text { tt sulfur)] }{ }^{b} \text { The heatin } \\
\text { sture content is the bec } \\
\text { osphere. Some overlal } \\
\text { ween } 10,500 \text { and } 11,50 \text { ( } \\
\text { not. }\end{array}$ \\
\hline
\end{tabular}

\subsection{Coal Properties}

Coal is a very general term covering an ample gap of different materials with different properties. As Schobert states [26]; "Coals are like snowflakes or human fingerprints: No two are exactly the same in every aspect". Coal is a heterogeneous material and does not have a defined molecular structure like polymers and biological macromolecules. It is very difficult to classify due to its multitude of characteristics. It does not dissolve completely in any solvent; it is not completely crystalline; it does not melt and cannot be distilled; heating coal causes its decomposition. It is thought that coal is a three-dimensional cross-linked structure consisting of aromatic ring systems linked by aliphatic carbon bridges or ether type oxygen bridges. Mild oxidation can reduce its heating value and destroy its ability to form coke.

\footnotetext{
* Table obtained from Schobert, H.[26] page 13
} 
The specific gravity of mineral-free coal varies with rank but generally ranges from 1.2 to 1.5. Ash is the product of heating the inorganic constituents during the burning of coal. It consists mainly of the oxides of sodium, calcium, magnesium, potassium, aluminum, silicon and iron. The ash content in coal varies according to its place of origin and does not depend on the rank of the coal. The fixed carbon content of the coal increases with rank (Table 2.1). This means that as rank increases and the volatile matter is removed, the large aromatic ring structures increase and this structure is less likely to break apartduring subsequent processing. Aromaticity increases as rank increases and ranges from about 0.6 in lignites to 0.9 in low-volatile bituminous coal. Aromaticity indicates the amount of aromatic carbons per total carbon present in the sample. On the average, the elemental composition of coal is 70-95\% carbon, 0-25\% oxygen, 1-5 \% hydrogen, $1 \%$ nitrogen and 1-8 \% sulfur. Analysis has shown the presence in coal of at least trace amounts of every known element except the noble gases and unstable radioactive elements.

\subsection{Coal and Coal-Derived Products}

As mentioned above, today the most important use of coal is for combustion to generate steam and produce electricity. The second most important use of coal is metallurgy coke production. Such coke is used as a feedstock for the reduction of metal oxides. Carbon has been the primary reducing agent in metal refining for centuries. Coal also is a source of many beneficial chemicals when the volatile carbonization products are collected and recovered.

The desirable properties of the coke are dictated by its end use. For metallurgical coke in iron smelting, it should have good mechanical strength, high porosity and low sulfur content. It should also be low in ash and phosphorus. Such coke is used in the blast furnaces to produce pig iron, which in turn is converted to steel. Breeze, i.e., coke pieces smaller than one-half to three-fourth of an inch, can be used to sinter iron ore into pellets for feeding blast furnaces. 
The process of heating coal in the absence of air is called carbonization. Coal can be carbonized to produce three substances: coke, flammable gas, and coal tar. The composition of coal tar depends on the carbonization conditions and the properties of the specific coal. Up to half of the coal tar can remain as pitch. Pitch is the residue that results from distillation of coal-tar, which previously removed volatile oils. The heavier oil is treated with acids. The tar acids are separated by distillation. The wash oil left after separating the tar acids and bases is distilled until anthracene oil is extracted and the remaining oil is pitch. The uses of pitch range from road tar or roofing tar to binders in making fuel briquettes or electrodes.

\subsection{Coke Ovens}

Coke ovens are operated primarily to convert bituminous coal to metallurgical coke, which is used to reduce iron ore to iron in the blast furnace. Coking is the operation of heating coal in the absence of oxygen to temperatures in excess of $1000{ }^{\circ} \mathrm{C}$ until all volatile matter is driven off. Coal-tar, light oil, ammonia liquor, gas and coke are products of this coking operation. Originally coal was cooked or distilled in mounds or heaps. The pile (or mound) was ignited and partially burned before the access to air was stopped thus allowing conversion of the hot coal to coke. The pile was then cooled, uncovered and the coke harvested. The beehive oven eventually displaced this method. In the beehive oven coal is burned internally to supply heat. Air was admitted to the mass through draught-holes, and thus a portion of the coal as well as most of the volatile products were consumed. The next stage of development was the construction of ovens in such a way that the hot gases of combustion could be drawn off and the heat contained in them was used for certain purposes, such as raising steam, etc. From this last design the by-product coke industry evolved. Recovery coke ovens have been used for years in the production of metallurgical coke. Not only does the by-product oven produce coke of satisfactory quality, but also the process is completed in much less time than the former methods (Figure 2.1). Moreover, valuable by-products, which form the basis of other important industries, are recovered. 


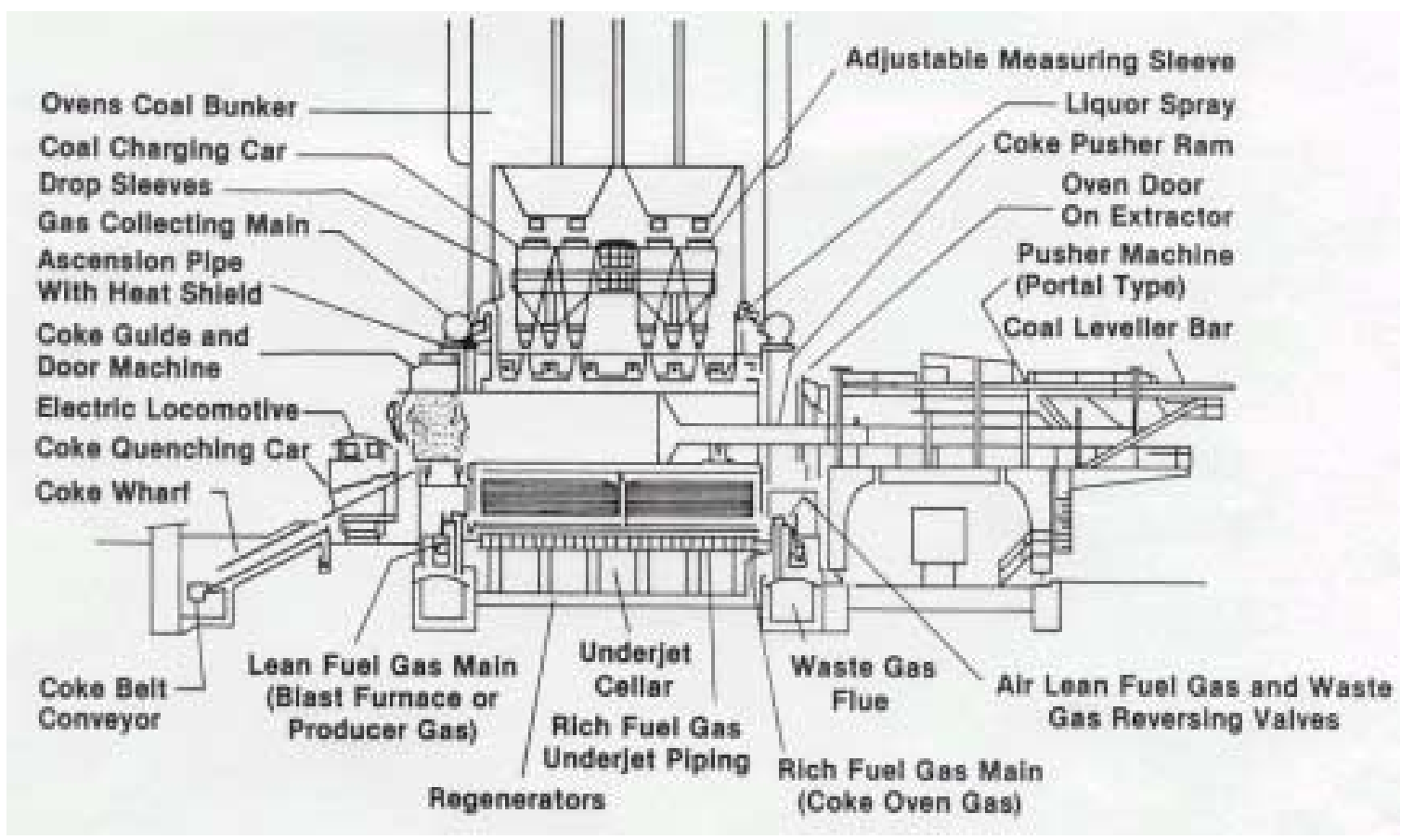

Figure 2.1: Cross-sectional representation of a battery from a modern recovery coke oven.

An emphasis has been placed on improving the control of air pollution in coke production. Since charging and emptying ovens produce most of the pollution, there has been an effort to scale up oven capacity, which would effectively reduce the number of potential sources of pollution by decreasing the times the oven is charged and discharged. In addition other processes are being considered as a substitute for conventional coke making.

\subsubsection{The Future of Coke Ovens}

Coal-based feedstocks for industrial applications are currently being derived from by-product coke ovens. Such feedstocks are declining at a rate of $3-4 \%$ per year due to coke imports, reduction in blast furnace steel making, construction of non-recovery coke ovens and environmental constraints in coke plants. It is expected that by the year 2010 the supply of domestic coal tar will decrease by $15 \%$ [6]. It is also expected that over the same time period the demand for pitch and coke for the aluminum industry will more than double. Moreover, petroleum-based coke and pitch will continue to increase in 
sulfur and metals making it a less desirable carbon source. The use of an alternative method for the production of pitches would eliminate the need for coke oven/coal tar processing with its inherent environmental concerns. Coal liquefaction continues to be an important option among the technologies proposed for the production of fuel and coalderived liquid products

\subsection{Pitches}

Nearly all industrially important carbons, such as needle coke, fibers, isotropic cokes, etc. originate from pitches. Pitch may be defined as a black, sticky-to-solid substance formed either by the distillation of coal tar from by-product recovery coke ovens or from the residues of a petroleum refinery. In general, both coal-tar pitch and petroleum pitch are complex mixtures of hundreds or even thousands of organic compounds predominantly aromatic, polyaromatic, alicyclic or aliphatic hydrocarbons and numerous polycyclic aromatic hydrocarbons. Coal-tar pitch is a residue produced by distillation or heat-treatment of coal tar (coke oven tar). For every ton of coal fed to the coke oven, approximately 25 to 50 pounds of coal-tar pitch is produced. Petroleum pitch is a residue from heat-treatment and distillation of petroleum fractions. Coal may be preferred in the manufacture of refinable distillates because the known reserves of crude oil in the world are decreasing while the world demand is growing. In addition, the reserves of coal worldwide are about five times more on a heat-value basis than the remaining recoverable oil reserves.

Mesophase pitch is a state in which the macromolecular components are exhibited as both an ordered solid and a fluid liquid. When certain pitches are heated above $350^{\circ}$ $\mathrm{C}$ they melt to form an isotropic liquid. After that, a dealkylation/condensation process occurs that increases the pitch aromaticity. This increase results in large and more planar molecules that can associate with each other. The molecules arrange themselves in layers that are free to move and glide over each other easily. The early stages of the molecular arrangement cause the alignment of the molecules in the form of tiny anisotropic spheres of liquid crystalline-like material. When these individual spheres come into contact with 


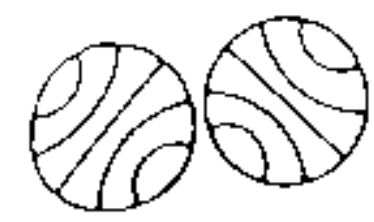

Before contact

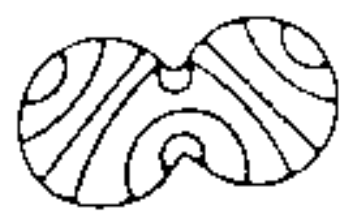

Just after contact

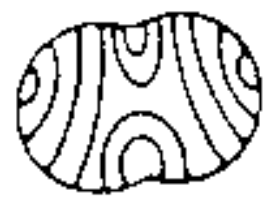

Short time ofter contact

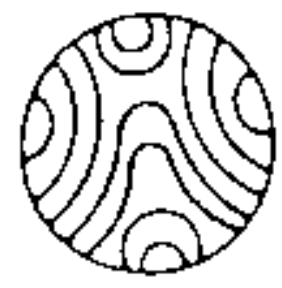

Partial Rearrangement

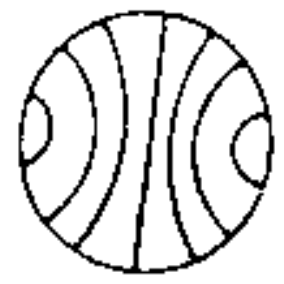

Total Rearrangement

Figure 2.2 Schematic diagram of growth and association of mesophase [5] 
each other they coalesce (Figure 2.2). This process can continue until the mass is completely coalesced and hence mesophase pitch is formed. Mesophase pitch is highly oriented and because of this it is used as a precursor for high modulus fibers and carbon composites.

\subsection{Petroleum Coke}

As with coal there are many different variations from which the petroleum coke is derived. Petroleum coke is derived from the heavy fraction of crude oil and therefore contains a large amount of carbon and very little hydrogen. Upgrading the petroleum heavy fraction converts it to lighter, more valuable products and specialty cokes. Several commercial petroleum coking methods have been developed in the U.S. to convert residue and similar materials to solid carbon. They include fluid contact, and atmospheric still coking.

Delayed coking has been used for over fifty years. This method has the ability to handle a wide variety of aromatic residua and the capability to produce cokes with controlled structure [5]. In delayed coking the material is pumped into the bottom of an insulated drum and coked typically for twenty-four (24) hours at $450^{\circ} \mathrm{C}$. Afterwards twenty-four (24) hours are required to cool and remove the coke. This product is then used in the manufacture of anodes, electrodes, sealing and lubricating materials, carbon brushes, compound brakes, etc.

\subsection{Carbon Properties}

Carbon is a unique element present in every day life and used in many industrial applications. It is utilized as a transportation fuel, to make electrodes and anodes for metal reduction, and for carbon fiber production. There are three spatially arranged crystalline forms of the element carbon: graphite, diamond and fullerenes. Graphite has

an $\mathrm{sp}^{2}$ spatial arrangement, occurs in nature and is the most common carbon form. It is comprised of carbon atoms bonded trigonally and arranged in planar sheets. The planes 
are usually stacked in the hexagonal $\mathrm{ABAB}$ sequence, although a sequence $\mathrm{ABCABC}$ is also encountered (Figure 2.3). Diamond has a sp ${ }^{3}$ spatial arrangement and is difficult and expensive to produce. In 1985, fullerene, the third form of carbon was discovered. It is shaped in the form of a soccer ball, with hexagons and pentagons of carbon atoms formed by the carbon bonding.

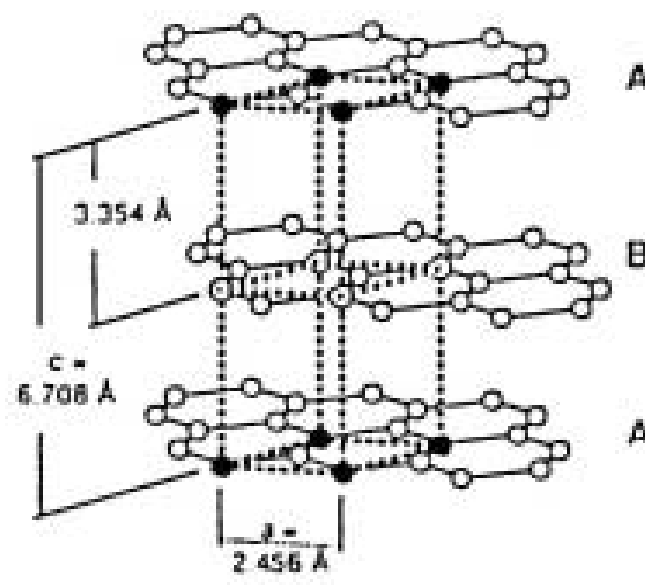

Hexagonal Unit Cell

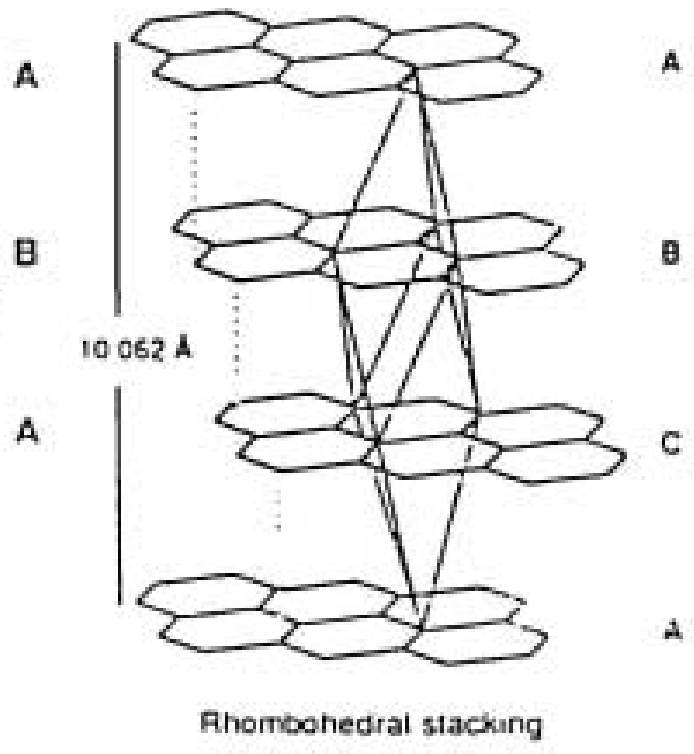

Figure 2.3: Crystalline forms of graphite

Ideally the layers occur with no fault, although in reality it is the difference in the nature of forces parallel and perpendicular to the graphite planes that gives graphite its diversity of properties. It is the ability to control the crystal structure of graphite that makes it possible to produce the different carbon products in use today. Artificial graphites are typically a mixture of highly-ordered material intertwined with amorphous or less-ordered material. The more ideally graphitic the carbon structure becomes, the greater the anisotropy exhibited in its physical properties. Conversely, the more these parameters depart from the ideal graphite structure, the more isotropic the physical properties become. The isotropy or anisotropy of the material is important when assessing suitability for certain applications. Figure 2.4 shows photomicrographs of semicokes obtained from pitches representing the extremes in graphitizability. The photo 
in Figure 2.4A is from a pitch that was of high molecular weight, of high oxygen content and low solubility in toluene. The small grains formed upon coking indicate that the mesophase development was very restrictive and hence the properties of this carbon are isotropic. The precursor of the coke in Figure 2.4B, on the other hand, allowed extensive mesophase development and coalescence resulting in a carbon that is highly graphitic and anisotropic.
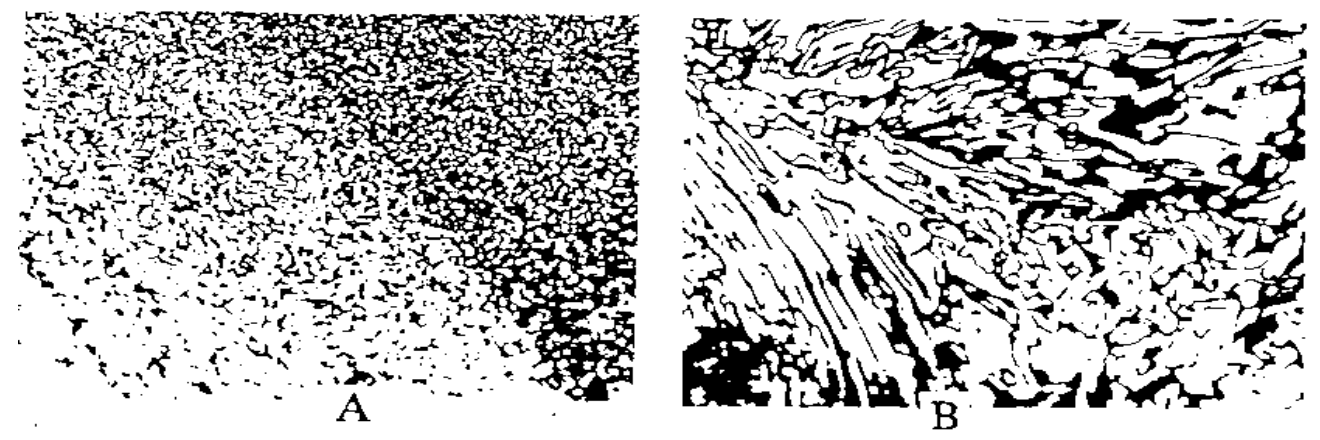

Figure 2.4: Representation of A) isotropic and, B)anisotropic carbon cokes

All carbon materials, except diamond and fullerenes, are based on the graphite structure. Precursor materials can be classified as graphitizable and non-graphitizable. Graphitizable carbons are those carbonaceous materials, which upon high-temperature treatment, are converted into graphitic carbons, while non-graphitizable carbons are not. Non-graphitizing materials are low in hydrogen and rich in oxygen, they produce a rigid disordered structure when heated. On the other hand, materials rich in hydrogen and low in oxygen tend to undergo alignment of molecular layers. This alignment of layers is what is known as graphitizing behavior. To distinguish between graphitizable and nongraphitizable carbons, the most frequently used method is optical microscopy which identifies the mesophase formation of the sample visually.

\subsection{Coal Liquefaction}

The primary objective of any coal-liquefaction process is to convert coal to a quality liquid hydrocarbon fuel by increasing the hydrogen-to-carbon ratio and removing sulfur, nitrogen, oxygen and ash. During coal liquefaction the weak alipahtic bonds are 
broken, separating large units of the coal structure into smaller molecules accompanied by the addition of hydrogen. From a chemical point of view another objective is to bring about the decomposition of aromatic-aliphatic, aromatic-aromatic, and a variety of carbon heteroatom bonds within the coal to form smaller fragments.

Two fundamentally different methods for coal liquefaction (direct and indirect) have been developed. The suitability of each method depends on a large number of factors including coal siting (place of origin), product and operational requirements. In indirect coal liquefaction, the coal is first converted to a synthesis gas (a mixture of $\mathrm{H}_{2}$ and $\mathrm{CO}$ ) which is then converted over a catalyst to methane or liquid hydrocarbon fuels. Direct liquefaction refers to any process in which coal and hydrogen are directly reacted at high pressure and temperature. A hydrogen donor solvent and/or catalyst may also be present. A general scheme of direct coal liquefaction is presented in Figure 2.5.

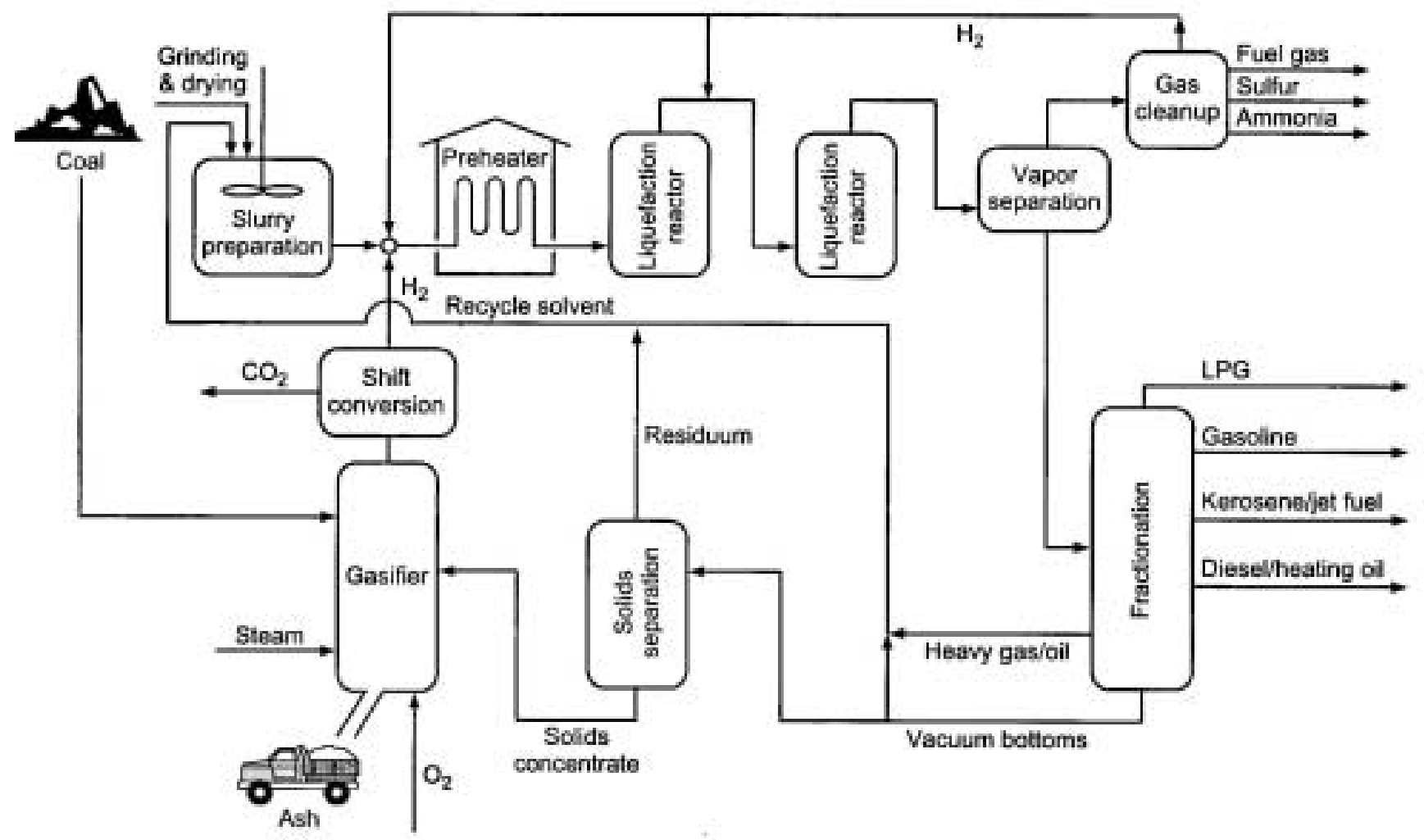

Figure 2.5: Schematic diagram of a typical direct Coal Liquefaction process. 
Several factors have to be considered in order to determine the appropriate reaction conditions in direct liquefaction. The reaction temperature was chosen over $350^{\circ} \mathrm{C}$ because below this temperature coal shows little reactivity toward hydrogen. The use of higher hydrogen pressure helps in attaining higher conversions. The coal is mixed with the solvent prior to charging the reactor because slurries are fed more easily into the reactor than solid particles. The use of a mixture of hydrogen $\left(\mathrm{H}_{2}\right)$ and hydrogen sulfide $\left(\mathrm{H}_{2} \mathrm{~S}\right)$, using $\mathrm{H}_{2} \mathrm{~S}$ as a catalyst, could increase the rate of reaction and affect the product distribution. The reaction conditions are optimized in order to facilitate the maximum transfer of hydrogen to the coal and increase the yield of the desired product.

The conversion from coal to oil has been modeled as a series of steps:

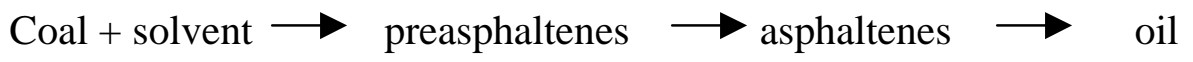

with some gas formation accompanying each step.

Asphaltenes comprise the most commonly used fraction of crude oil. Operationally defined on the basis of solubility, asphaltenes are the component of crude oil insoluble in n-alkanes such as n-heptane but soluble in aromatic solvents (e.g. toluene). Asphaltenes contain polyaromatic condensed rings with short aliphatic chains and polar heteroatoms such as nitrogen, oxygen, sulfur, and various metals. The properties of these asphaltenes may be tailored with solvent fractionation and heat treatment for use as precursors to high-value carbon products. [23]

When pitches are carbonized, polished and examined under reflected polarized light, complex surface features termed optical anisotropy or optical texture become apparent (Figure 2.4). It has been proposed that the optical anisotropy observed in cokes and pyrolyzed pitches is attributable to the occurrence of a carbonaceous liquid crystal, the so-called mesophase. Mesophase is produced by thermal treatment of pitch which contains a complex mixture of numerous aromatic hydrocarbons and is the result of condensation and polymerization of aromatic molecules in the pitch (see section 2.6 above). 
Since coal-tar pitch or mesophase pitch are the precursors for many carbon products, the desirable characteristics of the pitch as related to the carbon products are important. Maintaining a high yield of carbon from the pitch upon coking is of practical importance. This could result in high-density artifacts and enhanced structural strength. The control of carbon morphology determines its end use. The control of crystallinity determines the graphitizability in artificial graphites. The properties of these pitches are highly variable and dependent on the coal source.

\subsection{Characterization Techniques}

Certain characterization techniques for pitches and cokes have been developed after years of carbon study. The temperature of initiation of mesophase, the rate of its formation, and its evolution are important parameters which should be known when optimum conditions for the preparation of a carbon material must be established or the selection of an adequate precursor made. Furthermore, it is common practice to use the softening point as a rough guide to the behavior of the sample's ability to flow.

In addition, several American Society for Testing and Materials (ASTM) and Non-ASTM tests have been developed and will be used in this research to identify and classify the various pitches and cokes (Table 2.2). The results from these particular tests will aid in the determination of the yield and products that could be obtained from the pitches.

Table 2.2: Characterization tests for coal liquefaction fractions

\begin{tabular}{|c|c|}
\hline ASTM Tests & Non-ASTM Tests \\
\hline Softening Point ASTM D3104 & Solvent Extraction \\
\hline Coking Value ASTM D189 & $\begin{array}{c}\text { Mesophase } \\
\text { (Optical texture) }\end{array}$ \\
\cline { 1 - 1 } Ash Content ASTM D2415 & \\
\hline
\end{tabular}




\subsubsection{Solvent Fractionation}

Solvent fractionation has been used widely as a method of characterization, and recently it is effective in modifying the chemical structure of pitch. Since the mesogens and nonmesogens have different solubility parameters, they can be separated by solvent fractionation. This may enable the mesophase to be produced without extensive heat treatment.

\subsubsection{Softening Point}

The softening point is the temperature at which a particular fraction softens. The softening point reflects the ability of the sample to flow. It gives an indication of the consistency of the sample and it is useful when deciding its end use. Softening point data are required for applications such as binder pitch, impregnation pitch and fiber spinning.

\subsubsection{Coking Value}

Another important aspect of pitch characterization is the determination of the coking value. During coking, hydrogen and volatile matter are driven off from the pitch. Further heating produces a semicoke and this material is transformed to coke when contraction begins and carbonization is complete. The coking value gives an indication of the non-volatile matter in the sample and is intended to provide some indication of relative coke forming propensity. Typical acceptable coke yields are on the order of 50$60 \%$ by weight.

\subsubsection{Optical Texture}

The optical texture can be examined after the volatile matter is taken out of the carbonaceous sample and the sample analyzed under a polarized-light microscope. The use of an optical microscope makes possible the identification of the texture when the sample is rotated and yellow and blue domains are apparent. The optical texture gives an 
indication of the surface and graphitization properties of the fraction. The anisotropy or isotropy aid in the identification of the possible end uses of the different fractions. As mentioned above, an isotropic coke can be used in the fabrication of nuclear graphite while anisotropic coke can be used in the fabrication of electrodes.

\subsubsection{Ash Content}

Ash is a product of combustion that remains as a solid residue after the carbon in coal has been burned. Ash is mainly inorganic oxides of the mineral matter originally present in the parent coal. In the ash determination, a sample is carefully burned in a muffle furnace or by other suitable means, after which the residue is completely oxidized and the remaining ash stabilized. This is an indicator of the amount of inorganic material in the coal sample. The ash is determined by weighing the sample before combustion and the remaining ash residue after combustion. For carbon products, the inorganic or ashforming constituents are considered impurities

\subsubsection{Nuclear Magnetic Resonance and Ultimate Analysis}

Nuclear magnetic resonance (NMR) spectroscopy can be defined as the absorption and emission of electromagnetic radiation by the nuclei of certain. This phenomenon occurs when the nuclei of certain atoms are immersed in a static magnetic field and exposed to a second oscillating magnetic field. Some nuclei experience this phenomenon, and others do not, depending upon whether they possess a property called spin.

In order to examine the carbon species present in the asphaltene fraction, both conventional and high resolution solid-state NMR studies are performed. The conventional NMR techniques require samples in either liquid form or solution. The spectra acquired with conventional NMR are ${ }^{1} \mathrm{H}$ and ${ }^{13} \mathrm{C}$. High resolution NMR for solid coals can be obtained through the use of cross-polarization (CP). $\mathrm{CP}$ is a technique commonly employed in obtaining the ${ }^{13} \mathrm{C}$ spectra from a solid sample. The $\mathrm{CP}$ was used 
for signal-to -noise enhancement. The Single Pulse conventional experiment (SP) is used to remove or suppress the $\mathrm{H}-\mathrm{H}$ dipolar interactions in the acquisition of the ${ }^{1} \mathrm{H}$ spectra.

Nuclear Magnetic Resonance (NMR) is used to measure the aromaticity in the sample. From X-ray diffraction it is known that as the carbon content increases coal tends to become more like graphite [5]. At carbon contents above 85\%, the ring clusters in coal begin to stack and show some vertical arrangement. It is expected that as the carbon content increases the aromatic rings have fewer side chains. In many cases ${ }^{1} \mathrm{H}$ and ${ }^{13} \mathrm{C}$ NMR spectra can give quantitative information about the carbon and hydrogen forms of the coal or coal products. NMR provides information about the amount of $\mathrm{sp}^{2}$ and $\mathrm{sp}^{3}$ carbon atoms present in the different fractions. This is the same as saying the amount of aromatic and aliphatic carbon atoms present and as a consequence gives an indication of the amount of side chains on the large aromatic molecules.

The hydrogen atom contains only a single proton in its nucleus. Because this proton has no neutron with which to pair, the nucleus of hydrogen must have a spin and therefore is responsive in NMR experiments. This situation allows the technique to provide much information about the arrangement of hydrogen in organic compounds. Thus NMR provides a determination of the hydrogen distribution among various chemical moieties present in coal.

Ultimate analysis gives the elemental composition of coal. It tells the amount of $\mathrm{C}, \mathrm{H}, \mathrm{O}, \mathrm{N}$, and $\mathrm{S}$ present in the sample. The combination of it with NMR may help in the estimation of the possible graphitization of the sample by knowing the amount of carbon present in the fraction and the percent of which is aromatic and able to form a graphite-like structure. When compared to pitches with known graphitization properties, an extrapolation of the pitch can be estimated knowing the amount of carbon present and the aromaticity of the pitches being studied. 


\subsection{Summary Background Remarks}

The above analytical techniques will give the general characteristics that are directly related to coal conversion conditions. There is a difference in behavior of the products as the reaction conditions of liquefaction vary. For example, if the reaction temperature increases, the softening point of the heptane insoluble fraction decreases, the coking value decreases, and sample has larger mesophase domains.

The production of carbon materials from coal is expected to give better yield and quality than petroleum feedstock because of the increase of impurities in the petroleum such as sulfur and vanadium, that are detrimental to coke formation and use. Direct coal liquefaction is concentrated on producing a range of materials oriented towards premium light products and at the same time minimizing excessive by-product gases. In the conversion of coal to liquid products, several fractions can be selected. A potential economic advantage might be obtained by optimizing the process to produce high-value carbon precursors while using the other fractions as transportation fuel. Finally, the availability and reserves of coal are far greater than those of petroleum. 


\section{Chapter 3:}

\section{Experimental Procedures}

The characterization of the liquefaction fractions was accomplished by several analytical procedures. Special emphasis is placed on the asphaltene fraction. In order to determine the possible uses of these fractions, the properties of softening point, coking value, ash content, solubility, optical texture and mesophase formation were evaluated.

\subsection{Liquefaction Reaction}

At NETL/DOE direct liquefaction is employed to obtain crude liquefaction oil from coal. These reaction products form the basis of the work presented in this thesis. Coal liquefaction was accomplished in a 1-L semibatch autoclave reactor under various reaction conditions. The feed is comprised of coal along with either a coal-derived recycle solvent (V-1074) or a petroleum-derived solvent (Hondo) and $\mathrm{H}_{2}$ or a mixture of $\mathrm{H}_{2}$ and $\mathrm{H}_{2} \mathrm{~S}(97: 3)$ at a flow rate of $5+/-0.1 \mathrm{SCFH}$. The mixture of $3 \%$ hydrogen sulfide $\left(\mathrm{H}_{2} \mathrm{~S}\right)$ and $97 \%$ hydrogen $\left(\mathrm{H}_{2}\right)$ is used as a catalyst in some runs. The gas phase is flowing during the heat-up and reaction and is controlled by a Brooks mass flow meter. The gas phase is flowing during the reaction in order to keep the partial pressure of the gas constant and keep its concentration high to encourage a high liquefaction conversion. The pressure ranges between 500 and 1500 psig and the temperature between $350-425^{\circ} \mathrm{C}$. The reaction time is held constant at 60 minutes for most of the runs. A summary of the reaction conditions is presented in Table 3.1. The V-1074 is a heavy distillate oil obtained from a recycle stream of the coal liquefaction pilot plant in Wilsonville, Alabama which operated at a scale of 6 tons of coal per day. The Hondo solvent is the vacuum tower bottoms of the petroleum distillation performed at the Paramount Refinery Petroleum Corp. in California. The analyses of each of the solvents are presented in the Table 3.2. The coal in the reaction is Pittsburgh \#8. It is a bituminous coal indigenous to western Pennsylvania, eastern Ohio and West Virginia. The ultimate and proximate analyses for the coal are presented in Table 3.3. 
Table 3.1: Experimental conditions for liquefaction runs performed at NETL/DOE, Pittsburgh, PA

\begin{tabular}{|c|c|c|c|c|c|c|}
\hline Run & $\begin{array}{c}\text { Temperature } \\
\left({ }^{\mathbf{C}} \mathbf{C}\right)\end{array}$ & $\begin{array}{c}\text { Pressure } \\
(\mathbf{p s i g})\end{array}$ & Gas & Solvent & Coal & $\begin{array}{c}\text { Reaction } \\
\text { Time (min) }\end{array}$ \\
\hline 1 & 390 & 1500 & $\mathrm{H}_{2}$ & $\mathrm{~V}-1074$ & PGH \#8 & 60 \\
\hline 2 & 390 & 1500 & $\mathrm{H}_{2}$ & Hondo & PGH \#8 & 60 \\
\hline 3 & 350 & 1500 & $\mathrm{H}_{2}$ & V-1074 & PGH \#8 & 60 \\
\hline 4 & 350 & 1500 & $\mathrm{H}_{2}$ & Hondo & PGH \#8 & 60 \\
\hline 5 & 350 & 1000 & $\mathrm{H}_{2}$ & V-1074 & PGH \#8 & 30 \\
\hline 6 & 350 & 1000 & $\mathrm{H}_{2}$ & Hondo & PGH \#8 & 30 \\
\hline 7 & 390 & 1000 & $\mathrm{H}_{2}$ & $\mathrm{~V}-1074$ & PGH \#8 & 60 \\
\hline 8 & 425 & 1000 & $\mathrm{H}_{2}$ & $\mathrm{~V}-1074$ & PGH \#8 & 60 \\
\hline 9 & 425 & 1500 & $\mathrm{H}_{2}$ & $\mathrm{~V}-1074$ & PGH \#8 & 60 \\
\hline 10 & 425 & 1000 & $\mathrm{H}_{2}$ & $\mathrm{~V}-1074$ & PGH \#8 & 60 \\
\hline 11 & 425 & 500 & $\mathrm{H}_{2}$ & $\mathrm{~V}-1074$ & PGH \#8 & 60 \\
\hline 12 & 425 & 1500 & $\mathrm{H}_{2}$ & $\mathrm{H}$ Hondo & PGH \#8 & 60 \\
\hline 13 & 390 & 1500 & $3 \% \mathrm{H}_{2} \mathrm{~S}$ & $\mathrm{~V}-1074$ & PGH \#8 & 60 \\
\hline 14 & 410 & 1500 & $3 \% \mathrm{H}_{2} \mathrm{~S}$ & $\mathrm{~V}-1074$ & PGH \#8 & 60 \\
\hline 15 & 410 & 1000 & $3 \% \mathrm{H}_{2} \mathrm{~S}$ & $\mathrm{~V}-1074$ & PGH \#8 & 60 \\
\hline 16 & 410 & 500 & $3 \% \mathrm{H}_{2} \mathrm{~S}$ & $\mathrm{~V}-1074$ & PGH \#8 & 60 \\
\hline 17 & 390 & 1000 & $3 \% \mathrm{H}_{2} \mathrm{~S}$ & $\mathrm{~V}-1074$ & PGH \#8 & 60 \\
\hline 18 & 410 & 1000 & $3 \% \mathrm{H}_{2} \mathrm{~S}$ & $\mathrm{~V}-1074$ & None & 60 \\
\hline
\end{tabular}

Table 3.2: Properties of reaction solvents used

\begin{tabular}{|c|c|c|}
\hline Property & V-1074 & Hondo \\
\hline Carbon, \% & $89.2+/-0.20$ & $81.9+/-0.20$ \\
\hline Hydrogen, \% & $9.0+/-0.07$ & $10.6+/-0.07$ \\
\hline Oxygen, \% & $1.05+/-0.10$ & $1.6+/-0.10$ \\
\hline Nitrogen, \% & $0.7+/-0.03$ & $0.9+/-0.03$ \\
\hline Sulfur, \% & $<0.050$ & $5.0+/-0.05$ \\
\hline Ash, \% & $<0.1$ & $<0.1$ \\
\hline
\end{tabular}

* Data obtained from DOE/NETL 
Table 3.3:Ultimate and proximate analyses of Pittsburgh \#8 coal

\begin{tabular}{|c|c|}
\hline Property & Value \\
\hline Carbon, \% & 75.35 \\
\hline Hydrogen, \% & 5.04 \\
\hline Oxygen, \% & 7.27 \\
\hline Nitrogen, \% & 1.30 \\
\hline Sulfur, \% & 2.17 \\
\hline Chlorine, \% & 8.16 \\
\hline Volatile Matter, \% & 35.18 \\
\hline Fixed carbon, \% & 56.03 \\
\hline Ash, \% & 8.79 \\
\hline Moisture, \% & 1.62 \\
\hline
\end{tabular}

The reaction mixture for each run is $70 \%$ (280 grams) solvent and $30 \%$ (120 grams) coal. The temperature, pressure, gas and solvents are varied in order to obtain different product distributions. The coal is mixed with the solvent and then pumped into the reactor. The gas phase is added continuously. The temperature is then raised at an approximate rate of $2^{\circ} \mathrm{C} / \mathrm{min}$ with $1000+/-10 \mathrm{rpm}$ stirring. It is held at the desired reaction temperature for 60 minutes. A collection bottle is put in the exit gas stream to collect the condensable and gas products. Following the reaction, the reactor is cooled to ambient temperature at the same rate $\left(2^{\circ} \mathrm{C} / \mathrm{min}\right)$ without gas phase flowing, depressurized and the products removed. During the pressurization another gas sample is obtained and analyzed. Note that the liquefaction procedures for the different reaction conditions are performed entirely in DOE/NETL. 


\subsection{Characterization of Individual Fractions}

\subsubsection{Solvent Fractionation}

Solvent extraction is used to fractionate the liquefaction products because various solvents are selective for specific classes of organic compounds. The determination of solubility will also aid in identifying the characteristics of the species in the asphaltene fraction at the various reaction conditions.

When the reaction is complete and the reactor cooled down, tetrahydrofuran (THF) is used to remove the entire reaction product (i.e., raw reaction mixture plus solvent) from the reactor. The amount of THF is that necessary for the removal of the product from the reactor. This mixture is then sonicated in a one gallon glass jar for thirty (30) minutes and filtered in a Millipore pressure filtration unit with a pressure of about 30 psig $\mathrm{N}_{2}$ and a $0.45 \mu \mathrm{m}$ filter paper, in order to separate the insoluble and the soluble THF fractions. The THF-insoluble fraction will be referred to in the context of this research as the residue. The THF remaining in the soluble fraction is removed by means of a rotary evaporator and oven (Figure 3.1). Heptane is then added to this soluble fraction. The amount of heptane added is that necessary to remove the fraction from the rotary evaporator flask. The new mixture is sonicated for thirty (30) minutes and filtered again using the same procedure to isolate the heptane-soluble and heptane-insoluble fraction. The heptane-soluble fraction will be referred to in the context of this research as oil. These extractions are performed at DOE/NETL facility in Pittsburgh. The samples received at WVU from NETL for characterization are the residue, oil and THF-soluble, heptane-insoluble fractions. The amount of each fraction received from DOE/NETL is presented in Table 3.4. Note that the data in Table 3.4 were obtained directly from DOE/NETL raw data sheets. 


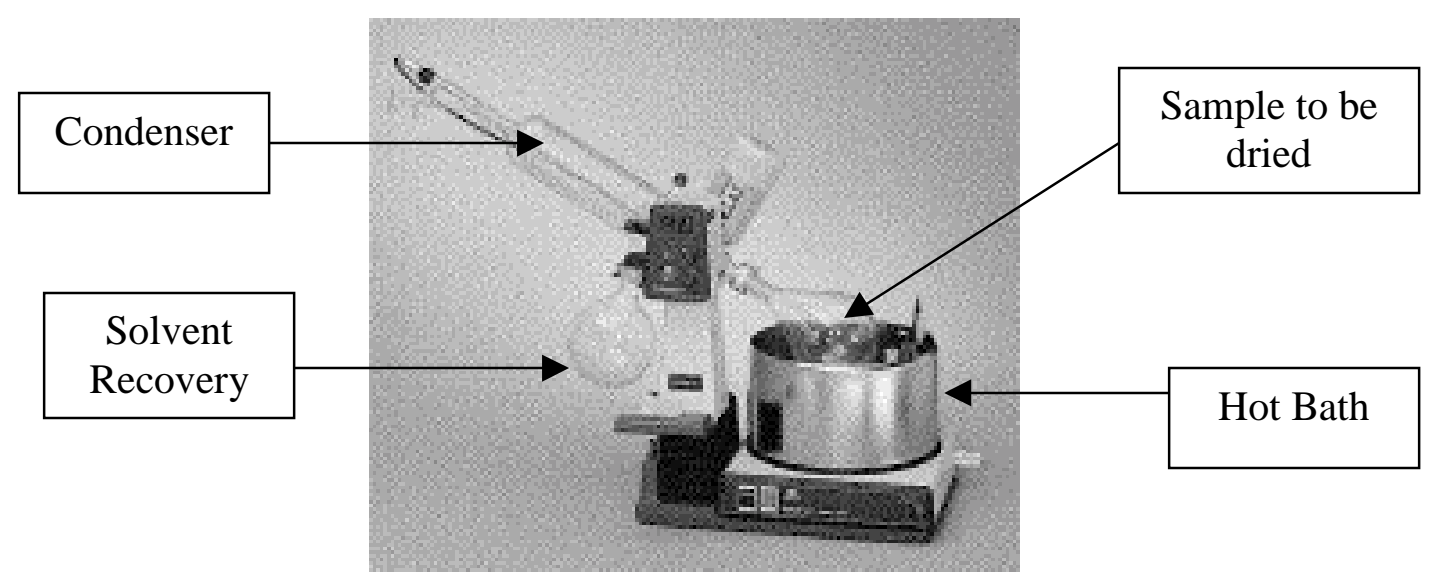

Figure 3.1: Rotary evaporator used for solvent removal

Table 3.4: Amount of fractions produced at DOE/NETL for various reaction conditions as shown in Table 3.1

\begin{tabular}{|c|c|c|c|}
\hline Run & THF Ins (g) & Hept Ins (g) & Hept Sol (g) \\
\hline 1 & 30.0 & 104.4 & 264.8 \\
\hline 2 & 29.7 & 65.0 & 245.5 \\
\hline 3 & 69.9 & 63.0 & 286.4 \\
\hline 4 & 94.9 & 76.3 & 238.1 \\
\hline 5 & 75.8 & 52.7 & 260.6 \\
\hline 6 & 103.1 & 74.9 & 209.7 \\
\hline 7 & 35.9 & 138.0 & 231.1 \\
\hline 8 & 38.8 & 127.0 & 196.3 \\
\hline 9 & 31.9 & 101.1 & 225.0 \\
\hline 10 & 36.7 & 148.5 & 188.8 \\
\hline 11 & 49.6 & 142.7 & 178.9 \\
\hline 12 & 97.9 & 69.1 & 153.8 \\
\hline 13 & 33.8 & 117.1 & 243.0 \\
\hline 14 & 28.8 & 98.8 & 268.4 \\
\hline 15 & 15.8 & 123.4 & 237.1 \\
\hline 16 & 37.8 & 127.5 & 220.3 \\
\hline 17 & 37.2 & 111.0 & 220.3 \\
\hline 18 & 1.6 & 18.9 & 378.6 \\
\hline & & & \\
\hline
\end{tabular}


Additional solvents were used on these fractions at the West Virginia University lab, namely toluene and N-methylpyrrolidone (NMP). The THF-soluble, heptaneinsoluble fraction is further extracted with toluene in order to separate the asphaltene and preasphaltene fractions. The toluene-soluble fraction is referred to as the asphaltene fraction while the insoluble fraction is referred to as preasphaltene fraction. The NMP extraction was performed in an effort to isolate valuable species in the THF residue, since NMP is typically a better solvent for coal than THF. The toluene and NMP dissolution performed at WVU is done using a Soxhlet extraction system. It consists of a condenser, thimble, round-bottom flask, reflux unit and is mounted in a heating source (Figure 3.2). The samples were extracted in a Soxhlet extractor following the procedure below. The samples are suspended in the solvent and quantitatively transferred to the Soxhlet thimble. The thimble is then loaded in the reflux unit and put on the heating source along with the round-bottom flask. It is then allowed to reflux for approximately twenty-four (24) hours. The soluble fraction liquid (sample in flask) is dried using a rotary evaporator (Figure 3.1) to remove the solvent. After the excess solvent is removed, the soluble fraction along with the insoluble fraction (sample in thimble) is dried in a Napco vacuum oven (Model 5831) with a nitrogen purge of $100 \mathrm{cc} / \mathrm{min}$ to a vacuum at $25-30 \mathrm{in}$. $\mathrm{Hg}$ for approximately twenty-four (24) hours.

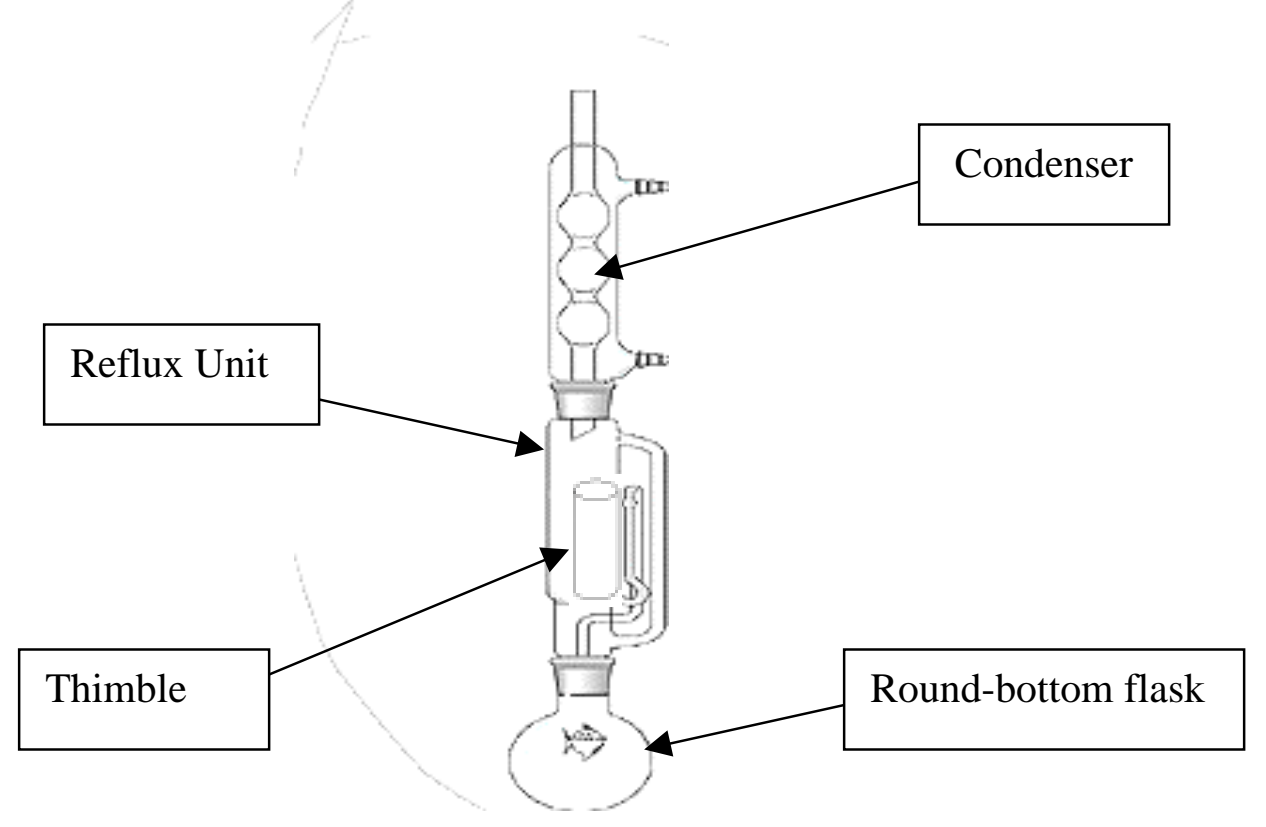

Figure 3.2: Soxhlet extraction system for the preasphaltene and asphaltene separation. 
A schematic of the overall fractionation procedure for this work is shown in Figure 3.3. Both soluble and insoluble fractions are then analyzed and characterized. The softening point, ash content and optical texture for all of the fractions are determined.

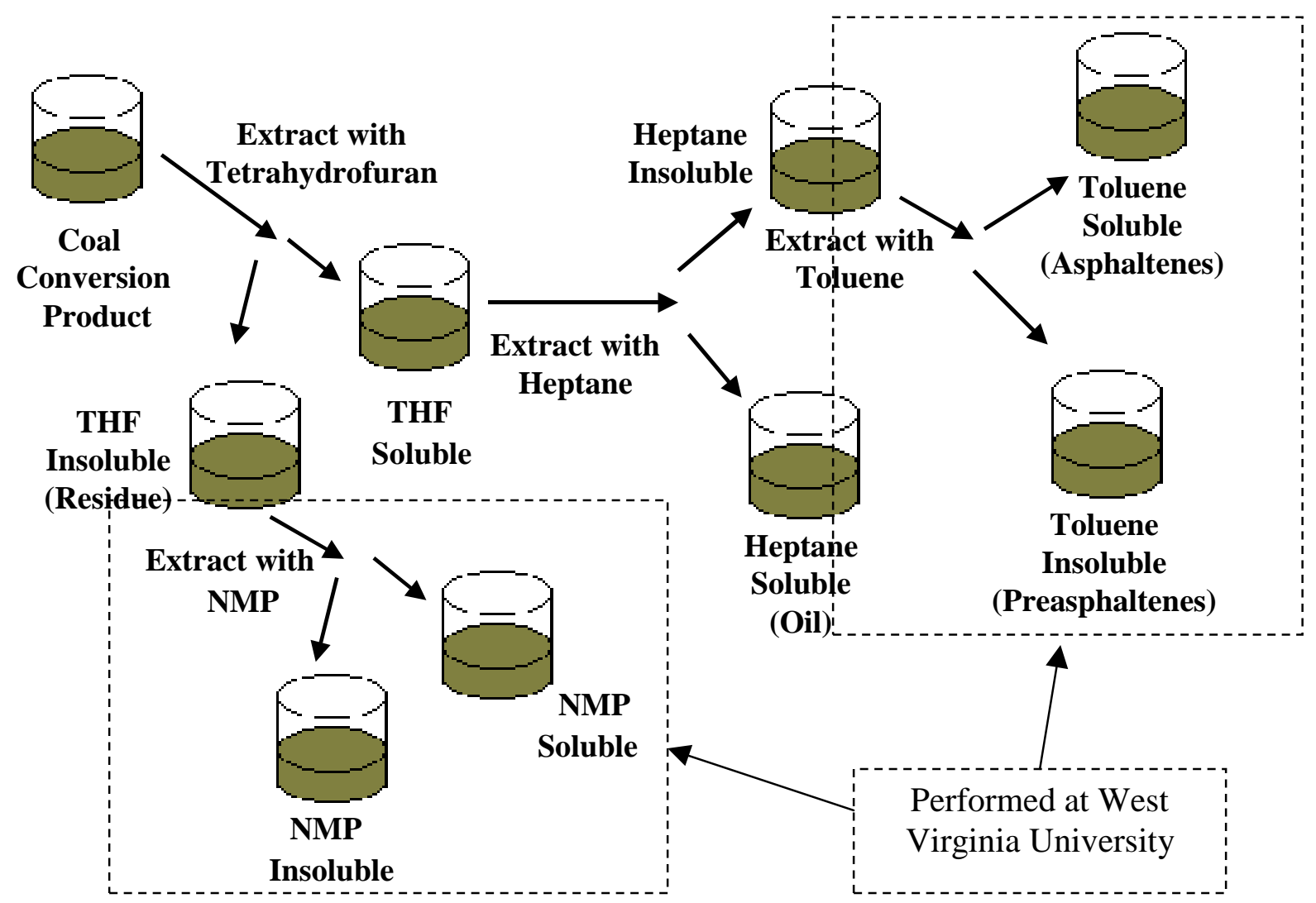

Figure 3.3: Solvent fractionation scheme followed by DOE/NETL and WVU

\subsubsection{Softening Point}

The softening point of each sample is determined by means of a Mettler FP80HT central processor and Mettler FP83HT dropping cell (Figure 3.4), following the ASTM D3104 [3] procedure at WVU. The sample is melted into the sample holder, introduced to the dropping cell, and programmed for a temperature range and heating rate. The softening point in this procedure is defined as the temperature at which the sample, 
suspended in a cylindrical cup with a 1/4-in. hole in the bottom, flows downward for a distance of 0.8 inch to interrupt a light beam, as the sample is heated at a linear rate in air. The softening point is displayed automatically by the apparatus the instant the light beam is interrupted. The parameters for most of the samples are a temperature range of about $100-200^{\circ} \mathrm{C}$ and a heating rate of $2^{\circ} \mathrm{C} / \mathrm{min}$. This test method also helps in determining the consistency of the sample and establishing its uniformity.
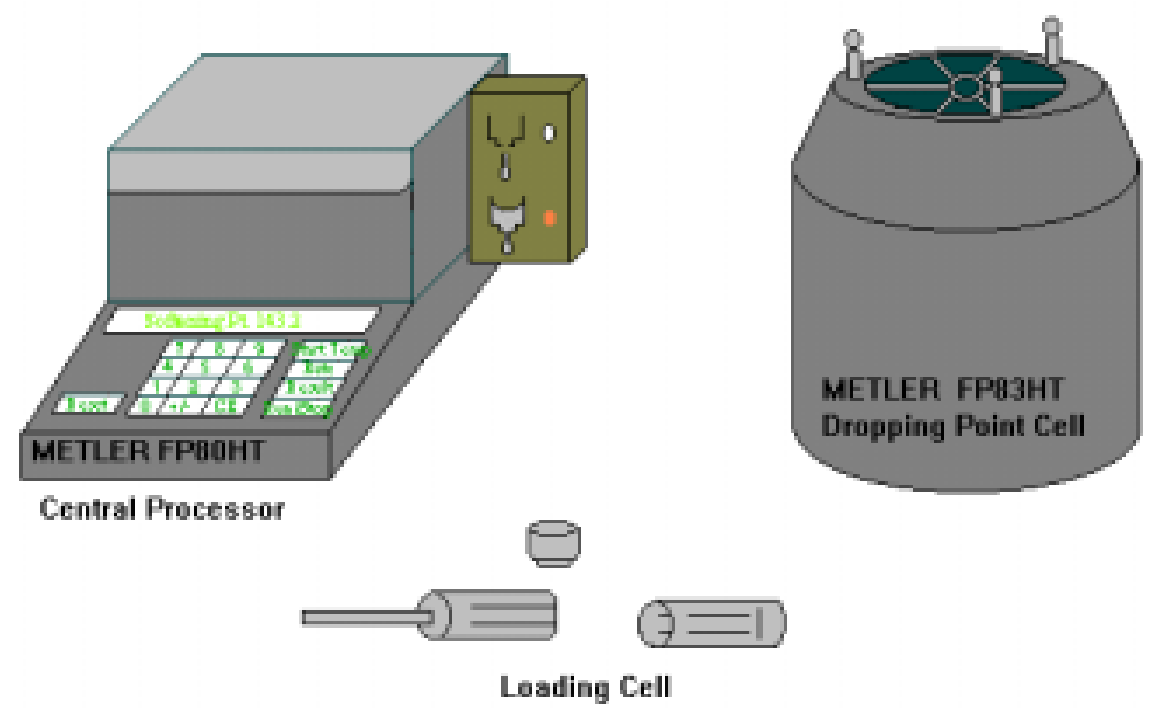

Figure 3.4 Mettler Softening Point Apparatus

\subsubsection{Coking Value}

The coking value of the candidate feedstock is also determined at WVU. Currently, two coking procedures are followed. One is the West Virginia University (WVU) method in which the sample is put in a crucible, which is then covered with coke breeze to prevent oxidation of the sample during the heating. The sample is then placed in a Fisher Scientific Isotemp Programmable Furnace Model 497 to be heated. This heating process is done gradually with a heating rate of $5^{\circ} \mathrm{C} / \mathrm{min}$ until a temperature of $600^{\circ} \mathrm{C}$ is reached. The sample is held at that temperature for two hours and then allowed to cool at a rate of $10^{\circ} \mathrm{C} / \mathrm{min}$ to ambient temperature. The coking value is intended to 
provide some indication of relative coke forming propensity. It is also a valuable piece of information since a high coking value is desired for industrial applications. The coking value is calculated as follows:

$$
\text { Coking Value, } \%=100(\mathrm{~A} / \mathrm{B})
$$

Where:

$$
\begin{aligned}
& A=\text { weight of the coke residue after heating (gram) } \\
& B=\text { weight of initial sample (gram) }
\end{aligned}
$$

A second technique for the determination of the coking value is the ASTM D189 [1] procedure which measures the Conradson carbon residue. Here the sample is coked at high temperature using a gas-fired burner. A high flame is directly applied to an arrangement of crucibles (sample placed in a porcelain crucible which is inside two covered iron crucibles). These crucibles are placed on a triangular wire support surrounded by an insulator covered with a circular iron hood (Figure 3.5). After ten (10) minutes of applying a strong direct flame, the burner is tipped to burn the vapors originating from the sample with a moderate flame. After thirteen (13) minutes a direct strong flame is again applied to the bottom of the crucible arrangement. The system is cooled to room temperature and the coking value is determined gravimetrically as previously mentioned using Equation 3.1.

Both methods were used in this research for two different purposes. To analyze the effect of reaction conditions the ASTM method was used due to its reproducibility and accuracy. Due to its slow heating in the production of the cokes, the WVU method was preferred by the investigator to identify the optical texture and mesophase formation in the different fractions. The values obtained from the ASTM method are the ones reported in the following tables and graphs. 


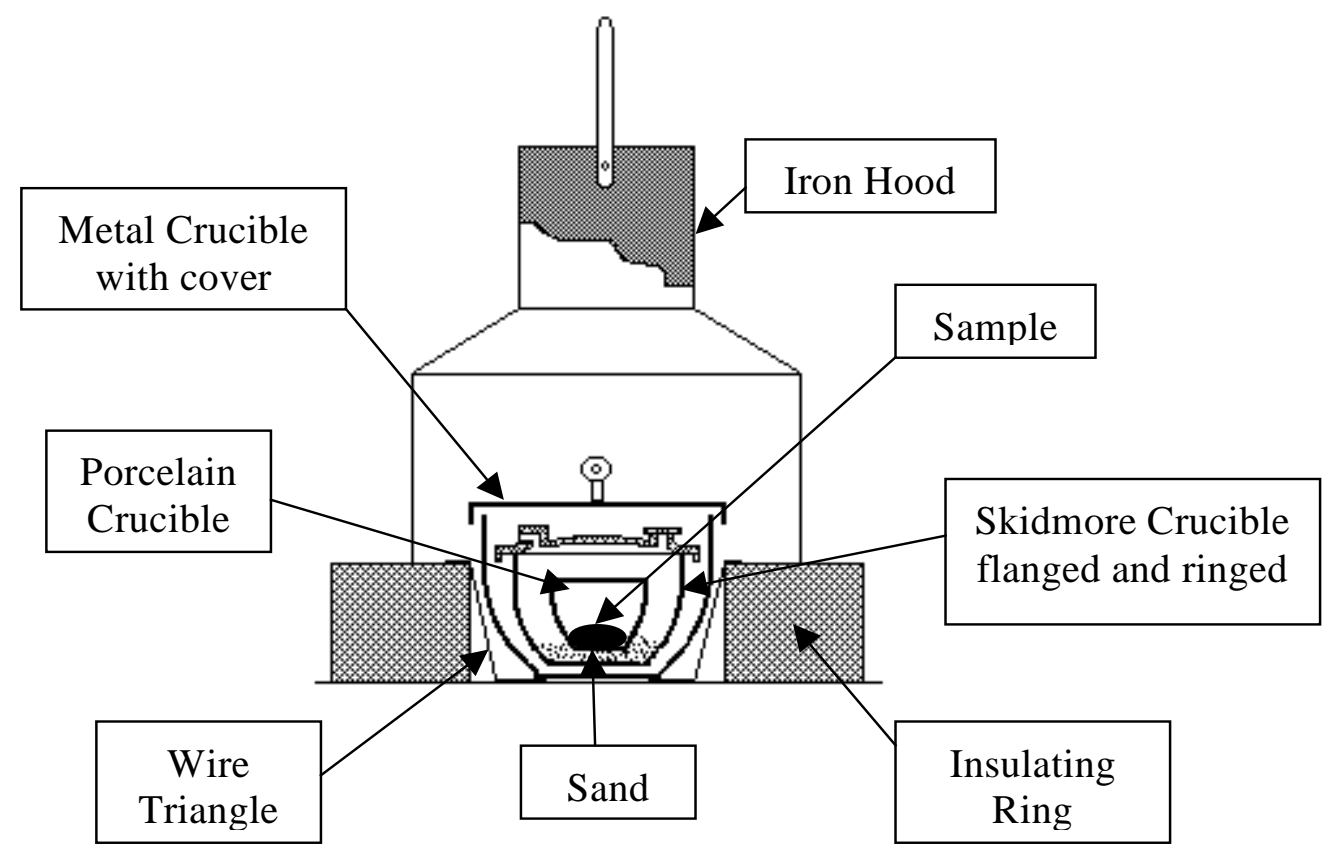

Figure 3.5: Apparatus for determining Conradson Carbon Residue (Coking Value) via ASTM D-189

\subsubsection{Optical Texture}

The optical texture of the samples is determined under an optical microscope (Zeiss Axiostop, West Germany) at WVU using the samples obtained after coking with the WVU method. A pellet of the sample is prepared by potting in epoxy resin and activator and labeling for identification. The pellets are then polished on a polishing table (Buchler Ltd. Metallurgical Apparatus) with different textured abrasive. In addition, they are polished with Alumina of two different particle sizes $(0.3 \mu \mathrm{m}$ and 0.5 $\mu \mathrm{m})$, resulting in a very smooth surface. The sample is then observed under the microscope and the optical texture of the coke is assessed visually. The presence of mesophase (Figure 3.6) indicates the graphitization tendency of the sample. The rectangle in Figure 3.6 points out the elongated crystalline domain. This is revealed by the interchange of colors which occurs by the rotation of the specimen stage illuminated with plane polarized light. The photograph in Figure 3.6 is of the coke from the oil fraction for the liquefaction run at $390{ }^{\circ} \mathrm{C}$ and 1500 psig $\mathrm{H}_{2}$ using the coal-based solvent 
(V-1074). The elongated domain of the sample indicates its anisotropy, which will result in a highly graphitic carbon as opposed to the isotropic coke where the domains would be more sphere -like. This is important in the determination of its future uses. The micrographs of the different fractions are presented in Appendix B.

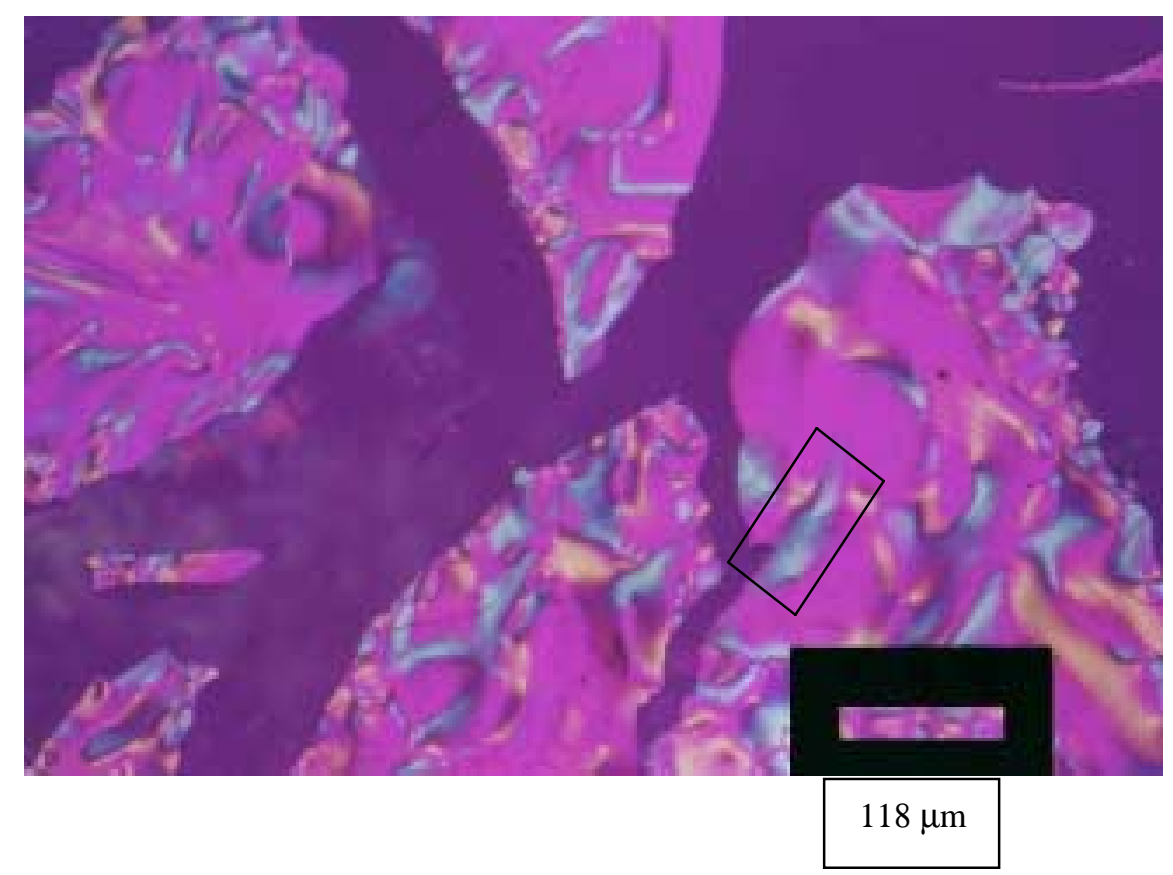

Figure 3.6: Mesophase in the oil fraction from liquefaction run at $390^{\circ} \mathrm{C}$ and $1500 \mathrm{psig}$ $\mathrm{H}_{2}$ using $\mathrm{V}-1074$ as a solvent

\subsubsection{Ash Content}

The ash content of the samples is determined following the ASTM D2415 [2] procedure at WVU in a Fisher Scientific Isotemp Programmable Furnace Model 497. The heating rate is $8^{\circ} \mathrm{C} / \mathrm{min}$ until reaching the temperature of $500{ }^{\circ} \mathrm{C}$, whereupon the heating rate is changed to $4^{\circ} \mathrm{C} /$ min until reaching the final temperature of $750^{\circ} \mathrm{C}$ and held there for three (3) hours. The sample is heated in air. It is then allowed to cool to ambient temperature at a rate of $10^{\circ} \mathrm{C} / \mathrm{min}$. The ash content is an indication of the amount of inorganic material present in the original sample. The ash content is calculated as follows: 
Where:

$$
\begin{aligned}
& A=\text { weight of residual ash (grams) } \\
& B=\text { initial weight of sample (grams) }
\end{aligned}
$$

\subsubsection{Ultimate Analysis}

The ultimate and proximate analyses were performed at DOE/NETL and Galbraith Laboratories in order to determine the moisture, ash and the amount of carbon, hydrogen, nitrogen, sulfur and oxygen present in the sample. The analysis is performed as following. Moisture is determined by heating the sample gently to $105^{\circ} \mathrm{C}$. The weight loss of the sample at this time represents the amount of water present in it. The carbon and hydrogen are measured by first burning the sample and collecting the resulting $\mathrm{CO}_{2}$ and water in chemicals that will absorb them. The weight of $\mathrm{CO}_{2}$ and water can then be used to calculate the weight of carbon and hydrogen by stoichiometry (e.g., 1 gram of $\mathrm{CO}_{2}$ contains $0.273 \mathrm{~g}$ of carbon). Sulfur is converted to sodium sulfate, which in turn is converted to barium sulfate which is insoluble in water and can be collected and dried. The weight of barium sulfate can be used to calculate the amount of sulfur from stoichiometry. Nitrogen is determined by converting it to ammonia and absorbing it in a known amount of acid followed by titration. The amount of ammonia is obtained and the nitrogen calculated. The amount of oxygen is determined by adding the percentage of the other four elements and subtracting this amount from 100. This analysis allowed the determination of $\mathrm{C} / \mathrm{H}$ ratio and was useful for correlating the observed behavior of the fraction in subsequent treatment. 


\subsubsection{Nuclear Magnetic Resonance}

A limited number of liquefaction fractions were analyzed by Nuclear Magnetic Resonance (NMR). The Western Research Institute in Laramie, WY performed NMR analyses. NMR is used to identify and determine the aromatic and aliphatic carbon present in the different fractions.

NMR carbon aromaticity measurements were made on a Chemagnetics CMX solid-state NMR spectrometer using the technique of cross polarization (CP) with magicangle spinning (MAS). NMR spectra were obtained using a ceramic NMR probe equipped with a 7.5-mm zirconia pencil rotor. The ceramic probe eliminates background signals that could arise from the NMR probe when running samples that have low organic carbon contents for which signal averaging over long periods of time is required. The spectra were recorded at a ${ }^{13} \mathrm{C}$ frequency of $25 \mathrm{MHZ}$, using a 90E pulse width of $5 \mathrm{~ms}$, a contact time of $1 \mathrm{~ms}$, a pulse delay of $1 \mathrm{~s}$, and a spinning rate of $4.5 \mathrm{kHz}$.

Single Pulse (SP) measurements were also made using a pulse delay of $60 \mathrm{~s}$. Carbon aromaticities (the percentages of aromatic carbon) obtained from the SP measurements using a $60 \mathrm{~s}$ pulse delay were in good agreement with those obtained by $\mathrm{CP}$ using a $1 \mathrm{~s}$ pulse delay.

For solid-state NMR the instrument is calibrated using a sample of hexamethyl benzene (HMB). Then the chemical shift of the methyl resonance of HMB is set relative to Tetramethysilane (TMS), so that even though TMS is not introduced into the sample, the chemical shifts are referenced to it. The different proton types were defined by the following chemical shift ranges relatively to TMS: aromatic protons, 9.30-6.30 ppm and alipahtic protons, $4.50-0.50 \mathrm{ppm}$. The actual NMR data are presented in Appendix E.

For liquid-state NMR $1 \mathrm{H}$ and 13C NMR spectra were obtained on a Bruker Avance DRX-400 NMR spectrometer. The experimental conditions for recording $1 \mathrm{H}$ spectra were recorded 16 scans, a $5 \mathrm{~s}$ pulse width, an acquisition time of $1.99 \mathrm{~s}$, a pulse 
delay of $20 \mathrm{~s}$, and $32 \mathrm{k}$ time domain points. A line-broadening factor of $0.10 \mathrm{~Hz}$ was applied to the transformed spectrum. The conditions for recording 13C NMR spectra were 4000 scans, a pulse width of $4.0 \mathrm{~s}$, an acquisition time of $0.47 \mathrm{~s}$, a pulse delay of $2.0 \mathrm{~s}$ and $32 \mathrm{k}$ time-domain points. Full broadband $1 \mathrm{H}$ decoupling was used to obtain the 13C spectra. A line-broadening factor of $2 \mathrm{~Hz}$ was applied to the transformed spectrum. 


\section{Chapter 4:}

\section{Results and Discussion}

The results from this research focus mainly on the determination and evaluation of the physical and chemical properties of various coal liquefaction fractions. The coal liquefaction reaction was performed at several reaction conditions which involved the variation of temperature, pressure, solvent and gas phase. These parameters are evaluated to determine the optimized conditions for the production of the desired product. Coking value, softening point, ash content, and mesophase formation are measured for the fractions from the coal liquefaction reaction. Overall mass and ash balances are also presented. In addition a limited number of fractions were sent for NMR and ultimate analysis. Each of these aspects is discussed below in the following sections.

In order to determine the accuracy of the methods used in the acquisition of the data presented the error was determined. Two types of errors are presented throughout this chapter, relative and absolute error. A relative error is cited as the percent variation of the average value of the number reported, e.g., An error of $+/-5 \%$ in a value of 30.1 means a range of error of 29.05 to 31.15 . In other words, $30.1 \%+/-(0.05 * 30.1)$. The relative error was determined by the difference between two values at the same conditions. Equation 4.1 was used to calculate such an error:

$$
\text { \%error }=\left(\frac{\mid \text { Value } \# 1-\text { Value } \# 2 \mid}{\left(\frac{\text { Value } \# 1+\text { Value } \# 2}{2}\right)}\right) * 100
$$

The absolute error reported herein was obtained from the outside laboratories. It is cited as the actual error of the value of the experimental data. It gives a range of error, e.g. An absolute error of $+/-1$ of a value of 30.1 means that the range of error is between 31.1 and 29.1. When errors are quoted in the text, they will always be specified as either relative or absolute error. 


\subsection{Mass Balance}

As mentioned previously, the coal liquefaction reaction was performed at DOE/NETL along with the THF and heptane extractions. The results of a mass balance calculation for the various reaction conditions are presented in Table 4.1. This table shows the mass balance values for the coal liquefaction and its fractions. The various run conditions are stated in Table 3.3. Adding the products of the reaction and subtracting this amount from the reagents (coal and solvent) fed to the reactor resulted in the mass balance. The product fractions considered for this mass balance are the THF-Insoluble, Heptane-Insoluble, Heptane-Soluble fractions and the Gas Products. The gas products values presented did not include the hydrogen, oxygen, or nitrogen at either the tail gas (gas collected during reaction) or flash gas (gas collected once the reaction was over) but all the others gases present. The values of the oxygen and nitrogen content for each run are presented in Appendix D. These values were obtained from DOE/NETL raw data sheets. For the mass balances in all but the last case, 120 grams of coal plus 280 grams of solvent (either Hondo or V-1074) constituted the raw reaction feed. In the last case the raw reaction feed consisted of 400 grams of the solvent $\mathrm{V}-1074$. This was done in order to assess the behavior of the solvent without coal in the reaction. In this run the product is concentrated in the heptane-soluble-fraction. As noted in Table 4.1, the reaction output does not add up to exactly the reaction input. In all but two cases, however the overall mass balances close to less than $10 \%$, which for this type of experiment is very good. Moreover, in all but six runs, the mass balances are negative, i.e., less mass remains after the reaction than is initially fed to the reactor.

This negative difference is most likely due to removal of the lighter reaction products during the solvent evaporation step which is performed after the solvent extraction. Moreover, the $\mathrm{H}_{2}$ gas purge during the reaction will carry some gases and volatiles out of the reactor. In order to collect the condensable and sample for gas analysis, a trap was attached to the outer gas stream. The condensables are then returned to the reactor and they go mainly to the heptane soluble (oil) fraction. For the results of the gas analysis, it was found that the presence of nitrogen and oxygen accounted for the 
Table 4.1: Overall mass balance of the coal liquefaction reactions

\begin{tabular}{|c|c|c|c|c|c|c|c|c|c|c|c|}
\hline Run & $\begin{array}{c}\text { In } \\
\text { Coal (g) }\end{array}$ & \begin{tabular}{|c|} 
In \\
Solvent (g)
\end{tabular} & $\begin{array}{l}\text { Total } \\
\text { In (g) }\end{array}$ & $\begin{array}{c}\text { Out } \\
\text { THF Ins (g) }\end{array}$ & $\begin{array}{c}\text { Out } \\
\text { THF Sol (g) }\end{array}$ & $\begin{array}{c}\text { Out } \\
\text { Hept Ins (g) }\end{array}$ & $\begin{array}{c}\text { Out } \\
\text { Hept Sol (g) }\end{array}$ & $\begin{array}{c}\text { Out } \\
\text { Gas products }(\mathrm{g})\end{array}$ & $\begin{array}{c}\text { Total } \\
\text { Out (g) }\end{array}$ & Out -In $(\mathrm{g})$ & $\begin{array}{c}\text { (Out-In)/Feed } \\
(\%)\end{array}$ \\
\hline 1 & 120.0 & 280.1 & 400.1 & 30.0 & 486.8 & 104.4 & 264.8 & 2.150 & 401.4 & 1.3 & 0.31 \\
\hline 2 & 120.0 & 280.5 & 400.5 & 29.7 & 332.3 & 65.0 & 245.5 & 2.923 & 343.2 & -57.3 & -14.31 \\
\hline 3 & 120.0 & 280.0 & 400.0 & 69.9 & 386.8 & 63.0 & 286.4 & 0.334 & 419.6 & 19.6 & 4.89 \\
\hline 4 & 120.1 & 280.1 & 400.2 & 94.9 & 342.0 & 76.3 & 238.1 & 0.427 & 409.7 & 9.5 & 2.39 \\
\hline 5 & 120.0 & 280.0 & 400.0 & 75.8 & 330.6 & 52.7 & 260.6 & 0.000 & 389.2 & -10.8 & -2.70 \\
\hline 6 & 120.0 & 280.0 & 400.0 & 103.1 & 298.8 & 74.9 & 209.7 & 1.235 & 388.9 & -11.1 & -2.77 \\
\hline 7 & 120.0 & 280.0 & 400.0 & 35.9 & 352.1 & 138.0 & 231.1 & 1.371 & 406.4 & 6.4 & 1.59 \\
\hline 8 & 120.0 & 280.0 & 400.0 & 38.8 & 337.5 & 127.0 & 196.3 & 7.412 & 369.5 & -30.5 & -7.62 \\
\hline 9 & 120.0 & 280.0 & 400.0 & 31.9 & 352.0 & 101.1 & 225.0 & 4.736 & 362.7 & -37.3 & -9.32 \\
\hline 10 & 120.0 & 280.0 & 400.0 & 36.7 & 339.5 & 148.5 & 188.8 & 5.826 & 379.8 & -20.2 & -5.04 \\
\hline 11 & 120.0 & 280.0 & 400.0 & 49.6 & 333.0 & 142.7 & 178.9 & 6.301 & 377.5 & -22.5 & -5.62 \\
\hline 12 & 120.0 & 280.0 & 400.0 & 97.9 & 247.0 & 69.1 & 153.8 & 12.568 & 333.4 & -66.6 & -16.66 \\
\hline 13 & 120.0 & 280.0 & 400.0 & 33.8 & 428.0 & 117.1 & 243.0 & 11.312 & 405.2 & 5.2 & 1.30 \\
\hline 14 & 120.0 & 280.0 & 400.0 & 28.8 & 392.1 & 98.8 & 268.4 & 3.011 & 399.0 & -1.0 & -0.25 \\
\hline 15 & 120.0 & 280.0 & 400.0 & 15.8 & 389.2 & 123.4 & 237.1 & 3.442 & 379.7 & -20.3 & -5.06 \\
\hline 16 & 120.0 & 280.0 & 400.0 & 37.8 & 372.1 & 127.5 & 220.3 & 13.005 & 398.6 & -1.4 & -0.35 \\
\hline 17 & 120.0 & 280.0 & 400.0 & 37.2 & 395.0 & 111.0 & 220.3 & 4.312 & 372.8 & -27.2 & -6.80 \\
\hline 18 & 0.0 & 400.0 & 400.0 & 1.6 & 431.4 & 18.9 & 378.6 & 13.060 & 412.2 & 12.2 & 3.04 \\
\hline
\end{tabular}

\footnotetext{
* Data obtained from DOE/NETL liquefaction raw sheets data. Run six (6) and fourteen (14) gas product includes only tail gas, flash number not available.
} 
majority of the mass in the gas mixture. Clearly these gases can not be part of the product. These values were not included as part of the gas products in the mass balance because this may be a result of a leakage in the connections to the trap or a problem with the Gas Chromatography (GC) analysis.

The negative mass balance can have consequences. The fact that some of the lighter reaction products are removed from the mixture, may result in a higher softening point for the fractions. The products would contain more of the heavier compounds and thus would need a higher temperature to flow (softening point). The ash content and coking value would also be affected and appear to be high because the volatile matter (i.e., lighter compounds) that might be present in the sample would have already been removed during the solvent evaporation and hence not accounted for in the ash and coke determination. If the difference in mass were due to poor technique, the only affected value would be the yield obtained for the different fractions and not necessarily their physical properties.

The six positive mass balances are no doubt due to some solvent retention in the reaction mass after solvent extraction. It is important to note here that the softening point of the fraction in particular could be affected by the presence of even small amounts of residual solvent in the sample. The softening point will decrease. The presence of solvent could also affect the other properties of the fractions as well, for example, a lower coking value and ash content smaller than the true value. The solubility would also be affected, making the sample appear more soluble, because of the presence of more light compounds in the fractions. On the whole, however, the mass balances for most of the reactions close to about $10 \%$ which for such a reactor system is quite reasonable.

\subsection{Ash Balance}

The ash balance for the liquefaction fractions was performed for all the reaction conditions and is presented in Table 4.2. The ash for all the reacted fractions and the feed was determined at WVU following the ASTM D 2415 Standard Test Method for Ash in. 
Table 4.2: Ash balance of the coal liquefaction fraction at all the reaction conditions

\begin{tabular}{|c|c|c|c|c|c|c|c|c|c|}
\hline Run & $\begin{array}{c}\text { Ahs In }(\mathrm{g}) \\
\text { Coal }\end{array}$ & $\begin{array}{c}\text { Ash In }(\mathrm{g}) \\
\text { Solvent }\end{array}$ & $\begin{array}{c}\text { Total Ash } \\
\text { In }(\mathbf{g})\end{array}$ & $\begin{array}{c}\text { Ash Out }(\mathrm{g}) \\
\text { THF Ins }\end{array}$ & $\begin{array}{c}\text { Ash Out(g) } \\
\text { Hept Ins }\end{array}$ & $\begin{array}{c}\text { Ash Out(g) } \\
\text { Hept Sol }\end{array}$ & $\begin{array}{c}\text { Total A sh } \\
\text { Out (g) }\end{array}$ & $\begin{array}{c}\text { Out-In } \\
(\mathrm{g})\end{array}$ & $\begin{array}{c}\text { (Out-In)/In } \\
(\%)\end{array}$ \\
\hline 1 & 10.32 & 0.140 & $\mathbf{1 0 . 4 6 0}$ & 9.345 & 0.303 & 0.424 & $\mathbf{1 0 . 0 7 1}$ & -0.389 & -3.7 \\
\hline 2 & 10.32 & 0.252 & $\mathbf{1 0 . 5 7 2}$ & 5.465 & 0.169 & 0.123 & $\mathbf{5 . 7 5 7}$ & -4.816 & -45.6 \\
\hline 3 & 10.32 & 0.14 & $\mathbf{1 0 . 4 6}$ & 10.904 & 0.107 & 0.544 & $\mathbf{1 1 . 5 5 6}$ & 1.096 & 10.5 \\
\hline 4 & 10.329 & 0.252 & $\mathbf{1 0 . 5 8 1}$ & 10.249 & 0.198 & 0.143 & $\mathbf{1 0 . 5 9 0}$ & 0.010 & 0.1 \\
\hline 5 & 10.32 & 0.14 & $\mathbf{1 0 . 4 6}$ & 10.385 & 0.058 & 0.521 & $\mathbf{1 0 . 9 6 4}$ & 0.504 & 4.8 \\
\hline 6 & 10.32 & 0.252 & $\mathbf{1 0 . 5 7 2}$ & 10.228 & 0.217 & 0.063 & $\mathbf{1 0 . 5 0 8}$ & -0.064 & -0.6 \\
\hline 7 & 10.32 & 0.14 & $\mathbf{1 0 . 4 6}$ & 10.939 & 0.304 & 0.046 & $\mathbf{1 1 . 2 8 9}$ & 0.829 & 7.9 \\
\hline 8 & 10.32 & 0.14 & $\mathbf{1 0 . 4 6}$ & 10.534 & 0.241 & 0.098 & $\mathbf{1 0 . 8 7 4}$ & 0.414 & 4.0 \\
\hline 9 & 10.32 & 0.14 & $\mathbf{1 0 . 4 6}$ & 10.559 & 0.192 & 0.810 & $\mathbf{1 1 . 5 6 1}$ & 1.101 & 10.5 \\
\hline 10 & 10.32 & 0.14 & $\mathbf{1 0 . 4 6}$ & 10.166 & 0.045 & 0.038 & $\mathbf{1 0 . 2 4 8}$ & -0.212 & -2.0 \\
\hline 11 & 10.32 & 0.14 & $\mathbf{1 0 . 4 6}$ & 8.878 & 0.100 & 0.125 & $\mathbf{9 . 1 0 4}$ & -1.356 & -13.0 \\
\hline 12 & 10.32 & 0.252 & $\mathbf{1 0 . 5 7 2}$ & 9.986 & 0.062 & 0.123 & $\mathbf{1 0 . 1 7 1}$ & -0.401 & -3.8 \\
\hline 13 & 10.32 & 0.14 & $\mathbf{1 0 . 4 6}$ & 11.289 & 0.129 & 0.122 & $\mathbf{1 1 . 5 4 0}$ & 1.080 & 10.3 \\
\hline 14 & 10.32 & 0.14 & $\mathbf{1 0 . 4 6}$ & 11.693 & 0.109 & 0.188 & $\mathbf{1 1 . 9 8 9}$ & 1.529 & 14.6 \\
\hline 15 & 10.32 & 0.14 & $\mathbf{1 0 . 4 6}$ & 5.040 & 0.123 & 0.119 & $\mathbf{5 . 2 8 2}$ & -5.178 & -49.5 \\
\hline 16 & 10.32 & 0.14 & $\mathbf{1 0 . 4 6}$ & 10.508 & 0.038 & 0.022 & $\mathbf{1 0 . 5 6 9}$ & 0.109 & 1.0 \\
\hline 17 & 10.32 & 0.14 & $\mathbf{1 0 . 4 6}$ & 13.615 & 0.222 & 0.050 & $\mathbf{1 3 . 8 8 7}$ & 3.427 & 32.8 \\
\hline 18 & 0 & 0.2 & $\mathbf{0 . 2}$ & 0.001 & 0.034 & 0.265 & $\mathbf{0 . 3 0 0}$ & 0.100 & 50.1 \\
\hline
\end{tabular}

\footnotetext{
* Ash content determination performed at West Virginia University
} 
Coal Tar and Pitch. The ash content was calculated by multiplying the amount of the individual fraction by the ash percentage of the sample. The ash content of the feed, comprised of ash from both the coal and solvent (either Hondo or V-1074), was subtracted from the sum of the ash of the reaction products comprised of THF Insoluble, Heptane Insoluble and Heptane Soluble. The various run conditions are presented in Table 3.1

Table 4.2 shows that the ash content of the output is different than the ash content of the input. Most of the runs give a positive ash balance which means that there is apparently more ash in the output than in the input. This result is consistent with a negative overall mass balance since loss of organic mass in the product fractions would lead to an artificially higher ash value in the products. Moreover, only six runs were negative, i.e., ash of the input feed is larger than the ash of the output.

The ash balance seems to follow a random distribution of error through the various reaction conditions and its trend is only slightly related to the mass balance difference. Since the ash balance calculations are based on the mass balance, an error in the mass balance will carry over to the ash balance. It is necessary to mention that the accuracy of the ash determination is generally good. It was found that there is only around $+/-5 \%$ relative error in the reproducibility of the ash determination. The runs with the anomalously high ash balances $(2,15,17$ and 18) can be explained further. In runs number two (2) and fifteen (15), the amount of the THF-insoluble is very small when compared to the other THF-Insoluble fractions. Since this fraction contributes to the main ash content of the product, this smaller mass causes the ash content of the output to decrease significantly. In run seventeen (17), the ash content of the THF-insoluble was higher than the other THF-insoluble fractions resulting in a large positive difference in the ash balance. In run number eighteen (18), the difference in the ash content is large because no coal is being fed to the reactor. Hence the amount of ash in both the products and the feed is very small making it difficult to determine with great accuracy. 


\subsection{Parameter Evaluation}

A total of eighteen (18) coal liquefaction runs were performed at DOE/NETL. In order to evaluate the effect of reaction temperature and solvent, nine runs were used. These runs were one (1) to five (5), seven (7) to nine (9) and twelve (12), (refer to Table 3.1 for reaction conditions). To analyze the effect of pressure run eleven (11) was compared to runs eight (8) and nine (9). When analyzing the effect of the $3 \% \mathrm{H}_{2} \mathrm{~S} / \mathrm{H}_{2}$ mixture, runs thirteen (13) and seventeen (17) are compared to runs one (1) and seven (7). The effect of reaction temperature and pressure using the $3 \% \mathrm{H}_{2} \mathrm{~S} / \mathrm{H}_{2}$ mixture was studied using runs fourteen (14) and fifteen (15) in addition of runs thirteen (13) and seventeen(17). Run ten (10) is a repeat of run eight (8). Data of runs six (6) and sixteen (16) were not presented because they could not be compared to any other run, and finally run eighteen (18) was the reaction of the solvent alone with the $\mathrm{H}_{2} \mathrm{~S}$ mixture and was not useful due to the different temperature.

\subsection{Solvent Fractionation}

The reaction conditions affect the product solubility of the various fractions in the different solvents. Accordingly, the amount of the specific species soluble in each fraction will vary and hence the physical and chemical nature of the fraction will be altered. Note that in the discussion below, the reaction products include portions of both the reacted coal and the solvent which was fed in excess to the reactor in 3:7 by weight coal to solvent ratio.

\subsubsection{THF Extraction}

The first of the series of extractions performed on the liquefaction products was the tetrahydrofuran (THF) extraction. This extraction has a relative experimental error of $+/-5.5 \%$. Figure 4.1 shows the solubility of the liquefaction product of the entire reaction mass of reacted coal plus solvent in THF. The data show the solubility in THF of the reaction product to be over $80 \%$ for all the reaction conditions using V-1074. The 


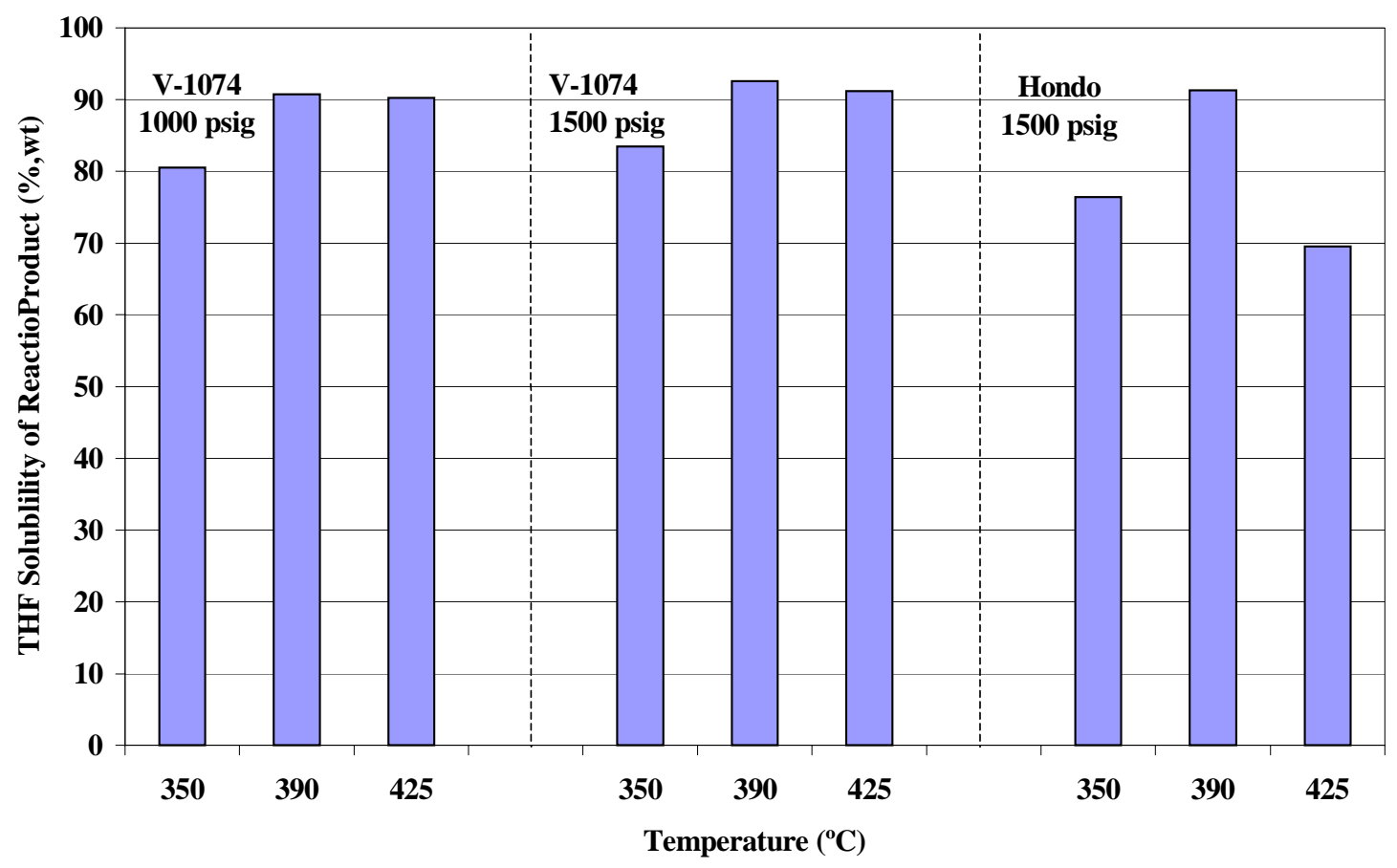

Figure 4.1: Effect of reaction temperature, pressure and solvent on the product solubility in THF for liquefaction in the presence of $\mathrm{H}_{2}$ gas 
solubility of the product increases as the reaction temperature is increased from 350$390^{\circ} \mathrm{C}$. It can also be noted that for the Hondo solvent, the THF solubility peaks at $390^{\circ} \mathrm{C}$ and decreases dramatically at $425^{\circ} \mathrm{C}$. The difference between $390^{\circ} \mathrm{C}$ and $425^{\circ} \mathrm{C}$ using V1074 is almost negligible and is within the experimental error. The use of Hondo as a reaction solvent shows the solubility of the product in THF to be lower for all the reaction temperatures than for the coal-derived solvent.

Figure 4.2 shows the relationship between pressure and THF solubility of the product for the $\mathrm{V}-1074$ solvent at $425^{\circ} \mathrm{C}$. The variation of reaction pressure shows a negligible change in the solubility in THF (about 3\%) from 500 psig to 1000 psig which is within the range of experimental error. A similar small difference of about $2 \%$ is seen between the reaction at $1000 \mathrm{psig}$ and the reaction at $1500 \mathrm{psig}$, again within the range of experimental error. In general, a negligible increase in THF solubility is obtained when the reaction pressure is increased. It is should be mentioned that the necessary amount of THF was used principally to remove the product from the reactor due to its good solubility in THF. This extraction also separates the majority of the ash from the overall reaction mass and concentrates it in the THF-insoluble fraction (residue).

Figure 4.3 presents the effect of the $3 \% \mathrm{H}_{2} \mathrm{~S} / \mathrm{H}_{2}$ on the product solubility in THF for the reaction with the $\mathrm{V}-1074$ solvent at $390^{\circ} \mathrm{C}$. It can be easily noted that addition of $\mathrm{H}_{2} \mathrm{~S}$ has no apparent effect on the THF solubility. At both 1000 psig and $1500 \mathrm{psig}$ the difference in value is $1 \%$ or less which is well within experimental error.

In Figure 4.4 the relationship between reaction temperature and THF solubility can be seen for the $\mathrm{V}-1074$ solvent and the $\mathrm{H}_{2} \mathrm{~S} / \mathrm{H}_{2}$ gas mixture. It is noted in this figure that an increase in temperature when using $\mathrm{H}_{2} \mathrm{~S} / \mathrm{H}_{2}$ at both 1000 and 1500 psig decreases the product solubility in THF significantly. 


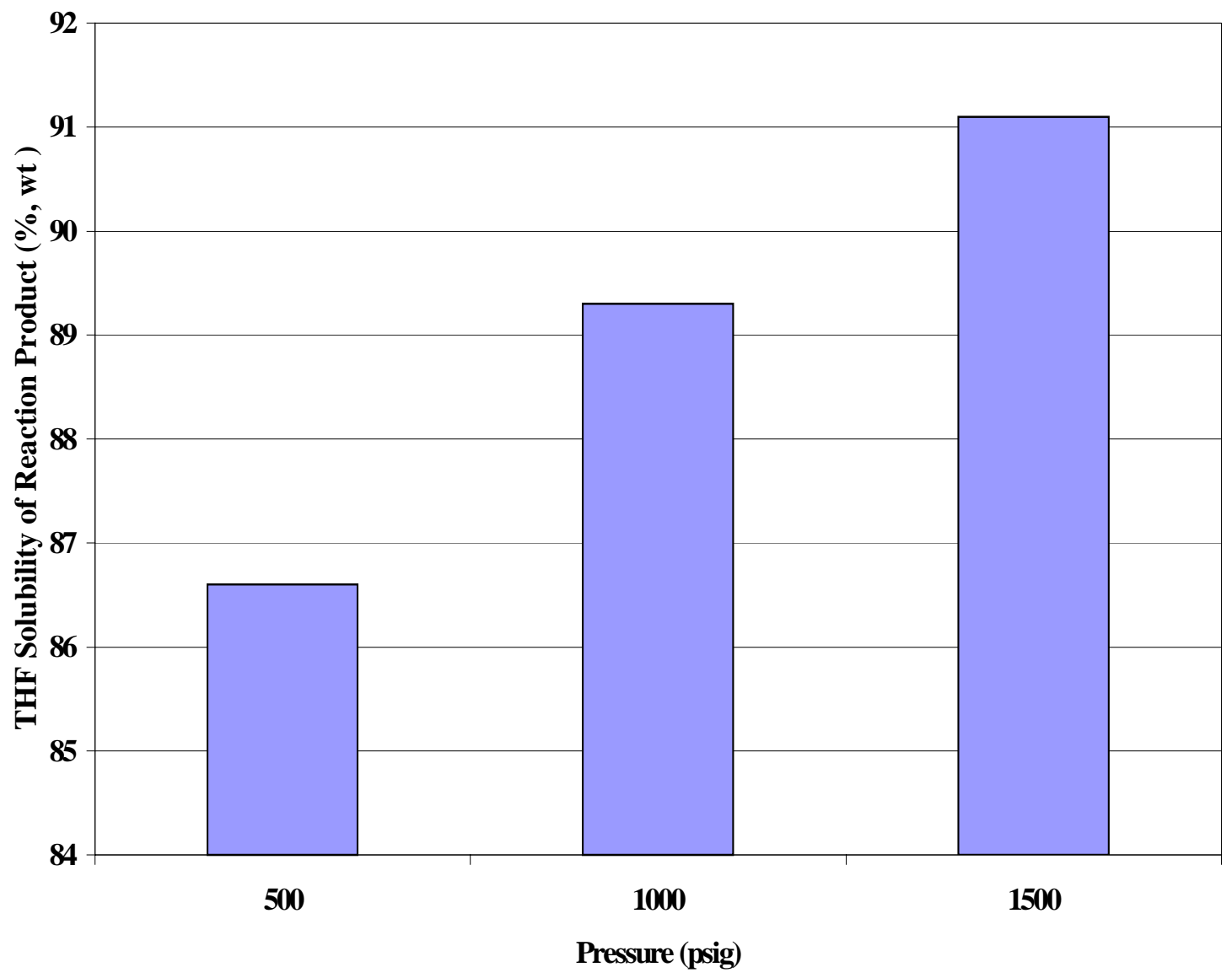

Figure 4.2: Effect of pressure on the product solubility in THF with solvent $\mathrm{V}-1074$ and $\mathrm{H}_{2}$ at $425^{\circ} \mathrm{C}$ 


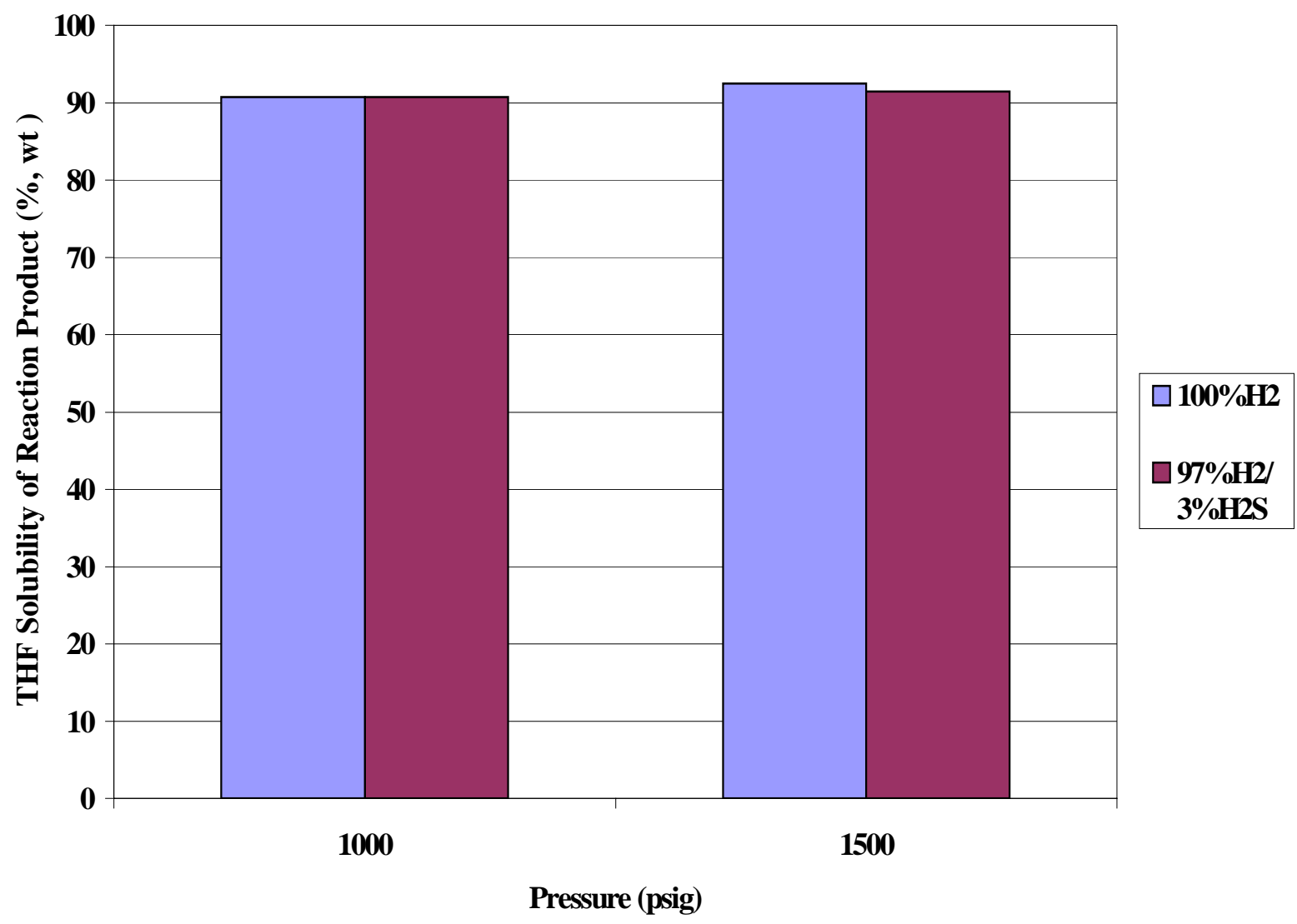

Figure 4.3: Effect of $3 \% \mathrm{H}_{2} \mathrm{~S} / 97 \% \mathrm{H}_{2}$ mixture at various pressures on the THF solubility at $390^{\circ} \mathrm{C}$ with reaction solvent V-1074 


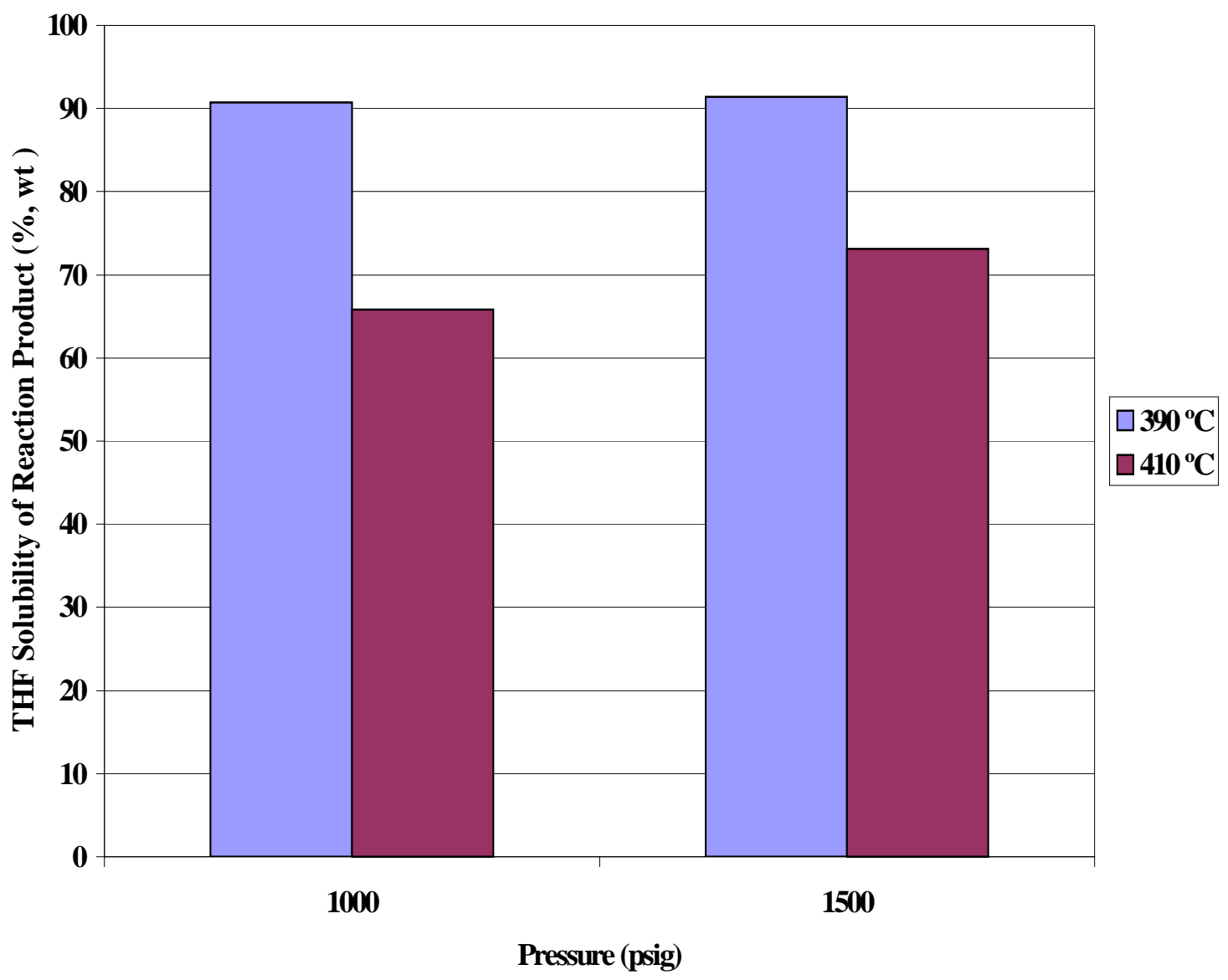

Figure 4.4: Effect of reaction temperature and pressure on THF solubility with reaction solvent $\mathrm{V}-1074$ and $3 \% \mathrm{H}_{2} \mathrm{~S} / 97 \% \mathrm{H}_{2}$ 


\subsubsection{Heptane Extraction}

The second extraction of the series is performed with heptane. Here the soluble fraction from the first THF extraction is further extracted with heptane. The heptane extraction isolates the oil fraction from the rest of the liquefaction product. Subsequent extraction will refine the products by selecting specific species, refer to Figure 3.3. The relative experimental error of this extraction is about $+/-4 \%$.

Figure 4.5 shows the effect of temperature, pressure and solvent on the solubility of the THF-soluble fraction in heptane. It can be noted that with reaction solvent V1074, the THF fraction at 1500 psig is more soluble in heptane than that obtained from the reaction at 1000 psig. Both fractions obtained at 1500 and 1000 psig have a higher solubility at $350^{\circ} \mathrm{C}$ and as the temperature is increased the solubility decreases. This difference is well within experimental error. An increase in temperature at 1500 psig with Hondo solvent causes an increase (about 3\%) in heptane solubility at $390^{\circ} \mathrm{C}$ followed by a decrease in solubility of about $21 \%$ at $425^{\circ} \mathrm{C}$.

Figure 4.6 shows the relationship between reaction pressure and heptane solubility of the THF-soluble fraction for reaction with $\mathrm{V}-1074$ solvent at $425^{\circ} \mathrm{C}$. It is noted that as the pressure increases, the solubility of the THF fraction in heptane increases. When the pressure is increased from 500 psig to 1000 psig the heptane solubility slightly increases about 4\%, while when the pressure is increased from 1000 psig to 1500 psig an increase of about $5 \%$ is achieved. This implies that as the amount of hydrogen present in the reactor increases, more hydrogenation of the coal is accomplished and hence more lighter molecules are formed.

The effect of the $3 \% \mathrm{H}_{2} \mathrm{~S} / 97 \% \mathrm{H}_{2}$ gas mixture in the reactor on the heptane solubility of the THF-soluble fraction is presented in Figure 4.7 for the V-1074 reaction solvent at $390^{\circ} \mathrm{C}$. At 1000 the $\mathrm{H}_{2} \mathrm{~S} / \mathrm{H}_{2}$ mixture causes a decrease in solubility of about 


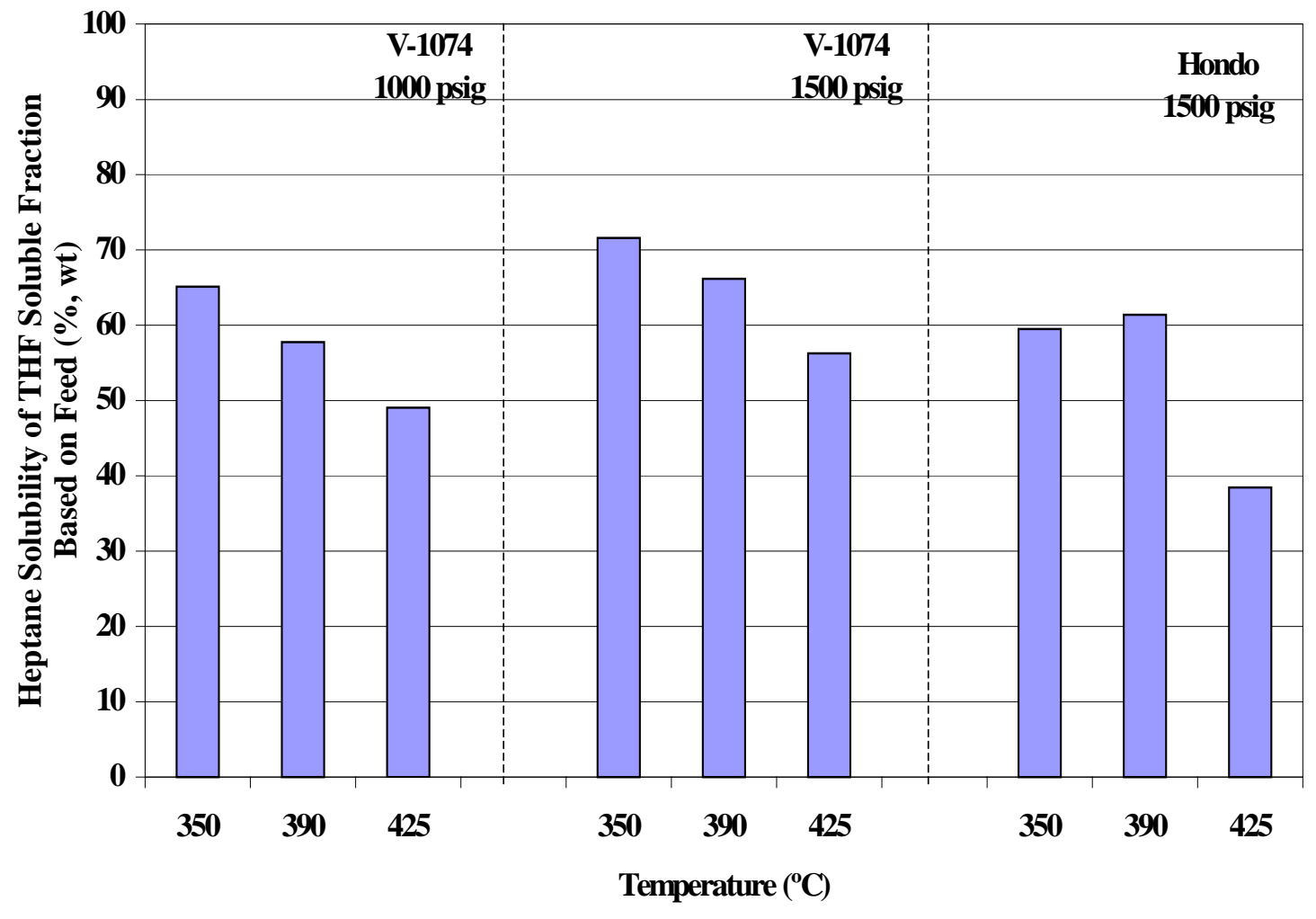

Figure 4.5: Effect of temperature on heptane solubility of the THF-soluble fraction at various reaction conditions in $\mathrm{H}_{2}$ 


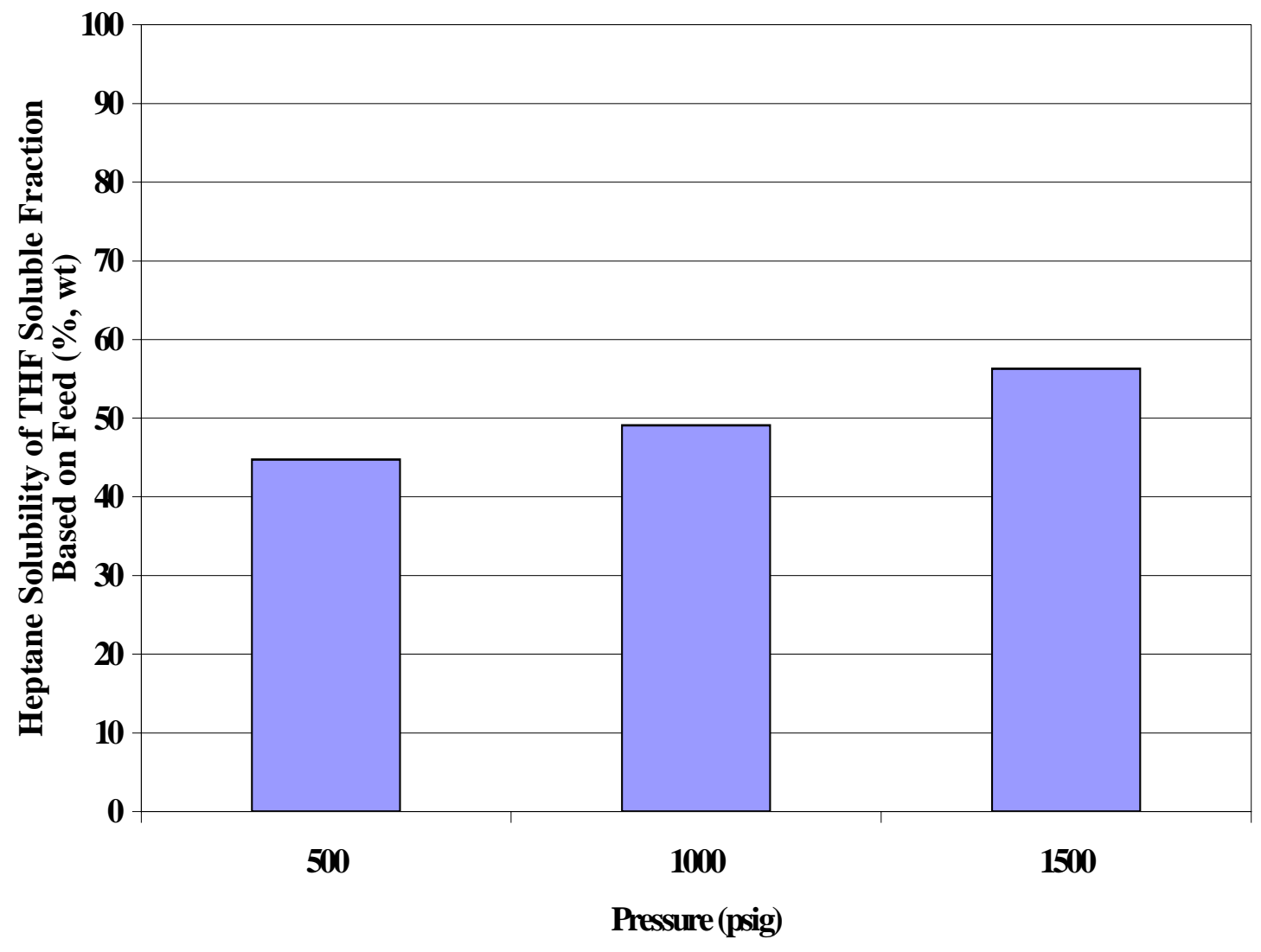

Figure 4.6: Effect of reaction pressure on heptane solubility of the THF-soluble fraction at $425^{\circ} \mathrm{C}$ with reaction solvent V-1074 and gaseous $\mathrm{H}_{2}$ 


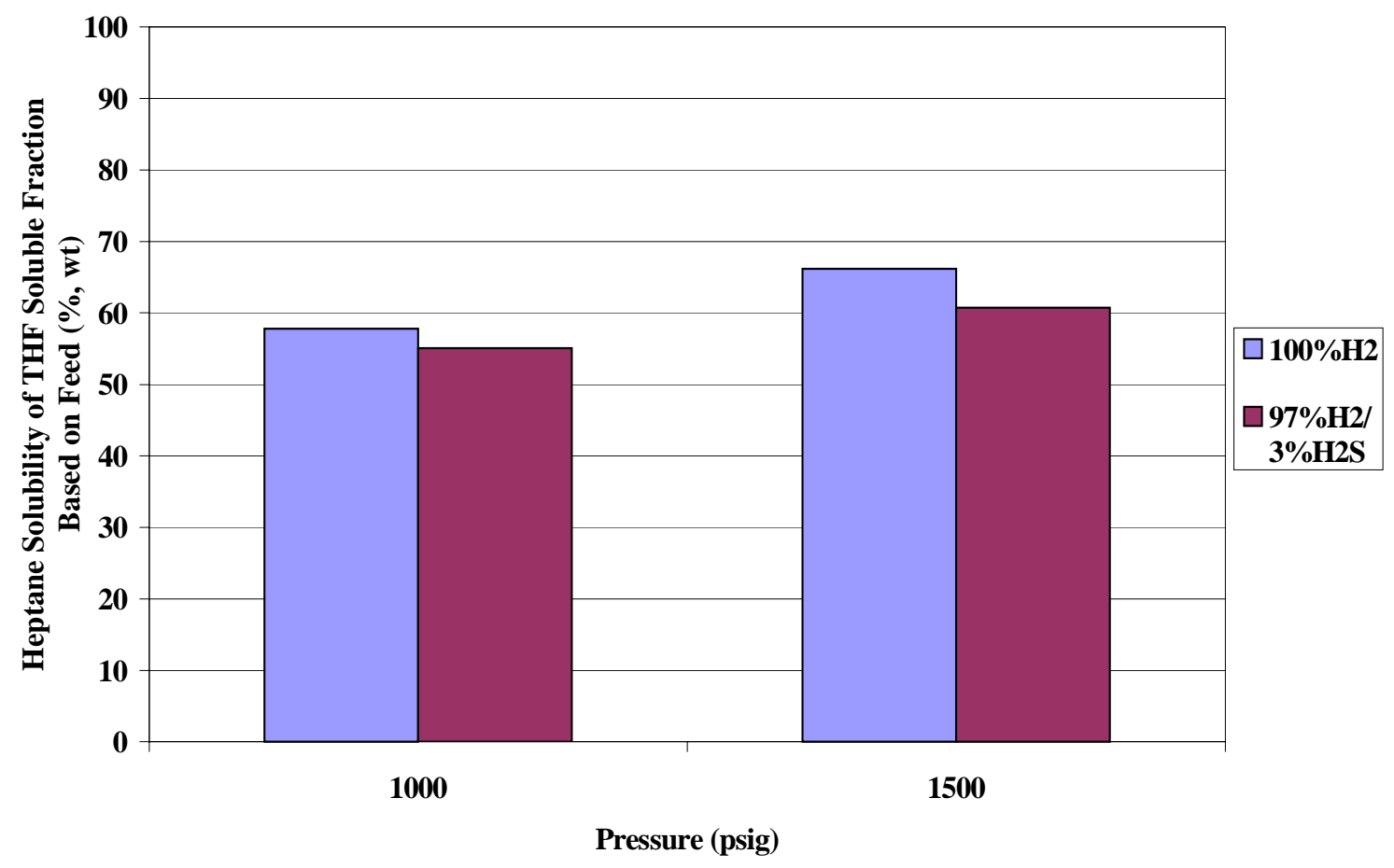

Figure 4.7: Effect of $\mathrm{H}_{2} \mathrm{~S} / \mathrm{H}_{2}$ mixture on heptane solubility of the THF-soluble fraction with reaction solvent V-1074 and $390^{\circ} \mathrm{C}$ 
$5 \%$ over the solubility attained when using gaseous $\mathrm{H}_{2}$ alone. The use of the $\mathrm{H}_{2} \mathrm{~S} / \mathrm{H}_{2}$ mixture and a reaction pressure of 1500 psig also caused a decrease in solubility of about $3 \%$ when compared to pure gaseous $\mathrm{H}_{2}$.

The effect of temperature and pressure on the heptane solubility of the THF fraction when using the $\mathrm{H}_{2} \mathrm{~S} / \mathrm{H}_{2}$ gas mixture is observed in Figure 4.8 for the V-1074 reaction solvent. For both reaction pressures 1000 and 1500 psig, an increase in reaction temperature causes a significant decrease in solubility of the THF fraction in heptane.

\subsubsection{Toluene Extraction}

The third of the series of extractions is the toluene extraction which isolates the toluene-soluble, asphaltene fraction. The insoluble fraction from the heptane extraction is obtained and extracted with toluene in a Soxhlet system. Figure 4.9 shows the effect of reaction temperature, solvent and pressure on the toluene solubility of the heptaneinsoluble fraction, the so-called asphaltene fraction. The relative experimental error carried in this extraction is $+/-4 \%$. This solubility is based on the total feed.

Figure 4.9 shows that as the reaction temperature increases, when using the solvent V1074, the toluene solubility of the heptane-insoluble fraction increases dramatically and levels off at 390 and $425^{\circ} \mathrm{C}$. Since the asphaltene fraction was previously defined as the THF-soluble fraction that is insoluble in heptane and soluble in toluene, this observation means that as the temperature increases the yield of the asphaltene fraction increases. It can also be noticed that as the overall reaction pressure increases, the amount of asphaltene decreases substantially for V-1074 solvent. The use of the Hondo solvent gives a higher amount of asphaltenes than the solvent V-1074 at 1500 psig and $350^{\circ} \mathrm{C}$ but

gives less of the asphaltene fraction at $390-425^{\circ} \mathrm{C}$ using V-1074. At $350^{\circ} \mathrm{C}$ and $1500 \mathrm{psig}$ $\mathrm{H}_{2}$ the highest solubility is encountered with the Hondo solvent, and thus the largest amount of asphaltenes is produced. In general, the amount of asphaltene decreases when increasing the reaction temperature for the Hondo solvent. 


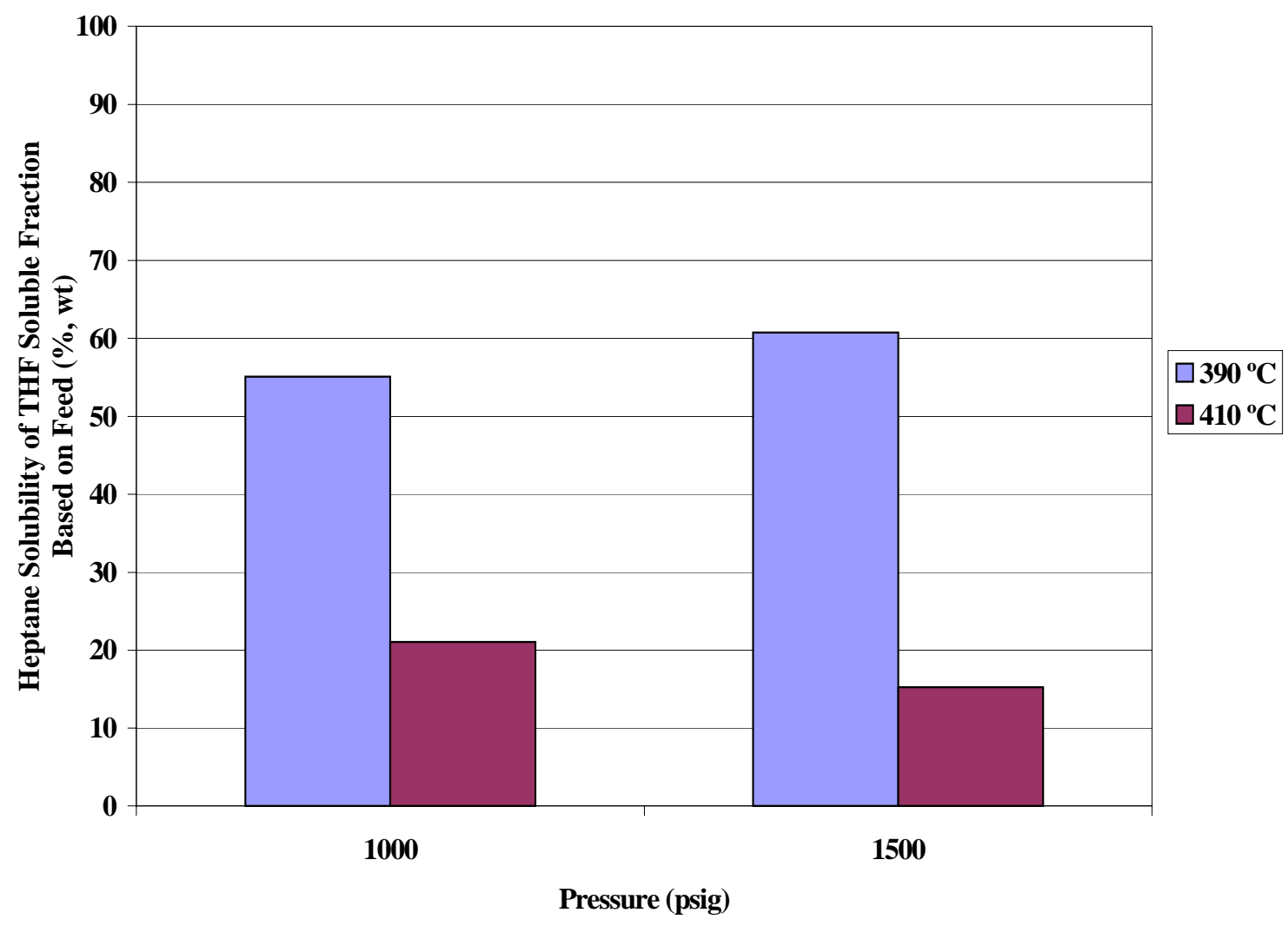

Figure 4.8: Effect of temperature and pressure on heptane solubility of the THF-soluble fraction with $\mathrm{V}-1074$ and $3 \% \mathrm{H}_{2} \mathrm{~S} / \mathrm{H}_{2}$ mixture 


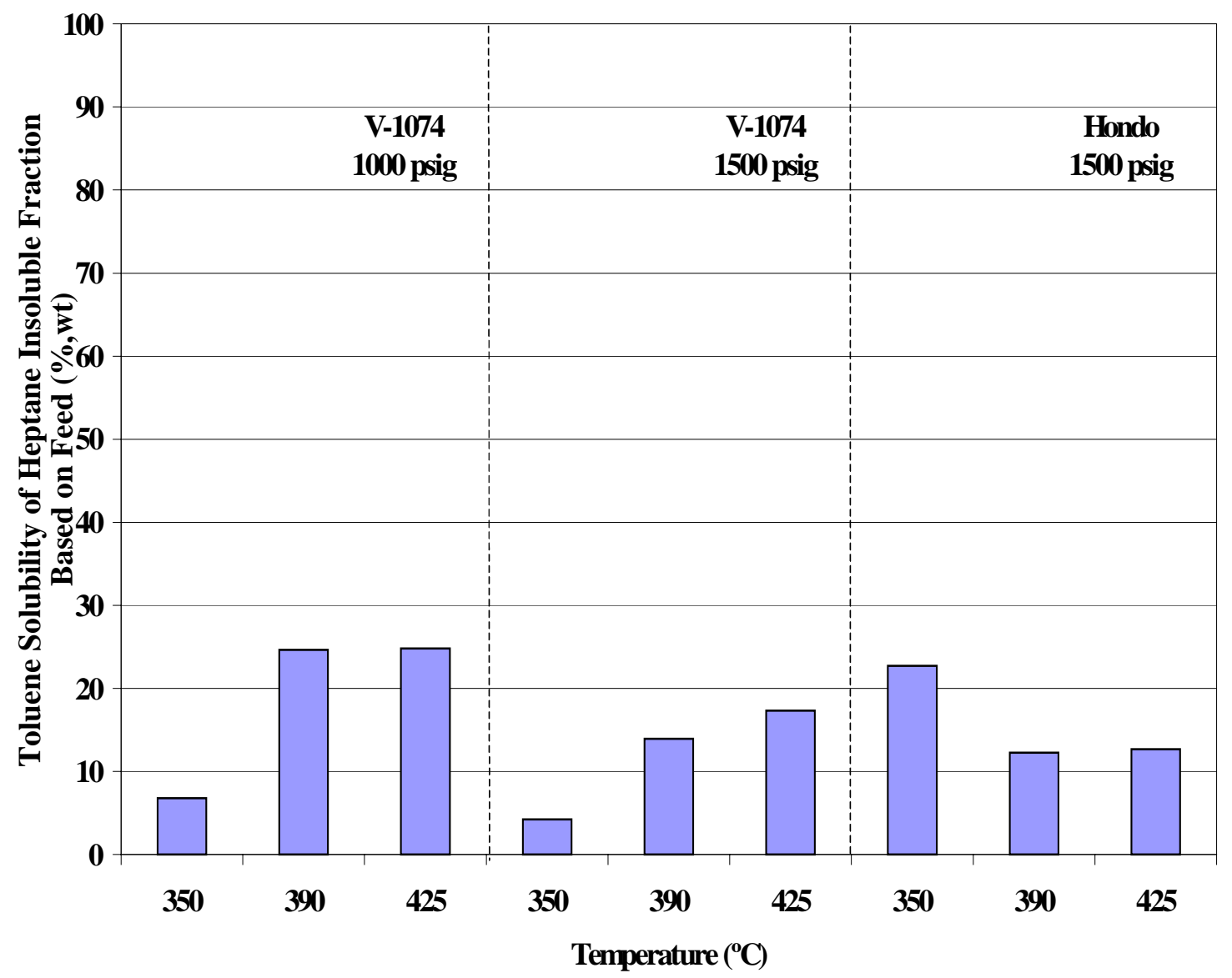

Figure 4.9: Effect of reaction temperature, $\mathrm{H}_{2}$ pressure and solvent on toluene solubility of the heptane-insoluble fraction and the production of the asphaltene fraction 
The effect of the $\mathrm{H}_{2}$ reaction pressure on the toluene solubility of the heptaneinsoluble fraction can be seen in Figure 4.10 for reaction with $\mathrm{V}-1074$ solvent at $425^{\circ} \mathrm{C}$. The plot shows that an increase in pressure from 500 to 1000 psig causes a slight decrease in toluene solubility. A decrease in solubility of about $7 \%$ is then attained as the reaction pressure is increased from 1000 to 1500 psig. These percentages are slightly above the experimental error, which means that the difference is significant.

The effect of the $\mathrm{H}_{2} \mathrm{~S} / \mathrm{H}_{2}$ gas mixture on the production of the asphaltene fraction was assessed for the reaction solvent V-1074 at $390^{\circ} \mathrm{C}$. Figure 4.11 shows that an increase in total pressure using the $\mathrm{H}_{2} \mathrm{~S}$ mixture will cause a slight decrease in the asphaltene fraction. A significant decrease occurs using using pure $\mathrm{H}_{2}$. In general, reaction at 1000 psig for both the $\mathrm{H}_{2} \mathrm{~S}$ mixture and the pure $\mathrm{H}_{2}$ gives a higher yield of the asphaltene fraction than at 1500 psig. The reaction at 1500 psig gives slightly more asphaltenes (increase in toluene solubility) with the use of the mixture of $\mathrm{H}_{2} \mathrm{~S}$ than with pure $\mathrm{H}_{2}$.

Figure 4.12 shows the relationship between reaction pressure and toluene solubility at various temperatures using the mixture of $\mathrm{H}_{2} \mathrm{~S}$ and hydrogen for the V-1074 solvent. The toluene solubility at 1000 psig is increased by about $4 \%$ when the reaction temperature is increased from 390 to $410^{\circ} \mathrm{C}$. The same increase in temperature will cause a slight decrease at 1500 psig. These differences are within experimental error. However, the reaction pressure of 1000 psig gives a higher amount of asphaltenes than the reaction performed at 1500 psig for both 390 and $410^{\circ} \mathrm{C}$.

\subsubsection{NMP Extraction}

The solubility of the THF-insoluble fraction (residue) in the solvent NMP was also studied in an effort to obtain additional useful carbon fractions. The extraction was performed following the same procedure as the toluene solubility. The only difference in the procedure was the addition of a vacuum pump in the rotary evaporation stage due to 


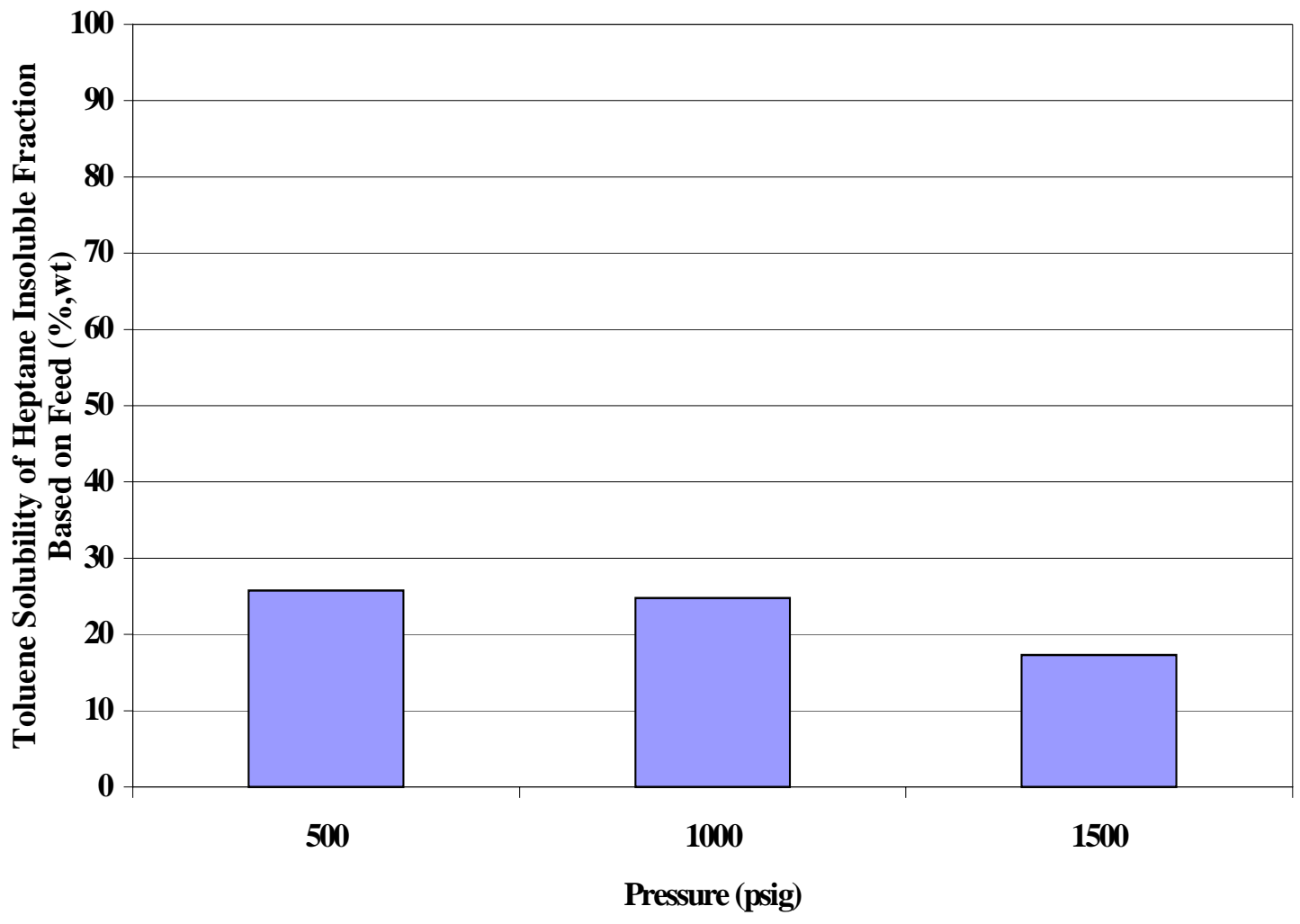

Figure 4.10: Effect of reaction pressure on toluene solubility of the heptane-insoluble fraction with solvent $\mathrm{V}-1074$ and $425^{\circ} \mathrm{C}$ using pure $\mathrm{H}_{2}$ gas 


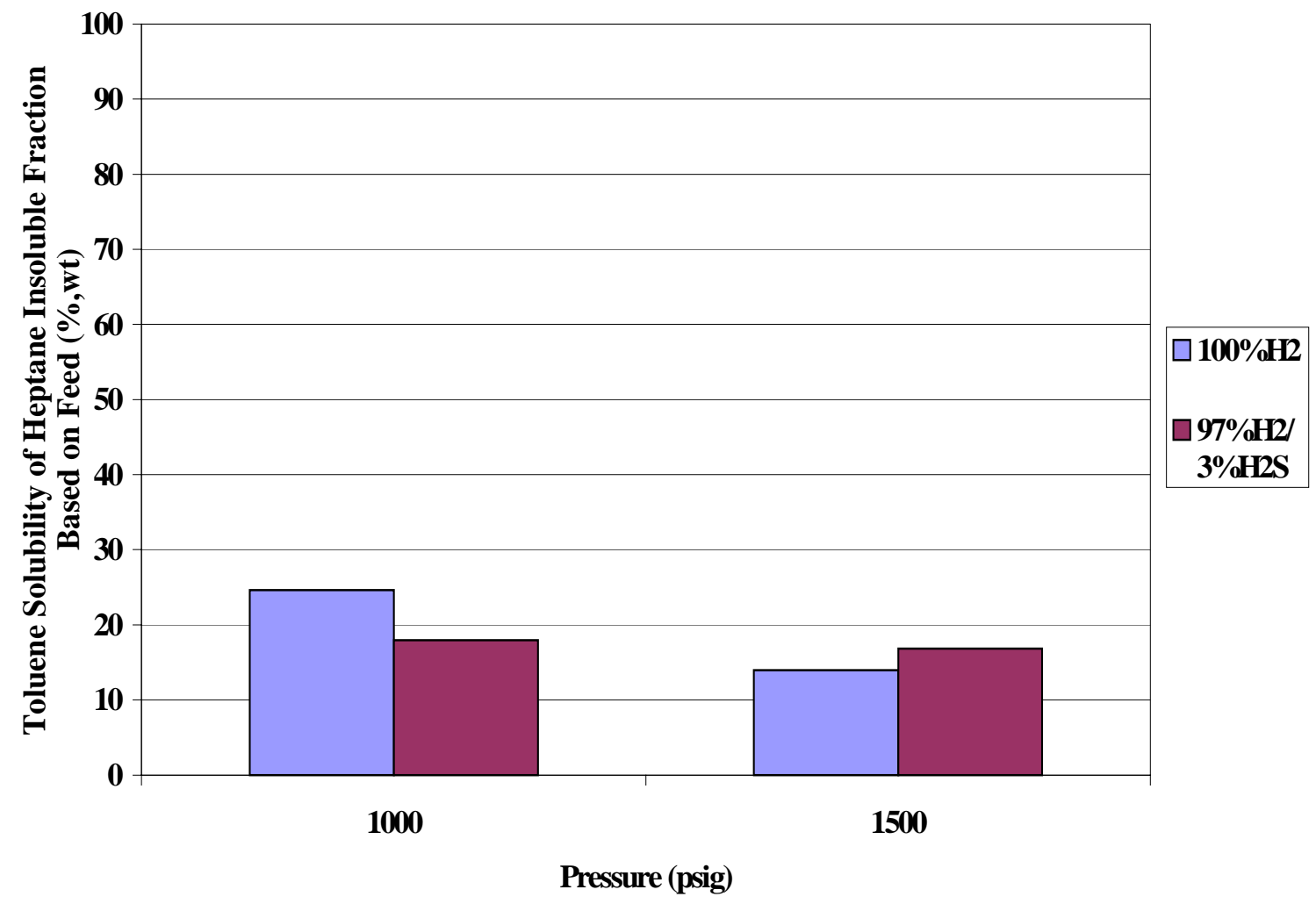

Figure 4.11: Effect of the $\mathrm{H}_{2} \mathrm{~S}$ gas mixture on the toluene solubility of the heptaneinsoluble fraction for the production of the asphaltene fraction with $\mathrm{V}-1074$ at $390^{\circ} \mathrm{C}$ 


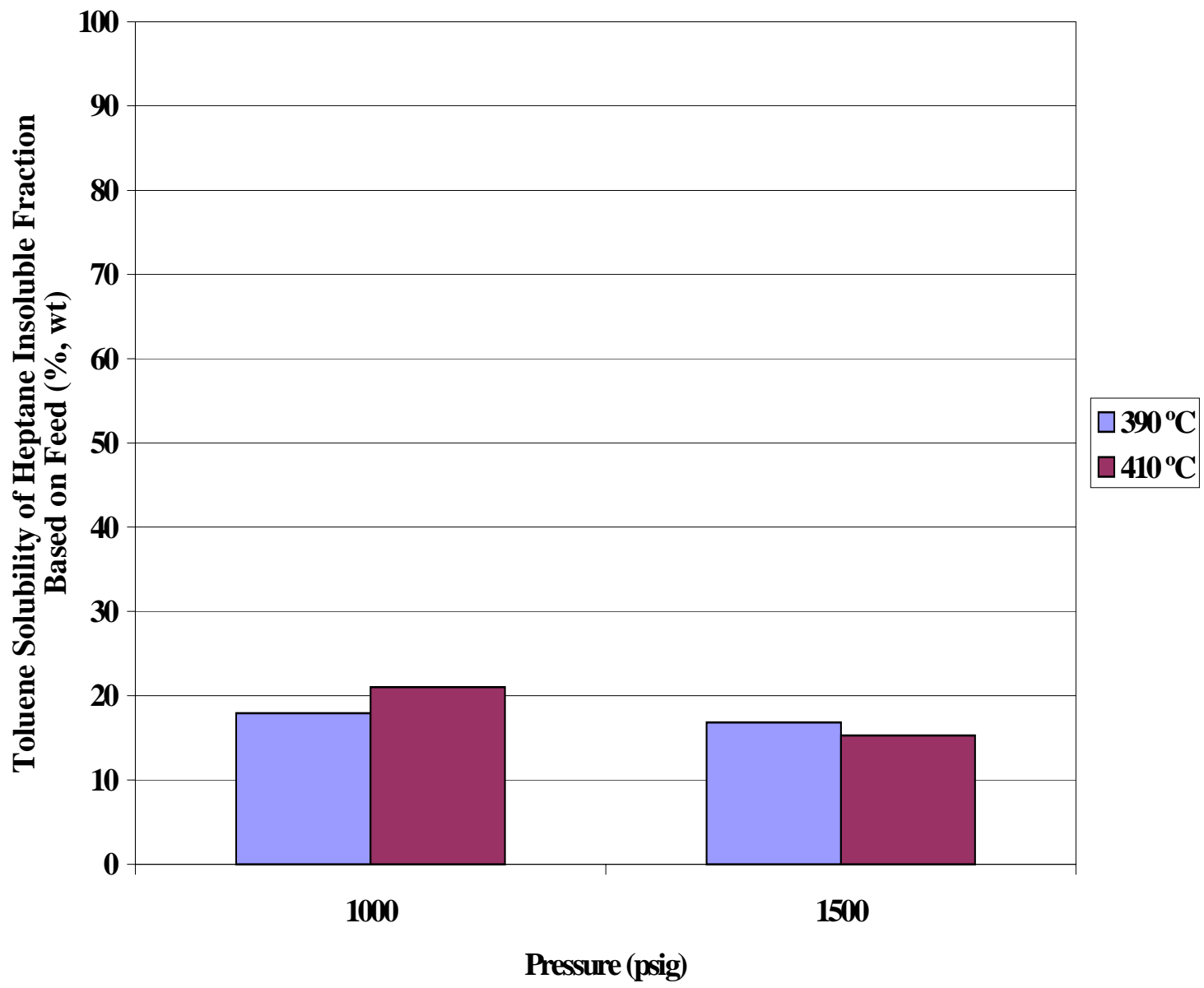

Figure 4.12: Effect of reaction pressure and temperature on toluene solubility of the heptane-insoluble fraction using the reaction solvent V-1074 and the $\mathrm{H}_{2} \mathrm{~S}$ mixture 
the high normal boiling point of NMP $\left(202^{\circ} \mathrm{C}\right)$. The use of the vacuum pump facilitated the removal of the solvent. The results of these extractions are not presented here due to an unexpected experimental development. After the extraction and the solvent removal were performed, the samples were dried in the vacuum oven. Upon removing the samples from the oven, the samples apparently gained weight. They were replaced in the oven and the temperature increased and they still gained weight. The oven was cleaned in order to test the hypothesis that species left on the oven walls evaporated and condensed on the sample thus increasing the sample weight. After several runs were performed taking all these precautions, the sample still showed an increase in weight. These extraction results were discarded as part of the analysis until the cause of this anomalous behavior is determined. One hypothesis is that some of the NMP solvent remained within the sample and the above evaporative methods were not effective for its removal.

\subsection{Liquefaction Fraction Yields}

The yield for each specific product fraction was determined. Yield is defined here as the amount in grams of each fraction produced per amount of total reaction feed mixture (coal and solvent) loaded into the reactor and expressed as a percentage. The amount in grams obtained after the THF and heptane extractions (THF-Insoluble, Heptane-Insoluble and Heptane-Soluble fractions) is divided by the amount of coal and solvent loaded onto the reactor. The yield of the toluene-soluble and toluene-insoluble fractions was determined by multiplying the yield of heptane-insoluble by the percent of its solubility in toluene. It is found that the mass balance will affect these numbers. The relative experimental error is about $+/-5.6 \%$.

Figure 4.13 shows the relationship between reaction temperature and pressure and the various fraction yields. The use of V-1074 and 1500 psig $\mathrm{H}_{2}$ gives higher values for the yield of the preasphaltene and oil fractions at all temperatures. The use of Hondo as the reaction solvent gives the lowest values for the preasphaltene and oil fractions at all temperatures and the highest amount of residue at 350 and $425^{\circ} \mathrm{C}$. At $390^{\circ} \mathrm{C}$ the amount 


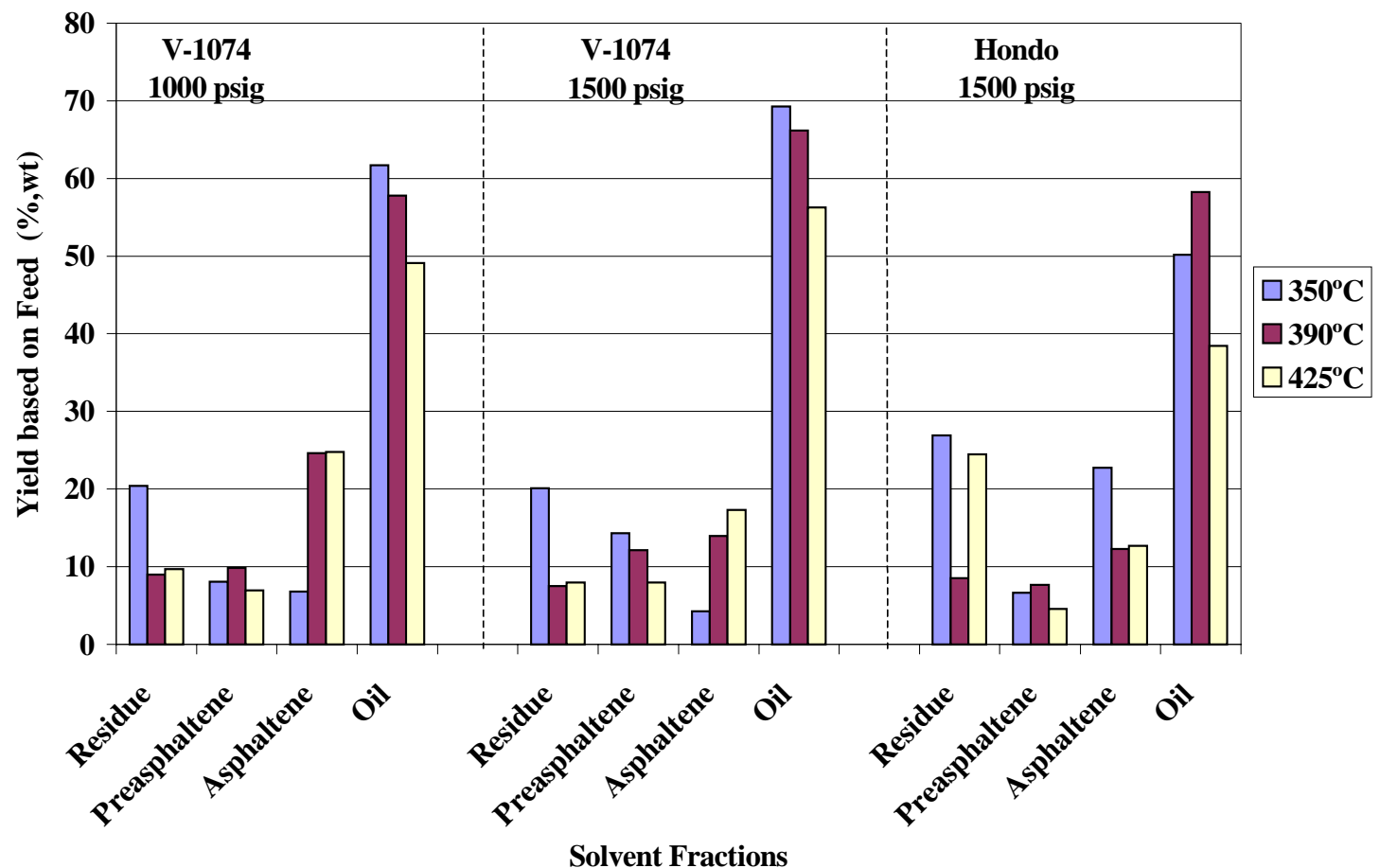

Figure 4.13: Effect of reaction temperature and pressure on liquefaction fraction yields at various reaction conditions with pure $\mathrm{H}_{2}$ gas based on the total mass (coal and solvent) fed to the reactor 
of residue is practically constant and independent of the reaction solvent or pressure. The asphaltene fraction has its maximum using V-1074 at 1000 psig $\mathrm{H}_{2}$ and 390 or $425^{\circ} \mathrm{C}$.

Figure 4.14 shows the effect of the use of the $3 \% \mathrm{H}_{2} \mathrm{~S} / \mathrm{H}_{2}$ gas mixture on the various fraction yields for the $\mathrm{V}-1074$ solvent at $390^{\circ} \mathrm{C}$. An increase in pressure of both pure $\mathrm{H}_{2}$ gas and the $3 \% \mathrm{H}_{2} \mathrm{~S}$ gas mixture shows an increase in the oil and preasphaltene fraction yields, while causing a decrease in the yields of the residue and asphaltene fractions. The use of the $3 \% \mathrm{H}_{2} \mathrm{~S} / \mathrm{H}_{2}$ gas mixture does not have a large impact on the preasphaltene and residue yield at either pressure. The oil fraction yield decreases by about $4 \%$ with the use of $\mathrm{H}_{2} \mathrm{~S}$ at both pressures, which is within the experimental error. The asphaltene fraction shows a decrease in yield at 1000 psig and a slight increase at 1500 psig.

Figure 4.15 presents the relationship between temperature and pressure and liquefaction fraction yield for the $\mathrm{V}-1074$ solvent and the $3 \% \mathrm{H}_{2} \mathrm{~S} / \mathrm{H}_{2}$ gas mixture. At 1500 psig an increase in temperature causes a slight decrease in yield for all the fractions. On the other hand, at 1000 psig an increase in temperature causes a slight increase in the oil and asphaltene fractions, no effect on the preasphaltene fraction and a decrease in the residue fraction. These changes in yield values are very small. Moreover, all are within experimental error. Thus, an increase of reaction temperature $\left(390\right.$ to $410^{\circ} \mathrm{C}$ ) and pressure (1000 to $1500 \mathrm{psig}$ ) while using the $3 \% \mathrm{H}_{2} \mathrm{~S} / \mathrm{H}_{2}$ gas mixture has little significant effect on the yield of the different fractions.

\subsection{Softening Point}

The Mettler softening points were determined for all the solvent fractions produced at the various reaction conditions. The procedure followed for this analysis is presented in Section 3.2.2. The procedure carries an absolute experimental error of about $+/-3^{\circ} \mathrm{C}$. 


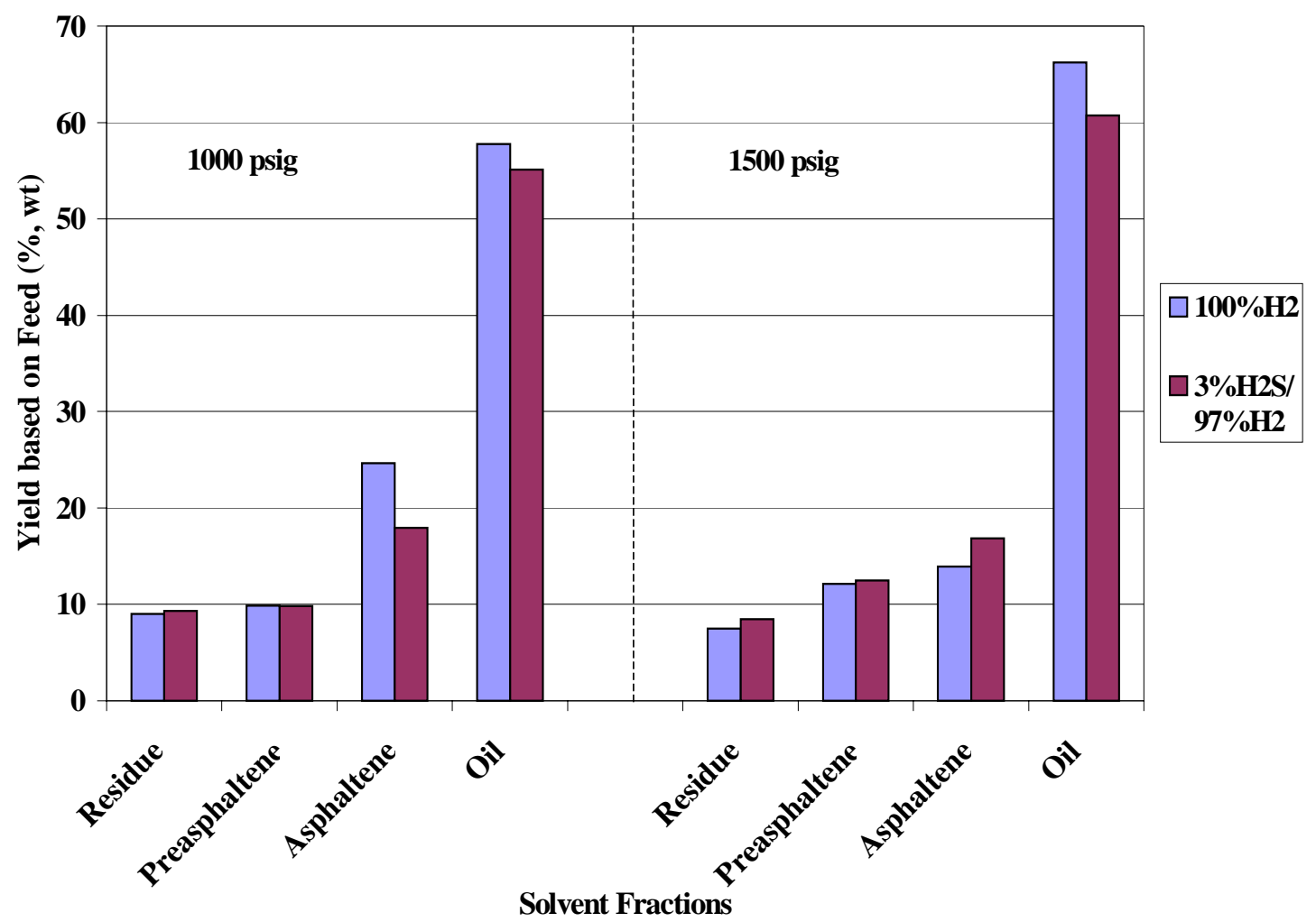

Figure 4.14: Effect of $3 \% \mathrm{H}_{2} \mathrm{~S} / \mathrm{H}_{2}$ mixture on the liquefaction fraction yields with $\mathrm{V}-1074$ and $390^{\circ} \mathrm{C}$ based on the total mass (coal and solvent) fed to the reactor 


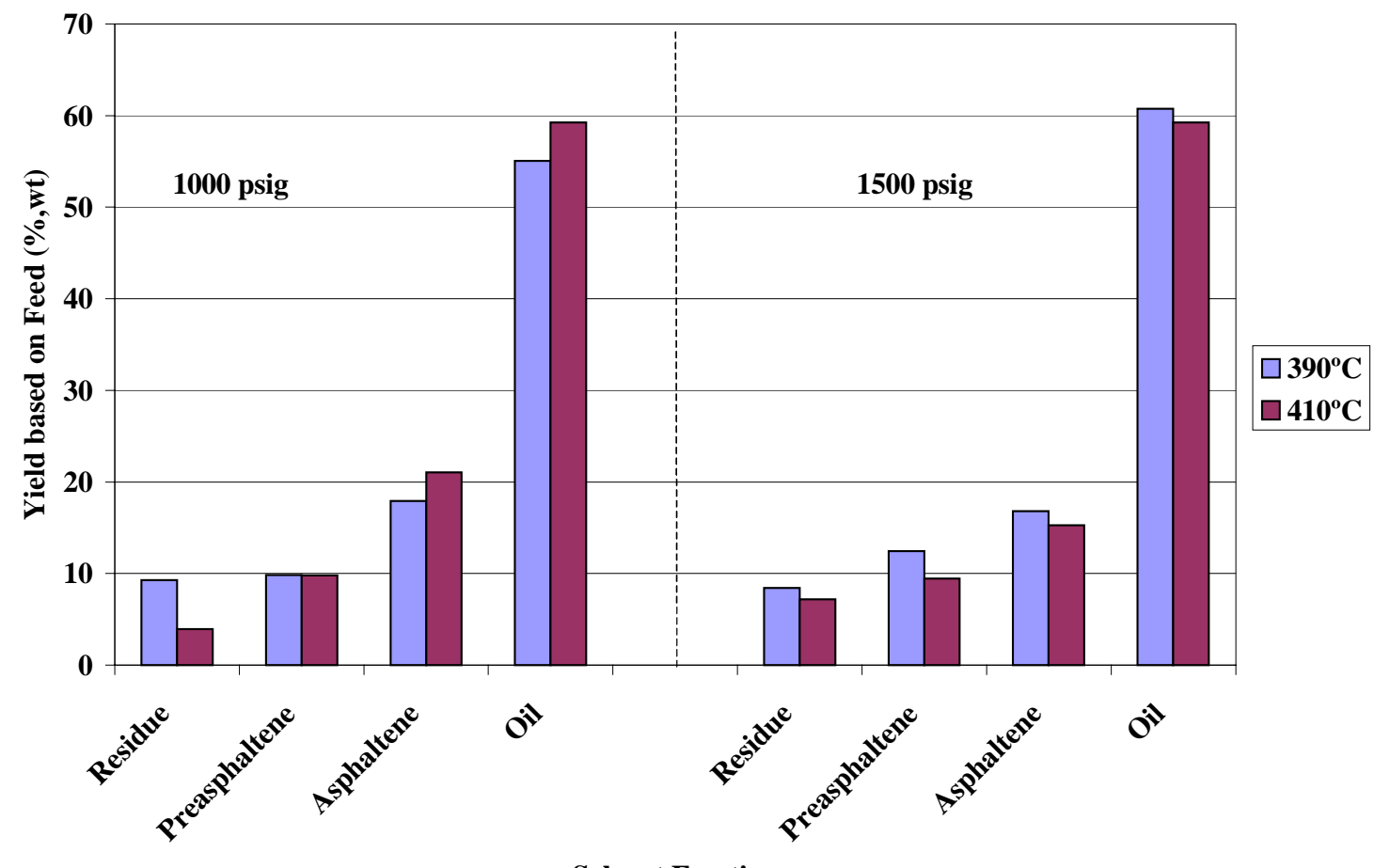

Solvent Fraction

Figure 4.15: Effect of reaction temperature and pressure on liquefaction fraction yields with $\mathrm{V}-1074$ and the $3 \% \mathrm{H}_{2} \mathrm{~S}$ mixture based on the total mass (coal and solvent) fed to the reactor 
Figure 4.16 shows the softening points of some of the samples. It is noticed that with the coal-derived solvent $(\mathrm{V}-1074)$ at $1000 \mathrm{psig}$ and at $390^{\circ} \mathrm{C}$ and $425^{\circ} \mathrm{C}$, a softening point of the asphaltene fraction is close to the desired value of $110^{\circ} \mathrm{C}$ for conventional coal tar binder pitch. With Hondo solvent, the softening point is very high for the same fraction. The softening points for the residue and preasphaltene fractions are not shown because they were considered too high to be useful as a binder pitch (i.e. $>200^{\circ} \mathrm{C}$ ). In addition they could not be determined with the equipment available. The softening point of the oil fraction does not change because it is liquid at room temperature. Using the Hondo solvent, the softening point for the asphaltene fraction shows a decrease as the reaction temperature is increased from 350 to $390^{\circ} \mathrm{C}$. An increase is then observed as the reaction temperature is increased from 390 to $425^{\circ} \mathrm{C}$. It was found that in general, the softening point of the asphaltene fraction from the $\mathrm{V}-1074$ reactions decreases as the reaction temperature is increased and the pressure is decreased. In fact, there is a nearly linear decrease in the softening point of the asphaltene fraction as the reaction temperature increases as shown in Figure 4.17. Thus, it can be seen that a reaction temperature of around $400^{\circ} \mathrm{C}$ should yield a product with the desired softening point of $110^{\circ} \mathrm{C}$, the same as that of conventional coal-tar binder pitch.

The effect of the use of the $3 \% \mathrm{H}_{2} \mathrm{~S} / \mathrm{H}_{2}$ gas mixture on the softening point was also analyzed. Figure 4.18 shows the effect of including $\mathrm{H}_{2} \mathrm{~S}$ in the reaction on the softening points of the asphaltene and the oil fractions for reaction in V-1074 at $390^{\circ} \mathrm{C}$. Again the softening points of the residue and preasphaltene fractions were not plotted because their values are greater than $200^{\circ} \mathrm{C}$ and could not be determined by the equipment available. The softening point of the oil fraction did not change because this fraction is liquid at ambient temperature. The use of the $\mathrm{H}_{2} \mathrm{~S}$ mixture causes a sharp increase in the softening point of the asphaltene fraction. The softening point of the asphaltene fraction obtained with pure $\mathrm{H}_{2}$ is closer to the desired value of $110^{\circ} \mathrm{C}$ for conventional coal-tar binder pitch.

The relationship of temperature and pressure on the softening point using the $\mathrm{H}_{2} \mathrm{~S} / \mathrm{H}_{2}$ mixture is shown in Figure 4.19 for reaction in the $\mathrm{V}-1074$ solvent. At 1000 psig, 


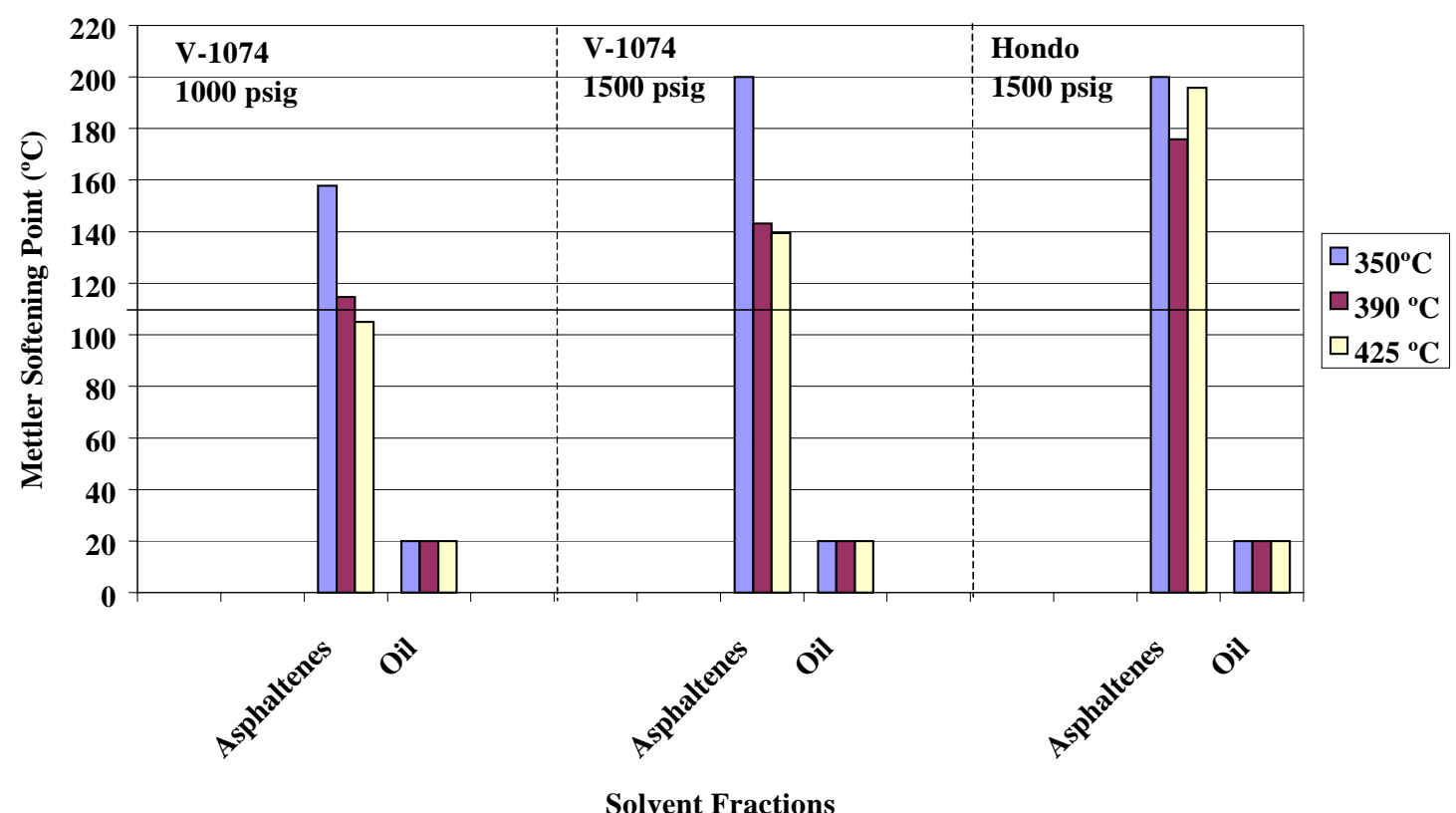

Figure 4.16: Effect of reaction temperature, pressure and solvent on the softening point of various fraction using pure $\mathrm{H}_{2}$ gas 


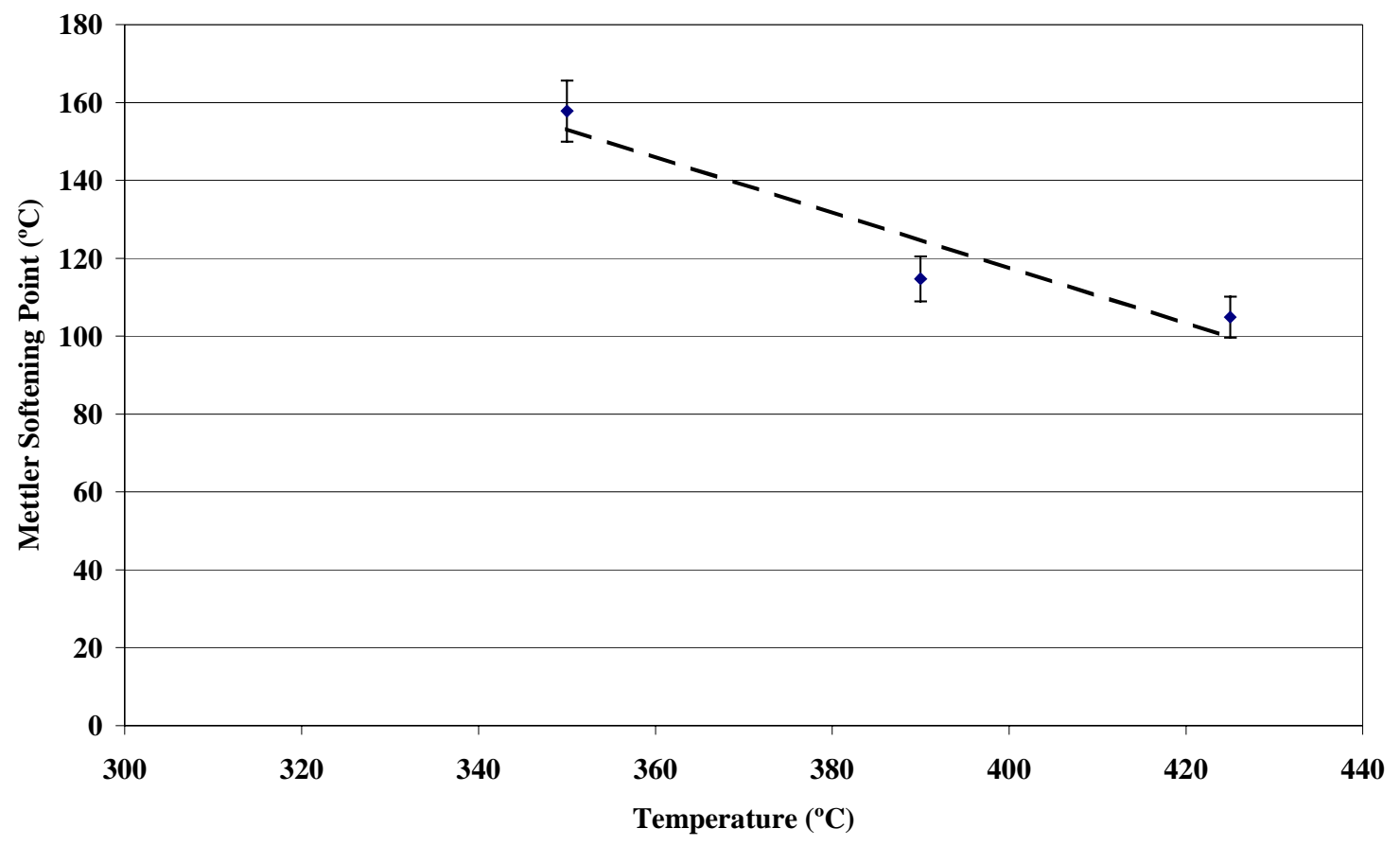

Figure 4.17: Effect of reaction temperature on softening point of the asphaltene fraction with reaction solvent V-1074 and $1000 \mathrm{psig}_{2}$ 


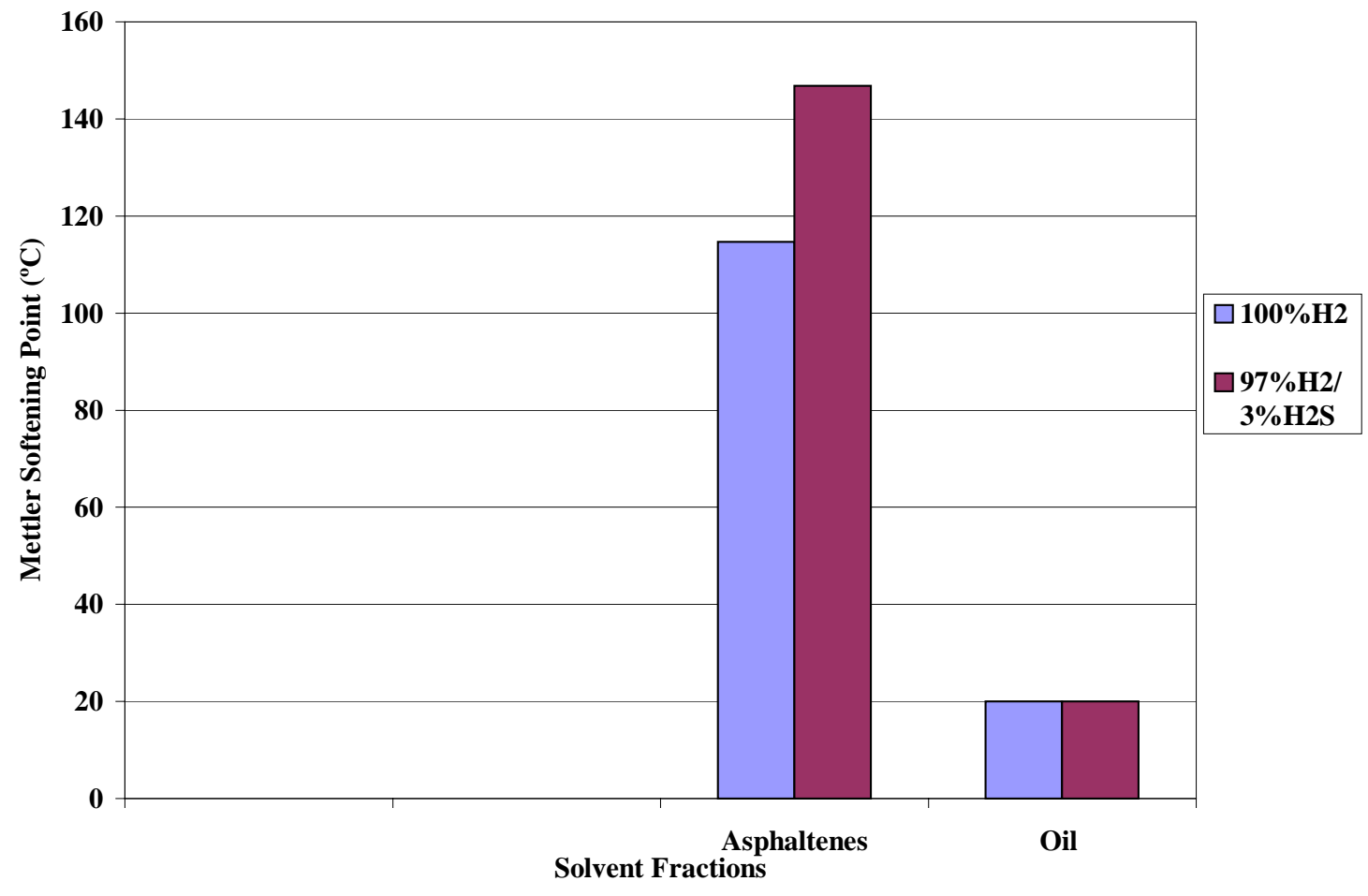

Figure 4.18: Effect of $3 \% \mathrm{H}_{2} \mathrm{~S} / \mathrm{H}_{2}$ gas mixture at 1000 psig on the softening point using the reaction solvent $\mathrm{V}-1074$ and $390{ }^{\circ} \mathrm{C}$ 


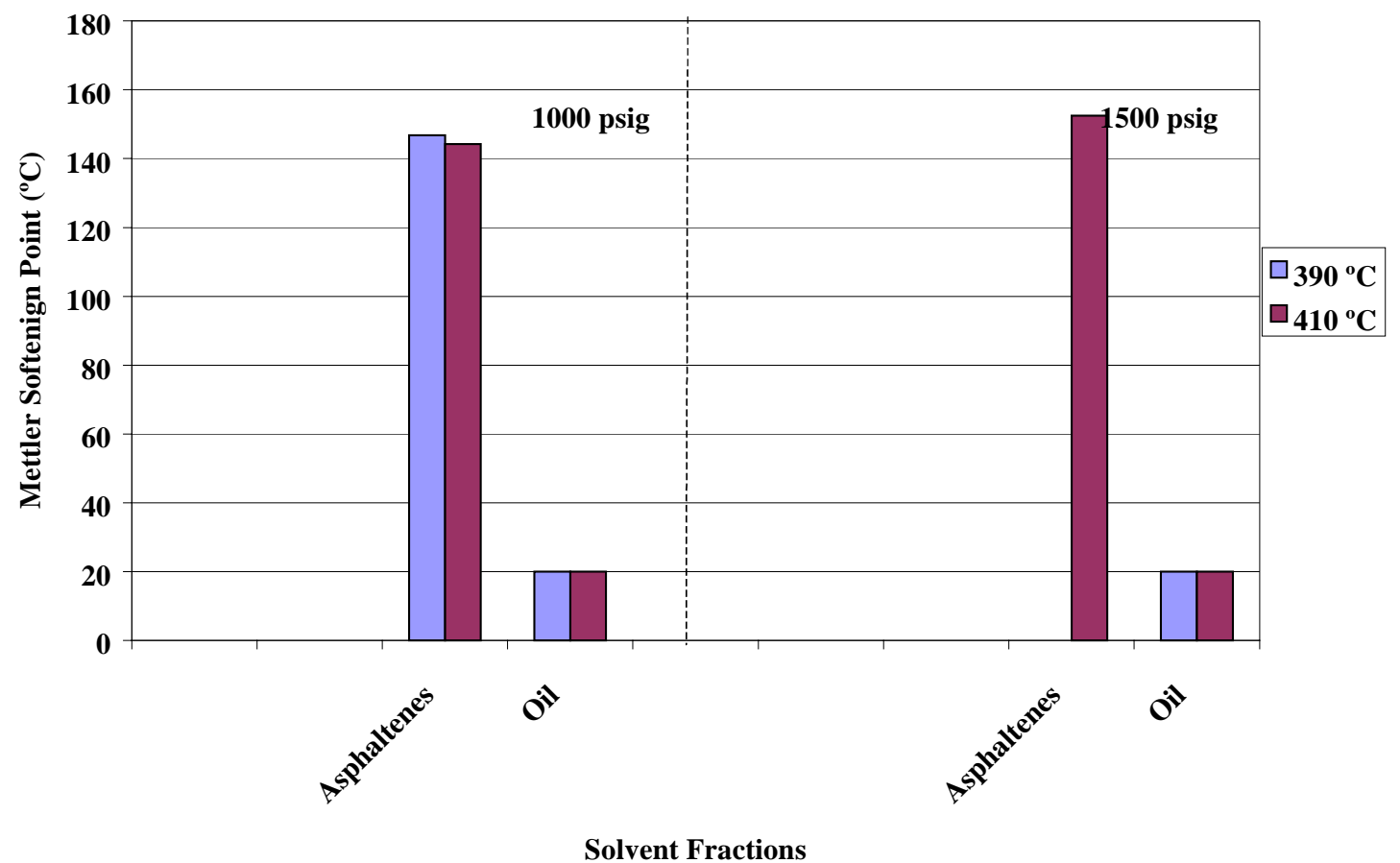

Figure 4.19: Variation of softening point with reaction temperature and pressure using solvent $\mathrm{V}-1074$ and the mixture of $3 \% \mathrm{H}_{2} \mathrm{~S} / \mathrm{H}_{2}$ gas

an increase in temperature causes a slight decrease in softening point for the asphaltene fraction, which is within experimental error. The softening point of the asphaltene 
fraction at $390{ }^{\circ} \mathrm{C}$ and $1500 \mathrm{psig}$ is not presented. When the softening point procedure was being performed on this sample, it did load properly in the sampling cup. Once the sampling cup was set in the Mettler apparatus, a small lead pellet is placed on top of the sample to help it flow (applying pressure). The sample is then heated linearly. However, the analysis was not completed because the sample moved upward (instead of downward), covered the pellet and the outside edges of the cup and loading cell. This strange behavior showed an apparent swelling or foaming of the sample which was not encountered with the other specimens. The softening points for the different reaction conditions using $3 \% \mathrm{H}_{2} \mathrm{~S} / \mathrm{H}_{2}$ gas mixture showed either a softening point higher than $110^{\circ} \mathrm{C}$ or the anomalous behavior described above.

In order to obtain the desired softening point (in this case $110^{\circ} \mathrm{C}$ ) the gas phase should be $\mathrm{H}_{2}$ along with the reaction solvent $\mathrm{V}-1074$. The softening point is a characteristic that can be modified by changes in reaction conditions and/or the amount of light compounds present. As pointed out earlier, the softening point is very sensitive to any residual solvent remaining in the sample. Hence these softening point values should be regarded with care.

\subsection{Coking Value Determination}

The coking value is a measure of the volatile matter present in the various fractions and its determination was described earlier in Section 3.2.3. This procedure has a relative experimental error of $+/-5 \%$. A composite plot showing the variation of coking value of the various fractions with all the reaction parameters is shown in Figure 4.20. With respect to the reaction solvent, the Hondo solvent for the most part gives a coking value greater than reaction with the V-1074 for all the fractions. It is also observed that as the reaction temperature increases, the coking values increase significantly for the residue, preasphaltene and asphaltene fractions, while the coking value of the oil fraction decreases slightly. When increasing the reaction pressure using V-1074, the coking 


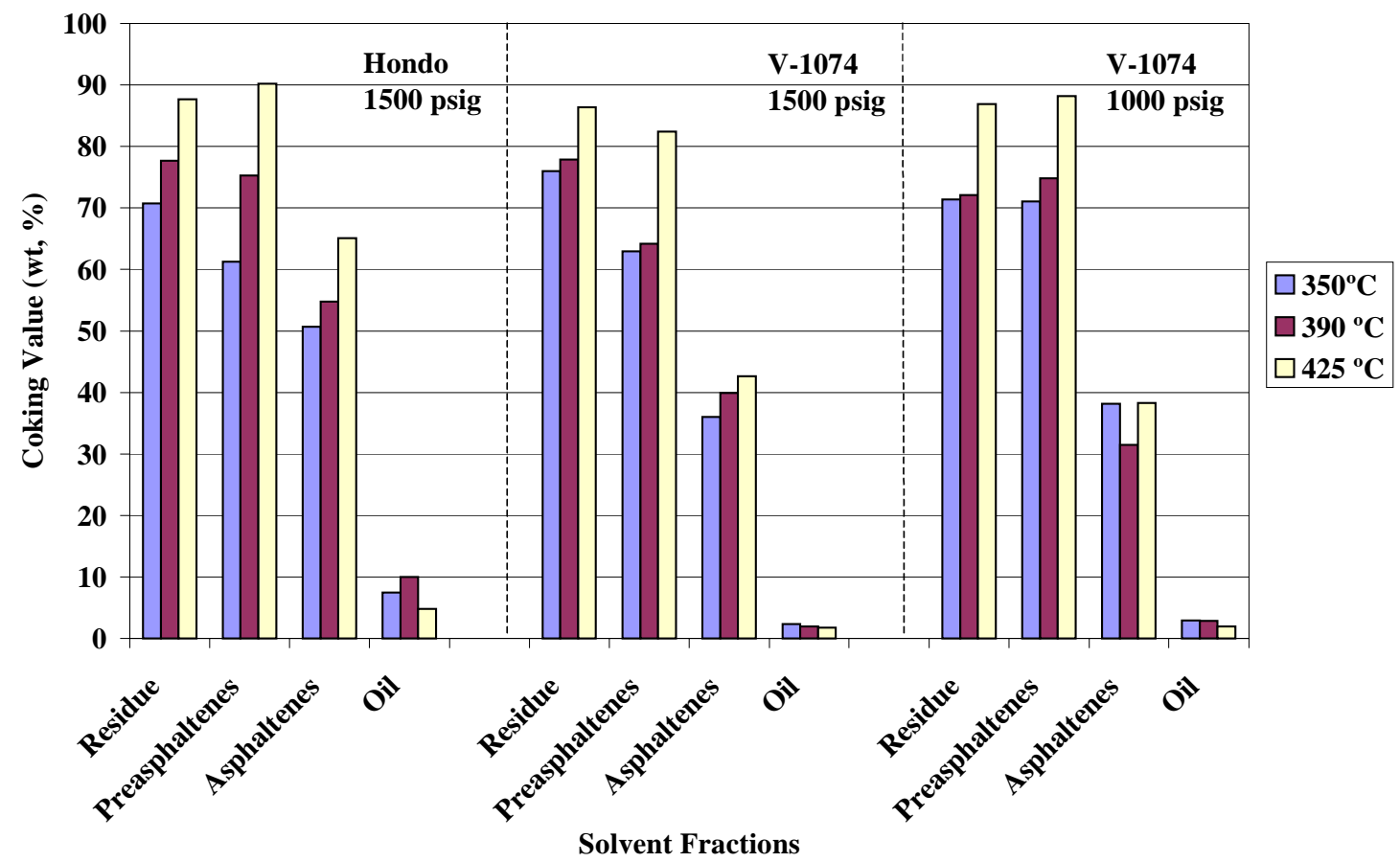

Figure 4.20: Variation of the coking value for the product fraction with reaction temperature, pressure and solvent using pure $\mathrm{H}_{2}$ in the gas phase 
values of the residue, oil and preasphaltene fractions generally decrease while that for the asphaltenes fraction stays roughly the same.

Figure 4.21 shows the effect of $\mathrm{H}_{2} \mathrm{~S} / \mathrm{H}_{2}$ mixture and overall gas pressure on coking value for reactions in $\mathrm{V}-1074$ solvent at $390^{\circ} \mathrm{C}$. When the gas mixture of $3 \%$ $\mathrm{H}_{2} \mathrm{~S} / 97 \% \mathrm{H}_{2}$ is used for both 1000 and 1500 psig the coking values of the residue, preasphaltene and asphaltene fractions increase while the coking value of the oil fraction decreases. In general, an increase in pressure using the mixture of $\mathrm{H}_{2} \mathrm{~S}$ results in an increase in coking value for all the fractions. This agrees with the fact that as the

pressure is increased, more hydrogen is available for the hydrogenation to be accomplished. Hence, more bond breakage occurs along with the formation of more aromatic compounds with fewer aliphatic side chains.

The effect of reaction temperature and pressure on the coking value for reaction with the $\mathrm{H}_{2} \mathrm{~S} / \mathrm{H}_{2}$ gas mixture was also studied and is shown in Figure 4.22 for the V-1074 solvent. It was found that an increase of pressure from 1000 to 1500 psig increases the coking values of the residue, preasphaltene and asphaltene fractions while that for the oil fraction remained roughly the same. An increase in reaction temperature causes an increase in coking values for all fractions at both 1000 and 1500 psig except for the preasphaltene fraction where the coking value decreases slightly. In general, the use of $\mathrm{H}_{2} \mathrm{~S}$ does not improve the overall reaction yield but does increase the coking value of most of the fractions. Perhaps the sulfur is forming S-S linkages in the organic molecules making them more resistant to volatilization.

\subsection{Optical Texture}

The examination of the optical texture of the cokes from the different fractions can aid in determining potential uses for these materials. The optical texture was determined by means of an optical microscope as described earlier in Section 3.2.4. A camera on the microscope helped record the images. The pictures of the cokes from the 


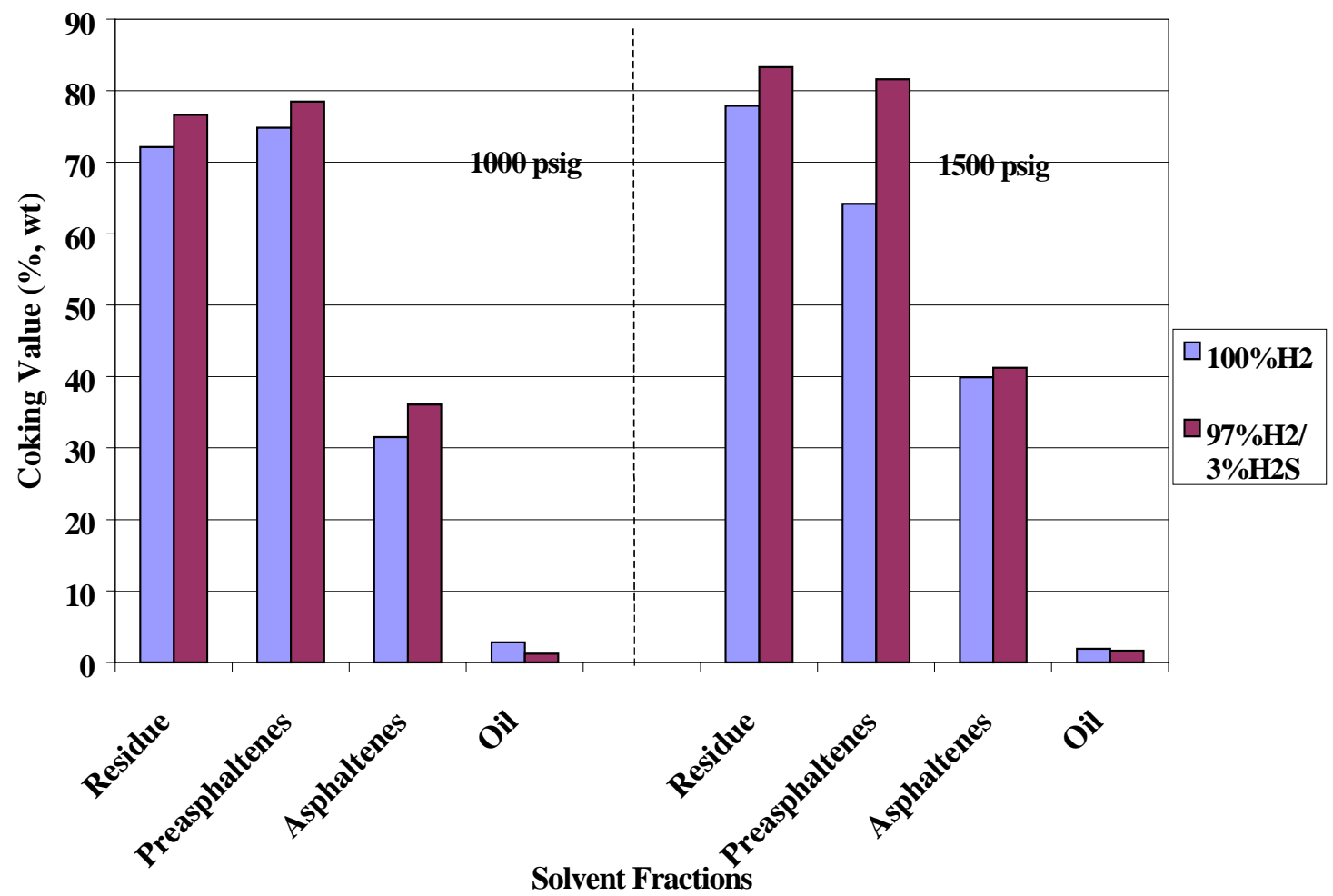

Figure 4.21: Effect of $\mathrm{H}_{2} \mathrm{~S}$ mixture and reaction pressure on the coking value using reaction solvent $\mathrm{V}-1074$ at $390^{\circ} \mathrm{C}$ 


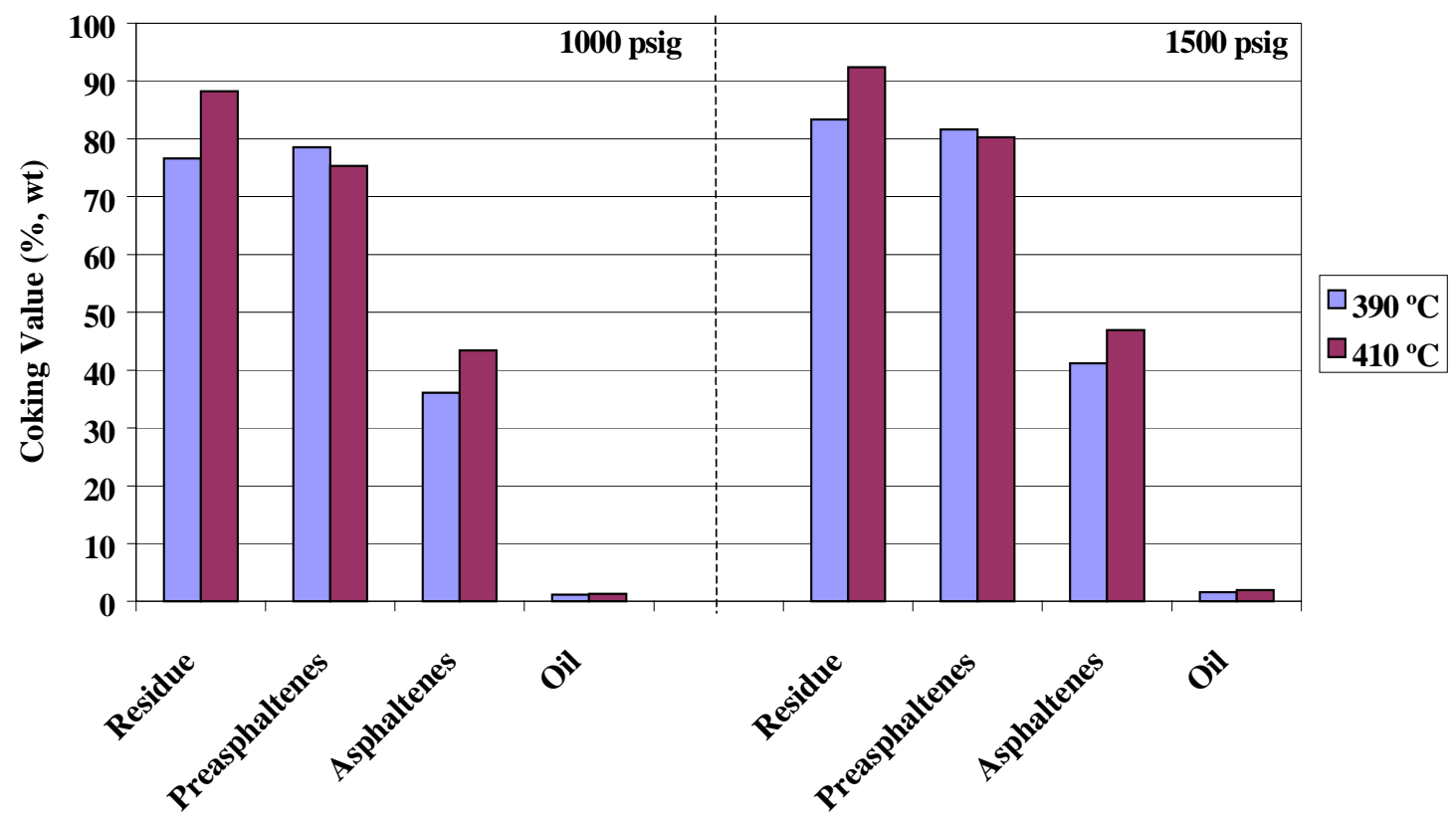

Solvent Fractions

Figure 4.22: Effect of reaction temperature and pressure on the coking value of the various fractions using solvent $\mathrm{V}-1074$ and the gas mixture of $3 \% \mathrm{H}_{2} \mathrm{~S} / \mathrm{H}_{2}$ 
different fractions as a function of the reaction conditions are presented in Appendix B. Throughout the analysis of all the samples, several general observations can be made. The cokes from the residue and preasphaltene fractions for all the different reaction conditions showed no optical texture. For all reaction conditions, the cokes from the oil fraction showed an anisotropic behavior which varied only in the size of the anisotropic domain. The cokes from asphaltene fraction showed both anisotropic and isotropic behavior and this varied with reaction conditions. Much of the discussion that follows is centered on the asphaltene fraction.

Table 4.3 presents a summary of the reaction conditions and the type of optical texture present in the cokes from the asphaltene fractions produced in this research. As noticed from Table 4.3, the use of Hondo solvent in the reaction gave either no optical texture or isotropic behavior for the asphaltene fraction. Notice that an increase in temperature when using the Hondo solvent alters the texture from no texture to an isotropic coke. On the other hand, the use of V-1074 produced cokes from the asphaltene fraction that were mostly anisotropic in nature. The fact that the asphaltenes from $\mathrm{V}$ 1074 showed anisotropy indicates that the use of the coal-derived solvent helps in the selection of species able to form a graphite-like structure which is desired for the production of electrodes and fibers.

Figure 4.23 shows micrographs of different cokes from the asphaltene fractions which were obtained at different reaction conditions. The cokes presented in Figures 4.23 a), c), e) were derived using Hondo solvent, a pressure of 1500 psig and a reaction temperature of $350^{\circ} \mathrm{C}, 390^{\circ} \mathrm{C}$ and $425^{\circ} \mathrm{C}$, respectively. The cokes presented in Figures $4.23 \mathrm{~b}), \mathrm{d}), \mathrm{f}$ ) were derived with $\mathrm{V}-1074$ solvent, a reaction pressure of 1500 psig and a reaction temperature of $350^{\circ}, 390^{\circ} \mathrm{C}$ and $425^{\circ} \mathrm{C}$, respectively. The pictures of the Hondo cokes show that as the reaction temperature is increased, the coke texture changes from no texture to isotropic as seen in Figures 4.23 a), c), e). For the anisotropic coke made with the coal-derived solvent, an increase in temperature causes an increase in the domain size of the crystallites as seen in Figures 4.23 b), d), f). 
Table 4.3: Optical texture present in the asphaltene fraction for different solvent and reactions conditions

\begin{tabular}{|c|c|c|c|c|c|}
\hline Run & Solvent & $\begin{array}{c}\text { Temperature } \\
\left({ }^{\circ} \mathbf{C}\right)\end{array}$ & $\begin{array}{c}\text { Pressure } \\
(\mathbf{p s i g})\end{array}$ & Gas Phase & Optical Texture \\
\hline 1 & Hondo & 350 & 1000 & $\mathrm{H}_{2}$ & No texture \\
\hline 2 & Hondo & 350 & 1500 & $\mathrm{H}_{2}$ & No texture \\
\hline 3 & Hondo & 390 & 1500 & $\mathrm{H}_{2}$ & Isotropy \\
\hline 4 & Hondo & 425 & 1500 & $\mathrm{H}_{2}$ & Isotropy \\
\hline 5 & V-1074 & 350 & 1500 & $\mathrm{H}_{2}$ & Anisotropy \\
\hline 6 & V-1074 & 390 & 1500 & $\mathrm{H}_{2}$ & Anisotropy \\
\hline 7 & V-1074 & 425 & 1500 & $\mathrm{H}_{2}$ & Anisotropy \\
\hline 8 & V-1074 & 350 & 1000 & $\mathrm{H}_{2}$ & Anisotropy \\
\hline 9 & V-1074 & 390 & 1000 & $\mathrm{H}_{2}$ & Anisotropy \\
\hline 10 & V-1074 & 425 & 1000 & $\mathrm{H}_{2}$ & Anisotropy \\
\hline 11 & $\mathrm{~V}-1074$ & 425 & 1000 & $\mathrm{H}_{2}$ & Anisotropy \\
\hline 12 & V-1074 & 425 & 500 & $\mathrm{H}_{2}$ & Anisotropy \\
\hline 13 & V-1074 & 390 & 1000 & $3 \% \mathrm{H}_{2} \mathrm{~S} / 97 \% \mathrm{H}_{2}$ & Anisotropy \\
\hline 14 & V-1074 & 410 & 1000 & $3 \% \mathrm{H}_{2} \mathrm{~S} / 97 \% \mathrm{H}_{2}$ & Anisotropy \\
\hline 15 & $\mathrm{~V}-1074$ & 390 & 1500 & $3 \% \mathrm{H}_{2} \mathrm{~S} / 97 \% \mathrm{H}_{2}$ & Anisotropy \\
\hline 16 & $\mathrm{~V}-1074$ & 410 & 1500 & $3 \% \mathrm{H}_{2} \mathrm{~S} / 97 \% \mathrm{H}_{2}$ & Anisotropy \\
\hline 17 & $\mathrm{~V}-1074$ & 410 & 500 & $3 \% \mathrm{H}_{2} \mathrm{~S} / 97 \% \mathrm{H}_{2}$ & Anisotropy \\
\hline 18 & $\mathrm{~V}-1074$ only & 410 & 1000 & $3 \% \mathrm{H}_{2} \mathrm{~S} / 97 \% \mathrm{H}_{2}$ & Anisotropy \\
\hline
\end{tabular}



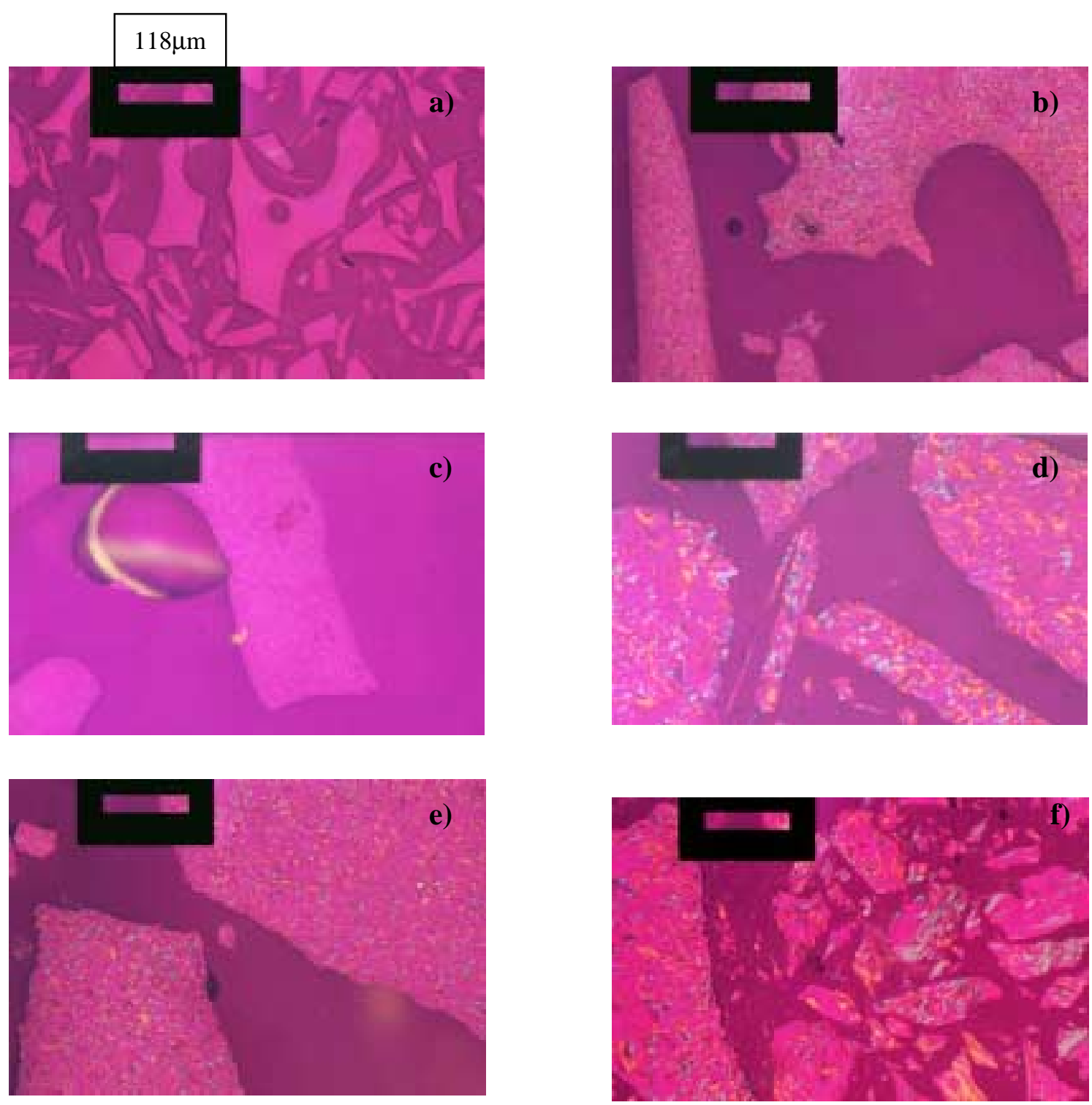

Figure 4.23: Micrographs of cokes made from the asphaltene fractions with reaction conditions of 1500 psig: a)Hondo and $350^{\circ} \mathrm{C}$; b) $\mathrm{V}-1074$ and $350^{\circ} \mathrm{C}$;

c) Hondo and $390^{\circ} \mathrm{C}$; d) V-1074 and $390^{\circ} \mathrm{C}$; e) Hondo and $425^{\circ} \mathrm{C}$;

f) $\mathrm{V}-1074$ and $425^{\circ} \mathrm{C}$. 


\subsection{Ash Content Determination}

The ash present in any carbonaceous sample interferes with the growth of the crystallite domain size and hence its usefulness as a carbon-product precursor. Table 4.4 shows the relation between ash content and reaction temperature, pressure and solvent. The determination of the ash content was described earlier in section 3.2.5. The ash determination for the residue and preasphaltene fractions carries a relative experimental error of $+/-5 \%$. The asphaltene and oil fractions have such a small ash content that it is barely detectable. Hence a larger error is expected for these values $(+/-15 \%)$.

As anticipated, most of the ash in the hydrogenation products is concentrated in the residue fraction. The presence of ash in the preasphaltene fraction suggests the presence of some salts that are soluble in THF but insoluble in heptane. Another possibility would be that the first extraction does not remove completely the ash and it goes to the soluble fraction. The ash present in the asphaltene and oil fractions for all the reaction variations is $0.36 \%$ or less. Using Hondo as the reaction solvent gives lower ash content for all fractions. Generally, the ash levels in the solvent extracted fractions (asphaltenes and oils) are very low since the ash is separated in the THF extraction/filtration step. Moreover, the amount of ash present in the residue is related to the reaction conversion. For example, if a reaction has a high conversion to soluble products, the residue will contain less organic matter resulting in a much higher percentage of ash. As noted in Table 4.4, for the runs at higher temperature, the ash

value of the residue is generally much higher indicating a larger conversion to soluble species.

Table 4.5 shows the effect of the $3 \% \mathrm{H}_{2} \mathrm{~S} / 97 \% \mathrm{H}_{2}$ gas mixture and pressure on the ash content of the various solvent fractions for the $\mathrm{V}-1074$ solvent at $390^{\circ} \mathrm{C}$. In general, when the $\mathrm{H}_{2} \mathrm{~S}$ mixture is employed in the reaction, the ash content is equal to or lower than those for pure $\mathrm{H}_{2}$ for the preasphaltene, asphaltene and oil fractions. On the other hand, the residue fraction shows an increase in ash indicating a higher overall conversion 
Table 4.4: Effect of reaction solvent, pressure and temperature on the ash content for reaction with pure $\mathrm{H}_{2}$ gas

\begin{tabular}{|c|c|c|c|}
\hline \multicolumn{5}{|c|}{$1000 \mathrm{psig} \mathrm{V}-1074$} \\
\hline Temperature & $350^{\circ} \mathrm{C}$ & $390^{\circ} \mathrm{C}$ & $425^{\circ} \mathrm{C}$ \\
\hline Residue & $13.9 \%$ & $30.3 \%$ & $27.2 \%$ \\
\hline Preasphaltene & $0.75 \%$ & $0.94 \%$ & $1.05 \%$ \\
\hline Asphaltene & $0.03 \%$ & $0.07 \%$ & $0.02 \%$ \\
\hline Oil & $0.02 \%$ & $0.02 \%$ & $0.05 \%$ \\
\hline \multicolumn{4}{|c|}{$1500 \mathrm{psig} \mathrm{V}-1074$} \\
\hline Residue & $350^{\circ} \mathrm{C}$ & $390^{\circ} \mathrm{C}$ & $425^{\circ} \mathrm{C}$ \\
\hline Preasphaltene & $15.2 \%$ & $29.9 \%$ & $33.1 \%$ \\
\hline Asphaltene & $0.24 \%$ & $0.86 \%$ & $1.46 \%$ \\
\hline Oil & $0.30 \%$ & $0.10 \%$ & $0.02 \%$ \\
\hline \multicolumn{5}{|c|}{$0.19 \%$} & $0.16 \%$ & $0.36 \%$ \\
\hline Residue & $1500 \mathrm{psig}$ and Hondo & \\
\hline Preasphaltene & $1.78 \%$ & $0.98 \%$ & $1.15 \%$ \\
\hline Asphaltene & $0.14 \%$ & $0.03 \%$ & $0.04 \%$ \\
\hline Oil & $0.06 \%$ & $0.18 \%$ & $0.08 \%$ \\
\hline
\end{tabular}

for both 1000 psig and 1500 psig. Moreover, it is found that at 1000 psig and 1500 psig, the use of the $3 \% \mathrm{H}_{2} \mathrm{~S} / \mathrm{H}_{2}$ gas mixture has barely any effect on the ash content of the preasphaltene, asphaltene and oil fractions. The difference presented in these values is small and within the experimental error. 
Table 4.5: Effect of $3 \% \mathrm{H}_{2} \mathrm{~S} / 97 \% \mathrm{H}_{2}$ mixture and pressure on ash content using reaction solvent $\mathrm{V}-1074$ and $390^{\circ} \mathrm{C}$

\begin{tabular}{|c|c|c|}
\hline \multicolumn{3}{|c|}{$\mathrm{V}-1074,1000 \mathrm{psig}, 390^{\circ} \mathrm{C}$} \\
\hline & $100 \% \mathrm{H}_{2}$ & $97 \% \mathrm{H}_{2} / 3 \% \mathrm{H}_{2} \mathrm{~S}$ \\
\hline Residue & $30.47 \%$ & $36.6 \%$ \\
\hline Preasphaltene & $0.94 \%$ & $0.82 \%$ \\
\hline Asphaltene & $0.07 \%$ & $0.02 \%$ \\
\hline Oil & $0.02 \%$ & $0.02 \%$ \\
\hline \multicolumn{3}{|c|}{$\mathrm{V}-1074,1500 \mathrm{psig}, 390^{\circ} \mathrm{C}$} \\
\hline & $100 \% \mathrm{H}_{2}$ & $97 \% \mathrm{H}_{2} / 3 \% \mathrm{H}_{2} \mathrm{~S}$ \\
\hline Residue & $31.2 \%$ & $33.4 \%$ \\
\hline Preasphaltene & $0.86 \%$ & $0.52 \%$ \\
\hline Asphaltene & $0.10 \%$ & $0.03 \%$ \\
\hline Oil & $0.16 \%$ & $0.22 \%$ \\
\hline
\end{tabular}

The effect of reaction temperature and pressure on the ash content using the $\mathrm{H}_{2} \mathrm{~S}$ mixture is shown in Table 4.6 for the V-1074 solvent. The ash content of the asphaltene fraction is less than $0.03 \%$. The ash content of the residue and preasphaltene fractions shows an increase as the temperature increases at 1500 psig while at 1000 psig the ash content of these fractions decreases as the temperature increases. For all temperatures and pressures, the highest ash content is mainly found in the residue and preasphaltene fractions. The use of $\mathrm{H}_{2} \mathrm{~S} / \mathrm{H}_{2}$ gas mixture has little effect on the ash content of the fractions except on the residue fraction. 
Table 4.6: Effect of reaction temperature and pressure on ash content using reaction solvent $\mathrm{V}-1074$ and $3 \% \mathrm{H}_{2} \mathrm{~S} / 97 \% \mathrm{H}_{2}$ gas phase

\begin{tabular}{|c|c|c|}
\hline \multicolumn{3}{|c|}{ V-1074, 1000 psig } \\
\hline & $390^{\circ} \mathrm{C}$ & $410^{\circ} \mathrm{C}$ \\
\hline Residue & $36.6 \%$ & $30.8 \%$ \\
\hline Preasphaltene & $0.82 \%$ & $0.51 \%$ \\
\hline Asphaltene & $0.02 \%$ & $0.03 \%$ \\
\hline Oil & $0.02 \%$ & $0.50 \%$ \\
\hline & V-1074, $1500 \mathrm{psig}$ & \\
\hline & $390^{\circ} \mathrm{C}$ & $410^{\circ} \mathrm{C}$ \\
\hline Residue & $33.4 \%$ & $40.6 \%$ \\
\hline Preasphaltene & $0.52 \%$ & $1.52 \%$ \\
\hline Asphaltene & $0.03 \%$ & $0.01 \%$ \\
\hline Oil & $0.22 \%$ & $0.07 \%$ \\
\hline
\end{tabular}

A low ash level could mean the production of a larger mass of a particular product fraction or and effective extraction and filtering process. It also leads to less interference in the formation of the graphite structure and easier condensation of aromatic rings.

\subsection{Ultimate Analysis and NMR Studies}

A limited number of samples were evaluated by NMR and for the ultimate analysis. Parsons Project Services, Inc performed the ultimate analysis at Department of Energy/National Energy Technology Laboratory (DOE/NETL) in Pittsburgh, PA. The 
coal analysis was performed by Galbraith in Knoxville, TN. A set of three asphaltene samples reacted with $\mathrm{V}-1074$ solvent at 1000 psig and at various temperatures was analyzed for ultimate analysis. The reaction solvents were also sent for analysis.

Figure 4.24 shows the carbon content as a function of reaction temperature for the asphaltene fraction. The absolute experimental error is $+/-0.2$. As the temperature increases the carbon content increases by about $4 \%$. An increase in temperature gives an asphaltene fraction with a higher carbon content. This might imply that, as the temperature is raised, the asphaltene fraction is higher in aromatic compounds which were retained in the toluene-soluble fraction.

Figure 4.25 presents the elemental content of sulfur $(\mathrm{S})$, nitrogen $(\mathrm{N})$, hydrogen $(\mathrm{H})$ and oxygen $(\mathrm{O})$ in the asphaltene fraction as a function of reaction temperature. Here oxygen is determined by difference. The absolute errors in the determination of the elemental content are +/- 0.07 for hydrogen determination, +/-0.05 for sulfur and +/-0.05 for nitrogen. As the reaction temperature increases, the amount of sulfur and nitrogen in the asphaltene fraction decreases. Thus, as the reaction temperature increases, the $\mathrm{H}_{2}$ in the gas phase may more readily react with the sulfur and nitrogen to form $\mathrm{H}_{2} \mathrm{~S}$ and $\mathrm{NH}_{3}$. Moreover, the oxygen present in the sample decreases as the reaction temperature increases. The fact that the oxygen decreases agrees with the optical texture observations presented earlier. A high oxygen content will restrict the mesophase formation in the samples. The asphaltene fraction obtained at the higher reaction temperature had a larger crystallite domain and smaller amount of oxygen, while the asphaltene fraction from a lower reaction temperature had a smaller crystallite domain and higher amount of oxygen. The presence of oxygen is known to introduce cross linking and hinder anisotropic development. In general, if a sample has high oxygen content then it is expected to have an isotropic behavior. 


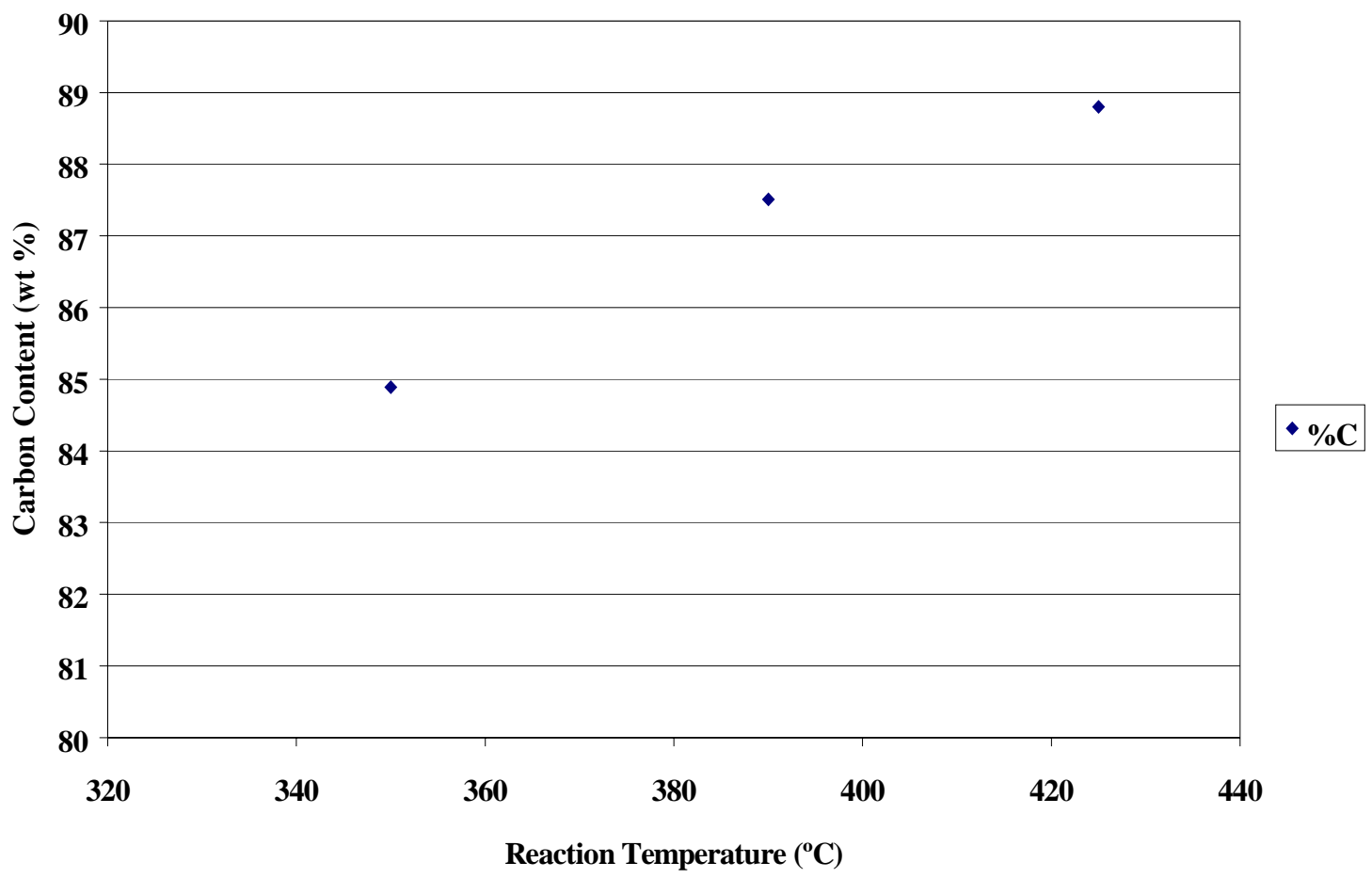

Figure 4.24: Effect of reaction temperature on carbon content in the asphaltene fraction using solvent V-1074 and 1000 psig of $\mathrm{H}_{2}$ 


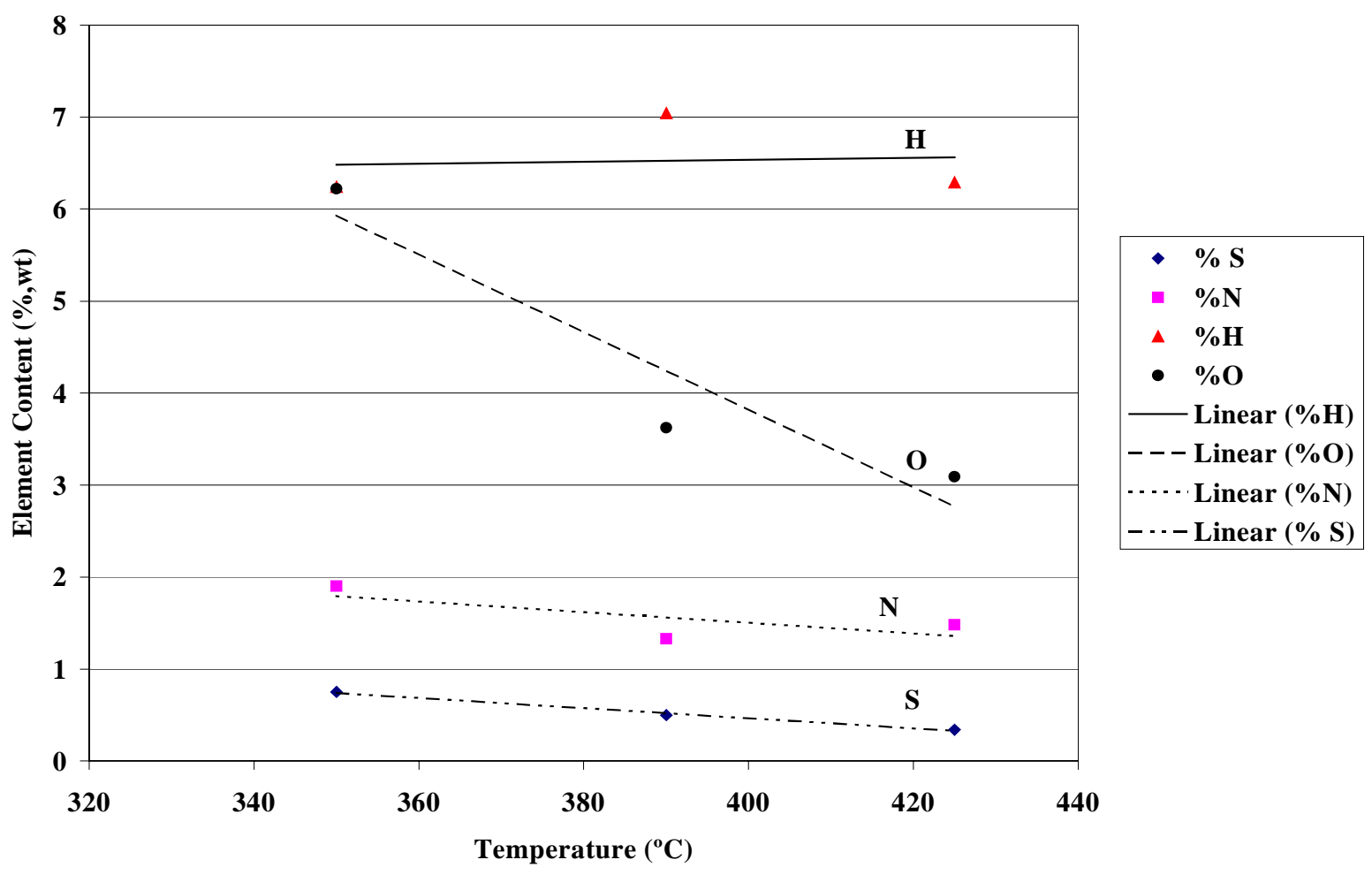

Figure 4.25: Effect of temperature on the content of sulfur, nitrogen, oxygen and hydrogen in the asphaltene fraction using solvent V-1074 and 1000 psig of $\mathrm{H}_{2}$ 
In Figure 4.25 it can also be noted that the amount of hydrogen in the asphaltene fraction may increases slightly until it reaches a temperature of $390^{\circ} \mathrm{C}$ and then decrease. This shows the optimum temperature for hydrogenation at $390^{\circ} \mathrm{C}$ at least for the asphaltene fraction. At this point the $\mathrm{H} / \mathrm{C}$ ratio on a weight basis is the maximum with these particular reaction conditions (Table 4.7). The hydrogen content of the asphaltene fraction is around $6-7 \%$.

Both the V-1074 and Hondo solvents were also analyzed for ultimate analysis and the elemental content is presented in Table 4.8. The V-1074 solvent shows a higher content of carbon and a much lower content of sulfur, nitrogen and hydrogen than the Hondo solvent. Since $70 \%$ of the reaction sample is solvent, the solvent should have a high carbon content to contribute to the final product. A low sulfur and oxygen content is also very desirable. Note that in all the results presented herein, the solvent added to the reactor is not removed but counted as part of the product mixture. The high sulfur and nitrogen of the Hondo solvent probably react with hydrogen at reaction conditions to form $\mathrm{H}_{2} \mathrm{~S}$ and $\mathrm{NH}_{3}$. These compounds must then be scrubbed from the gas phase and more importantly would represent a major loss in expensive hydrogen. Hence the Hondo solvent is not attractive in this regard.

Table 4.7: $\mathrm{H} / \mathrm{C}$ for the asphaltene fractions at 1000 psig of $\mathrm{H}_{2}$ using $\mathrm{V}-1074$

\begin{tabular}{|c|c|}
\hline $\begin{array}{c}\text { Reaction } \\
\text { Temperature }\end{array}$ & $\begin{array}{c}\mathbf{H} / \mathbf{C} \\
\text { (weight basis) }\end{array}$ \\
\hline $350^{\circ} \mathrm{C}$ & 0.0735 \\
\hline $390^{\circ} \mathrm{C}$ & 0.0804 \\
\hline $425^{\circ} \mathrm{C}$ & 0.0708 \\
\hline
\end{tabular}


Table 4.8: Ultimate analysis results for the solvents alone

\begin{tabular}{|c|c|c|}
\hline Analyte & $\mathbf{V - 1 0 7 4}$ & Hondo \\
\hline Sulfur & $0.38 \%$ & $4.19 \%$ \\
\hline Carbon & $88.59 \%$ & $84.71 \%$ \\
\hline Hydrogen & $9.45 \%$ & $10.51 \%$ \\
\hline Nitrogen & $0.60 \%$ & $0.96 \%$ \\
\hline Oxygen & $0.98 \%$ & $0.37 \%$ \\
\hline
\end{tabular}

NMR results were performed at the Western Research Institute in Laramie, WY. The actual NMR data sheets are presented in Appendix E. Both solid and liquid phase NMR analyses were performed on a limited number of the asphaltene fractions. The samples were sent as solids for the NMR analyses. The sample was then dissolved in chloroform and the liquid-state (conventional) ${ }^{13} \mathrm{C}$ and ${ }^{1} \mathrm{H}$ NMR analyses were performed. Since the sample did not dissolve completely in chloroform, the solid state NMR analyses i.e, single pulse (SP) and cross-polarization (CP), were performed. The estimated relative error from a solid-state ${ }^{13} \mathrm{C}$ NMR determination is considered to be $+/$ $2 \%$ of the total carbon present in the sample. The solid-state measurements gave a higher aromaticity number than those for the liquid-state. This is due to the insolubility of the samples. When preparing the samples for NMR, it was found that they were not completely soluble in chloroform. Hence some aromatic carbon species could have remained in the insoluble part and were not included in the determination of the aromaticities.

The relationship between the protonated and alkyl substituted aromatic carbons with temperature is shown in Figure 4.26. The alkyl substituted carbon is an aromatic carbon attached to an alkyl group. The protonated carbon is an aromatic carbon attached to hydrogen. The fraction of protonated aromatic carbon increases until it reaches a maximum at $390^{\circ} \mathrm{C}$, then decreases slightly as the temperature is increased. Interestingly, the fraction of alkyl substituted aromatic carbon remains nearly constant. For all the reaction temperatures, the fraction of protonated aromatic carbon is higher than that of the alkyl substituted aromatic carbon. A decrease in the amount of protonated aromatic 


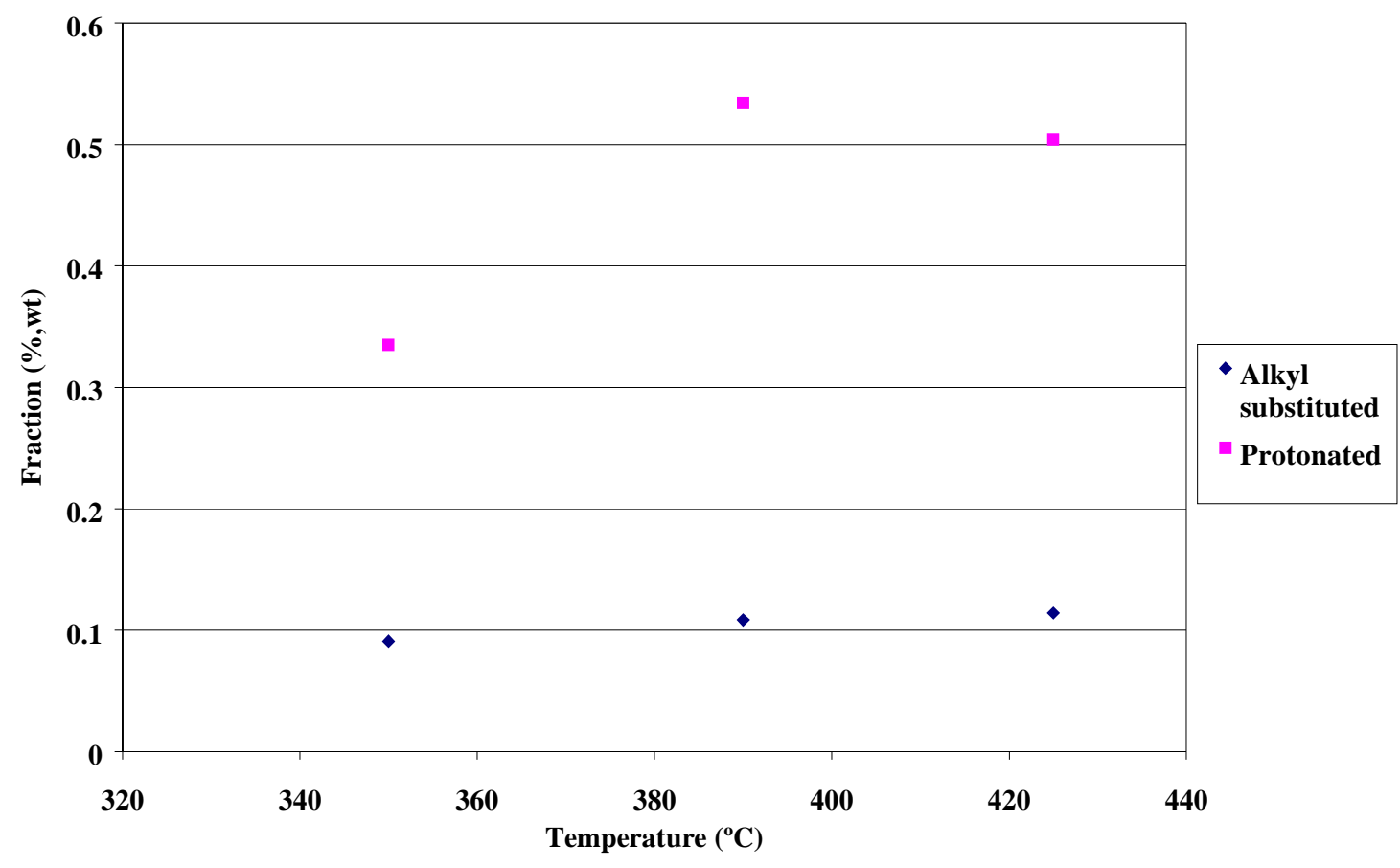

Figure 4.26: Comparison of the protonated and alkyl substituted aromatic carbons present in the asphaltene fraction as a function of reaction temperature. Reaction solvent is V-1074 and the gas phase is pure $\mathrm{H}_{2}$ 
carbon as temperature is increased implies the formation of larger, multi-ring aromatic structures.

Figure 4.27 gives the relationship between the reaction temperature and the $\mathrm{sp}^{2}$ (aromatic) to $\mathrm{sp}^{3}$ (aliphatic) ratio present in the asphaltene fractions. This figure shows a decrease in the $\mathrm{sp}^{2}$ to $\mathrm{sp}^{3}$ ratio as temperature increases until reaching a minimum at $390^{\circ}$ $\mathrm{C}$, then it increases significantly. Again this shows that an increase in temperature causes an increase in aromatic carbons and a loss in aliphatic species.

Figure 4.28 shows the effect of reaction temperature on solid and liquid state fractional aromaticities of the samples. The fractional aromaticity is defined as the amount of aromatic carbons per total amount of carbon and in the case of ${ }^{1} \mathrm{H}$ the same applies but for hydrogen. As mentioned earlier, cross polarization (CP) and single pulse (SP) are techniques used to determine the ${ }^{13} \mathrm{C}$ in a solid-state sample. On the other hand, what is referred to here as ${ }^{13} \mathrm{C}$ and ${ }^{1} \mathrm{H}$ analysis is the conventional NMR analysis preformed in the liquid state or on a solution. From the ${ }^{13} \mathrm{C}, \mathrm{CP}$ and SP analyses the amount of aromatic carbon atoms is determined while the ${ }^{1} \mathrm{H}$ analysis aids in the determination of the aromatic hydrogen atoms. Figure 4.28 shows that the aromaticity fraction decreases until $390^{\circ} \mathrm{C}$ and then increases, again showing a maximum aromaticity at $425^{\circ} \mathrm{C}$ for all the NMR techniques used. The reaction at $1000 \mathrm{psig}$ and $425^{\circ} \mathrm{C}$ gives the highest aromaticity in the asphaltene fraction independent of the technique used. These data indicate the formation of large multi-ring aromatic structures. As shown previously in Figures 4.23 b), d), and f), higher reaction temperatures produced cokes from the asphaltenes with much larger crystalline domains. Such large domains are representative of large multi-ring structures which are evidenced by the NMR data.

\subsection{Reaction Solvents}

Throughout this work a difference has been observed in the behavior of the petroleum-derived and coal-derived solvent. The main reason of this difference being their composition (Table 4.8). The use of Hondo solvent yielded higher coking values for 


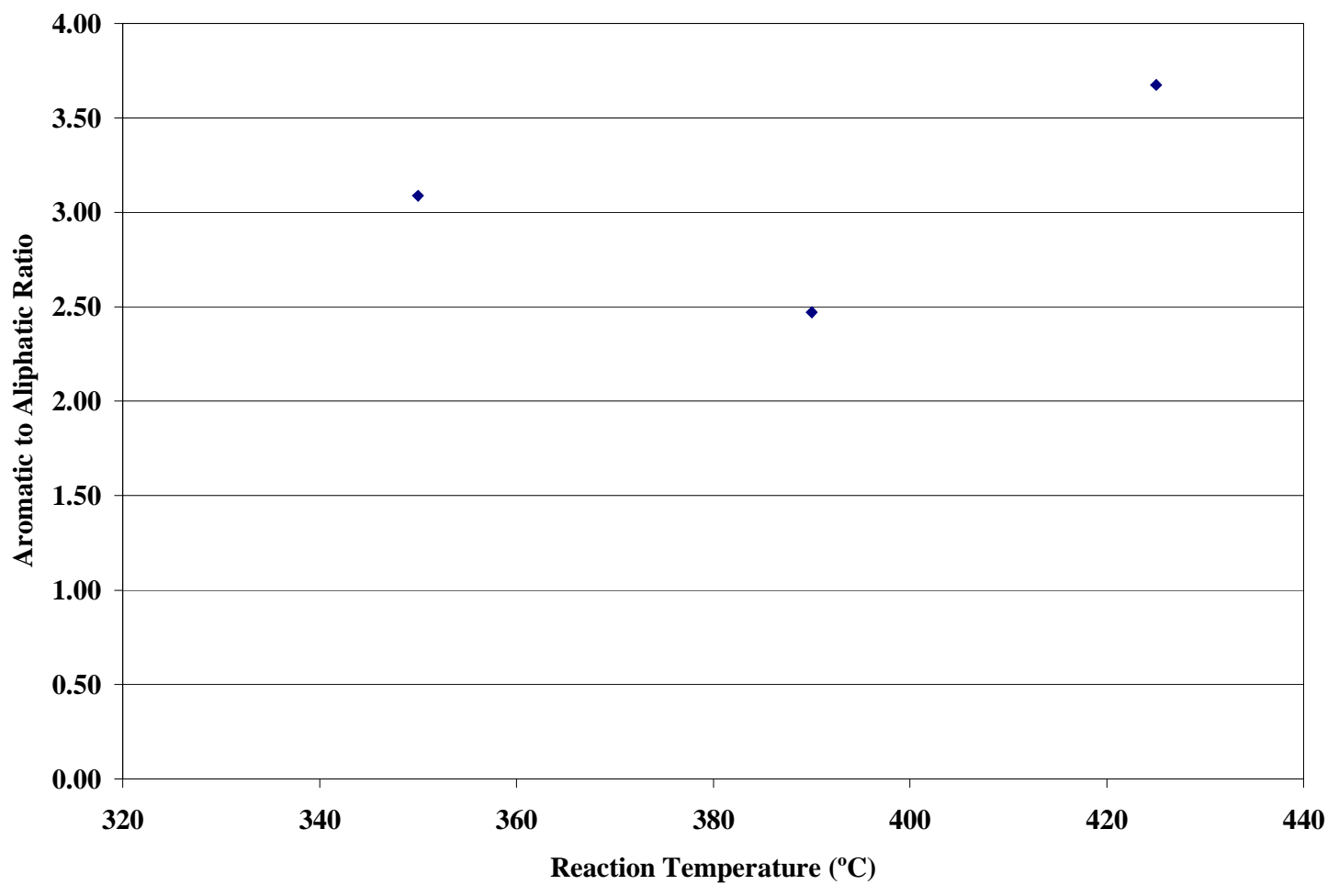

Figure 4.27: Graph of aromatic $\left(\mathrm{sp}^{2}\right)$ to alipahtic $\left(\mathrm{sp}^{3}\right)$ carbon ratio in the asphaltene fraction as a function of reaction temperature using the reaction solvent $\mathrm{V}-1074,1000$ psig and $\mathrm{H}_{2}$ in the gas phase 


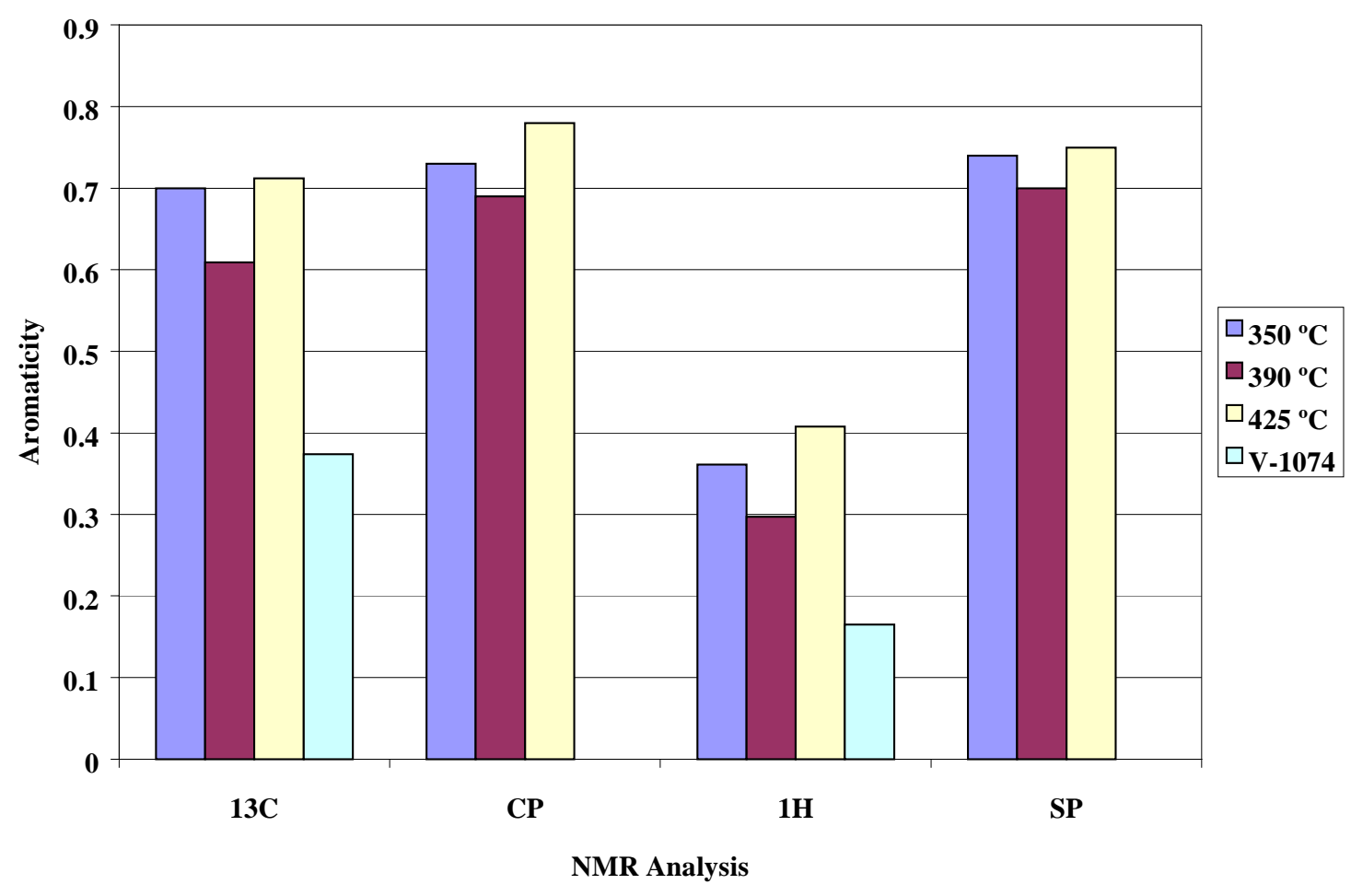

Figure 4.28: Effect of reaction temperature on solid and liquid state aromaticity determination for the asphaltene fraction with solvent V-1074 at 1000 psig. $13 \mathrm{C}$ and $1 \mathrm{H}$ are analyses performed in the liquid-state sample and $\mathrm{CP}$ and $\mathrm{SP}$ are done in the solid-state. 
the asphaltene fractions than V-1074. This could be mainly due to the fact that V-1074 has a lower boiling point while Hondo is a heavier fraction. The softening point of the asphaltene fraction is also higher with the Hondo solvent.

Both raw solvents (Hondo and V-1074) were characterized. The coking values, softening points, ash content, optical texture, in addition, MNR for coal-derived solvent and ultimate analyses were obtained. Their solubility in toluene was also determined. It was found that Hondo is slightly more soluble in toluene (97\%) than V-1074 (92\%). The coking value of Hondo (16\%) was also higher than that of V-1074 (1.5\%). In addition the ash content of Hondo $(0.09 \%)$ was slightly higher than that of V-1074 $(0.05 \%)$. When analyzing the micrographs of the cokes made from these solvents, both showed anisotropy, but the crystallite domains of Hondo were smaller than that of V-1074. Finally, the high sulfur content of the Hondo solvent will cause problems in processing, emission of $\mathrm{H}_{2} \mathrm{~S}$ and higher sulfur in the product fractions, all of which is undesirable.

\subsection{Discussion of Results}

The results presented above should be regarded with caution since slight differences in the production of the liquefaction products can have large effects on the properties of the various fractions. However, the general trends should be valid. The mass balances on the liquefaction reaction may indicate the presence of residual extraction solvent in some of the fractions and/or the possibility of the loss of light species during the solvent extraction. However, on the whole, the overall mass balances closed to typically less than $10 \%$ which for such a complex multistep procedure is quite good. The overall ash balances are not as good since the errors in the individual mass balances and ash determinations are compounded in the ash balance. But the low ash values for the asphaltene and oil fractions are proof that solvent extraction is capable of producing products with ash levels comparable to or better than conventional pitches.

The results herein suggest that the reaction conditions suitable for the production

of feedstocks for different carbon products can be determined at least qualitatively. In 
order to produce a higher yield of the desired products, pure $\mathrm{H}_{2}$ gas should be used in the gas phase. Even though the addition of $\mathrm{H}_{2} \mathrm{~S}$ increases the coking value of the residue and preasphaltene, this increase does not justify the use of $\mathrm{H}_{2} \mathrm{~S}$ because these two fractions have poor characteristics. They are high in ash (>10\%), show no optical texture upon coking, and no useful softening point $\left(>200^{\circ} \mathrm{C}\right)$. Any increased yield afforded by the $\mathrm{H}_{2} \mathrm{~S}$ was minimal as well.

The optimum reaction temperature for the Hondo solvent and coal was found to be $390^{\circ} \mathrm{C}$. The asphaltene fraction at these conditions gives an isotropic coke. It also has the lowest softening point $\left(175^{\circ} \mathrm{C}\right)$ within the temperature range and low ash content $(0.03 \%)$ along with a good coking value $(54.8 \mathrm{wt} \%)$. The reaction pressure used was 1500 psig. However, the large sulfur content of the Hondo make it an unattractive solvent for hydrogenation and carbon products because of the reasons mentioned above.

To produce the anisotropic material, the V-1074 solvent should be used with coal and pure $\mathrm{H}_{2}$ gas. The desired uses and the important properties of the resultant carbon product dictate the optimum reaction conditions. The reaction condition that gives the largest amount of the oil fraction is $1500 \mathrm{psig}$ and $350^{\circ} \mathrm{C}$. The reaction condition that gives the and highest asphaltene yield $(25 \%)$ is $390^{\circ} \mathrm{C}$ at $1000 \mathrm{psig}_{2}$. A softening point $\left(114.7^{\circ} \mathrm{C}\right)$ close to that of a typical coal-tar pitch, the lowest ash content $(0.02 \%)$ and a low coking value (32\%) for the asphaltene fraction are also achieved under these conditions. For the asphaltene fraction, these same reaction parameters produce the highest amount of protonated aromatic carbons $(0.51)$, the lowest $\mathrm{sp}^{2}$ to $\mathrm{sp}^{3}$ carbon ratio (2.49) and highest $\mathrm{H} / \mathrm{C}(0.08$, wt). The highest coking value in the asphaltene fraction (42\%) could be obtained with reaction temperature of $425^{\circ} \mathrm{C}$ and reaction pressure of 1500 psig. To obtain the highest solubility in toluene, 78\%, (asphaltene production) higher aromaticity and a higher amount of $\mathrm{sp}^{2}$ carbons in the asphaltene fraction, a pressure of 1000 psig and a temperature of $425^{\circ} \mathrm{C}$ should be used. These conditions also produce the cokes with the largest crystallite domain size and a softening point of $104.9^{\circ} \mathrm{C}$ and a coking value of $38.3 \%$. 
The information presented in the previous sections gives an indication of the formation of larger aromatic rings as the reaction temperature increases. Figure 4.24 shows an increase in carbon content as reaction temperature increases. This must be accompanied by the removal of other species like hydrogen, sulfur and nitrogen. Figure 4.25 indicates an overall decrease of hydrogen, sulfur and oxygen as the reaction temperature increases, thus supporting the previous argument. Figure 4.26 shows an increase in protonated carbon with reaction temperature which implies more aromatic carbons and fewer aliphatic chains. In Figure 4.27 the aromatic to aliphatic carbon ratio also increases with temperature suggesting the formation of more aromatic carbon. Figure 4.28 again confirms the presence of higher aromaticity with higher temperature. The aromatic character of the asphaltene fraction is substantiated in the micrographs that show an increase in domain size of the coke as the reaction temperature is raised. Since larger aromatic rings are present, a more aligned structure is formed during coking.

Different reaction conditions give optimum values for different properties. The optimum reaction conditions for the production of the asphaltene fraction from coal and $\mathrm{V}-1074$ solvent are $390^{\circ} \mathrm{C}$ and $1000 \mathrm{psig}$, because, even though the coking values are lower, the quality and properties of the products are excellent.

The residue fraction is not useful to manufacture carbon products due to its high ash content, which interferes with its graphitizability. The preasphaltene fraction from any reaction has a relatively low ash content and a good coking value. It could be used for isotropic cokes. The oil fraction might be used for fuel.

In general, the asphaltene fraction could be used in the production of carbon products. The asphaltene obtained using V-1074 at 1000 psig and $380^{\circ} \mathrm{C}$ could be used as a replacement of coal tar binder pitch because its softening point $\left(114.7^{\circ} \mathrm{C}\right)$ is close to that of the standard binder pitch now in use $\left(110^{\circ} \mathrm{C}\right)$. Its coking value is low $(32 \%)$ when compared to binder pitch coking value (55\%). Its ash content is $0.02 \%$ and is an order of magnitude better than that of a typical binder pitch (0.24\%). Anisotropic coke and binder pitch are needed for the production of both graphite electrodes and anodes. 
The fact that the asphaltene fraction has an anisotropic behavior using V-1074 opens the possibility for its use in the production of carbon fibers as well. This may be facilitated by heat treatment of the asphaltene fraction to form a pitch with a softening point $\left(\sim 220^{\circ} \mathrm{C}\right)$ closer to typical fiber spinning temperature. 


\section{Chapter 5:}

\section{Conclusions and Recommendations}

After evaluating the characteristics of each of the hydrogenation fractions several conclusions can be drawn. The main observation is that the asphaltene fraction is a suitable precursor for anisotropic carbons. In addition, the properties of the asphaltene fraction can be tailored by varying the processing conditions of the hydrogenation. In general, there is a difference in behavior between products derived exclusively from coal (coal and coal-derived solvent) and those generated from coal and petroleum oil when materials are produced and compared at the same conditions. The optimum reaction conditions (i.e, $390^{\circ} \mathrm{C}, 1500 \mathrm{psig}$ ) for producing the asphaltene fraction as an acceptable substitute for binder pitch give a very small ash content and a good coking value. In terms of quality, the suitable conditions also yield a material with a proper softening point and anisotropic behavior.

\subsection{Conclusions}

The coal liquefaction process is considered as an option for the production of carbon products because it is not an oxidation reaction, so that the sulfur and nitrogen in the coal will not be transformed into $\mathrm{SO}_{\mathrm{X}}$ and $\mathrm{NO}_{\mathrm{X}}$, but could instead be removed as hydrogen sulfide and ammonia respectively.

Solvent extraction of the product of coal liquefaction was performed in order to obtain various fractions. It was found that the selection of specific components by a combination of reaction and solvent extraction alters the softening point of the fraction and improves its processing characteristics and physical properties thereby enabling the subsequent production of mesophasic fibers, isotropic fibers, electrode binders and composite-impregnating pitch. The asphaltene fraction is the most attractive of all fractions for subsequent processing to carbon products. 
An increase in temperature results in an increase in the conversion. This results in an increase in low-molecular-weight species in the heptane-insoluble fraction which end up as asphaltenes. Thus the softening point is decreased and the asphaltene properties are altered. As the reaction temperature increases the softening point decreases.

The coal-derived solvent had less sulfur content, and thus resulted in a low sulfur content in the asphaltene fraction, while the Hondo solvent has higher sulfur content. The sulfur in the coal and solvent may react with $\mathrm{H}_{2}$ and leave the system as $\mathrm{H}_{2} \mathrm{~S}$ gas, wasting valuable $\mathrm{H}_{2}$.

No optical texture was present in the residue and preasphaltene fractions where the ash content was high. Hence it is thought that the ash content interfered with the formation of the graphite layers. The optical texture for the asphaltene fraction was enhanced as the reaction temperature was increased for the same solvent (e.g., Hondo, V1074). The use of coal-derived solvent produced anisotropic cokes while the use of petroleum-derived solvent produced isotropic cokes or coke with no optical activity at all.

The fraction with higher aromaticity and higher aromatic-to-aliphatic ratios resulted in anisotropic coke with larger domains of optical texture. The coal-derived solvent was far superior in this regard than the petroleum-derived solvent.

The parameters obtained from all the analytical procedures allowed the determination that the asphaltene fraction could serve as an adequate substitute for coal-tar pitch for the production of anodes and electrodes. The experimental reaction conditions produced the asphaltene fraction with a reasonable coking value and softening point, mesophase formation and a small ash content. These conditions are found to be $390^{\circ} \mathrm{C}, 1500 \mathrm{psig}$ of $\mathrm{H}_{2}$ and the reaction solvent V-1074. THF-insoluble (residue) fraction was evaluated for production of premium carbon products without any success. The preasphaltene fraction was evaluated and it was concluded that it could be used in the production of isotropic cokes due to its high coking value and relatively low ash content. 


\subsection{Recommendations for Future Work}

A mass balance analysis should be performed in future experimentation prior to characterization of the products in order to rule out the possibility of residual solvent altering the properties of the fractions. Further analysis is required in the determination of the weight gain in the NMP solubility test performed on the residue fraction.

It is recommended that the coal liquefaction product be extracted using the same steps presented here to obtain the asphaltene fraction. The asphaltene fraction could be used as a replacement of coal-tar binder pitch, while the oil fraction could be used as fuel. The remaining fractions can be burned. In future research the production of fibers from the anisotropic asphaltene fraction and/or the production of coal-tar pitch should be studied to establish the necessary processing parameters for their bulk production. Also a study could be performed into the possible of mixing of the asphaltene fractions from different reaction conditions to obtain the desired properties.

If this process were to be instituted on the industrial scale a study of the

characteristics of the liquefaction product with only toluene extraction should be accomplished. This study modification would simplify the process and hence aid in the cost reduction. 


\section{References}

1. ASTM D 189 Standard Test Method for Conradson Carbon Residue of Petroleum Products

2. ASTM D 2415 Standard Test Method for Ash in Coal Tar and Pitch

3. ASTM D 3104 Standard Test Method for Softening Point of Pitches (Mettler Softening Point Method)

4. ASTM D4616 Standard Test Method for Microscopical Analysis by Reflected Light and Determination of Mesophase in a Pitch

5. "A study on the Carbonization of Coal-Derived Pitches" Thesis by Jianli Yang, West Virgnia University, Chemical Engineerign Department, Dec. 1994

6. A University, Industry, Goverment Cooperative Research Partnership. "Non-Fuel Use of Coal: Coal-Derived Carbon Materials". Nov. 12, 1993. The National Research Center for Coal and Energy ( NRCCE), West Virginia University, PO Box 6064, Morgantown, WV 26506-6064

7. Azami K., Yamamoto, S., Yokono, T. and Sanada, T.. "In-situ monitoring for mesophase formation processes of various pitches by means of high-temperature ${ }^{13}$ C-NMR”, Carbon Vol 30, No. 7 pp. 943-945, 1991.

8. Barr J.B. and I.C Lewis "Characterization of pitches by differential scanning calorimetry and thermomechanical analysis”, Termochimica Acta 52 (1982) 297304.

9. "Coal Based Nuclear Graphites for the New Production Gas Cooled Reactor", Technical Report for the period March, 1991 - February 1994. West Virginia University, 1994. Grant No.DE-FG02-91NP00159 West Virginia University, 1994.

10. Cooper, G. Stanley By-Product Coking, 1923: Van Nostrand Company, New York,

11. Cugini A. V, B.C Bockrath, K. S. Rothenberger, D.V. Martello, J.W Zondlo, L. Laureano-Perez, P.G. Stansberry and R. M. Enick, "Research on Carbons from Coal at FETC”, $24^{\text {th }}$ Biennial Conference on Carbon, Extended Abstracts and Program Vol. 1, July 11-16, 1999, .

12. Edstrom T. and I.C Lewis "Chemical structure and graphitization: X-Ray Diffraction studies of graphites derived from polynuclear aromatics”, Carbon Vol 7, pp. 85-91, 1969

13. Field, L.D. and S. Sternhell. Analytical NMR. John Wiley \& Sons, Chichester, 1989 
14. Greinke R.A. and I.C. Lewis "Carbonization of Naphthalene and Dimethylnaphthalene”, Carbon Vol 22, No. 3 pp. 305-314, 1984

15. International Energy Agency, Coal Liquefaction A Technology Review. OECD, Paris 1982

16. Lewis I.C. “Chemistry of Carbonization” Carbon, Vol. 20 No. 6, pp. 519-529, 1982.

17. Lewis I.C. and L.S Singer. "Further Electron Spin Resonance Studies of the pyrolisis of aromatic hydrocarbon”, Carbon Vol 5 pp. 373-381, 1967.

18. Marsh, H. Coal Carbonization: Formation Properties and Relevance of Microstructures in Resultant Coke, Coke Oven Techniques, Information Symposium, Luxembourg, 23 and 24 September 1981, p 73-87.

19. Marsh H., E. A. Heintz, F. Rodríguez-Reinoso, Introduction to Carbon Technologies, University of Alicante Publications, Spain, 1997. 658 p.

20. Nalwaya V., V. Tangtayakom, P. Piumsomboon and S. Fogler "Studies on Asphaltenes through Analysis of Polar Fractions" Ind. Eng. Chem. Res. 1999,38, 964-972

21. Oberlin A. “Carbonization and Graphitization”, Carbon Vol. 22 No. 6 pp. 521-541, 1982.

22. "Pollution Problem" Round Table A, Coke Oven Techniques, Information Symposium, Luxembourg, 23 and 24 September 1981, p 73-87.

23. Pullen J.R. "Solvent extraction of coal", Report number ICTIS/TR16, Novenber 1981, IEA Coal Research, London,

24. Rand B. "Pitch precursors for advance carbon materials-rheological aspects", Fuel Vol. 66, Nov. 1987, p. 1499-1502

25. Sakai M., M. Yoshihara and M. Inagaki "Determination of intrinsic viscosity of fractionated pitches and discussion on shape and size of molecules", Carbon Vol 19, pp. 83-87 1981

26. Schobert, H.H. Coal: The Energy Source of the Past and the Future. American Chemical Society, USA, 1987

27. Schobert, H.H. and C. Song, "Moving Coal into the $21^{\text {st }}$ Century" Earth and Mineral Science Vol 611993 pp.51-55 
28. Semih E. and R.G. Jenkins "Carbonization of petroleum feedstocks I: Chemical constitution of feedstock asphaltenes and mesophase development", Carbon Vol 27, No. 6 1989, pp. 877-887

29. Semih E. and R.G. Jenkins "Carbonization of petroleum feedstocks II: Chemical constitution of feedstock asphaltenes and mesophase development", Carbon Vol 27, No. 6 1989, pp. 889-897

30. Song, C. and Schobert, H.H., "Non-fuel uses of coals and synthesis of chemicals and materials" Fuel Vol 75, No. 6, 1996, pp. 724-736

31. "The influence of temperature and solvent on intrinsic viscosity of fractionated pitches", Letters to the editor Carbon Vol 21, No. 6 1983, pp. 601-603

32. Tsai, S.C. Fundamentals of Coal Beneficiation and Utilization. Elsevier Scientific Publishing Co, Amsterdam, The Netherlands, 1982

33. Van Krevelen, D.W., F.J. Huntjens and H.N.M. Dormans "Chemical Structure and Properties of Coal XVI - Plastic Behavior on Heating”, Fuel Vol. 35, 1956. p. 462 475.

34. Watt W. and B. V. Perov Strong Fibers, NHC Publications, North- Holland Amsterdam, 1985. p 495-575.

35. White, K. L., B. L. Knutson and G. Kimber. "Extraction of Coal Tar Pitch using a mixture of compressed $\mathrm{CO}_{2}$ and Toluene" Ind. Eng. Chem. Res. 1999, 38, 33603366

36. Yen, T. F. Chemistry and Structure of Coal-Derived Asphaltenes: Quarterly Progress Report for the period October-December 1975. Energy Research and Development Administration. 25 p. 


\section{APPENDICES}




\section{Appendix A. Safety Requirements, Equipment and Supplies}

Laboratory safety requirements are continuously reviewed. Major areas of concern are the location of safety equipment, toxicity of the chemicals, high temperature, open flame, electrical and mechanical equipment.

All the characterization techniques in this research include high temperatures or electrical apparatus. When working with electrical equipment, it is important to avoid water near the plugs and connections and do not touch any hot surface. Whenever needed, use tweezers to work with hot objects. The Soxhlet extraction needs the use of toxic and flammable solvents like toluene, THF and NMP. Working in the hood at all times is necessary as well as wearing protective gloves when handling these chemicals is necessary. In the determination of coking value, the burner and all the standard equipment should be used in the hood due to vapor emissions from the samples being studied. Vapors should not be inhaled. When using the vacuum oven it is necessary to make sure that the trap has dry ice and methanol. When drying in the vacuum oven, always use a purge of nitrogen to avoid any explosion that could occur as a result of any electrical or static spark. It is necessary to always wear protective glasses, lab coat and gloves at all times when working in the lab. These are to maintain safety and to avoid contact of chemicals with skin and eyes.

The laboratory is equipped with chemical hoods, fire extinguishers, chemical safety showers, chemical spill kits and several eye wash stations. Other available equipment includes gloves, organic vapor masks, dust masks, face shields, protective clothing and eye protection. Material safety data sheets (MSDS) have been obtained for all chemicals used in the laboratory, and are placed at the lab entrance for rapid access in case of emergency. Tetrahydrofuran is an extremely flammable liquid and vapor, and may form explosive peroxides. It is harmful if swallowed or inhaled and causes irritation to the skin, eyes, and respiratory tract. It affects the nervous system. Toluene is a poison, and is harmful or fatal if swallowed, inhaled or absorbed through skin. It may affect the 
liver, kidneys, blood system, or central nervous system, and causes irritation to skin, eyes and respiratory tract. It is also a flammable liquid or vapor. NMP causes irritation to skin, eyes and respiratory tract. It is harmful if swallowed or inhaled and is combustible as a liquid or vapor. Coal and coal liquefaction fractions are combustible, and harmful if swallowed or inhaled. They may cause irritation to skin and eyes. Coal derived products tend to be mutagenic and carcinogenic. A list of people to contact and the protective equipment needed in the area is posted at the entrance to the laboratory. Specific emergency procedures are placed near all the equipment to direct the shut down in case of emergency. 


\section{Supplies}

An approximation of supplies needed for this research is as follows:

- The asphaltenes to be analyzed will be provided from different reaction runs at different process conditions (e.g. temperature, pressure, solvent) by the Federal Energy Technology Center/ Department of Energy.

The typical range of reaction conditions is as follows:

Coal Pittsburgh \# 8:120 gm/ run

V-1074, coal-based solvent: 280 gm/run

Hondo, petroleum-based solvent: 280 gm/ run

Hydrogen: as needed

Hydrogen sulfide: as needed

- Solvents:

Toluene: $200 \mathrm{ml}$ per extraction

Tetrahydrofuran (THF): $200 \mathrm{ml}$ per extraction

NMP: $200 \mathrm{ml}$ per extraction

- To make the microscope pellets

Resin: 10 grams of resin per sample

Activator: 2 grams per sample

- To polish the microscope specimens Alumina $\left(\mathrm{Al}_{2} \mathrm{O}_{5}\right)$ with size particles 0.3 $\mu \mathrm{m}$ and $0.05 \mu \mathrm{m}$ are used as needed 


\section{Appendix B. Micrographs of Cokes}

The following pictures were obtained in a Zeiss Axiostop microscope with a magnification of X160. A filter was used in order to obtain the different colors and identify the domains. The samples were coked using the WVU coking value determination procedure. 

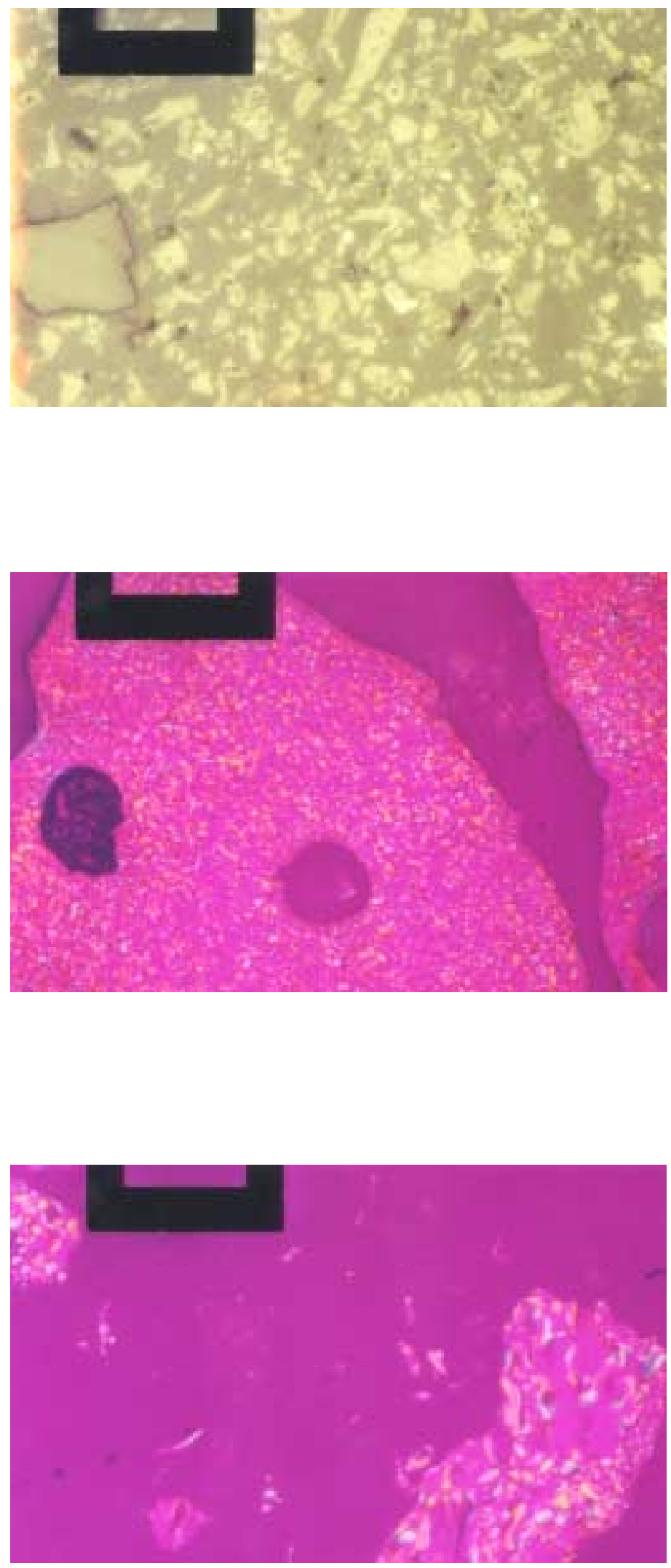

Figure B.1:

BCP- 393, THF Insolubles with reaction conditions of: Solvent: V-1074; $390{ }^{\circ} \mathrm{C}$ 1500 psig $\mathrm{H}_{2}$
Figure B.2:

BCP- 393, Heptane Insolubles with reaction conditions of: Solvent: V-1074; $390^{\circ} \mathrm{C}$; 1500 psig $\mathrm{H}_{2}$
Figure B.3:

BCP- 393, Heptane Solubles with reaction conditions of: Solvent: V-1074; $390{ }^{\circ} \mathrm{C}$; 1500 psig $\mathrm{H}_{2}$ 


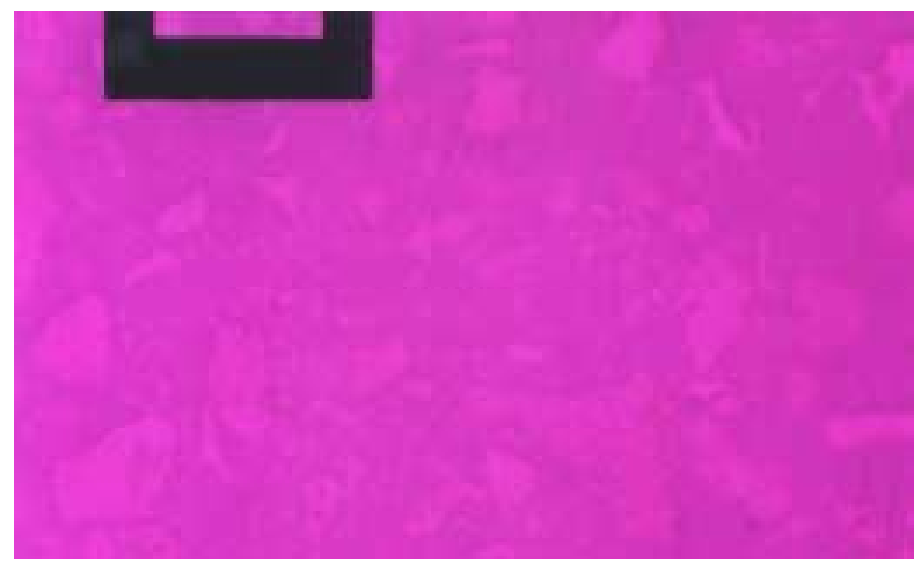

Figure B.4:

BCP- 393, Heptane Insoluble and Toluene Insoluble with reaction conditions of:

Solvent: V-1074; $390^{\circ} \mathrm{C}$; 1500 psig $\mathrm{H}_{2}$

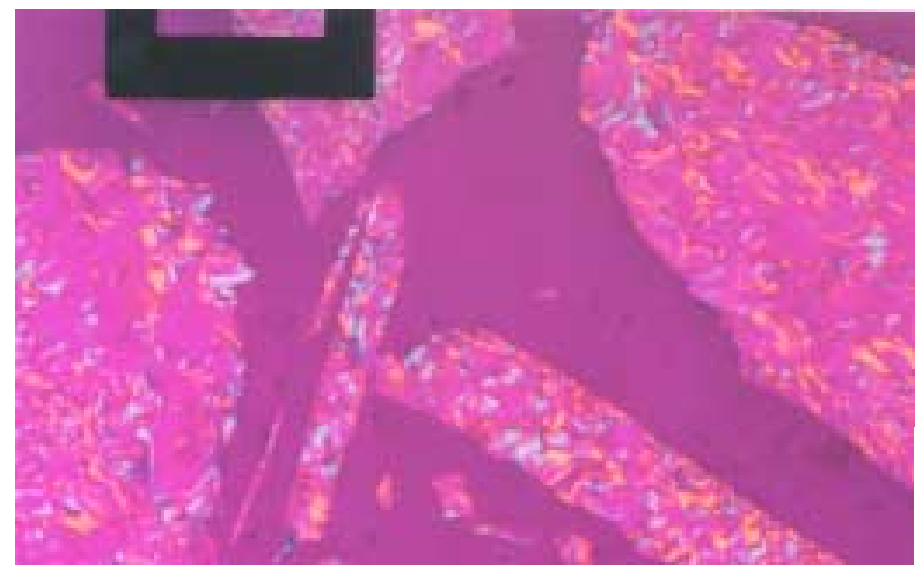

Figure B.5:

BCP- 393, Heptane Insoluble and Toluene Soluble with reaction conditions of:

Solvent: V-1074; $390{ }^{\circ} \mathrm{C}$; 1500 psig $\mathrm{H}_{2}$ 

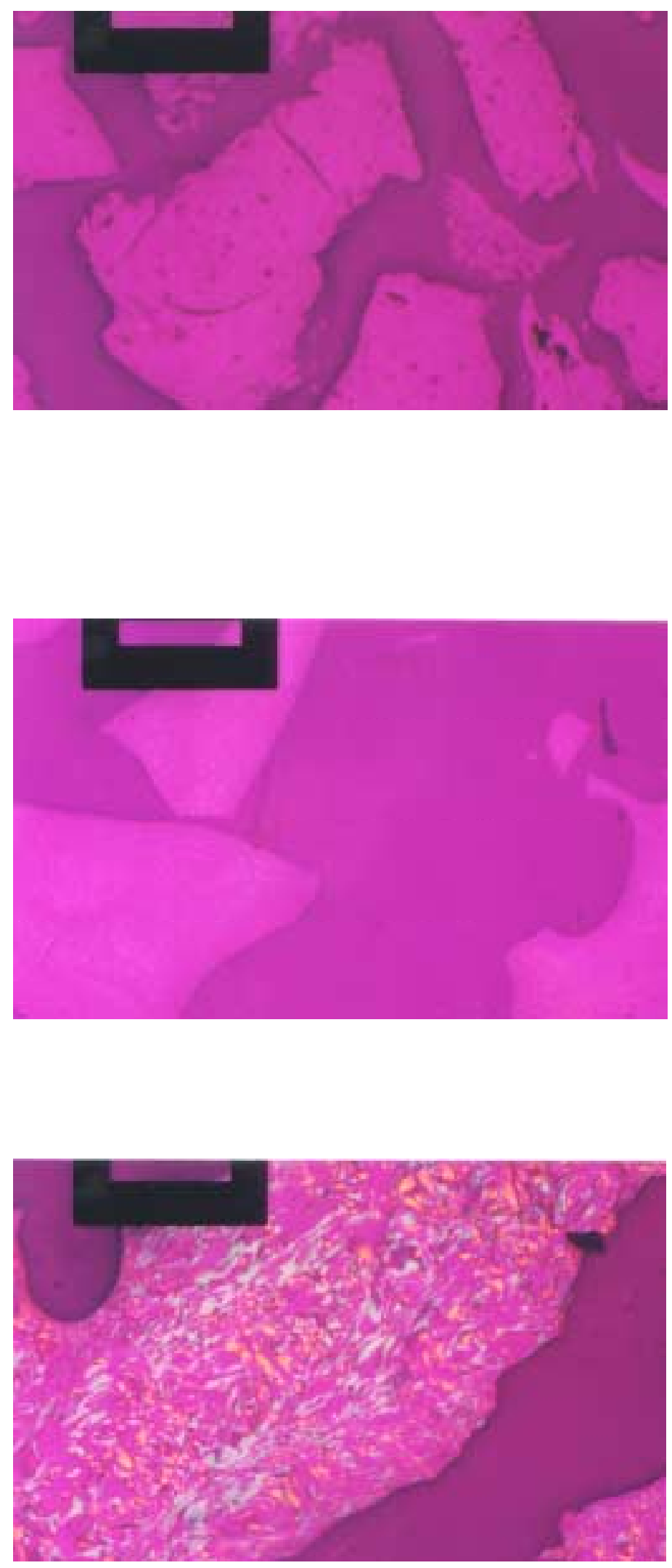

\section{Figure B.6:}

BCP- 394, THF Insolubles with reaction conditions of:

Solvent: Hondo; $390^{\circ} \mathrm{C}$; 1500 psig $\mathrm{H}_{2}$
Figure B.7:

BCP- 394, Heptane Insolubles with reaction conditions of: Solvent: Hondo; $390^{\circ} \mathrm{C}$; 1500 psig $\mathrm{H}_{2}$
Figure B.8:

BCP- 394, Heptane Solubles with reaction conditions of: Solvent: Hondo; $390^{\circ} \mathrm{C}$; 1500 psig $\mathrm{H}_{2}$ 


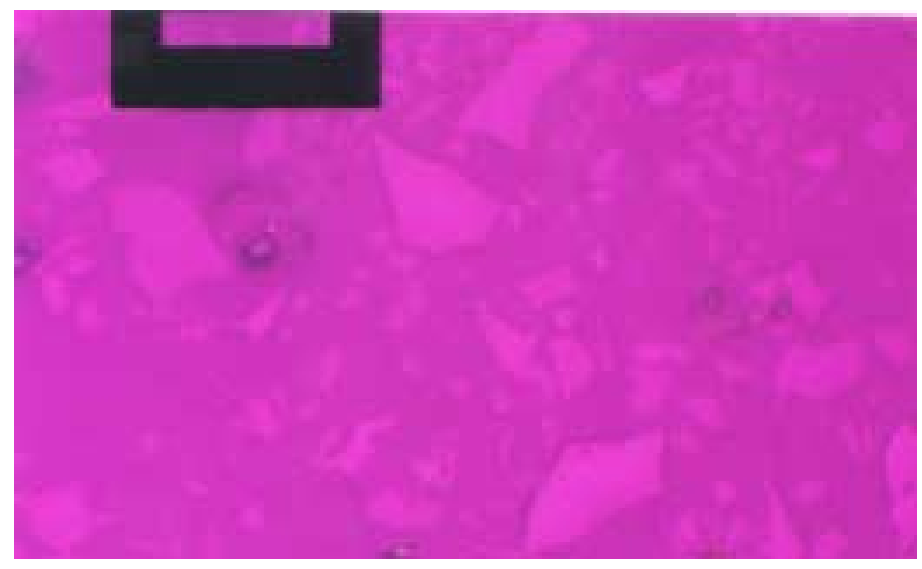

\section{Figure B.9:}

BCP- 394, Heptane Insoluble and Toluene Insoluble with reaction conditions of:

Solvent: Hondo; $390{ }^{\circ} \mathrm{C}$; 1500 psig $\mathrm{H}_{2}$

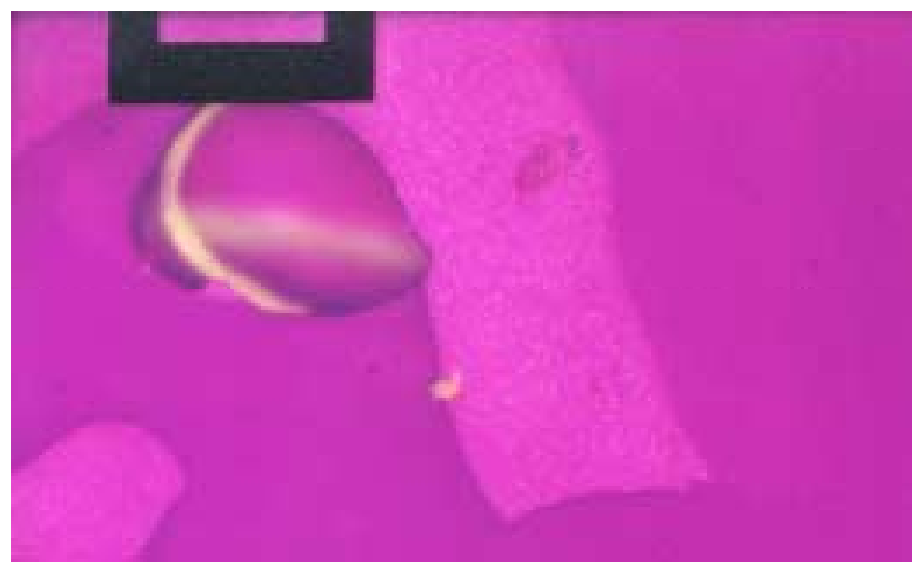

Figure B.10:

BCP- 394, Heptane Insoluble and Toluene Soluble with reaction conditions of:

Solvent: Hondo; $390{ }^{\circ} \mathrm{C}$; 1500 psig $\mathrm{H}_{2}$ 


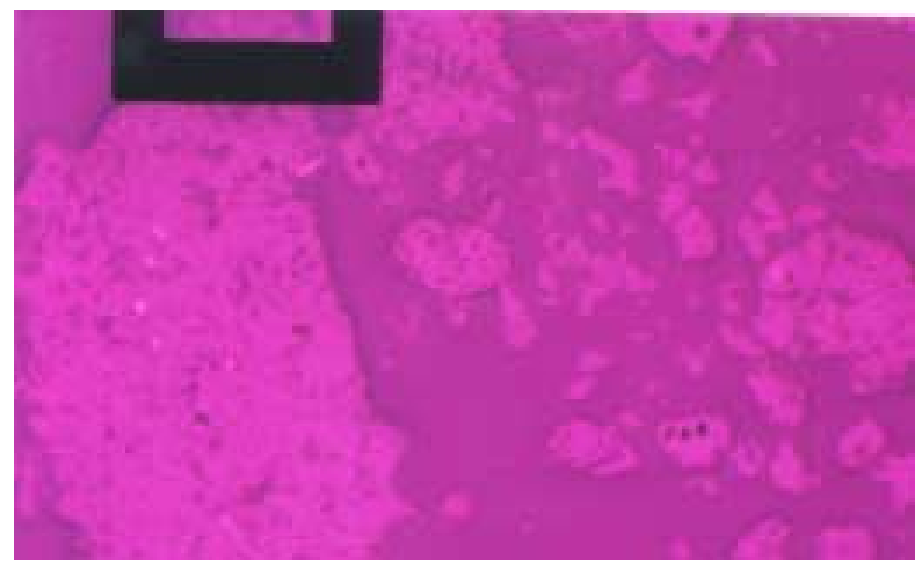

Figure B.11:

BCP- 395, THF Insolubles with reaction conditions of:

Solvent: V-1074; $350{ }^{\circ} \mathrm{C}$;

1500 psig $\mathrm{H}_{2}$

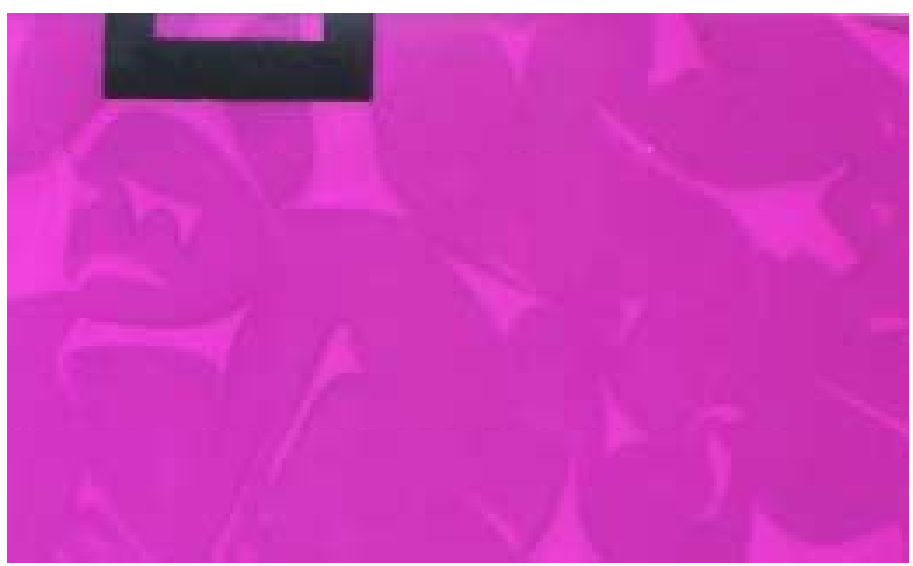

Figure B.12:

BCP- 395, Heptane Insolubles with reaction conditions of: Solvent: V-1074; $350{ }^{\circ} \mathrm{C}$; 1500 psig $\mathrm{H}_{2}$

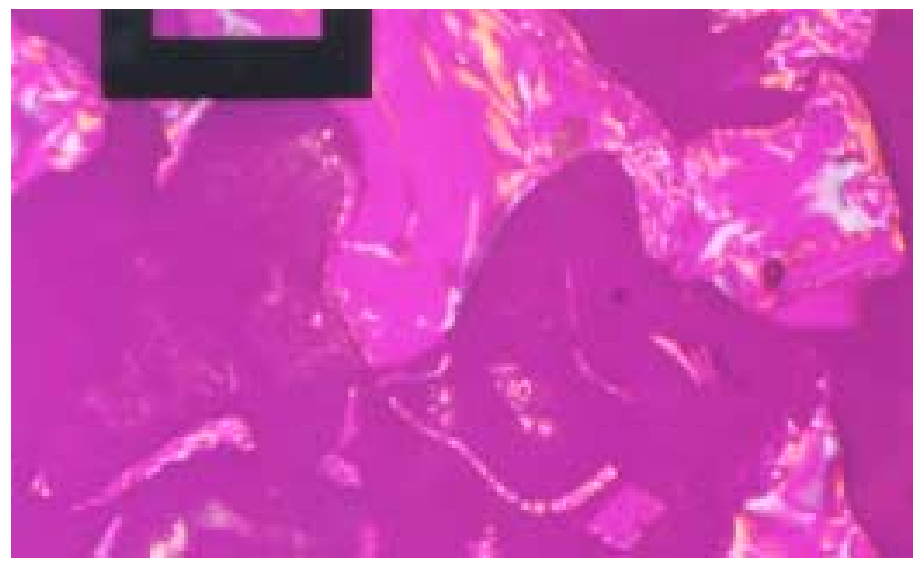

Figure B.13:

BCP- 395, Heptane Solubles with reaction conditions of: Solvent: V-1074; $350{ }^{\circ} \mathrm{C}$; 1500 psig $\mathrm{H}_{2}$ 


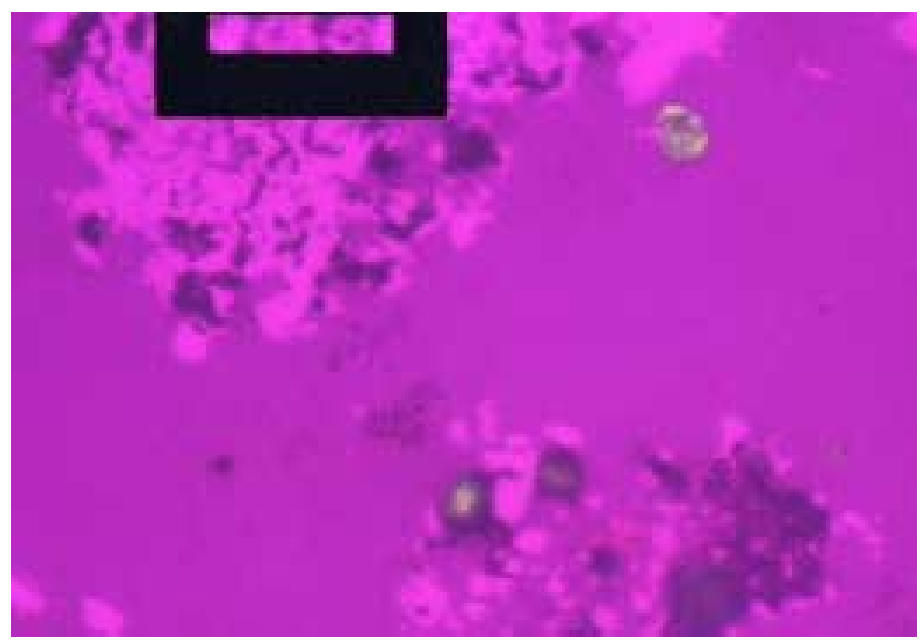

Figure B.14:

BCP- 395, Heptane Insoluble and Toluene Insoluble with reaction conditions of:

Solvent: V-1074; $350{ }^{\circ} \mathrm{C}$;

1500 psig $\mathrm{H}_{2}$

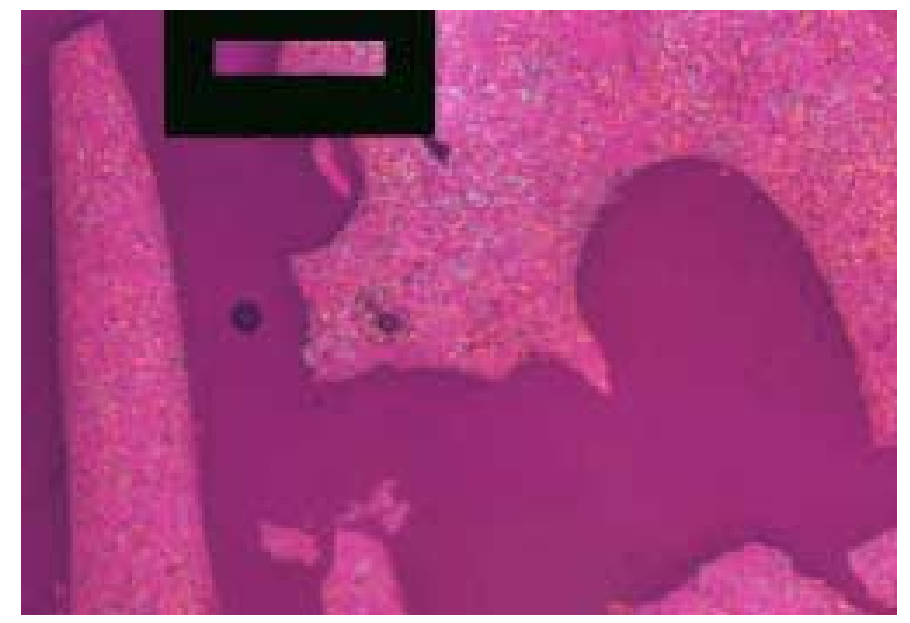

Figure B.15:

BCP- 395, Heptane Insoluble and Toluene Soluble with reaction conditions of:

Solvent: V-1074; $350{ }^{\circ} \mathrm{C}$;

1500 psig $\mathrm{H}_{2}$ 


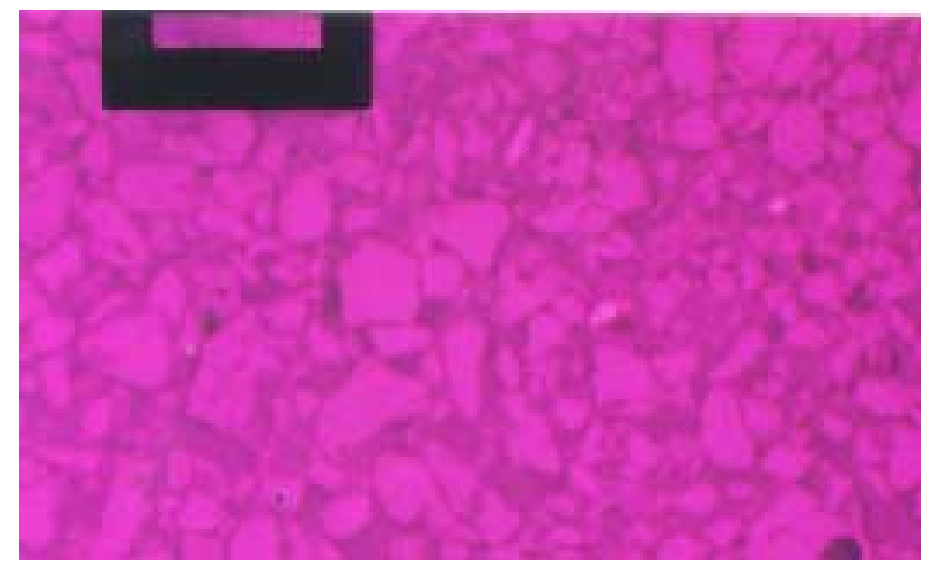

\section{Figure B.16:}

BCP- 396, THF Insolubles with reaction conditions of:

Solvent: Hondo; $350^{\circ} \mathrm{C}$; 1500 psig $\mathrm{H}_{2}$

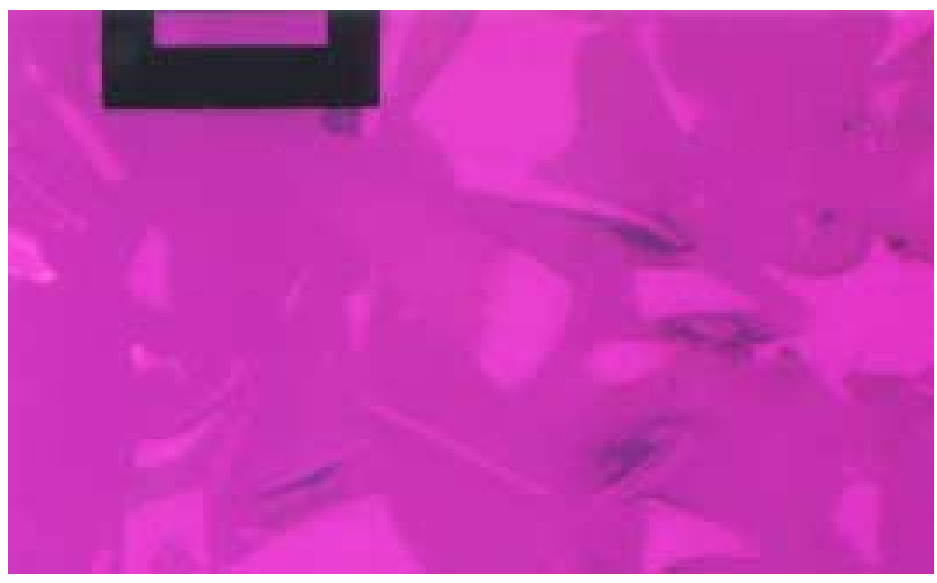

Figure B.17:

BCP- 396, Heptane Insolubles with reaction conditions of: Solvent: Hondo; $350{ }^{\circ} \mathrm{C}$; 1500 psig $\mathrm{H}_{2}$

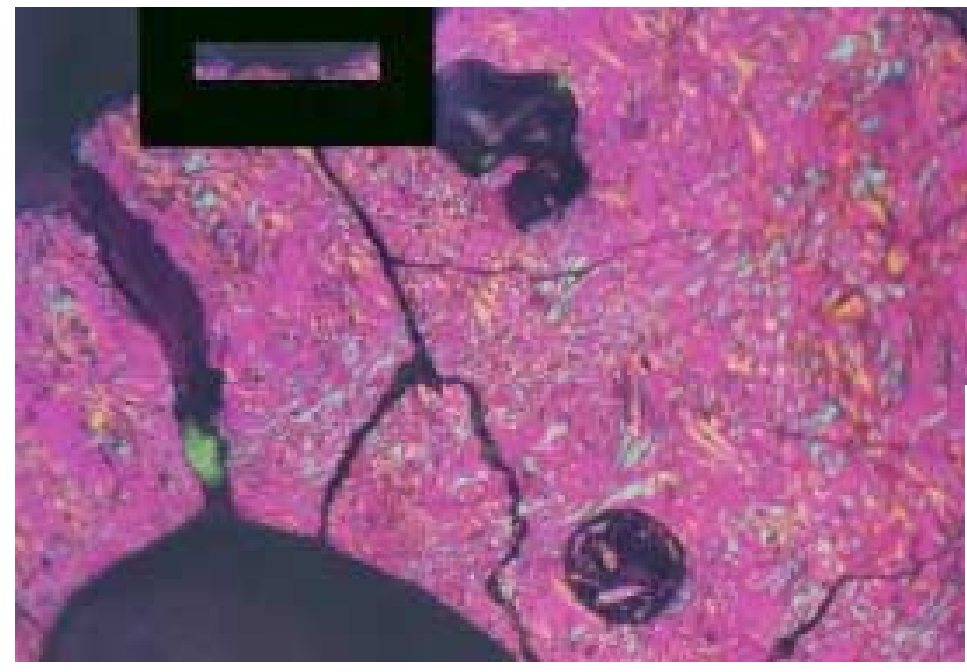

Figure B.18:

BCP- 396, Heptane Solubles with reaction conditions of: Solvent: Hondo; $350{ }^{\circ} \mathrm{C}$; 1500 psig $\mathrm{H}_{2}$ 

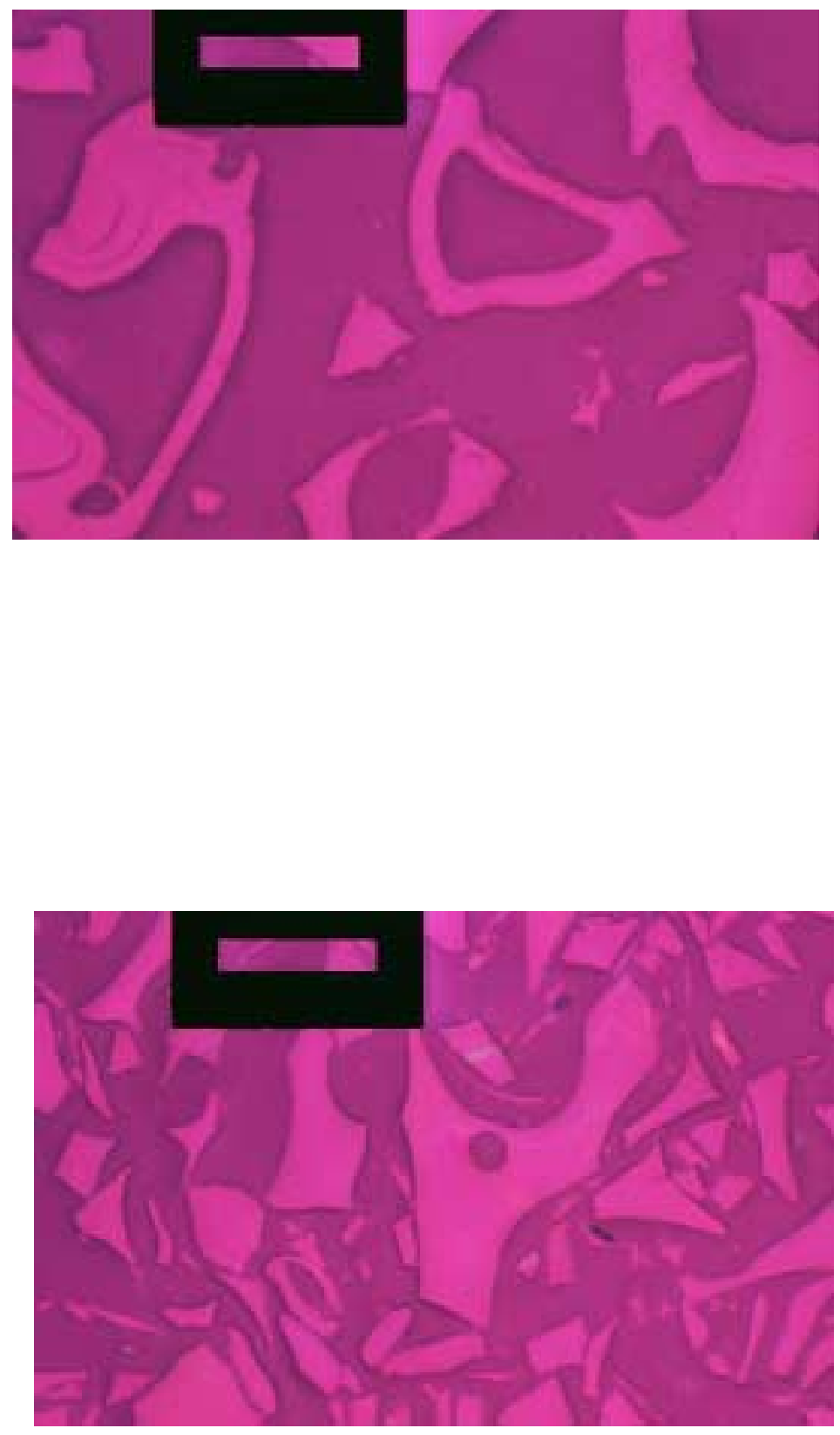

Figure B.19:

BCP- 396, Heptane Insoluble and Toluene Insoluble with reaction conditions of:

Solvent: Hondo; $350{ }^{\circ} \mathrm{C}$; 1500 psig $\mathrm{H}_{2}$
Figure B.20:

BCP- 396, Heptane Insoluble and Toluene Soluble with reaction conditions of:

Solvent: Hondo; $350^{\circ} \mathrm{C}$; 1500 psig $\mathrm{H}_{2}$ 


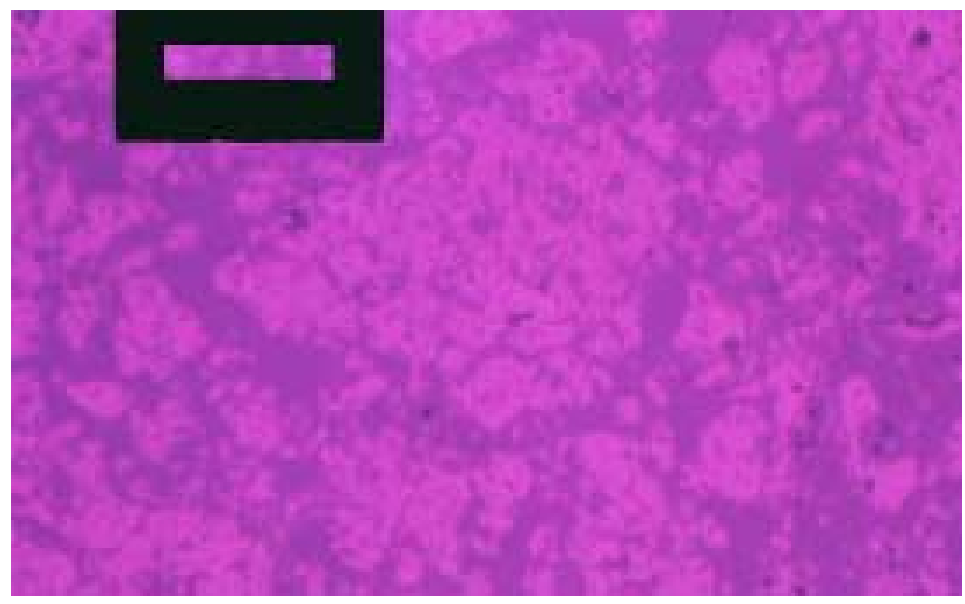

\section{Figure B.21:}

BCP- 397, THF Insolubles with reaction conditions of:

Solvent: V-1074; $350{ }^{\circ} \mathrm{C}$;

1000 psig $\mathrm{H}_{2}$

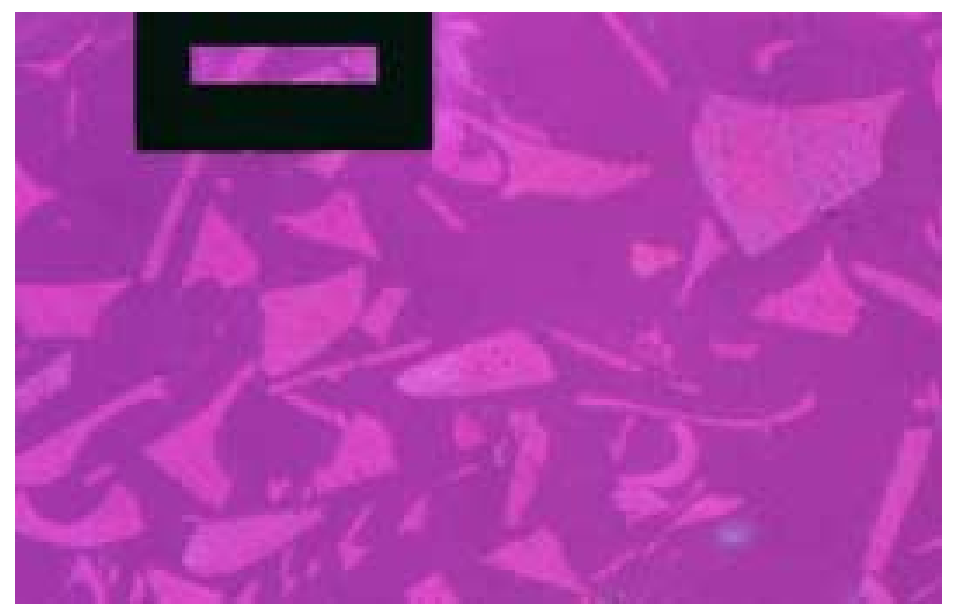

Figure B.22:

BCP- 397, Heptane Insolubles with reaction conditions of: Solvent: V-1074; $350{ }^{\circ} \mathrm{C}$; 1000 psig $\mathrm{H}_{2}$

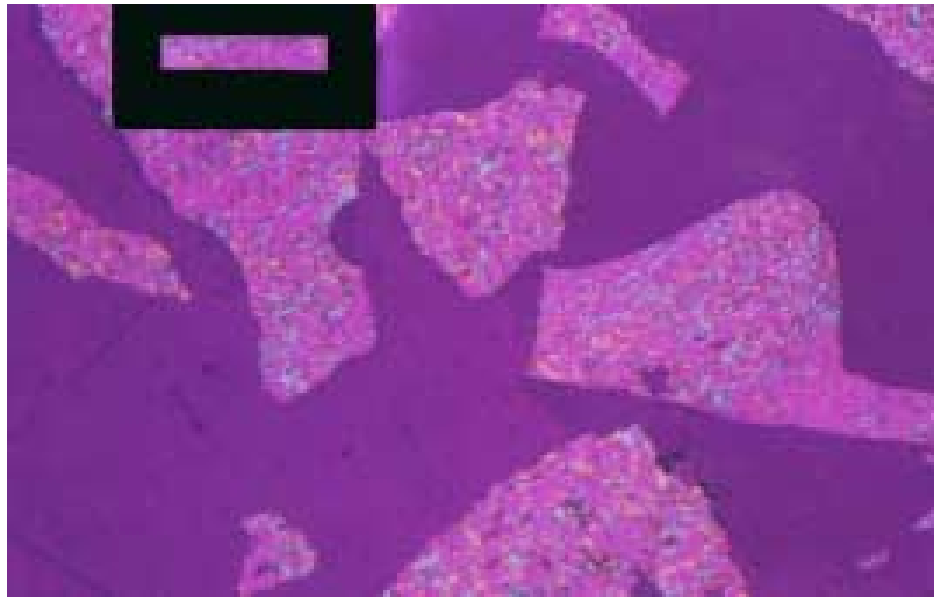

Figure B.23:

BCP- 397, Heptane Soluble with reaction conditions of:

Solvent: V-1074; $350{ }^{\circ} \mathrm{C}$; 1000 psig $\mathrm{H}_{2}$ 

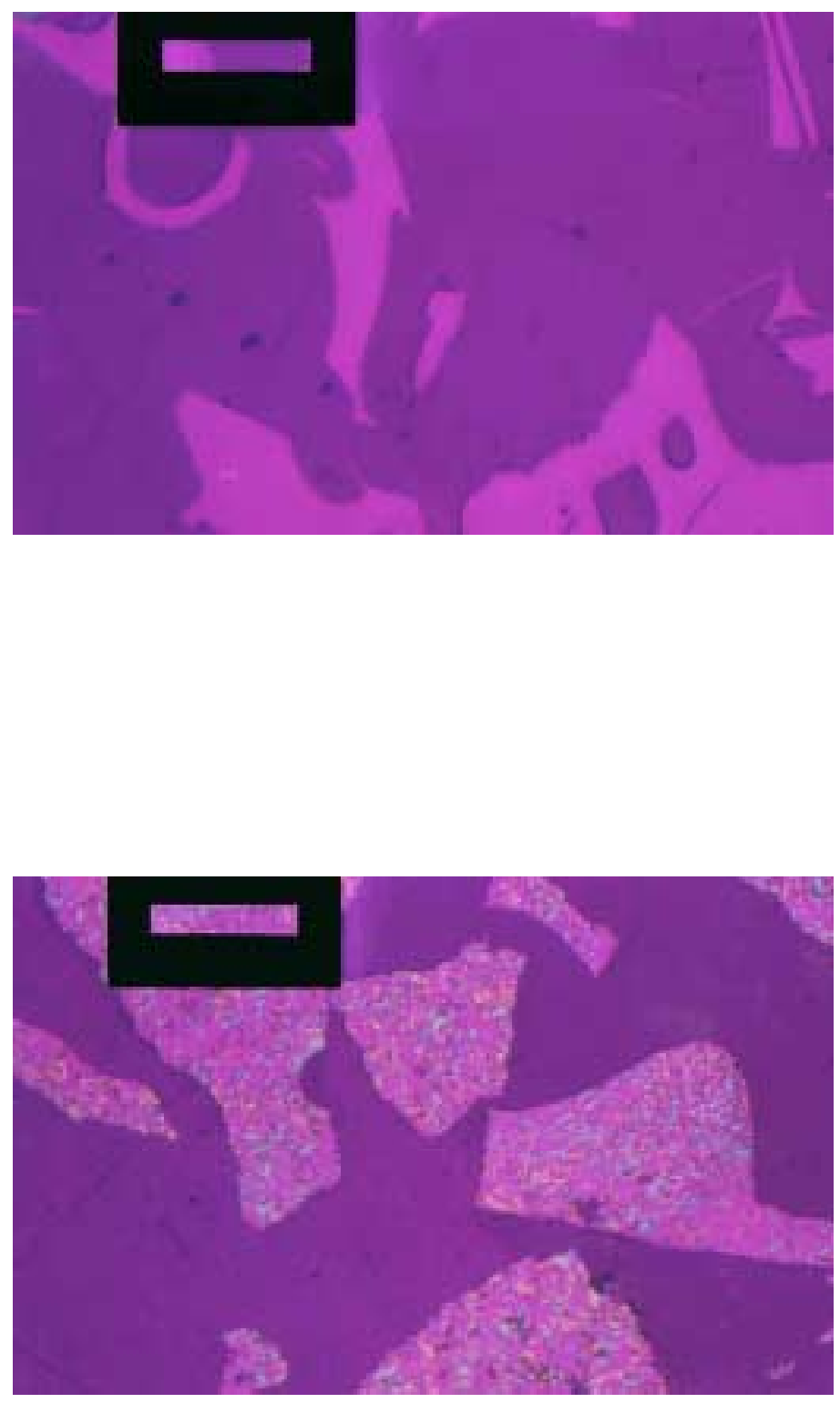

Figure B.24:

BCP- 397, Heptane Insoluble and Toluene Insoluble with reaction conditions of:

Solvent: V-1074; $350{ }^{\circ} \mathrm{C}$; 1000 psig $\mathrm{H}_{2}$

\section{Figure B.25:}

BCP- 397, Heptane Insoluble and Toluene Soluble with reaction conditions of:

Solvent: V-1074; $350^{\circ} \mathrm{C}$; 1000 psig $\mathrm{H}_{2}$ 


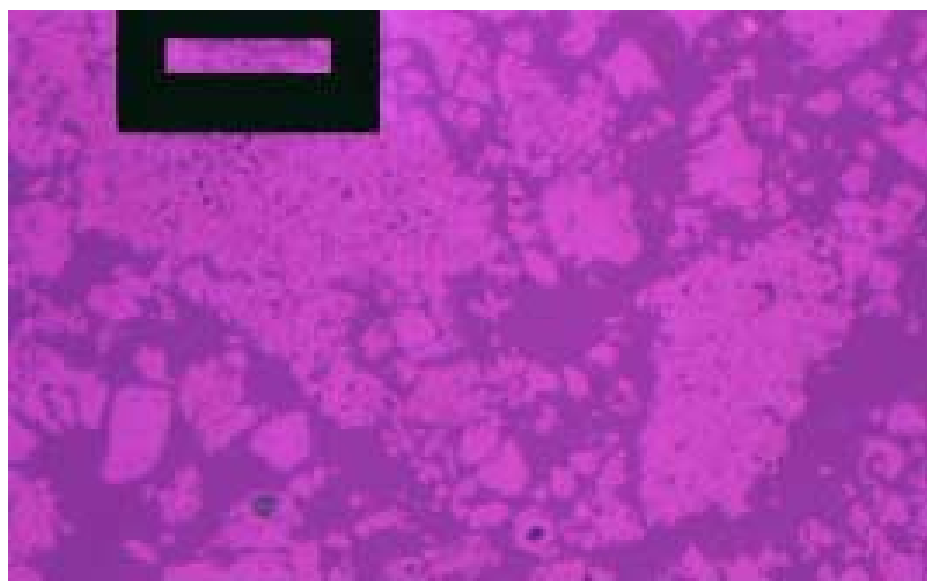

Figure B.26:

BCP-398, THF Insolubles

with reactions conditions of:

Solvent: Hondo; $350^{\circ} \mathrm{C}$;

1000 psig $\mathrm{H}_{2}$

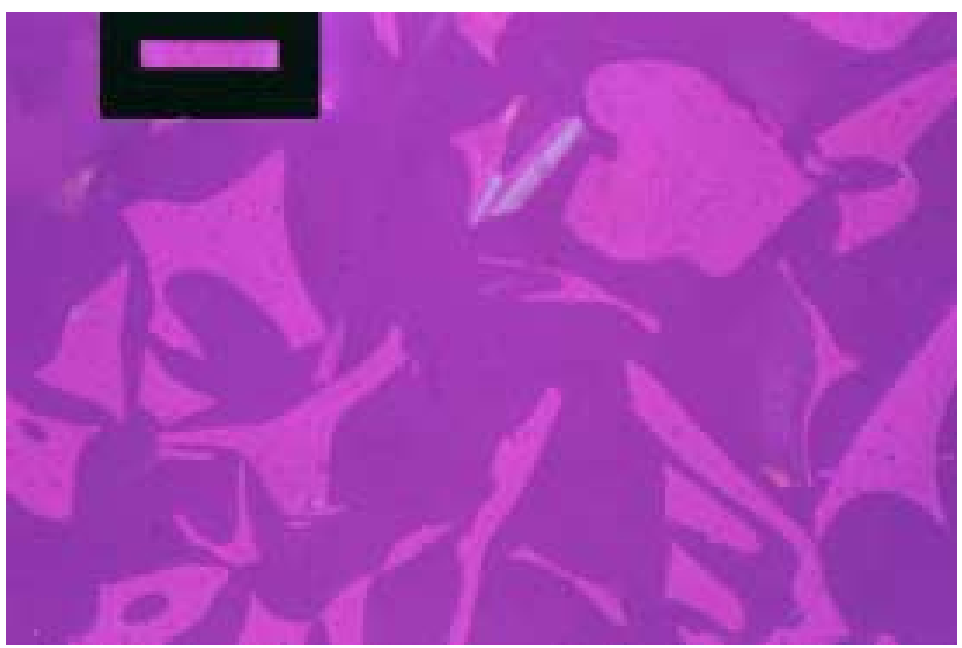

Figure B.27:

BCP-398, Heptane Insoluble with reactions conditions of: Solvent: Hondo; $350{ }^{\circ} \mathrm{C}$;

1000 psig $\mathrm{H}_{2}$

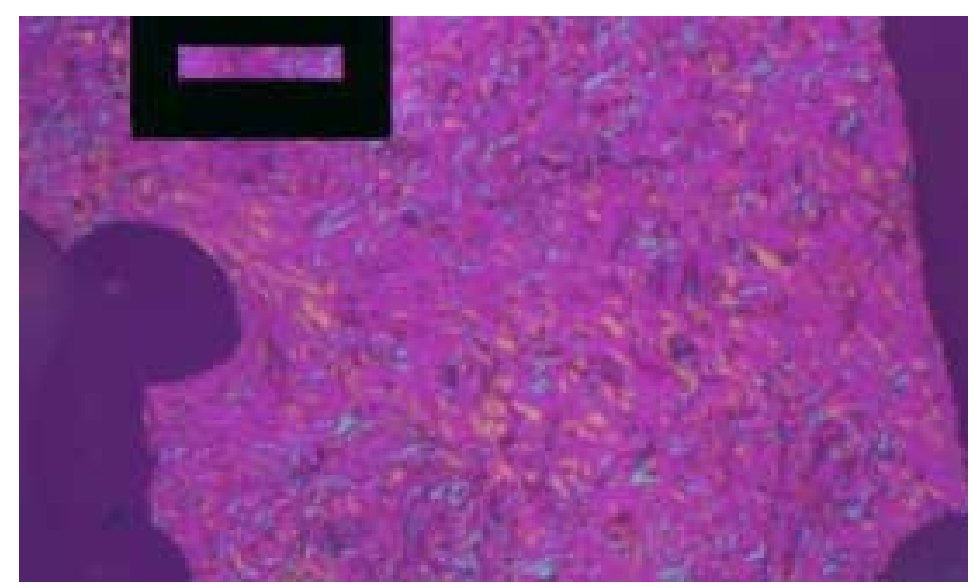

Figure B.28:

BCP-398, Heptane Soluble with reactions conditions of: Solvent: Hondo; $350{ }^{\circ} \mathrm{C}$; 1000 psig $\mathrm{H}_{2}$ 


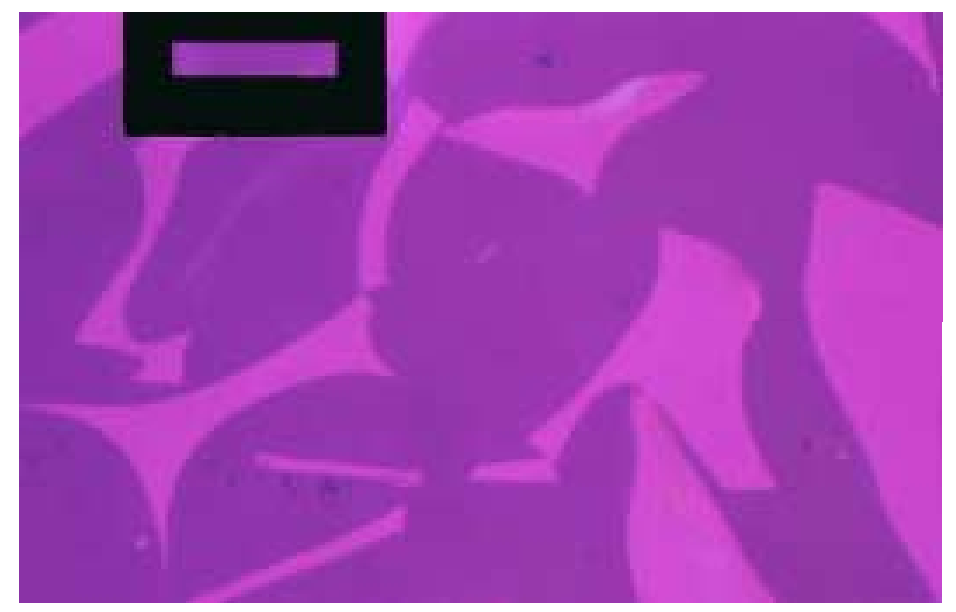

Figure B.29:

BCP-398, Heptane Insoluble and Toluene Soluble with reactions conditions of: Solvent: Hondo; $350{ }^{\circ} \mathrm{C}$; 1000 psig $\mathrm{H}_{2}$ 


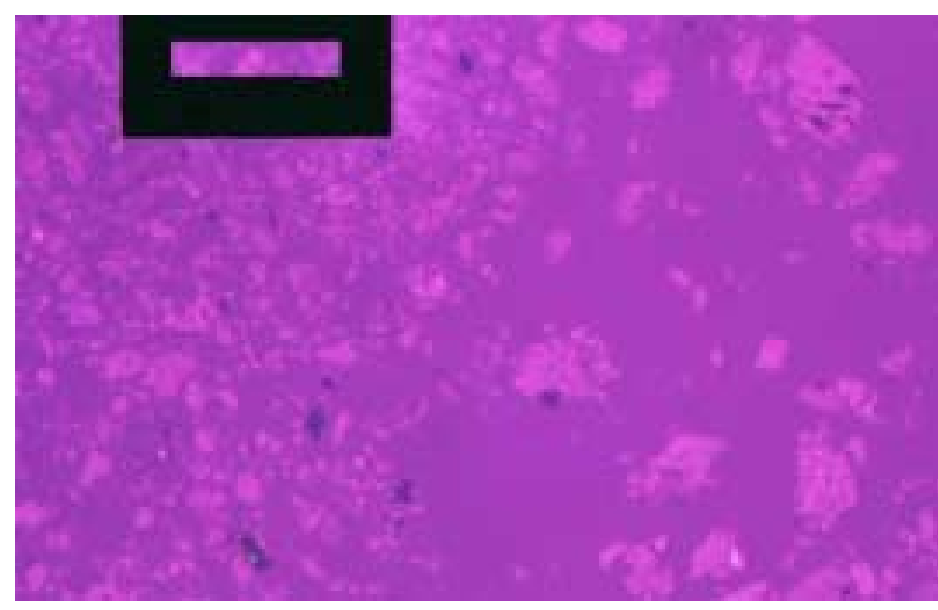

Figure B.30:

BCP-399, THF Inoluble with reactions conditions of:

Solvent: V-1074; $390{ }^{\circ} \mathrm{C}$;

1000 psig $\mathrm{H}_{2}$

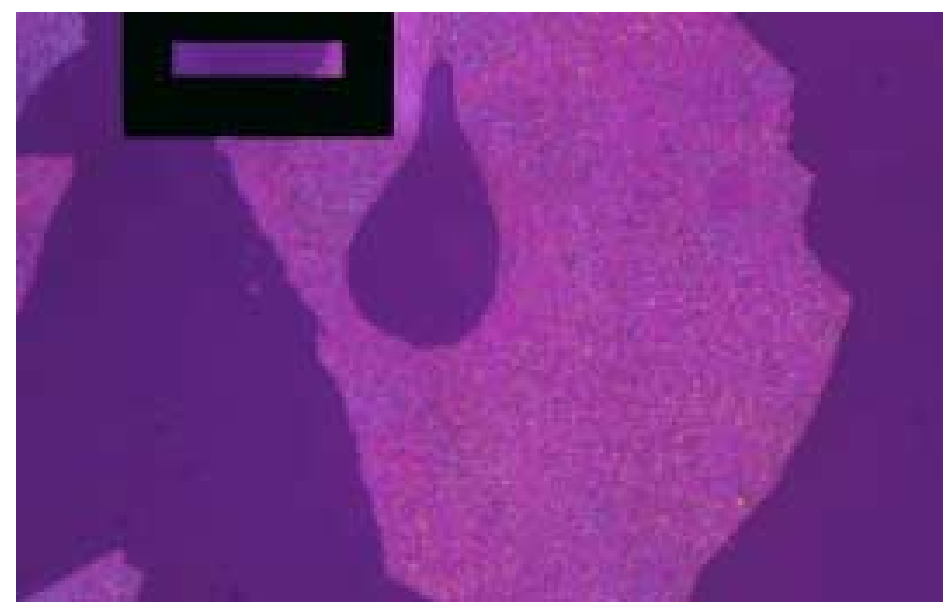

Figure B.31:

BCP-399, Heptane Insoluble with reactions conditions of: Solvent: V-1074; $390{ }^{\circ} \mathrm{C}$;

1000 psig $\mathrm{H}_{2}$

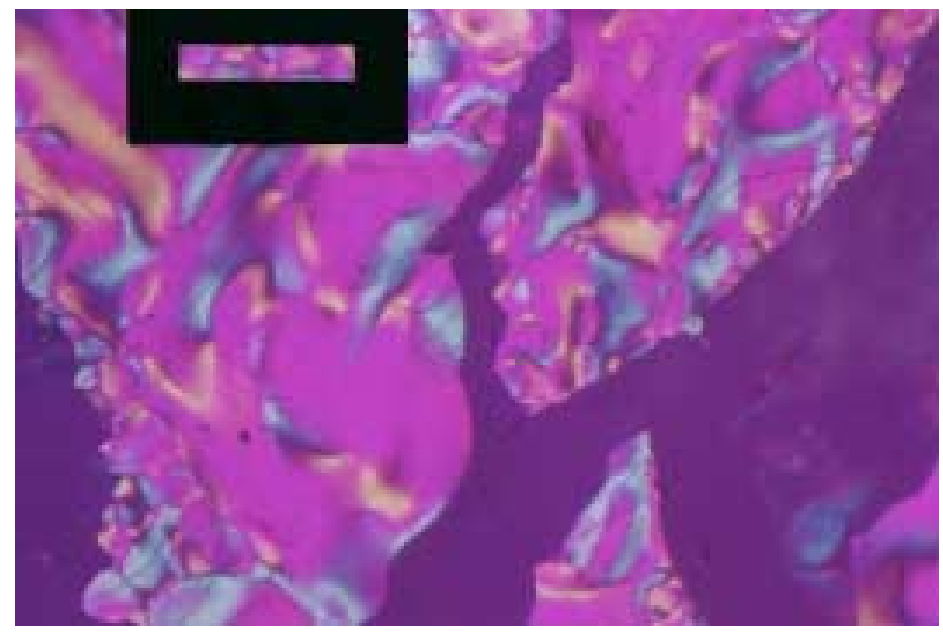

Figure B.32:

BCP-399, Heptane Soluble with reactions conditions of: Solvent: V-1074; $390{ }^{\circ} \mathrm{C}$; 1000 psig $\mathrm{H}_{2}$ 


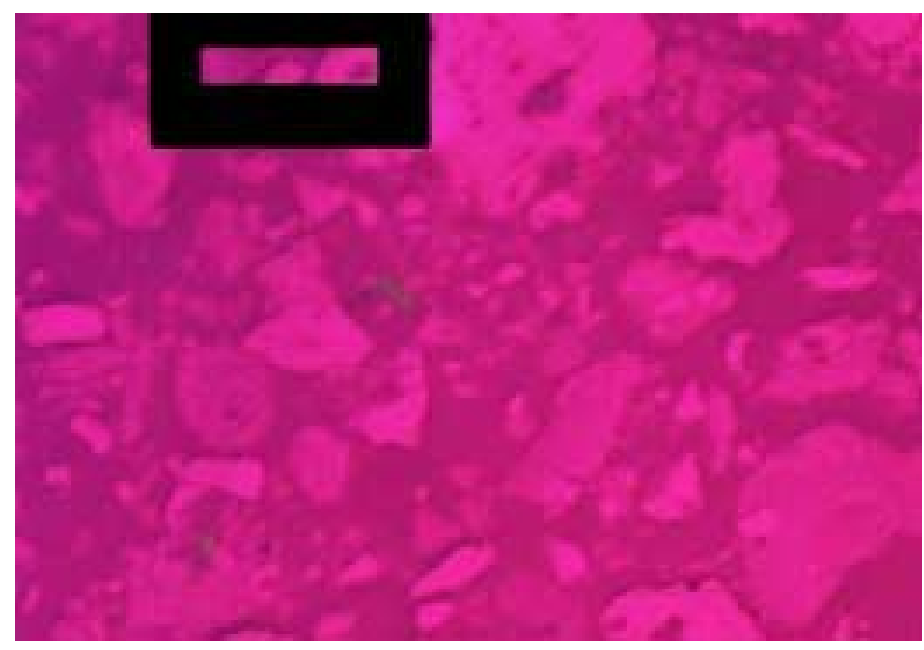

Figure B.33:

BCP-399, Heptane Insoluble and Toluene Insoluble with reactions conditions of:

Solvent: V-1074; $390^{\circ} \mathrm{C}$; 1000 psig $\mathrm{H}_{2}$

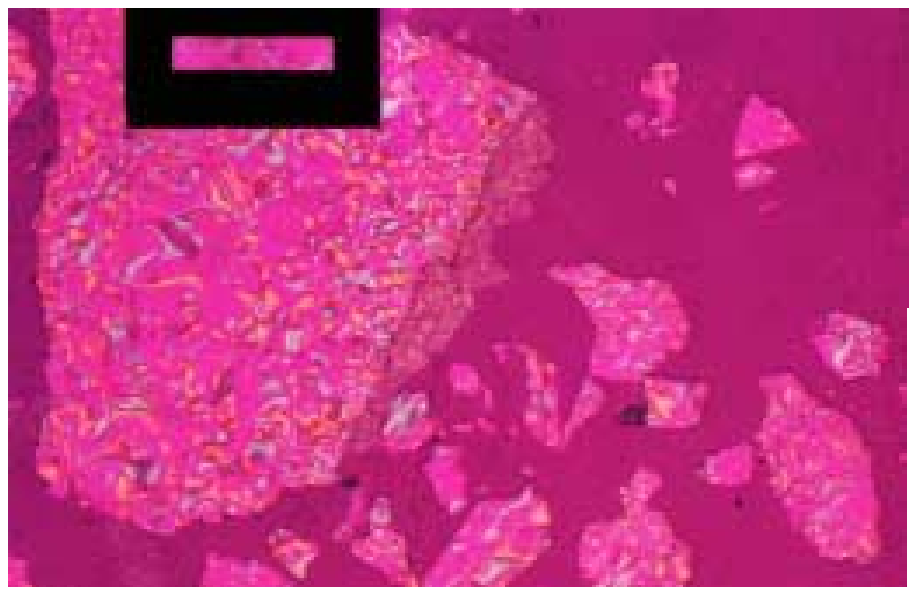

Figure B.34:

BCP-399, Heptane Insoluble and Toluene Soluble with reactions conditions of: Solvent: V-1074; $390{ }^{\circ} \mathrm{C}$; 1000 psig $\mathrm{H}_{2}$ 


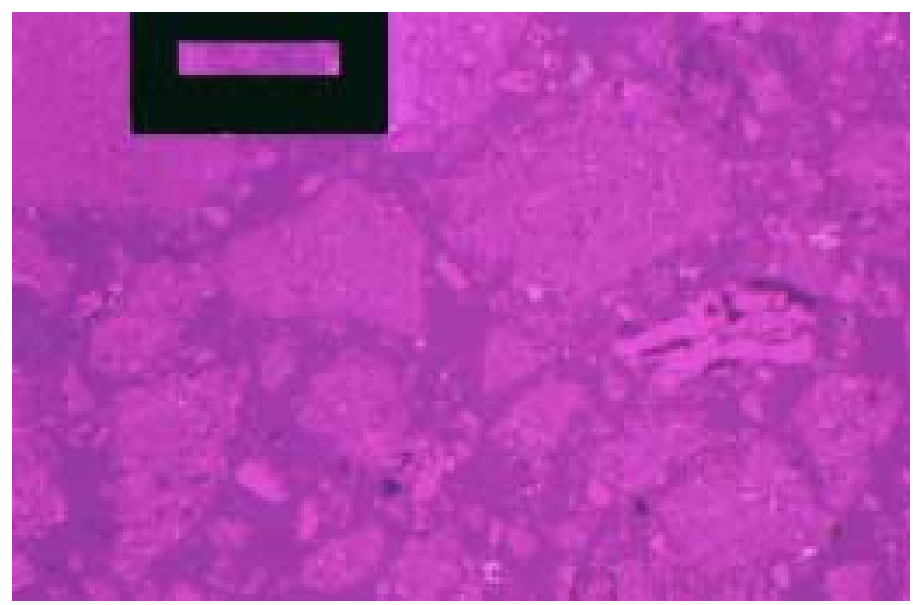

\section{Figure B.35:}

BCP-400, THF Insoluble with reactions conditions of: Solvent: V-1074; $425^{\circ} \mathrm{C}$; 1000 psig $\mathrm{H}_{2}$

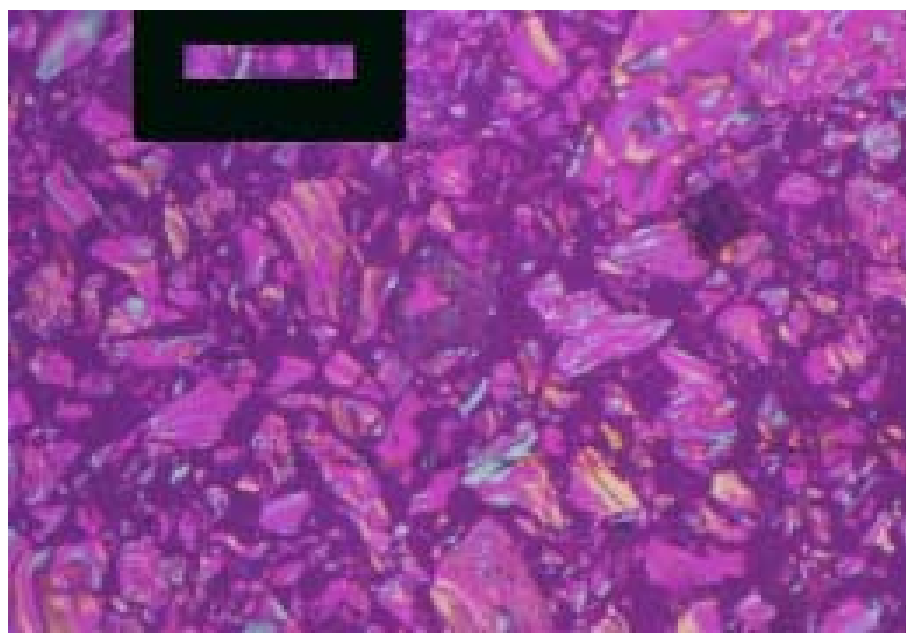

\section{Figure B.36:}

BCP-400, Heptane Insoluble with reactions conditions of: Solvent: V-1074; $425^{\circ} \mathrm{C}$; 1000 psig $\mathrm{H}_{2}$

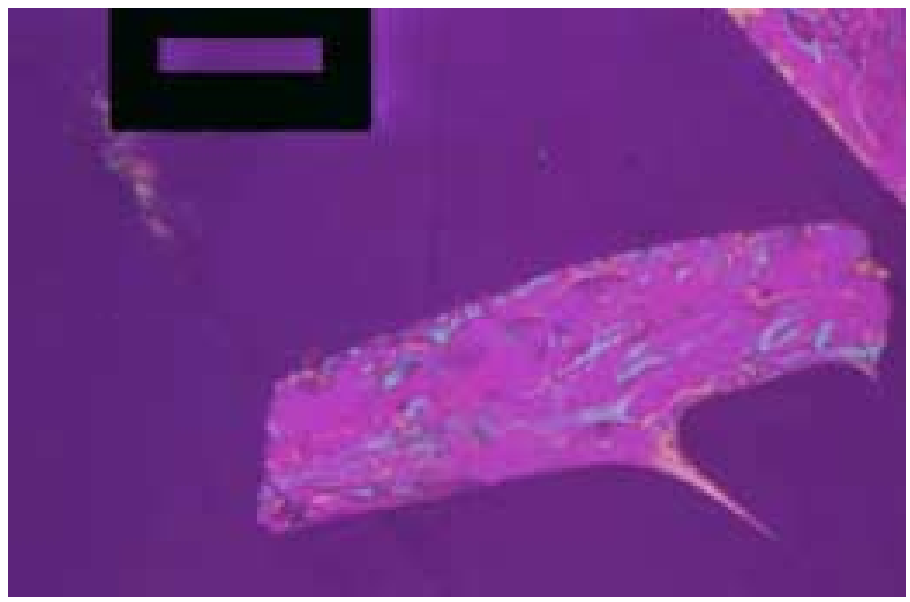

Figure B.37:

BCP-400, Heptane Soluble with reactions conditions of: Solvent: V-1074; $425^{\circ} \mathrm{C}$; 1000 psig $\mathrm{H}_{2}$ 


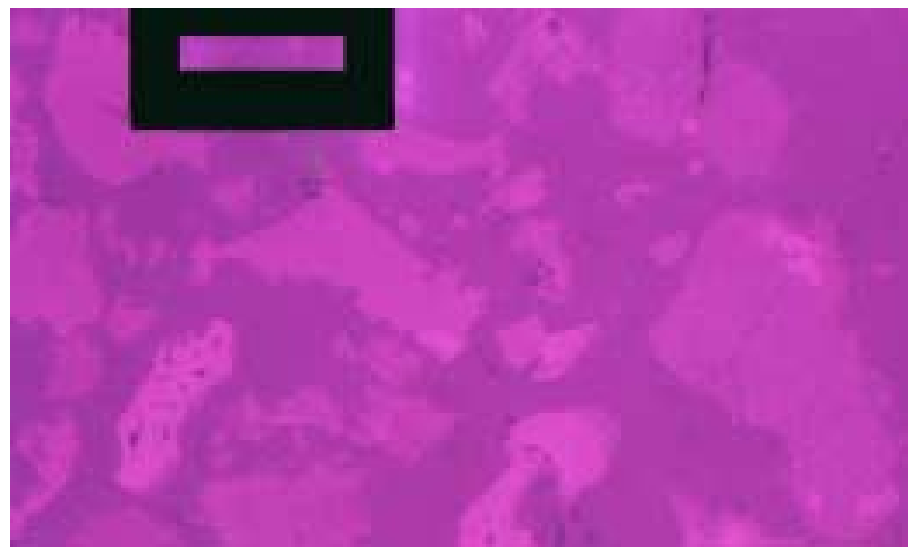

\section{Figure B.38:}

BCP-400, Heptane Insoluble and Toluene Insoluble with reactions conditions of: Solvent: V-1074; $425^{\circ} \mathrm{C}$; 1000 psig $\mathrm{H}_{2}$

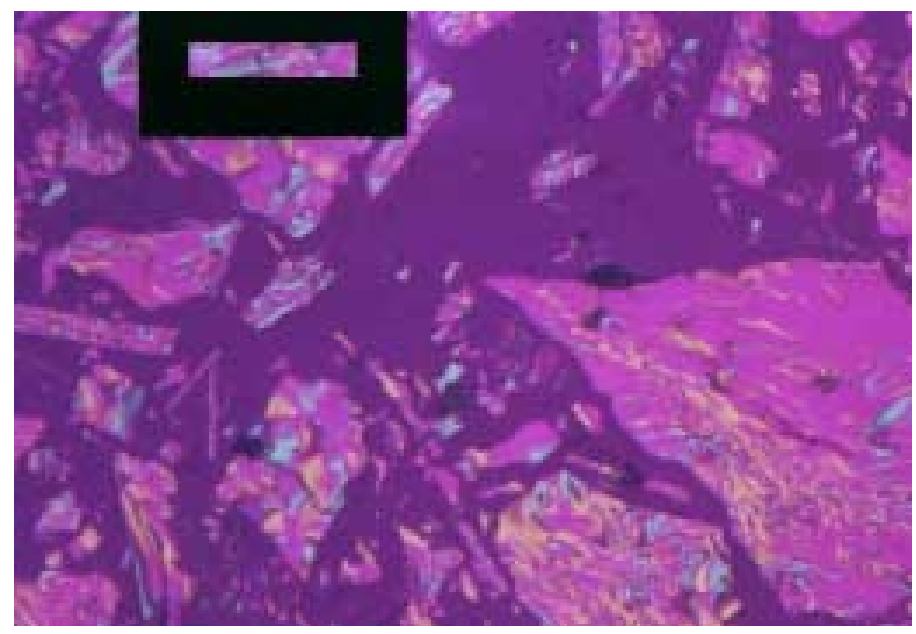

Figure B.39:

BCP-400, Heptane Insoluble and Toluene Soluble with reactions conditions of: Solvent: V-1074; $425^{\circ} \mathrm{C}$; 1000 psig $\mathrm{H}_{2}$ 


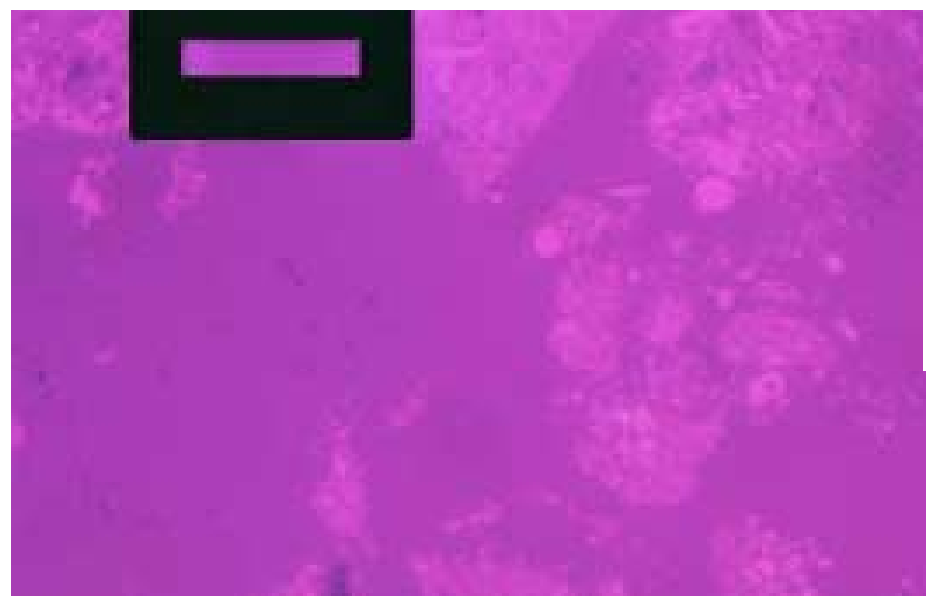

\section{Figure B.40:}

BCP-401, THF Insoluble with reactions conditions of: Solvent: V-1074; $425^{\circ} \mathrm{C}$; $1500{\text { psig } \mathrm{H}_{2}}$

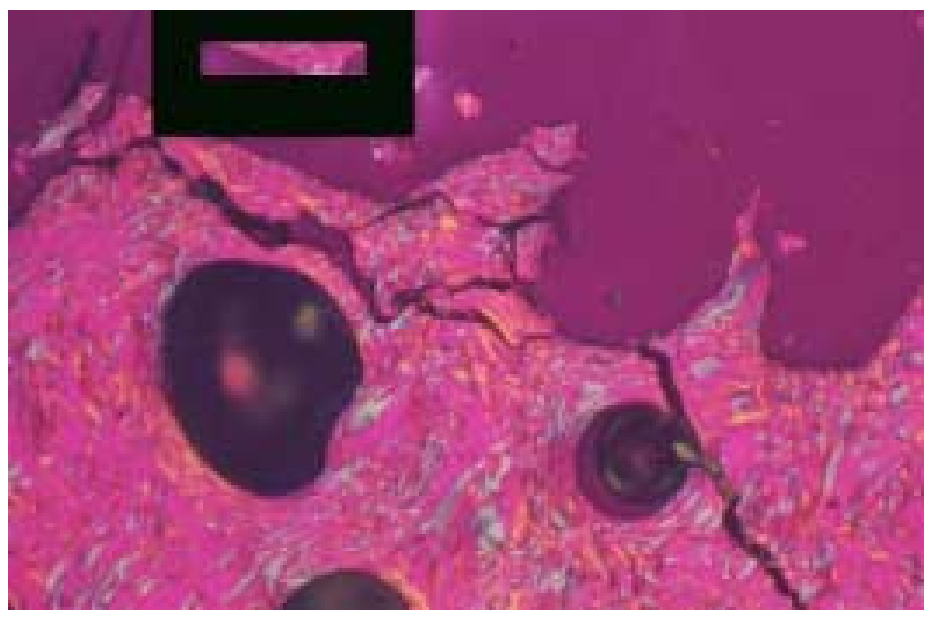

Figure B.41:

BCP-401, Heptane Insoluble with reactions conditions of: Solvent: V-1074; $425^{\circ} \mathrm{C}$; 1500 psig $\mathrm{H}_{2}$

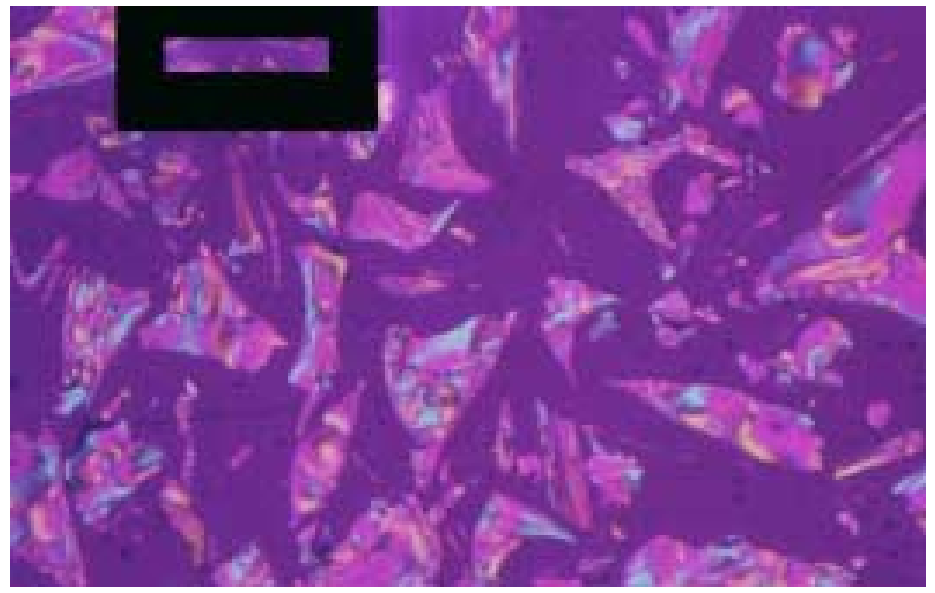

Figure B.42:

BCP-401, Heptane Soluble with reactions conditions of: Solvent: V-1074; $425^{\circ} \mathrm{C}$; 1500 psig $\mathrm{H}_{2}$ 


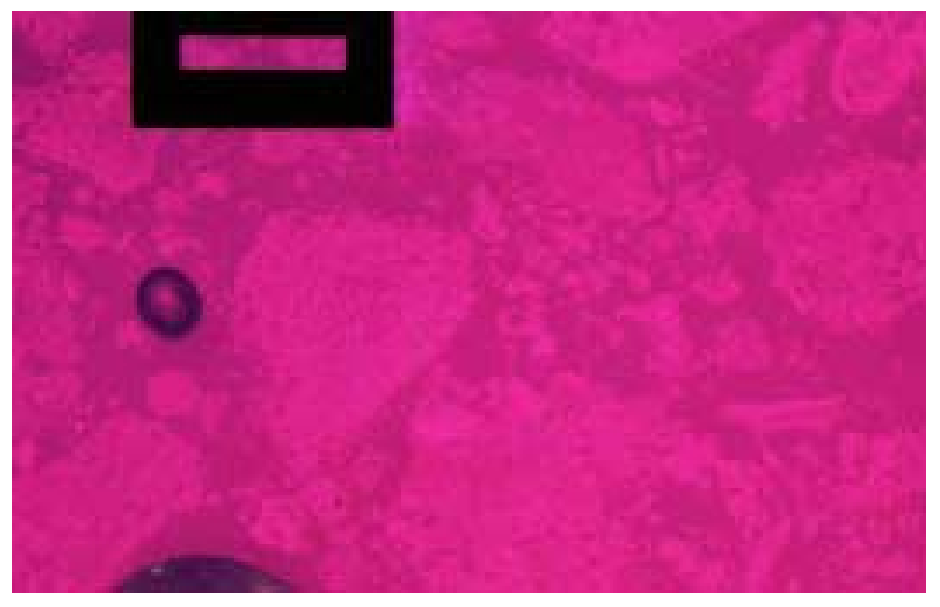

Figure B.43:

BCP-401, Heptane Insoluble and Toluene Insoluble with reactions conditions of: Solvent: V-1074; $425^{\circ} \mathrm{C}$; 1500 psig $\mathrm{H}_{2}$

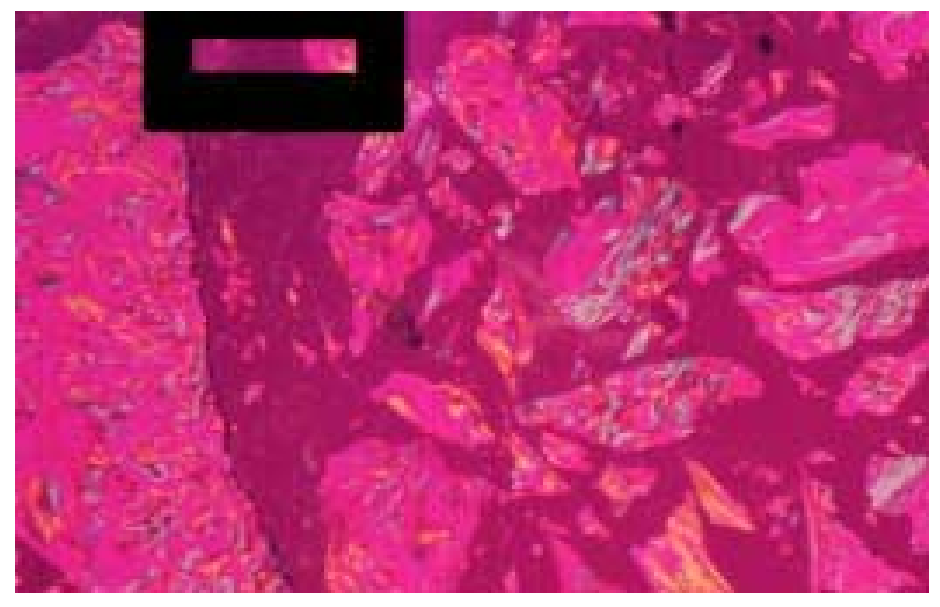

Figure B.44:

BCP-401, Heptane Insoluble and Toluene Soluble with reactions conditions of: Solvent: V-1074; $425^{\circ} \mathrm{C}$; 1500 psig $\mathrm{H}_{2}$ 


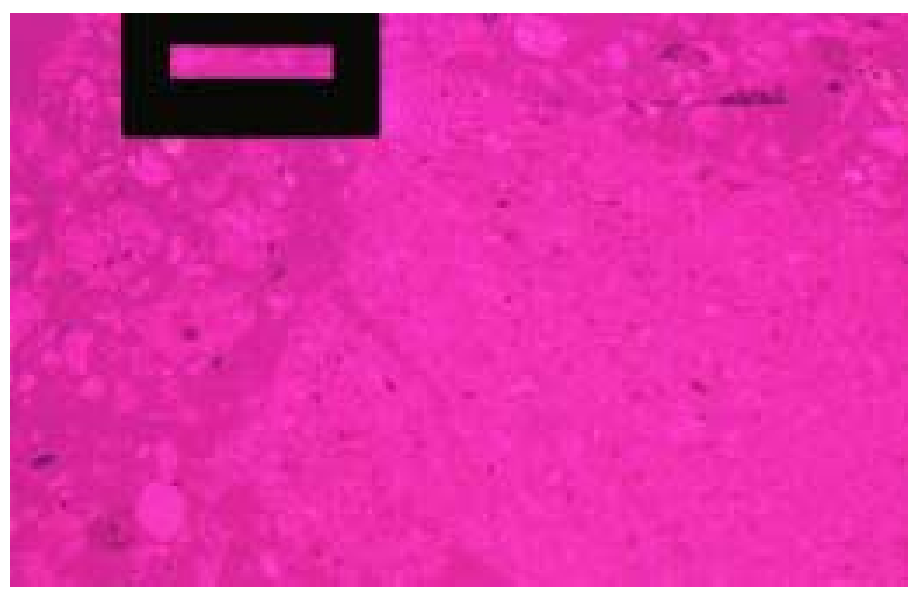

Figure B.45:

BCP-403, THF Insoluble

with reactions conditions of:

Solvent: V-1074; $425^{\circ} \mathrm{C}$;

1000 psig $\mathrm{H}_{2}$

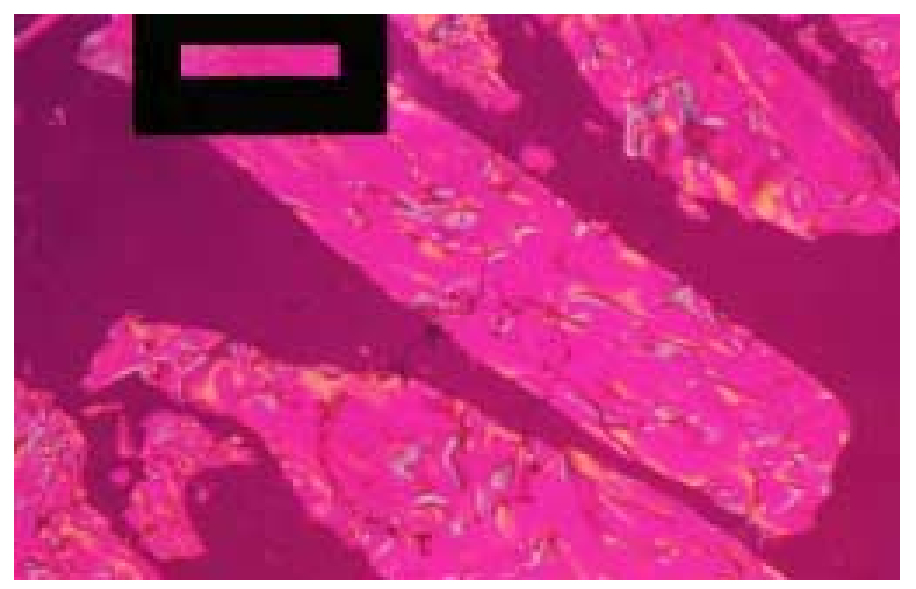

Figure B.46:

BCP-403, Heptane Insoluble with reactions conditions of: Solvent: V-1074; $425^{\circ} \mathrm{C}$; 1000 psig $\mathrm{H}_{2}$

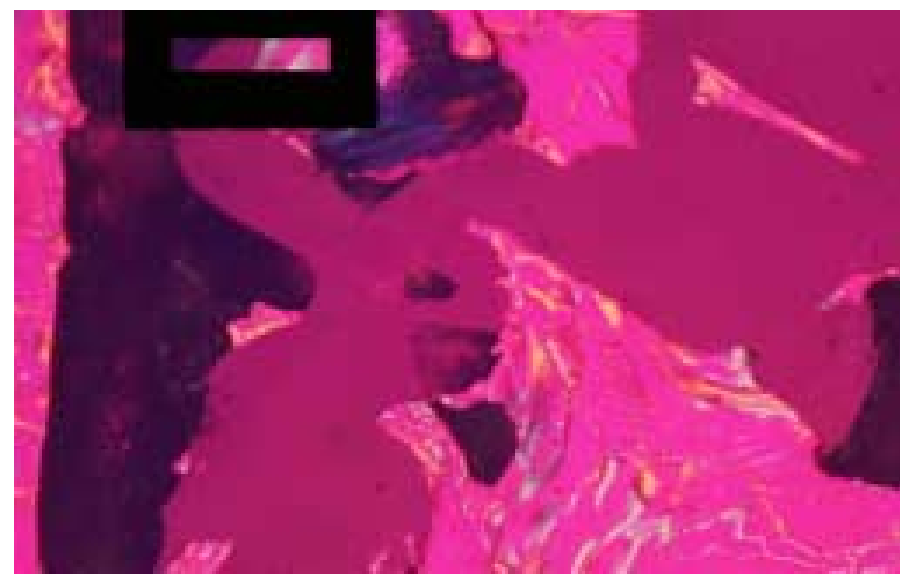

Figure B.47:

BCP-403, Heptane Soluble with reactions conditions of: Solvent: V-1074; $425^{\circ} \mathrm{C}$; 1000 psig $\mathrm{H}_{2}$ 


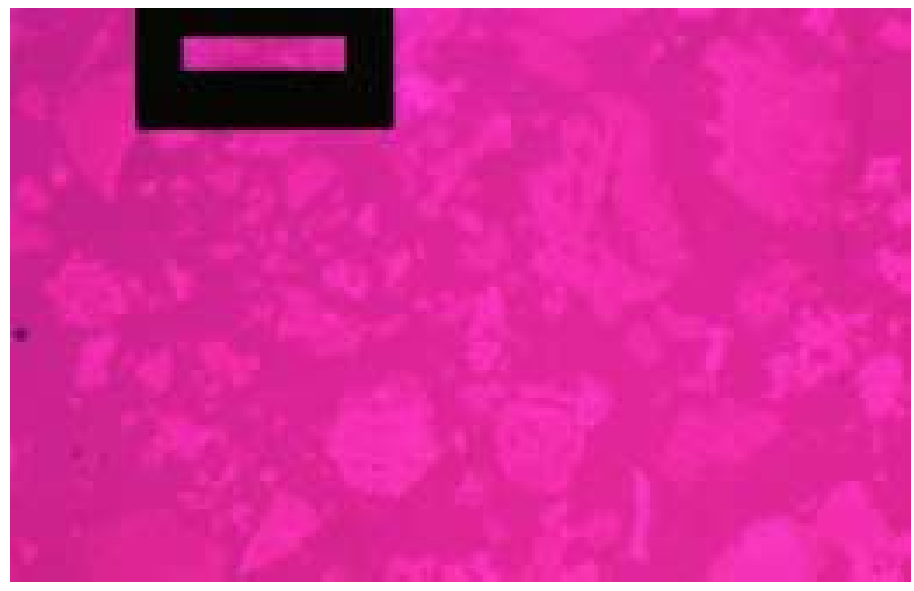

\section{Figure B.48:}

BCP-403, Heptane Insoluble and Toluene Insoluble with reactions conditions of: Solvent: V-1074; $425^{\circ} \mathrm{C}$; 1000 psig $\mathrm{H}_{2}$

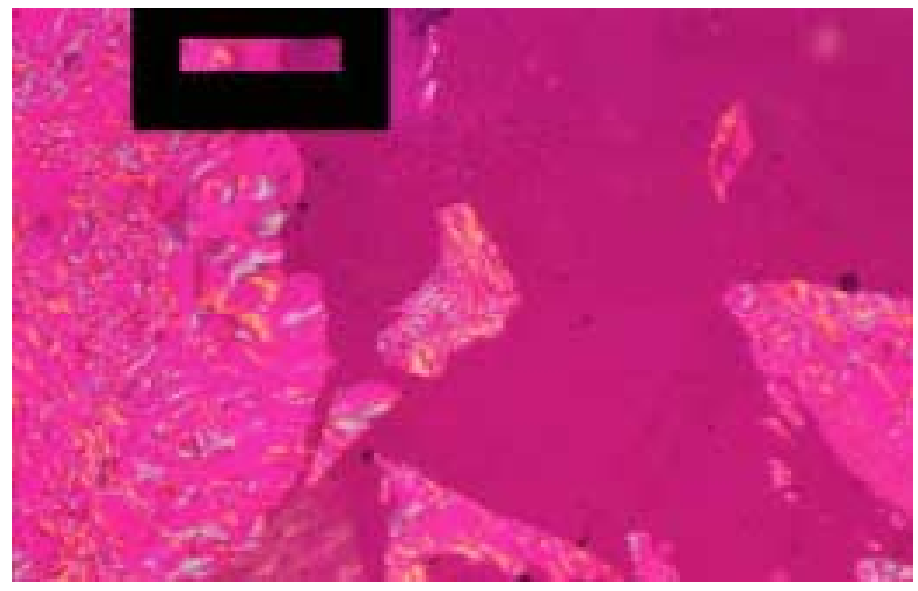

Figure B.49:

BCP-403, Heptane Insoluble and Toluene Soluble with reactions conditions of: Solvent: V-1074; $425^{\circ} \mathrm{C}$; 1000 psig $\mathrm{H}_{2}$ 


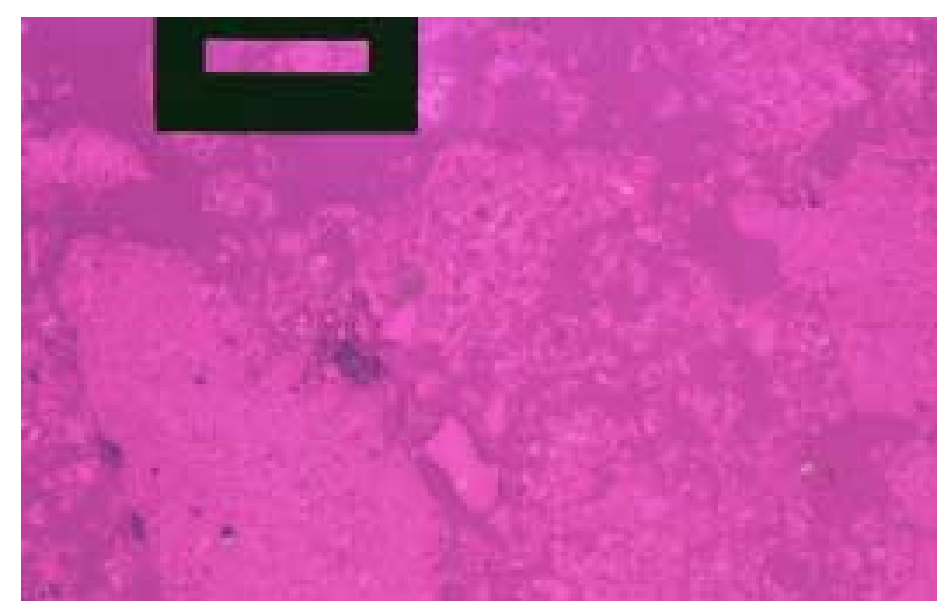

Figure B.50:

BCP-404, THF Insoluble with Reaction conditions of:

Solvent: V-1074, $425^{\circ} \mathrm{C}$

500 psig $\mathrm{H}_{2}$

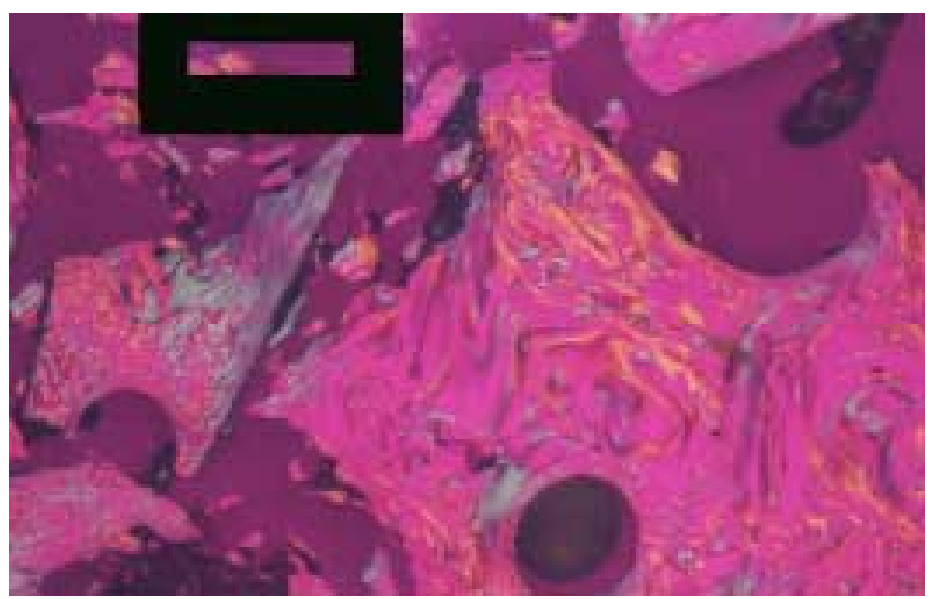

\section{Figure B.51:}

BCP-404, Heptane Insoluble with reaction conditions of: Solvent: V-1074, $425^{\circ} \mathrm{C}$ 500 psig $\mathrm{H}_{2}$

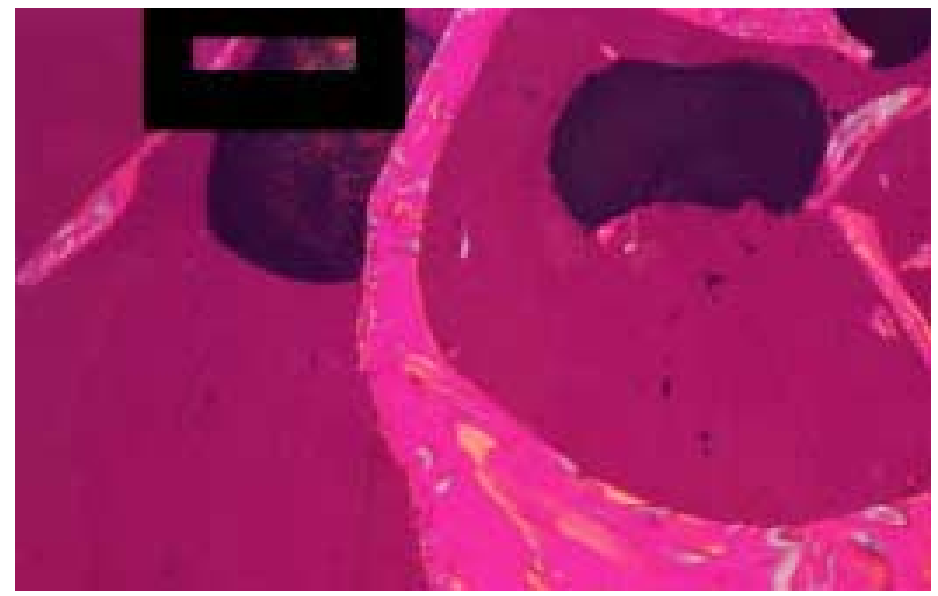

Figure B.52:

BCP-404, Heptane Soluble with reaction conditions of:

Solvent: V-1074, $425^{\circ} \mathrm{C}$ 500 psig $\mathrm{H}_{2}$ 


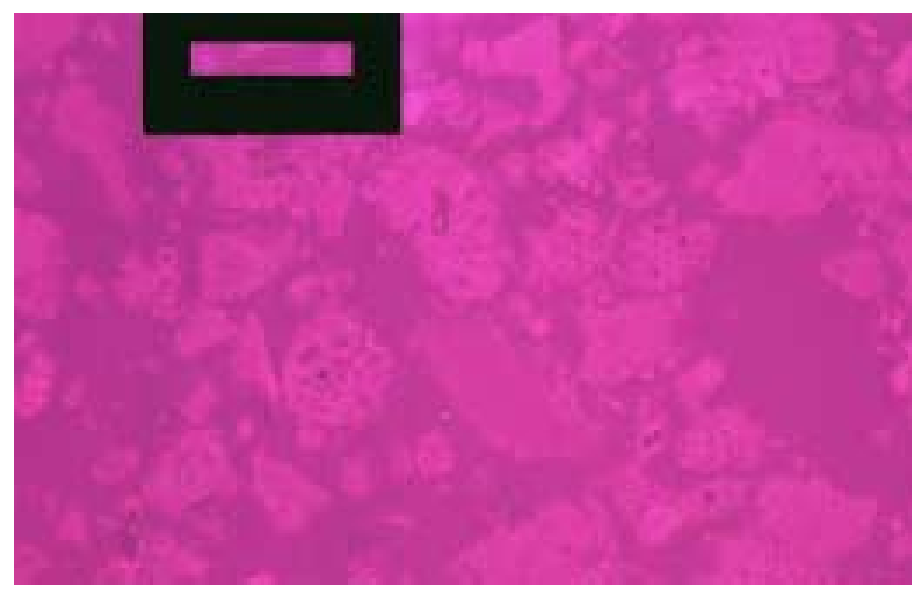

Figure B.53:

BCP-404, Heptane Insoluble and Toluene Insoluble with reaction conditions of: Solvent: V-1074, $425^{\circ} \mathrm{C}$ 500 psig $\mathrm{H}_{2}$

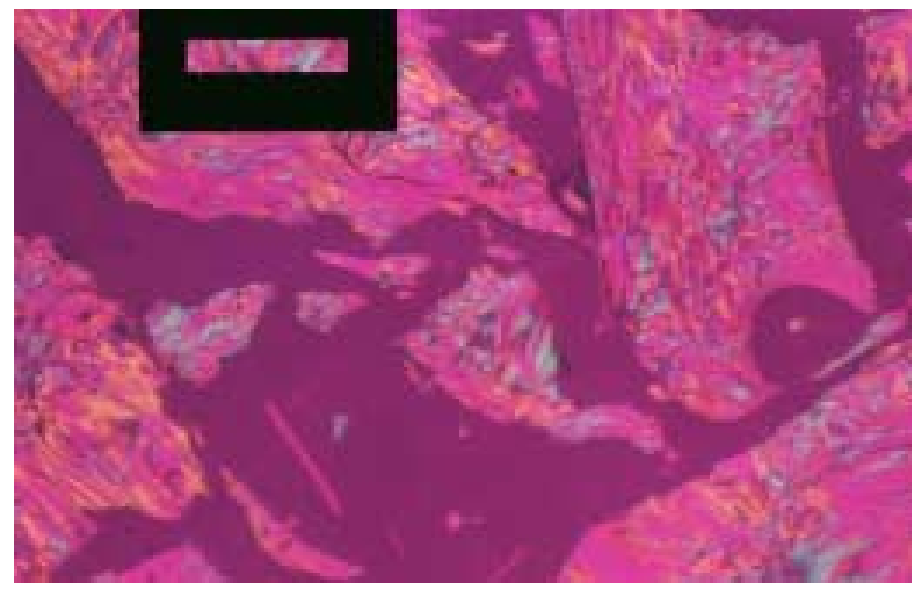

Figure B.54:

BCP-404, Heptane Insoluble and Toluene Soluble with reaction conditions of: Solvent: V-1074, $425^{\circ} \mathrm{C}$ 500 psig $\mathrm{H}_{2}$ 


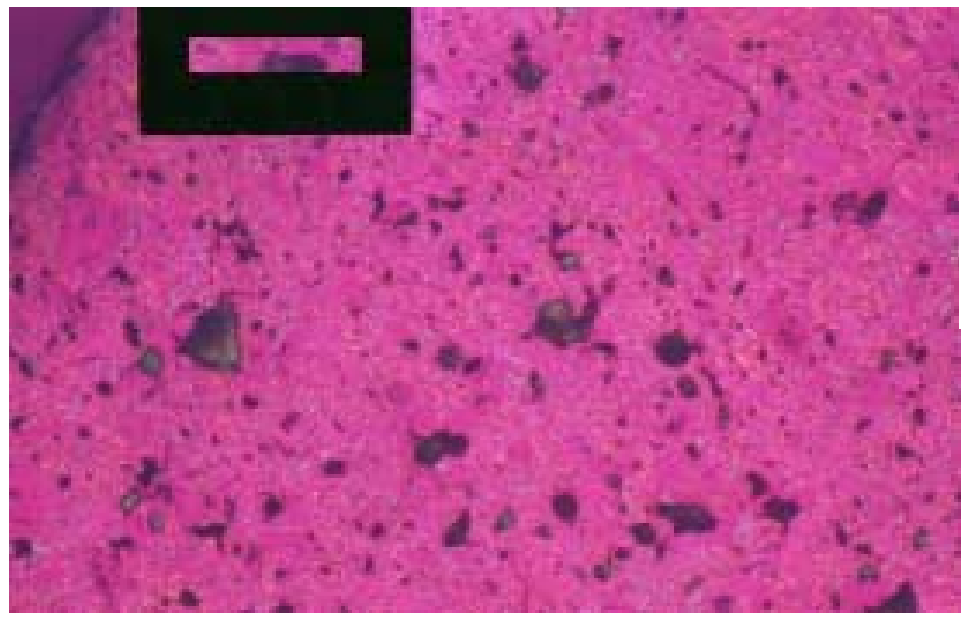

Figure B.55:

BCP-405, THF Insoluble with reaction conditions of:

Solvent: Hondo, $425^{\circ} \mathrm{C}$

1500 psig $\mathrm{H}_{2}$

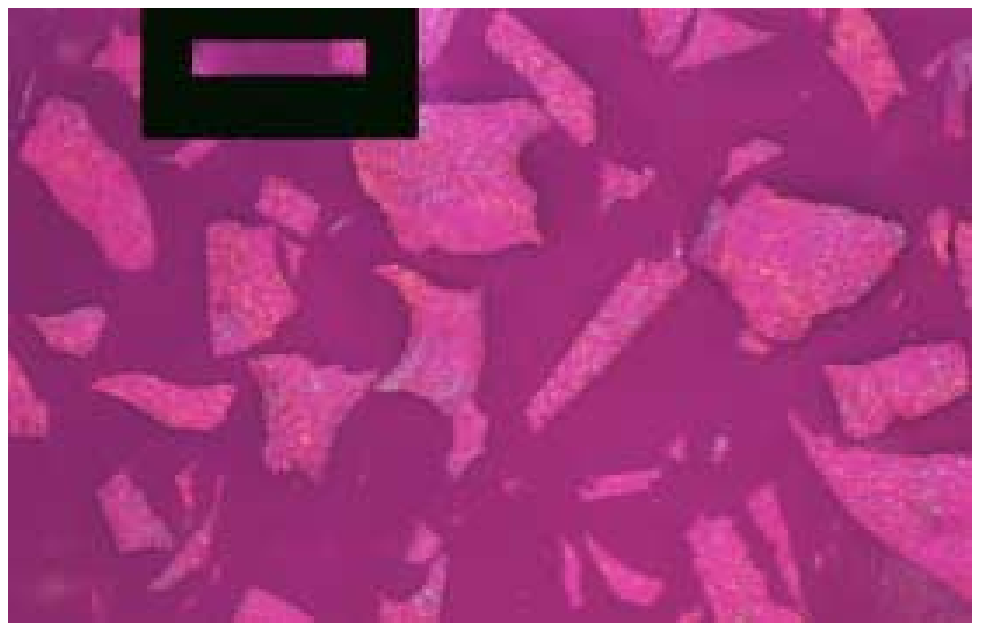

Figure B.56:

BCP-405, Heptane Insoluble with reaction conditions of:

Solvent: Hondo, $425^{\circ} \mathrm{C}$

1500 psig $\mathrm{H}_{2}$

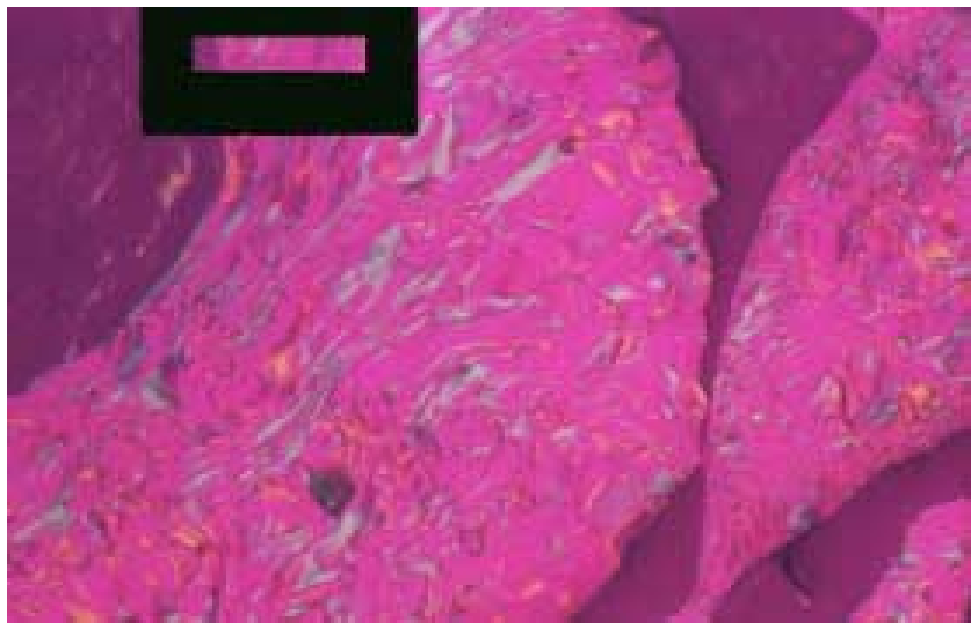

Figure B.57:

BCP-405, Heptane Soluble with reaction conditions of: Solvent: Hondo, $425^{\circ} \mathrm{C}$ 1500 psig $\mathrm{H}_{2}$ 


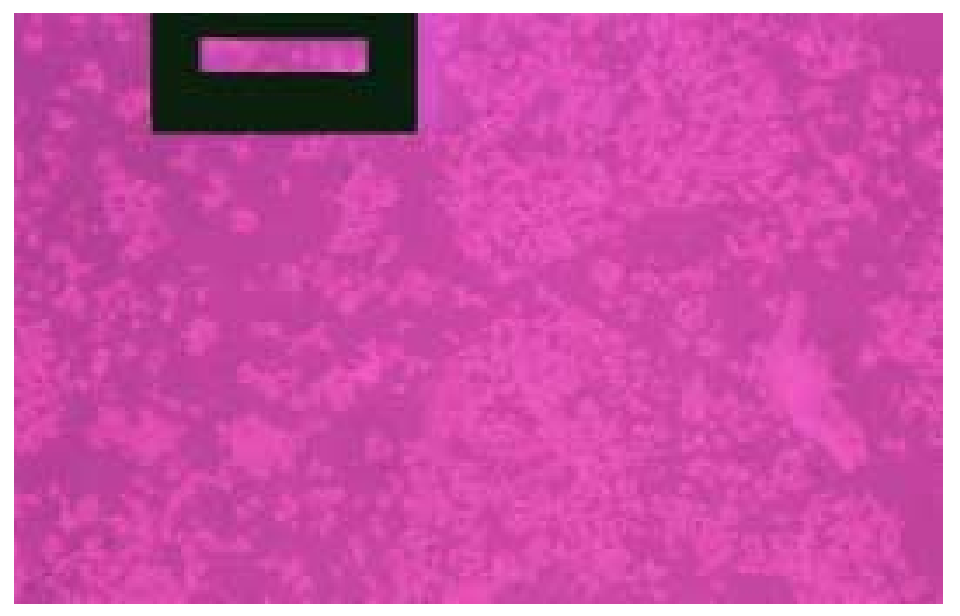

Figure B.58:

BCP-405, Heptane Insoluble and Toluene Insoluble with reaction conditions of: Solvent: Hondo, $425^{\circ} \mathrm{C}$ 1500 psig $\mathrm{H}_{2}$

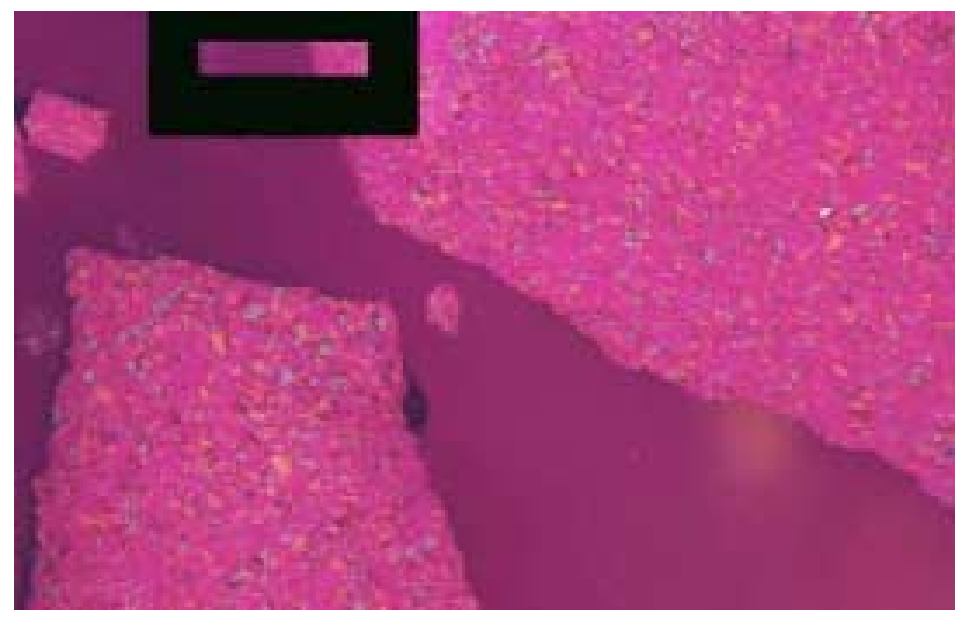

Figure B.59:

BCP-405, Heptane Insoluble and Toluene Soluble with reaction conditions of: Solvent: Hondo, $425^{\circ} \mathrm{C}$ 1500 psig $\mathrm{H}_{2}$ 


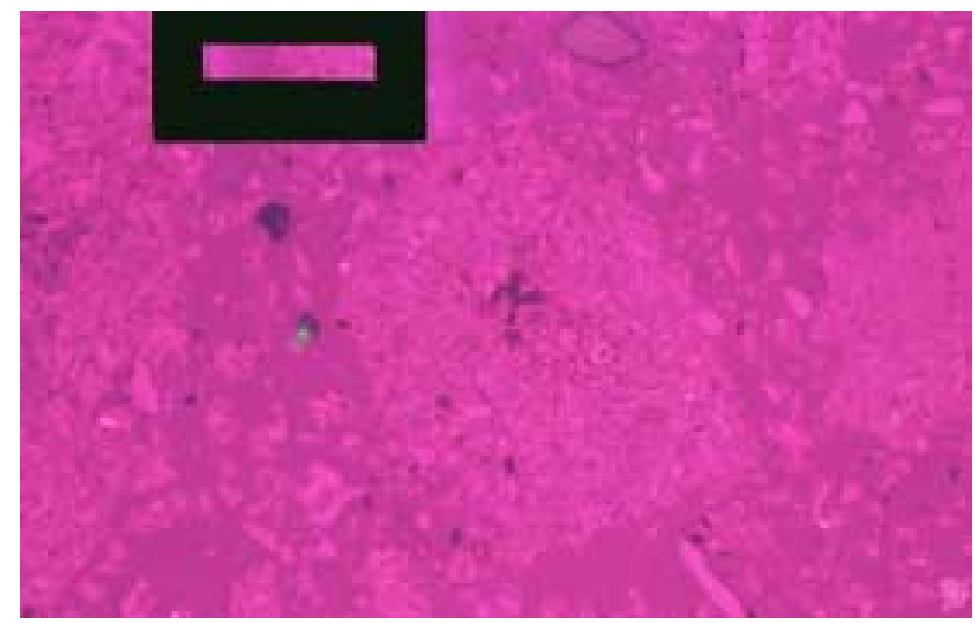

Figure B.60:

BCP-406, THF Insoluble with Reaction conditions of:

Solvent: V-1074, $390{ }^{\circ} \mathrm{C}$

1500 psig $97 \% \mathrm{H}_{2} / 3 \% \mathrm{H}_{2} \mathrm{~S}$

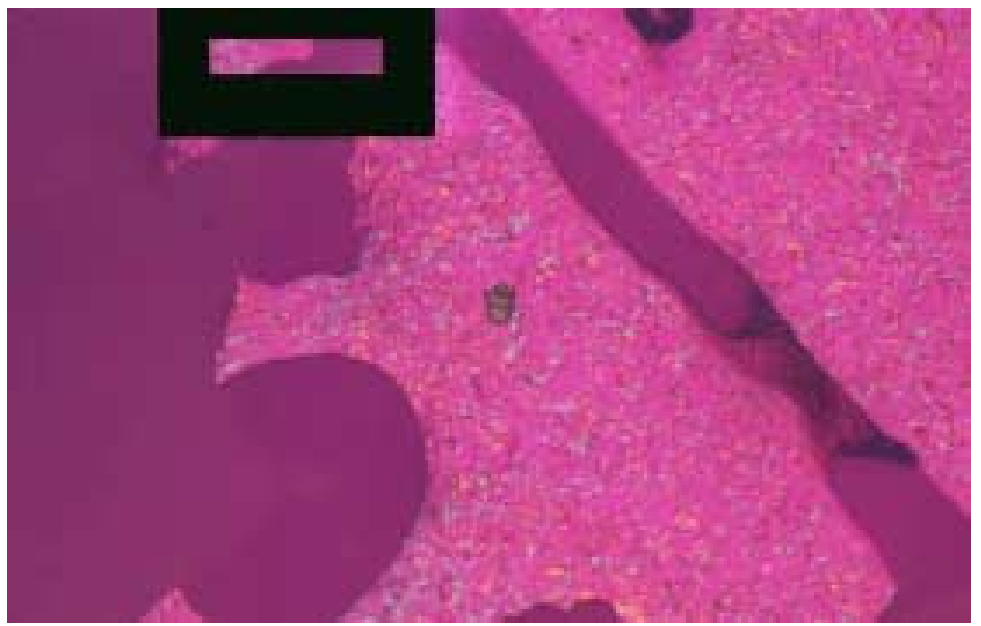

Figure B.61:

BCP-406, Heptane Insoluble with Reaction conditions of: Solvent: V-1074, $390^{\circ} \mathrm{C}$ 1500 psig $97 \% \mathrm{H}_{2} / 3 \% \mathrm{H}_{2} \mathrm{~S}$

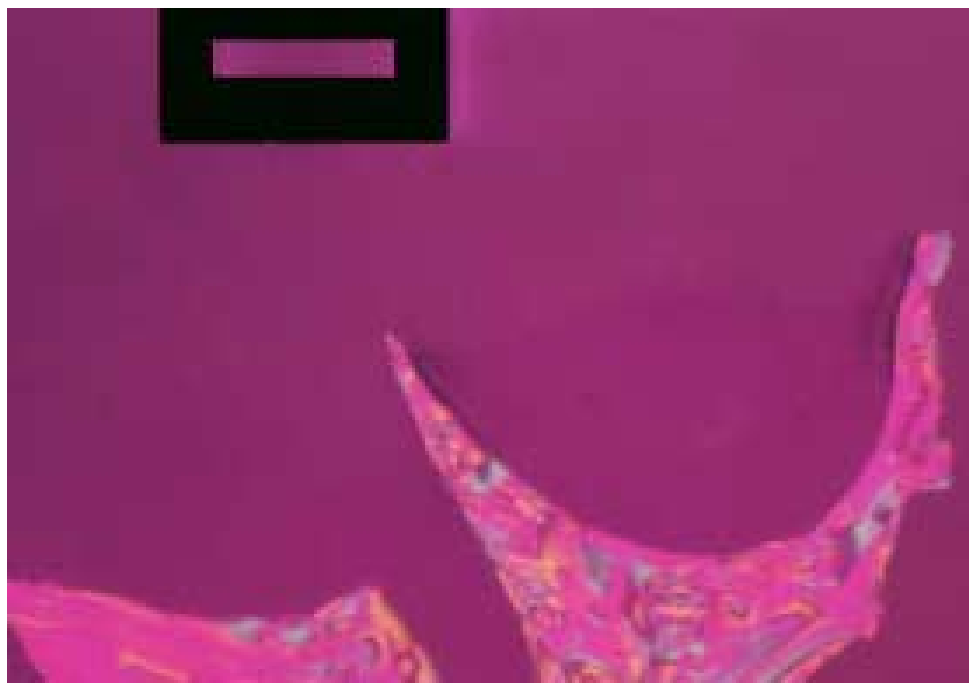

Figure B.62:

BCP-406, Heptane Soluble with Reaction conditions of: Solvent: V-1074, $390{ }^{\circ} \mathrm{C}$ 1500 psig $97 \% \mathrm{H}_{2} / 3 \% \mathrm{H}_{2} \mathrm{~S}$ 


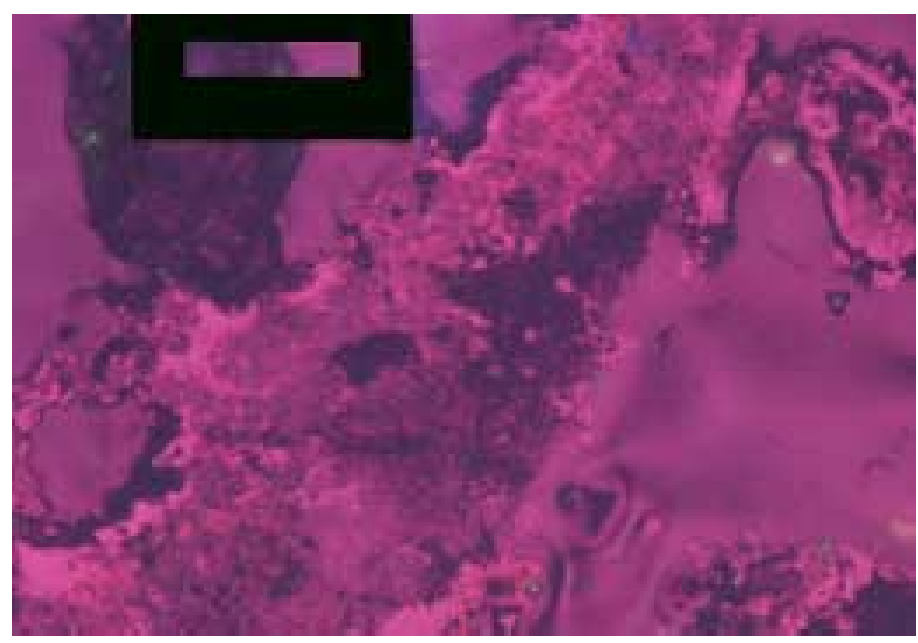

Figure B.63:

BCP-406, Heptane Insoluble and Toluene Insoluble with Reaction conditions of: Solvent: V-1074, $390{ }^{\circ} \mathrm{C}$ 1500 psig $97 \% \mathrm{H}_{2} / 3 \% \mathrm{H}_{2} \mathrm{~S}$

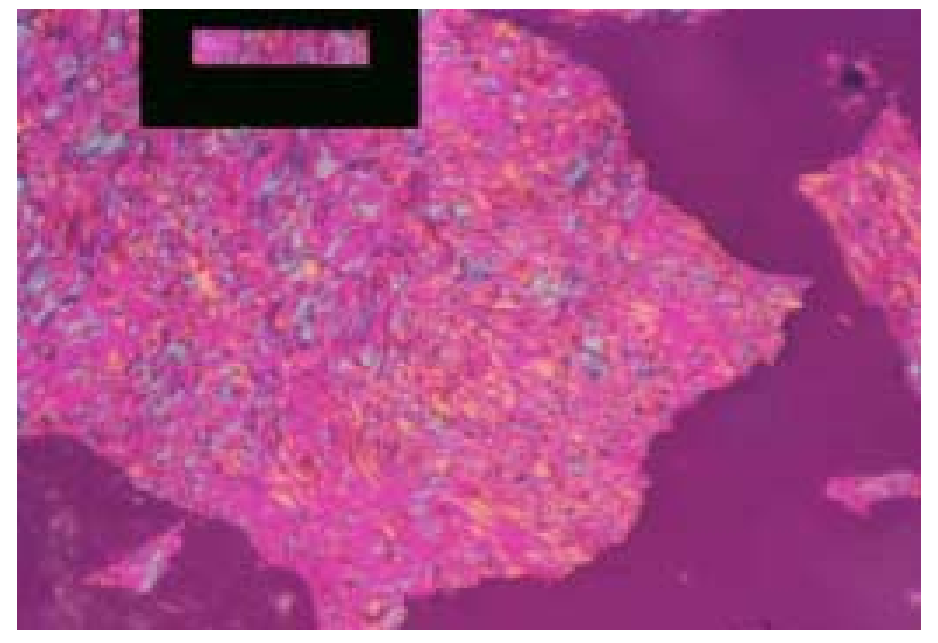

Figure B.64:

BCP-406, Heptane Insoluble and Toluene Soluble with Reaction conditions of: Solvent: V-1074, $390{ }^{\circ} \mathrm{C}$ 1500 psig $97 \% \mathrm{H}_{2} / 3 \% \mathrm{H}_{2} \mathrm{~S}$ 


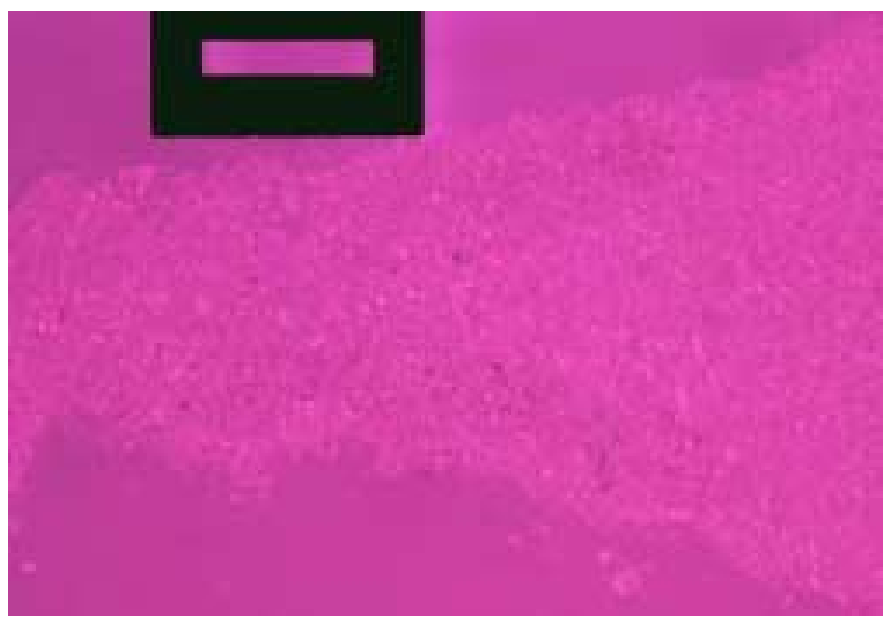

\section{Figure B.65:}

BCP-407, THF Insoluble with

Reaction conditions of:

Solvent: V-1074, $410^{\circ} \mathrm{C}$

1500 psig $97 \% \mathrm{H}_{2} / 3 \% \mathrm{H}_{2} \mathrm{~S}$

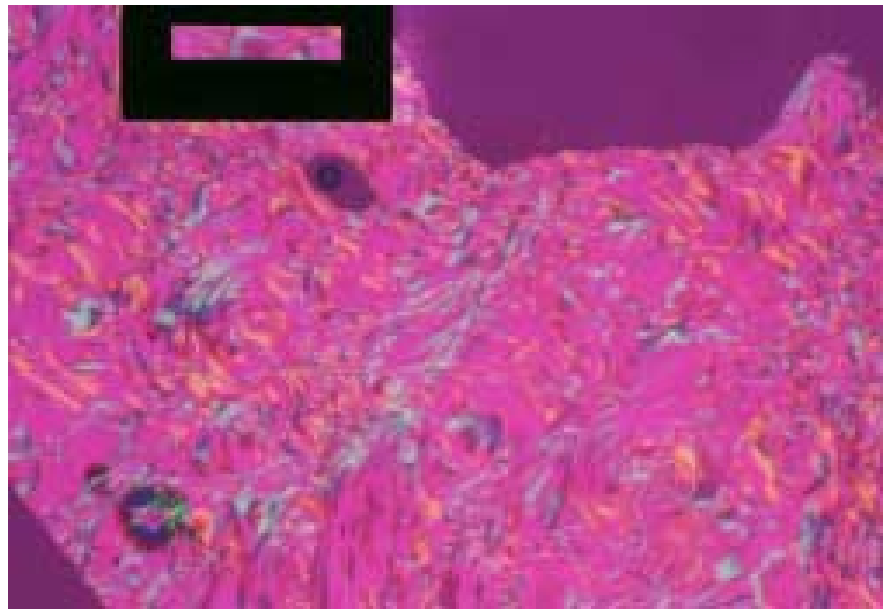

Figure B.66:

BCP-407, Heptane Insoluble with Reaction conditions of:

Solvent: V-1074, $410{ }^{\circ} \mathrm{C}$

1500 psig $97 \% \mathrm{H}_{2} / 3 \% \mathrm{H}_{2} \mathrm{~S}$

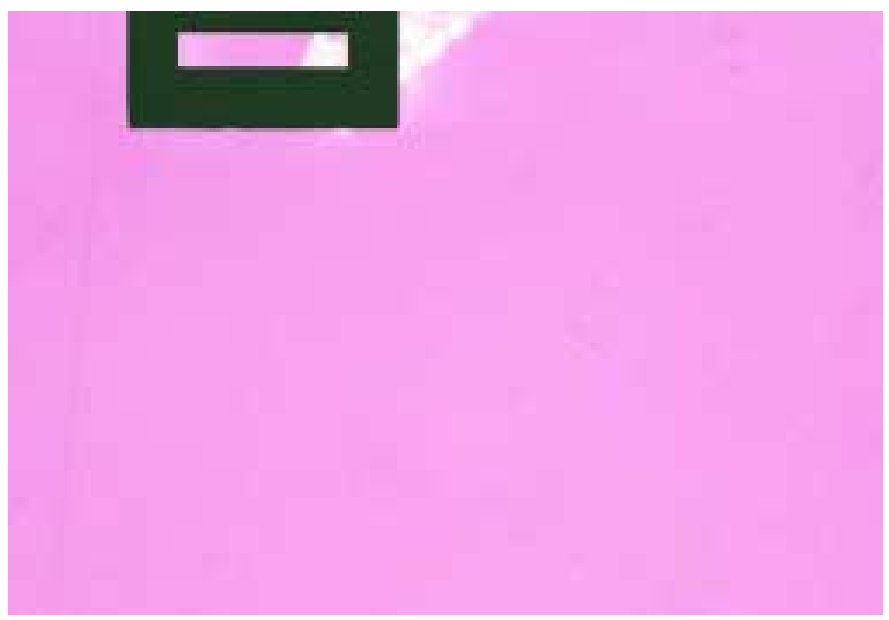

Figure B.67:

BCP-407, Heptane Soluble with

Reaction conditions of:

Solvent: V-1074, $410^{\circ} \mathrm{C}$

1500 psig $97 \% \mathrm{H}_{2} / 3 \% \mathrm{H}_{2} \mathrm{~S}$ 


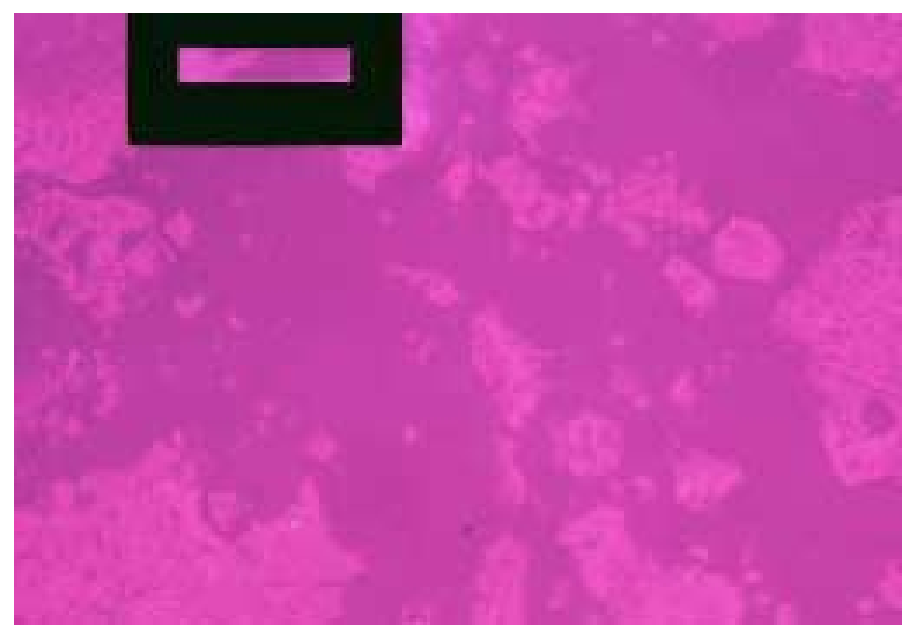

Figure B.68:

BCP-407, Heptane Insoluble and Toluene Insoluble with

Reaction conditions of:

Solvent: V-1074, $410^{\circ} \mathrm{C}$

1500 psig $97 \% \mathrm{H}_{2} / 3 \% \mathrm{H}_{2} \mathrm{~S}$

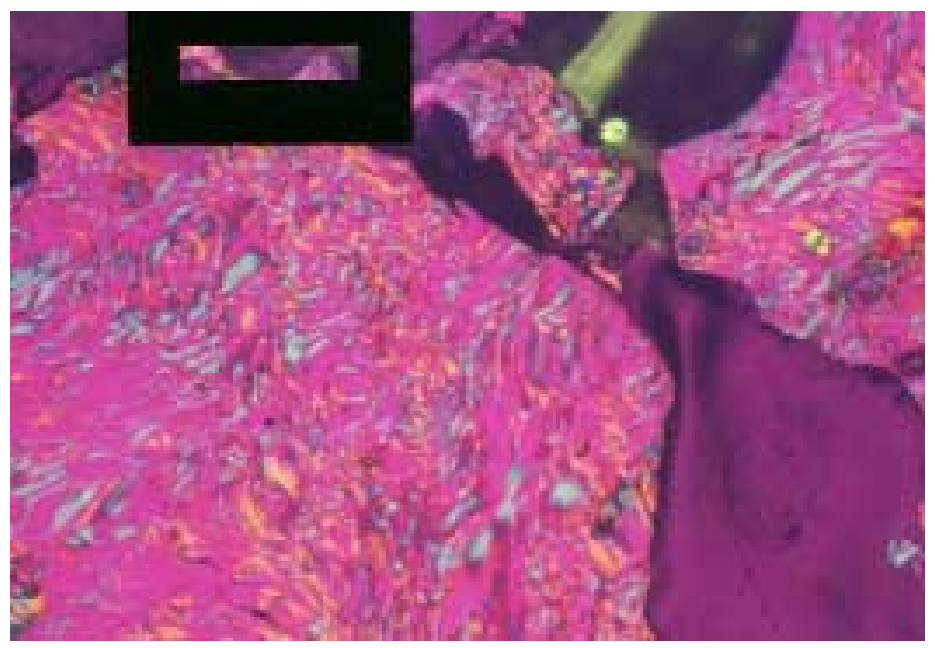

Figure B.69:

BCP-407, Heptane Insoluble and Toluene Soluble with Reaction conditions of:

Solvent: V-1074, $410{ }^{\circ} \mathrm{C}$ 1500 psig $97 \% \mathrm{H}_{2} / 3 \% \mathrm{H}_{2} \mathrm{~S}$ 


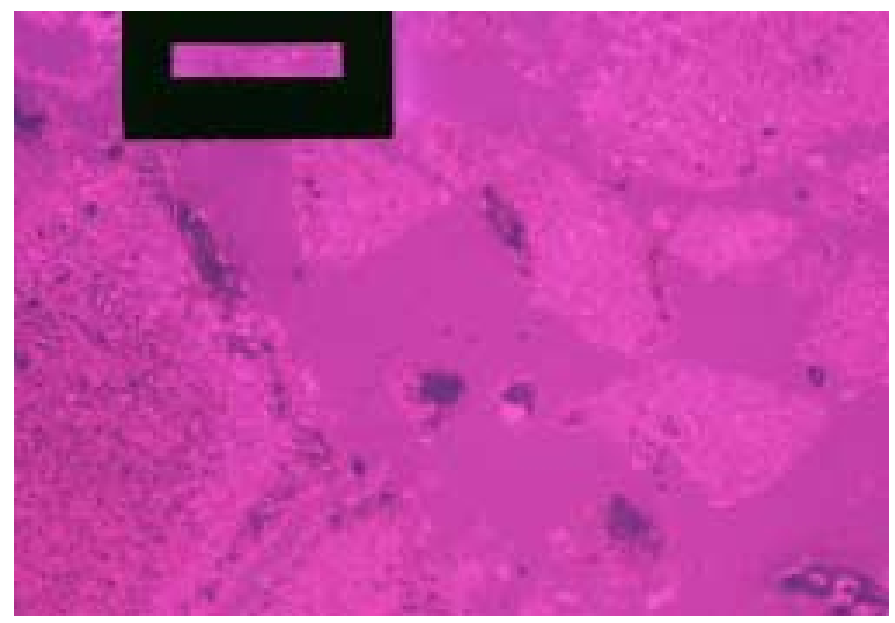

Figure B.70:

BCP-408, THF Insoluble with

Reaction conditions of:

Solvent: V-1074, $410^{\circ} \mathrm{C}$

1000 psig $97 \% \mathrm{H}_{2} / 3 \% \mathrm{H}_{2} \mathrm{~S}$

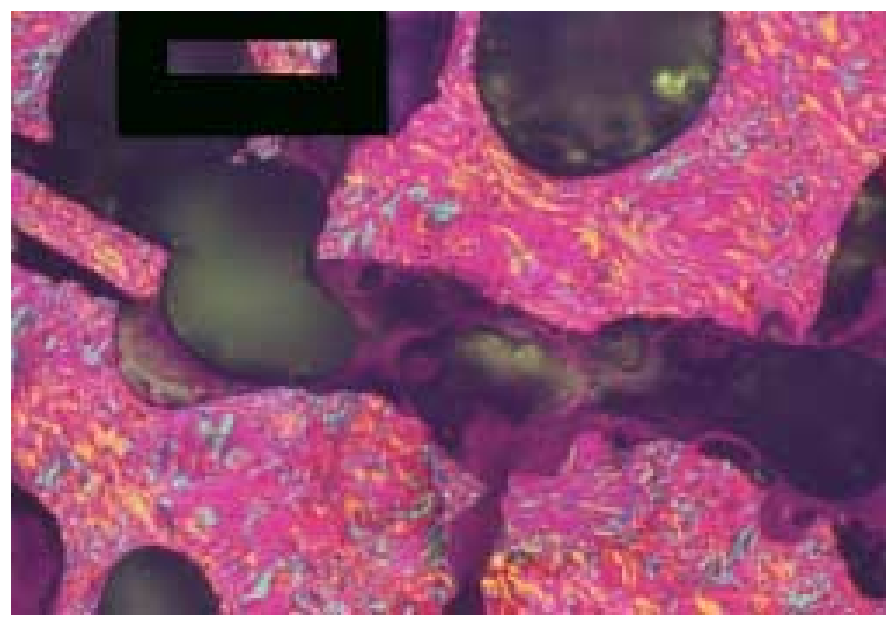

\section{Figure B.71:}

BCP-408, Heptane Insoluble with Reaction conditions of:

Solvent: V-1074, $410^{\circ} \mathrm{C}$

1000 psig $97 \% \mathrm{H}_{2} / 3 \% \mathrm{H}_{2} \mathrm{~S}$

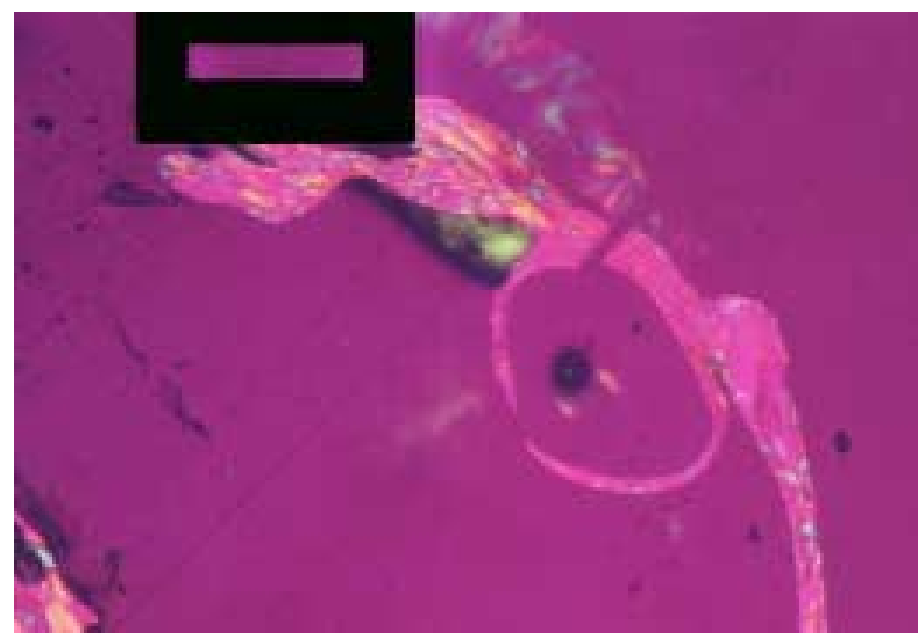

Figure B.72:

BCP-408, Heptane Soluble with Reaction conditions of:

Solvent: V-1074, $410^{\circ} \mathrm{C}$ 1000 psig $97 \% \mathrm{H}_{2} / 3 \% \mathrm{H}_{2} \mathrm{~S}$ 


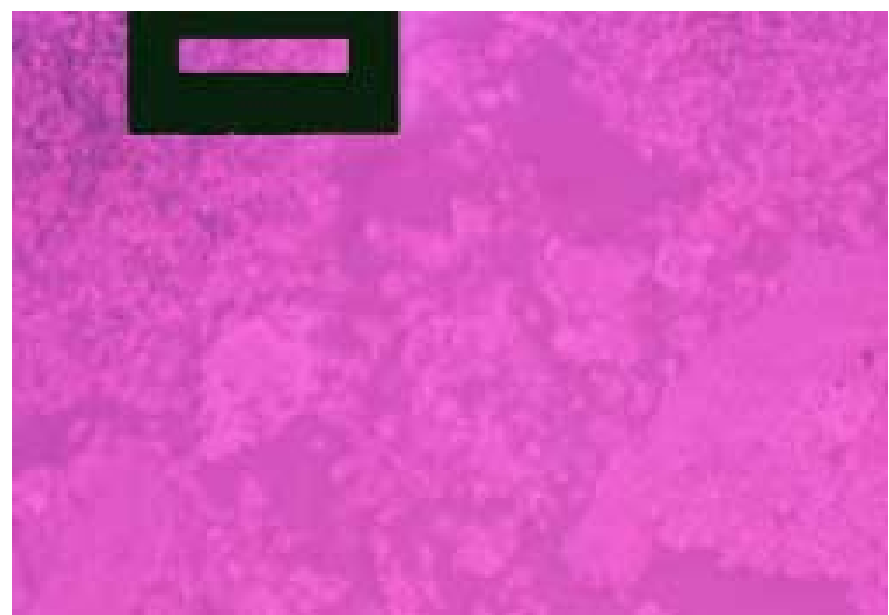

Figure B.73:

BCP-408, Heptane Insoluble and Toluene Insoluble with Reaction conditions of: Solvent: V-1074, $410{ }^{\circ} \mathrm{C}$ 1000 psig $97 \% \mathrm{H}_{2} / 3 \% \mathrm{H}_{2} \mathrm{~S}$

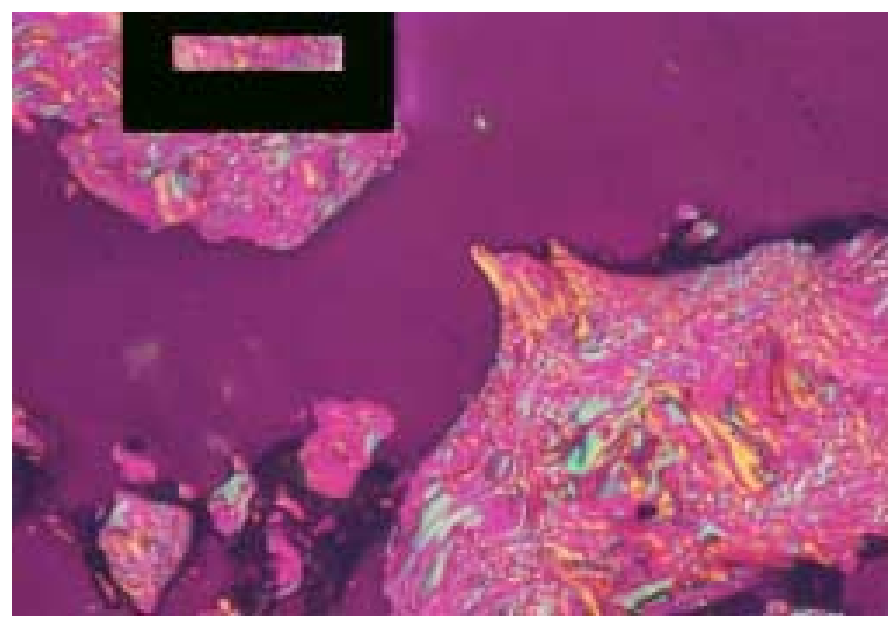

Figure B.74:

BCP-408, Heptane Insoluble and Toluene Soluble with Reaction conditions of: Solvent: V-1074, $410{ }^{\circ} \mathrm{C}$ 1000 psig $97 \% \mathrm{H}_{2} / 3 \% \mathrm{H}_{2} \mathrm{~S}$ 


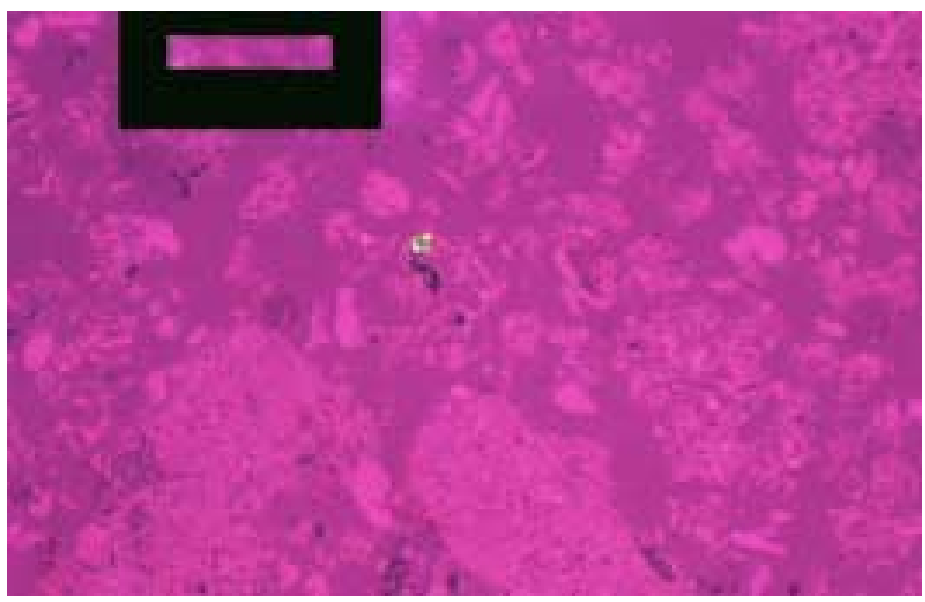

Figure B.75:

BCP-409, THF Insoluble with

Reaction conditions of:

Solvent: V-1074, $410{ }^{\circ} \mathrm{C}$

500 psig $97 \% \mathrm{H}_{2} / 3 \% \mathrm{H}_{2} \mathrm{~S}$

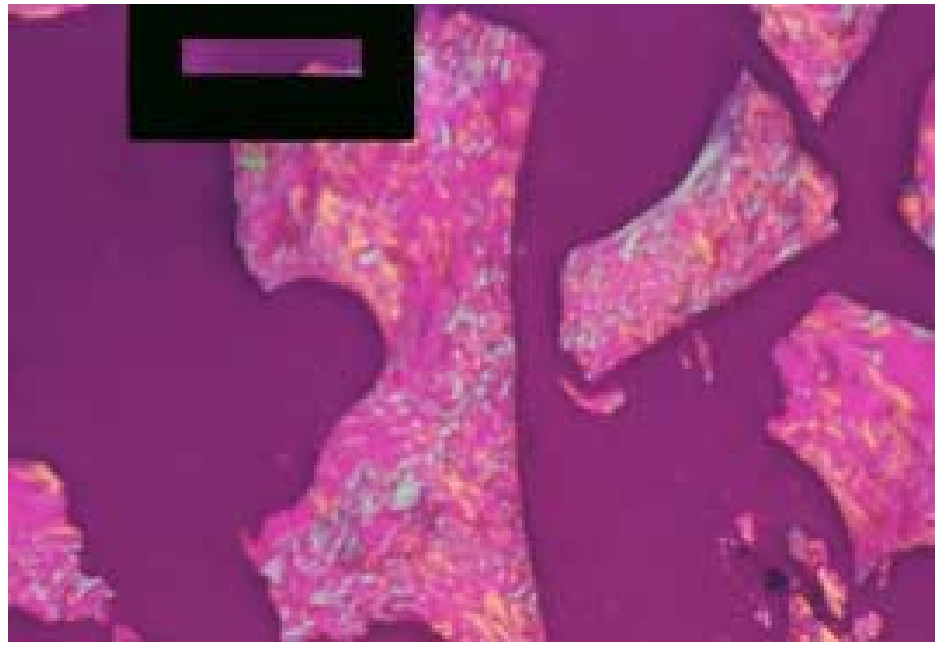

Figure B.76:

BCP-409, Heptane Insoluble with Reaction conditions of: Solvent: V-1074, $410{ }^{\circ} \mathrm{C}$ 500 psig $97 \% \mathrm{H}_{2} / 3 \% \mathrm{H}_{2} \mathrm{~S}$

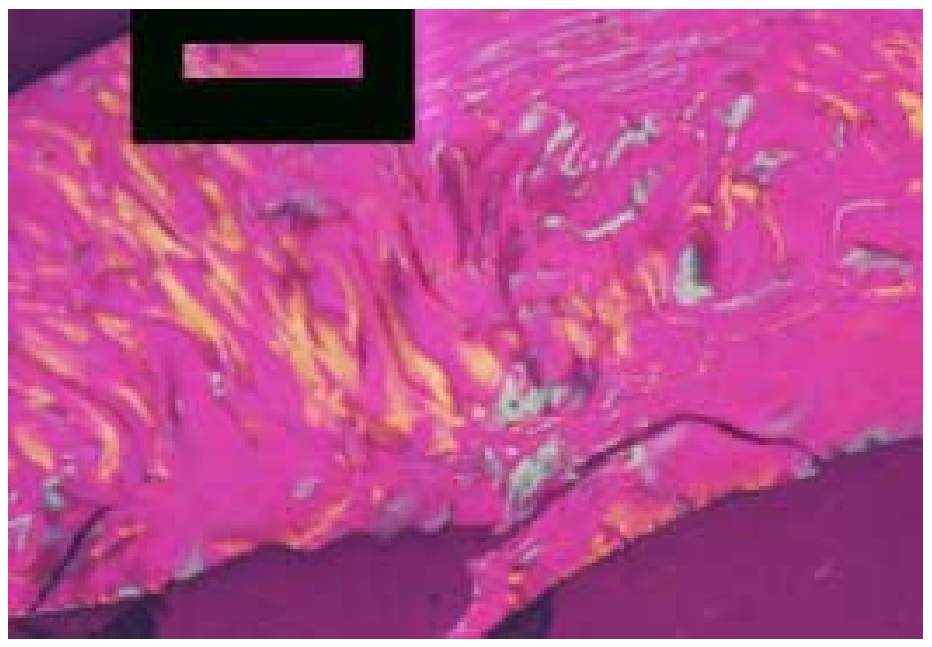

Figure B.77:

BCP-409, Heptane Soluble with Reaction conditions of: Solvent: V-1074, $410^{\circ} \mathrm{C}$ 500 psig $97 \% \mathrm{H}_{2} / 3 \% \mathrm{H}_{2} \mathrm{~S}$ 


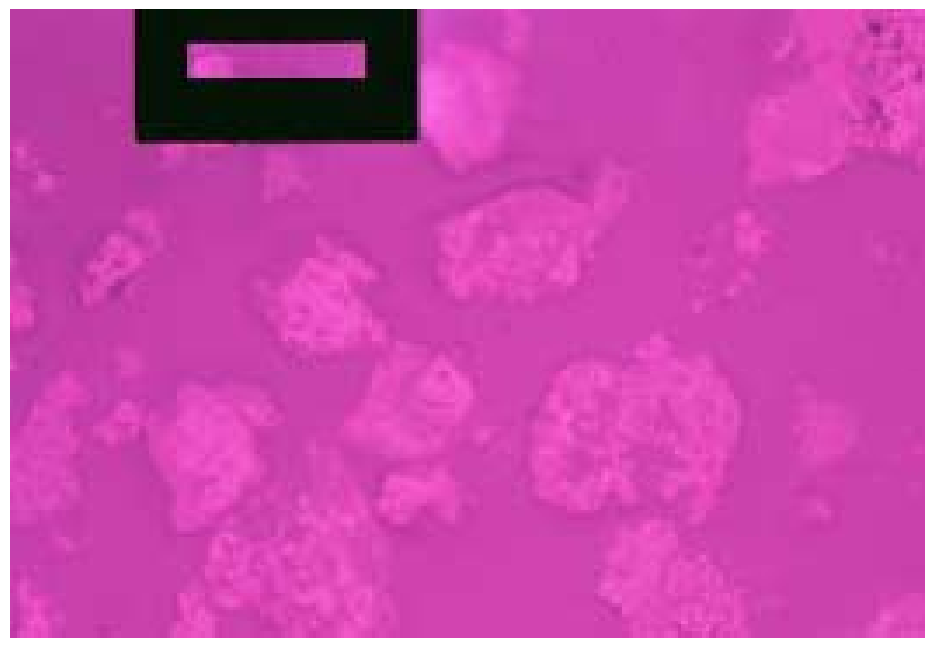

Figure B.78:

BCP-409, Heptane Insoluble and Toluene Insoluble with Reaction conditions of: Solvent: V-1074, $410{ }^{\circ} \mathrm{C}$ 500 psig $97 \% \mathrm{H}_{2} / 3 \% \mathrm{H}_{2} \mathrm{~S}$

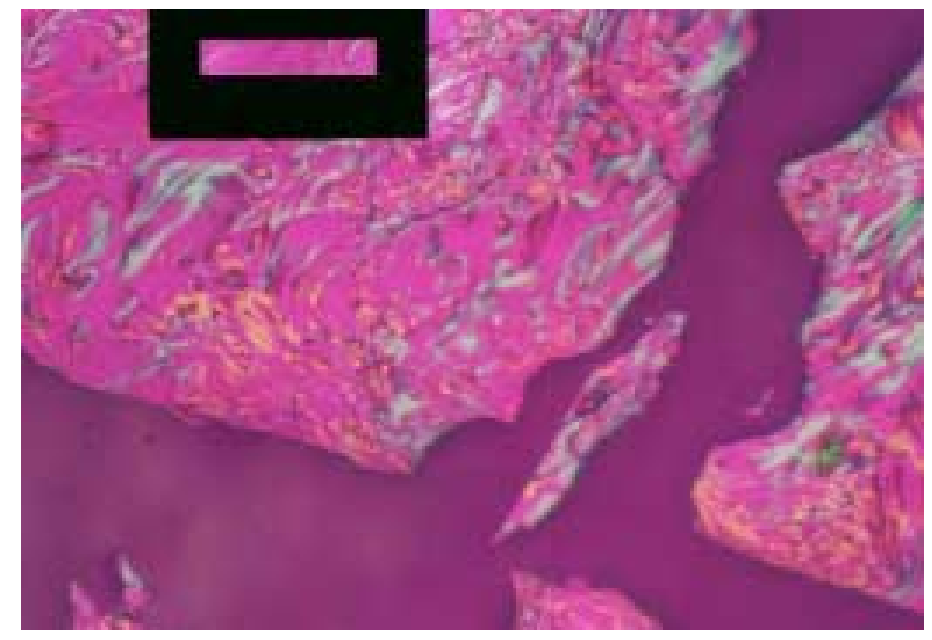

Figure B.79:

BCP-409, Heptane Insoluble and Toluene Soluble with Reaction conditions of: Solvent: V-1074, $410{ }^{\circ} \mathrm{C}$ 500 psig $97 \% \mathrm{H}_{2} / 3 \% \mathrm{H}_{2} \mathrm{~S}$ 


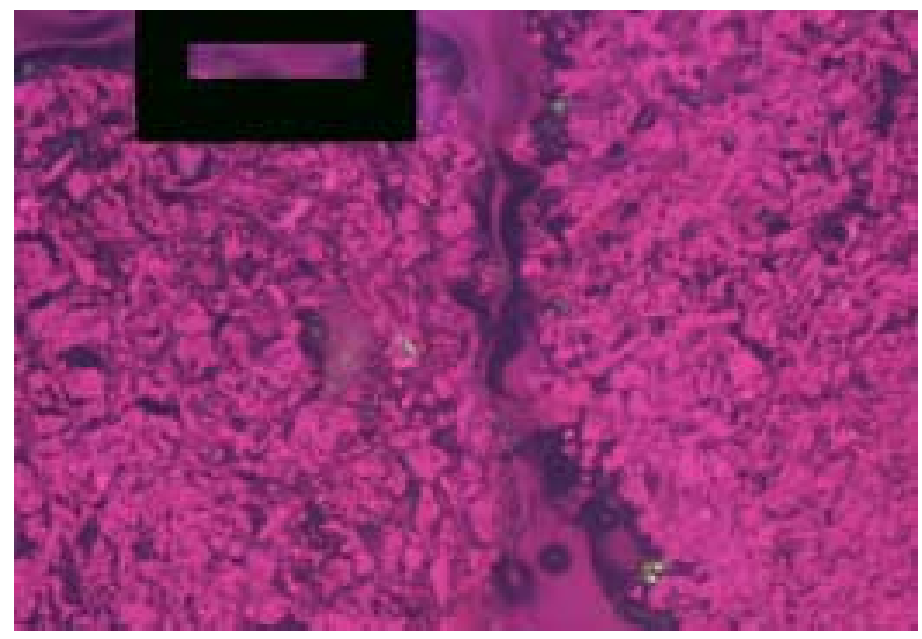

Figure B.80:

BCP-410, THF Insoluble with

Reaction conditions of:

Solvent: V-1074, $390{ }^{\circ} \mathrm{C}$

1000 psig $97 \% \mathrm{H}_{2} / 3 \% \mathrm{H}_{2} \mathrm{~S}$

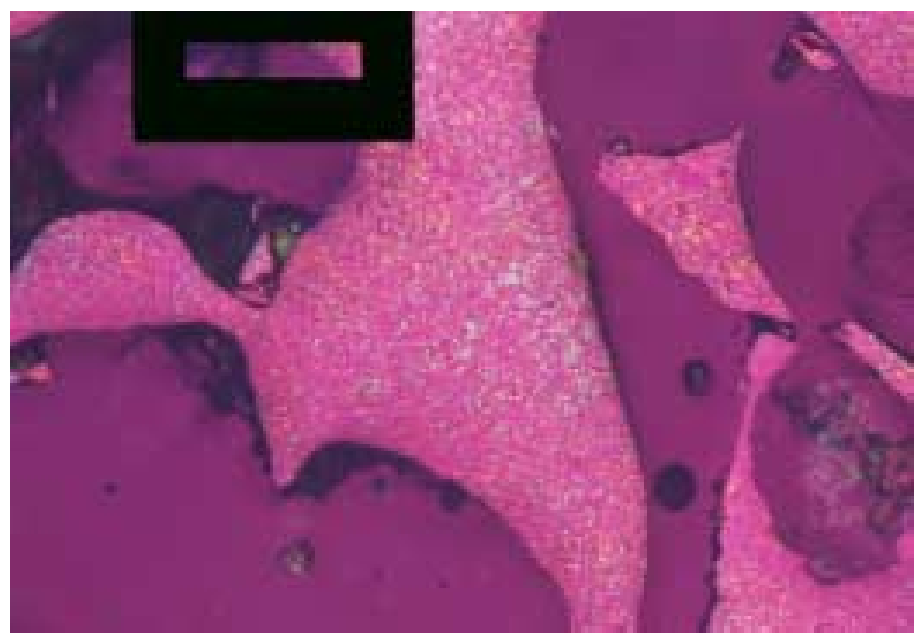

Figure B.81:

BCP-410, Heptane Insoluble with Reaction conditions of:

Solvent: V-1074, $390{ }^{\circ} \mathrm{C}$

1000 psig $97 \% \mathrm{H}_{2} / 3 \% \mathrm{H}_{2} \mathrm{~S}$

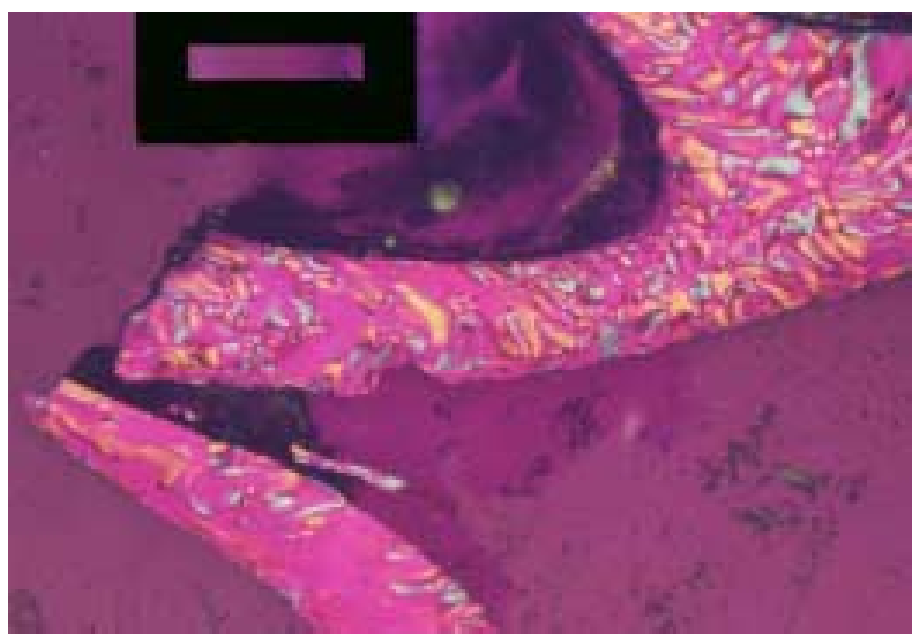

Figure B.82:

BCP-410, Heptane Soluble with Reaction conditions of:

Solvent: V-1074, $390{ }^{\circ} \mathrm{C}$ 1000 psig $97 \% \mathrm{H}_{2} / 3 \% \mathrm{H}_{2} \mathrm{~S}$ 


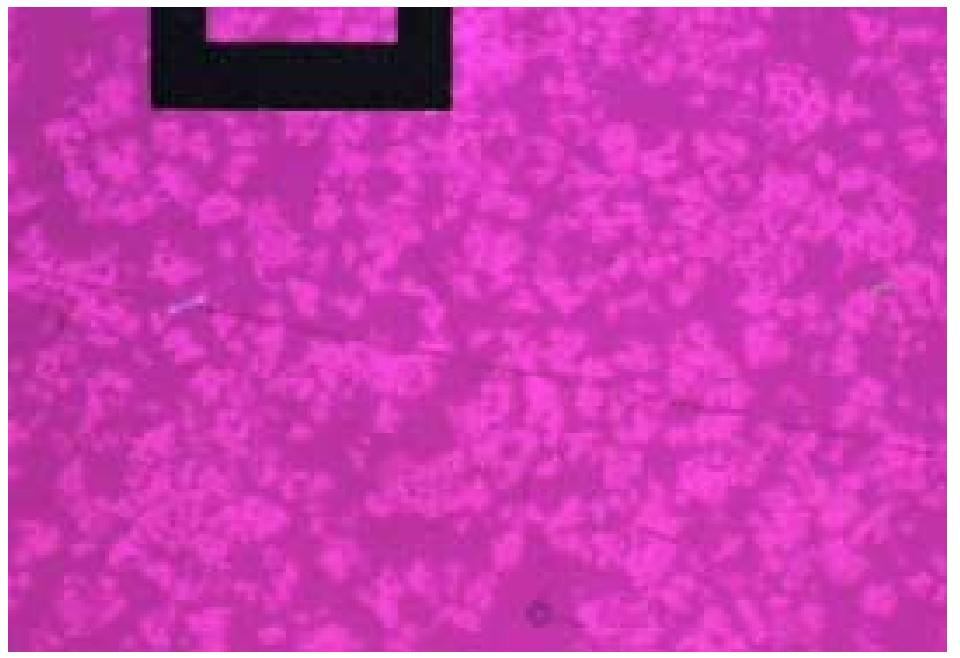

Figure B.83:

BCP-410, Heptane Insoluble and Toluene Insoluble with Reaction conditions of: Solvent: V-1074, $390{ }^{\circ} \mathrm{C}$ 1000 psig $97 \% \mathrm{H}_{2} / 3 \% \mathrm{H}_{2} \mathrm{~S}$

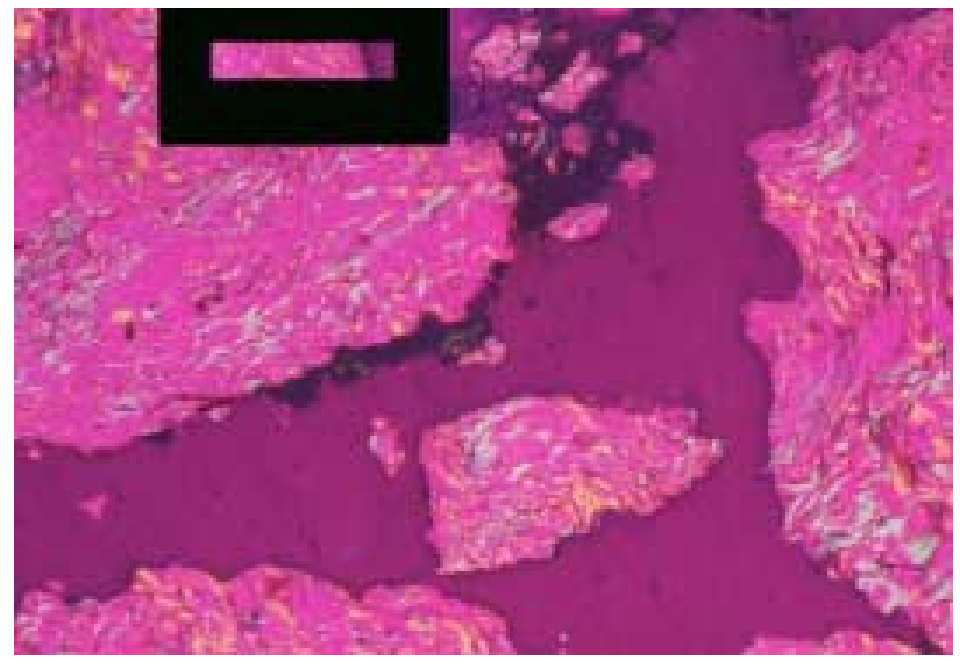

Figure B.84:

BCP-410, Heptane Insoluble and Toluene Soluble with Reaction conditions of: Solvent: V-1074, $390{ }^{\circ} \mathrm{C}$ 1000 psig $97 \% \mathrm{H}_{2} / 3 \% \mathrm{H}_{2} \mathrm{~S}$ 


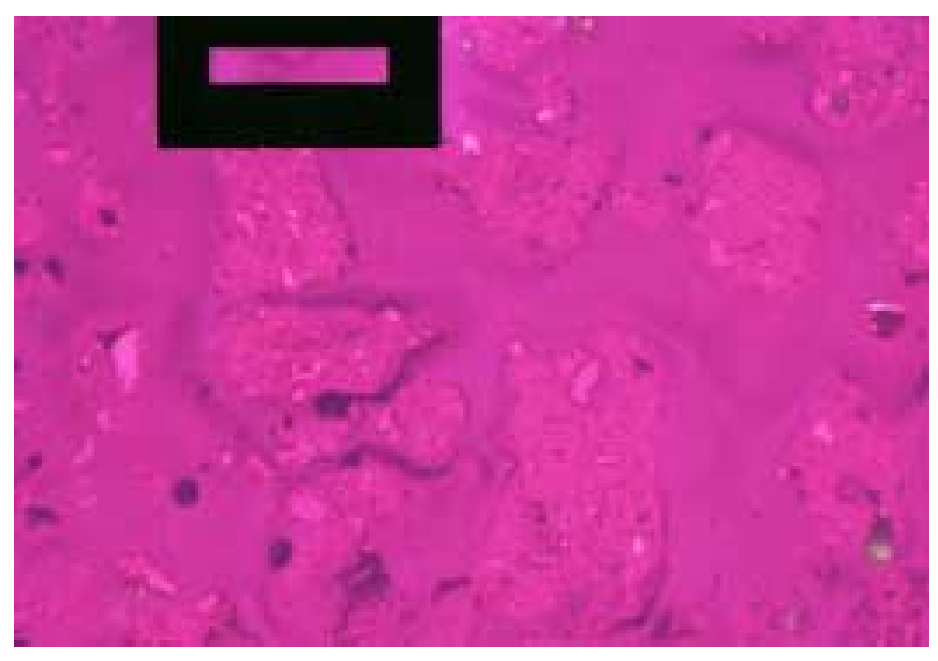

\section{Figure B.85:}

BCP-411, THF Insoluble with Reaction conditions of:

Solvent: V-1074 only, $410{ }^{\circ} \mathrm{C}$ $1000 \mathrm{psig} 97 \% \mathrm{H}_{2} / 3 \% \mathrm{H}_{2} \mathrm{~S}$

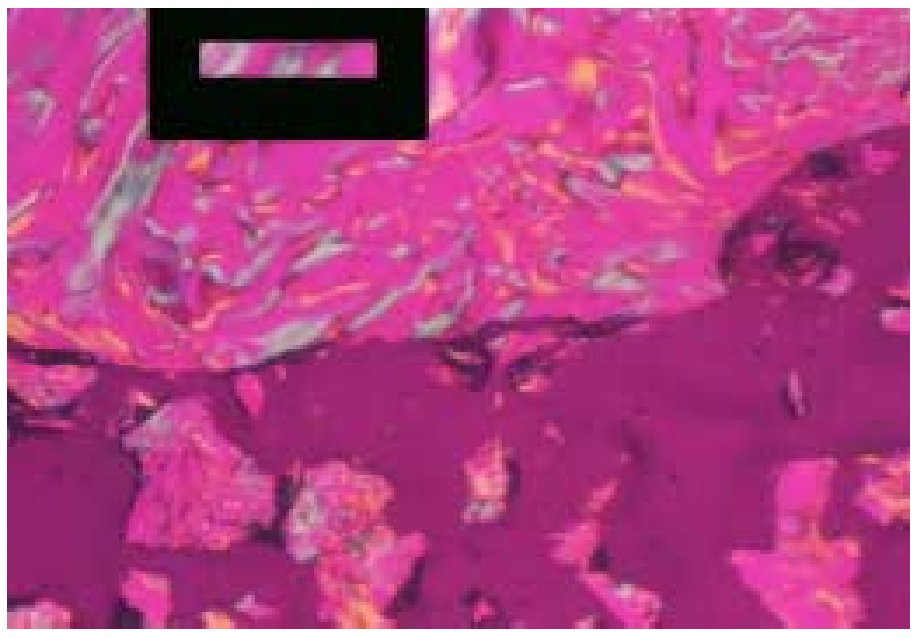

\section{Figure B.86:}

BCP-411, Heptane Insoluble with Reaction conditions of: Solvent: V-1074 only, $410{ }^{\circ} \mathrm{C}$ $1000 \mathrm{psig} 97 \% \mathrm{H}_{2} / 3 \% \mathrm{H}_{2} \mathrm{~S}$

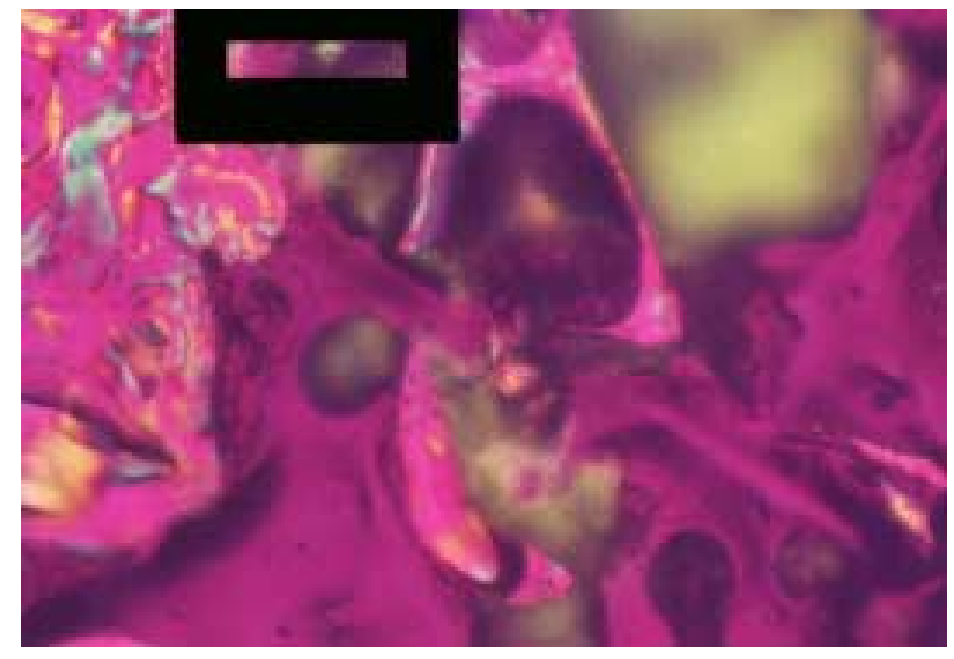

Figure B.87:

BCP-411, Heptane Soluble with Reaction conditions of:

Solvent: V-1074 only, $410{ }^{\circ} \mathrm{C}$ 1000 psig $97 \% \mathrm{H}_{2} / 3 \% \mathrm{H}_{2} \mathrm{~S}$ 


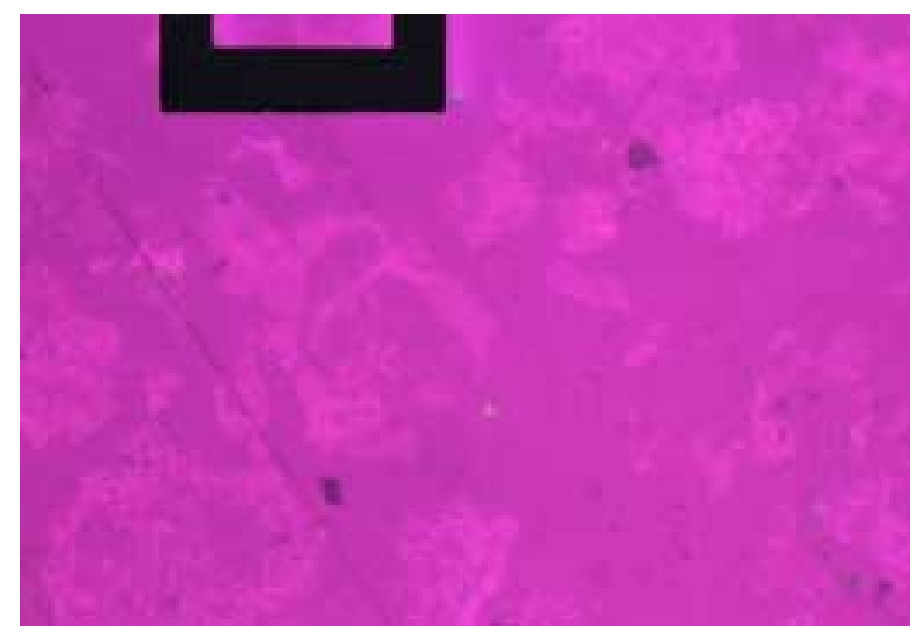

Figure B.88:

BCP-411, Heptane Insoluble and Toluene Insoluble with Reaction conditions of:

Solvent: V-1074 only, $410{ }^{\circ} \mathrm{C}$ 1000 psig $97 \% \mathrm{H}_{2} / 3 \% \mathrm{H}_{2} \mathrm{~S}$

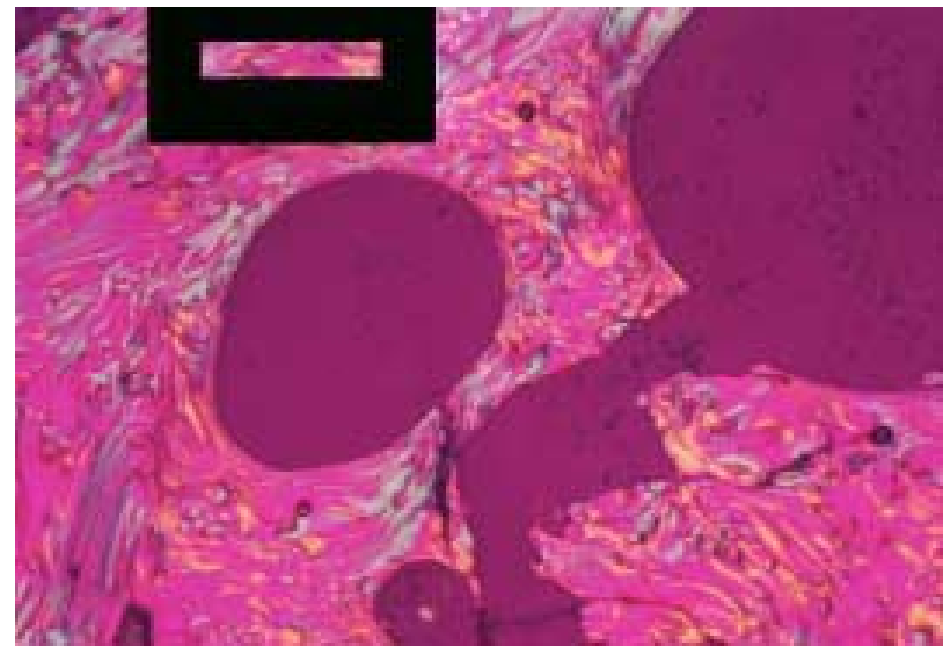

Figure B.89:

BCP-411, Heptane Insoluble and Toluene Soluble with Reaction conditions of:

Solvent: V-1074 only, $410{ }^{\circ} \mathrm{C}$ 1000 psig $97 \% \mathrm{H}_{2} / 3 \% \mathrm{H}_{2} \mathrm{~S}$ 


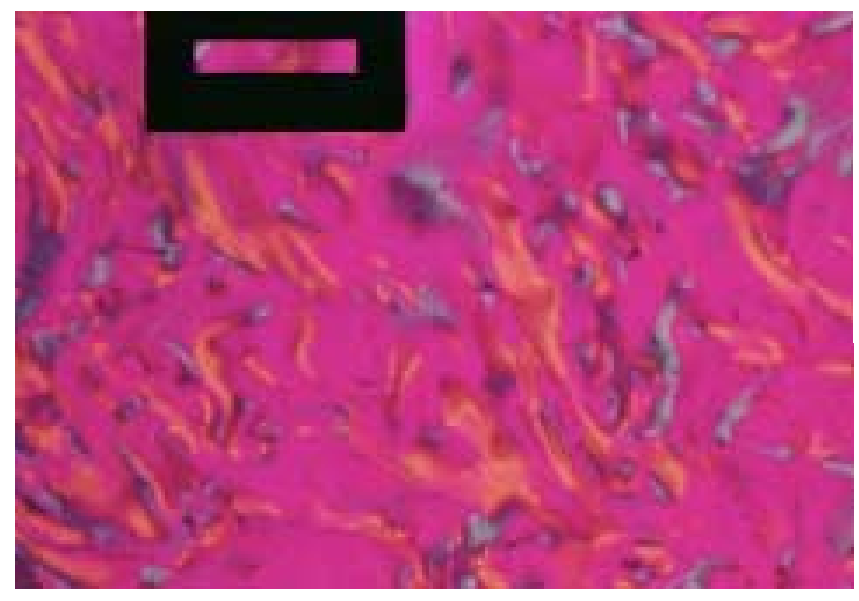

Figure B.90:

Coal-derived reaction solvent

V-1074

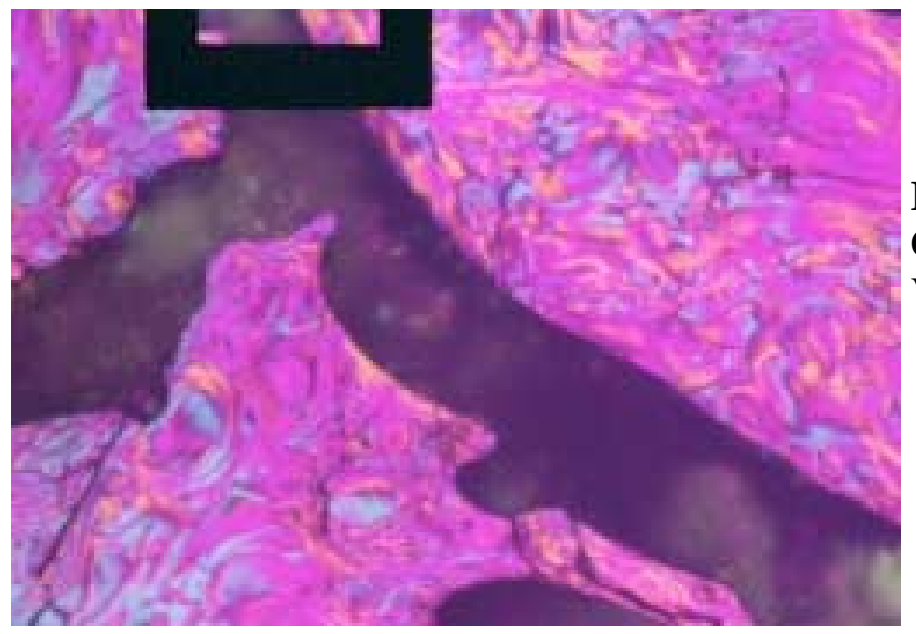

Figure B.91:

Coal-derived reaction Solvent V-1074 toluene soluble 


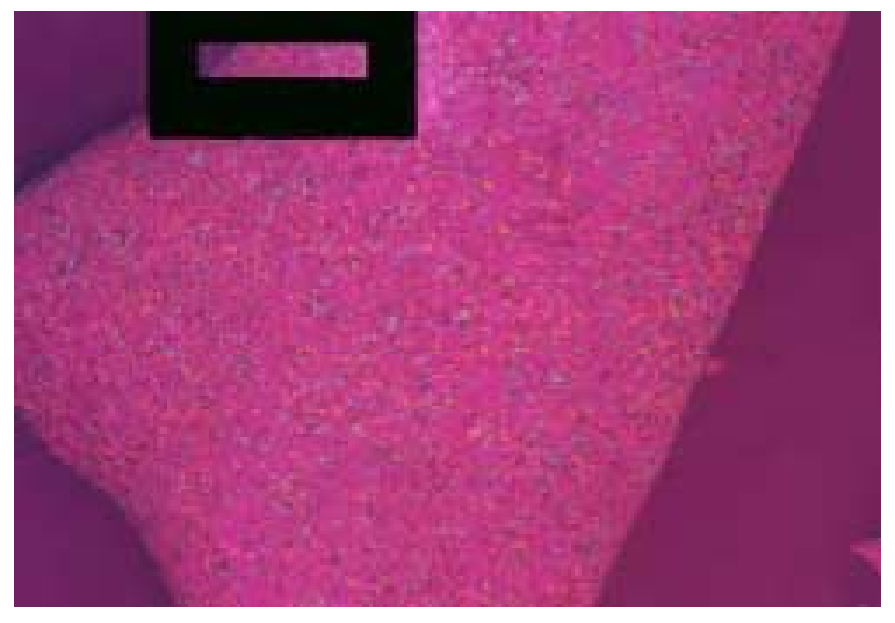

Figure B.92:

Petroleum-derived reaction solvent Hondo

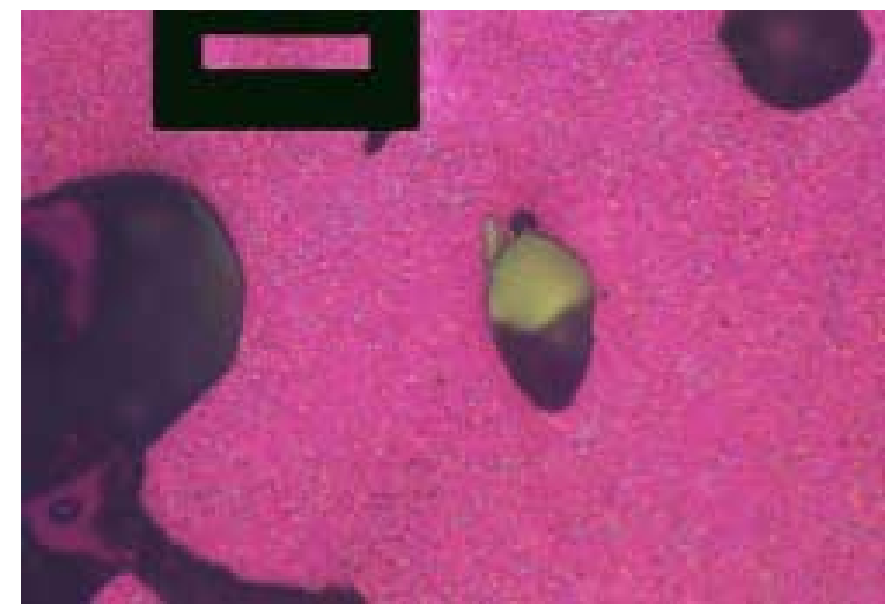

\section{Figure B.93:}

Petroleum-derived reaction solvent Hondo toluene soluble 


\section{Appendix C}

\section{Raw Data}

The results presented here are those obtained in WVU for all the runs. The slashed boxes were runs that were unable to complete. The asterisk $\left(^{*}\right)$ means that those samples did not have a softening point that could be determined by the equipment available or were liquid at room temperature. The letters ND (not determined) means that either there were not enough sample to do the experiment or that fraction was not used for the respective extraction. The @ symbols represent the samples with the swelling behavior when measuring the softening point.

In an effort to gain some idea of how much coal is converted, the overall reaction yield (coal conversion) based on coal alone was determined. The overall reaction yield (i.e., conversion of coal to THF-solubles) here is calculated by subtracting the amount of THF-insoluble (residue fraction) from the amount of raw coal introduced as feed and dividing this amount by the coal fed to the reactor. This is done assuming that the residue fraction comes only from unconverted coal. The relative experimental error for the overall reaction yield is $+/-2.5 \%$. 
Table C.1: Carbon Products from Coal Raw Data

\begin{tabular}{|c|c|c|c|c|c|c|c|c|}
\hline Reactor & Sample & $\begin{array}{l}\text { Coking Value } \\
\text { WVU Method }\end{array}$ & $\begin{array}{l}\text { Coking Value } \\
\text { ASTM Method }\end{array}$ & $\begin{array}{c}\text { Ash } \\
\text { Content }\end{array}$ & $\begin{array}{c}\text { Toluene } \\
\text { Solubility }\end{array}$ & $\begin{array}{c}\text { NMP } \\
\text { Solubility }\end{array}$ & $\begin{array}{c}\text { Softening } \\
\text { Point }\end{array}$ & $\begin{array}{l}\text { Overall Coal } \\
\text { Conversion }\end{array}$ \\
\hline \multirow{7}{*}{$\begin{array}{c}\text { BCP- } 393 \\
\text { V-1074 } \\
1500 \text { psig } \\
390^{\circ} \mathrm{C}\end{array}$} & THF Insoluble & $84.20 \%$ & $77.90 \%$ & $31.15 \%$ & ND & & $*$ & coal-alone basis \\
\hline & Heptane Insol & $37.20 \%$ & $43.10 \%$ & $0.29 \%$ & $53.4 \%$ Sol & ND & $196.1^{\circ} \mathrm{C}$ & \multirow{6}{*}{$75.00 \%$} \\
\hline & Heptane Sol & $2.60 \%$ & $1.93 \%$ & $0.16 \%$ & ND & ND & $*$ & \\
\hline & Hept Ins/Tol Ins & $81.00 \%$ & $64.20 \%$ & $0.86 \%$ & $\sim 0 \%$ & ND & $*$ & \\
\hline & Hept Ins/Tol Sol & $49.50 \%$ & $50.80 \%$ & $0.10 \%$ & $\sim 100 \%$ & ND & $143.2^{\circ} \mathrm{C}$ & \\
\hline & Hep Ins/THF Sol & $53.00 \%$ & ND & $0.22 \%$ & ND & ND & ND & \\
\hline & THF Sol/Tol Ins & ND & $56.90 \%$ & $\mathrm{ND}$ & $\sim 0 \%$ & ND & ND & \\
\hline \multirow{6}{*}{$\begin{array}{c}\text { BCP- } 394 \\
\text { Hondo } \\
1500 \text { psig } \\
390^{\circ} \mathrm{C}\end{array}$} & THF Insoluble & $85.90 \%$ & $71.70 \%$ & $17.80 \%$ & ND & & $*$ & \multirow{6}{*}{$71.50 \%$} \\
\hline & Heptane Insol & $26.60 \%$ & $50.80 \%$ & $0.26 \%$ & $72.0 \%$ Sol & & $>200^{\circ} \mathrm{C}$ & \\
\hline & Heptane Sol & $6.70 \%$ & $4.38 \%$ & $0.05 \%$ & ND & & $*$ & \\
\hline & Hept Ins/Tol Ins & $80.70 \%$ & $76.20 \%$ & $1.50 \%$ & $\sim 0 \%$ & & $*$ & \\
\hline & Hept Ins/Tol Sol & $29.20 \%$ & $47.30 \%$ & $0.07 \%$ & $\sim 100 \%$ & & $175.9^{\circ} \mathrm{C}$ & \\
\hline & THF Sol/Tol Ins & ND & $56.90 \%$ & $\mathrm{ND}$ & $\sim 0 \%$ & & ND & \\
\hline \multirow{5}{*}{$\begin{array}{c}\text { BCP- } 394 \\
\text { 2nd ext } \\
\text { Hondo } \\
1500 \text { psig } \\
390^{\circ} \mathrm{C} \\
\end{array}$} & THF Insoluble & $83.80 \%$ & $77.70 \%$ & $18.40 \%$ & ND & & $*$ & \multirow{5}{*}{$86.90 \%$} \\
\hline & Heptane Insol & $68.40 \%$ & $62.10 \%$ & $0.33 \%$ & $61.5 \%$ Sol & & $>200^{\circ} \mathrm{C}$ & \\
\hline & Heptane Sol & $14.10 \%$ & $10.00 \%$ & $0.18 \%$ & ND & & $*$ & \\
\hline & Hept Ins/Tol Ins & $77.40 \%$ & $75.30 \%$ & $0.98 \%$ & $\sim 0 \%$ & & * & \\
\hline & Hept Ins/Tol Sol & $45.45 \%$ & $52.65 \%$ & $0.03 \%$ & $\sim 100 \%$ & & $>200^{\circ} \mathrm{C}$ & \\
\hline \multirow{5}{*}{$\begin{array}{c}\text { BCP- } 395 \\
\text { V-1074 } \\
1500 \text { psig } \\
350^{\circ} \mathrm{C}\end{array}$} & THF Insoluble & $79.80 \%$ & $76.00 \%$ & $15.60 \%$ & ND & & $*$ & \multirow{5}{*}{$41.80 \%$} \\
\hline & Heptane Insol & $60.20 \%$ & $61.90 \%$ & $0.17 \%$ & $22.8 \%$ Sol & & $>200^{\circ} \mathrm{C}$ & \\
\hline & Heptane Sol & $3.98 \%$ & $2.35 \%$ & $0.19 \%$ & ND & & $*$ & \\
\hline & Hept Ins/Tol Ins & $75.60 \%$ & $62.90 \%$ & $0.24 \%$ & $\sim 0 \%$ & & $>200^{\circ} \mathrm{C}$ & \\
\hline & Hept Ins/Tol Sol & $46.55 \%$ & $41.70 \%$ & $0.30 \%$ & $\sim 100 \%$ & & $144.1^{\circ} \mathrm{C}$ & \\
\hline
\end{tabular}


Table C.1: Carbon Products from Coal Raw Data (cont.)

\begin{tabular}{|c|c|c|c|c|c|c|c|c|}
\hline Reactor & Sample & $\begin{array}{l}\text { Coking Value } \\
\text { WVU Method }\end{array}$ & $\begin{array}{l}\text { Coking Value } \\
\text { ASTM Method }\end{array}$ & $\begin{array}{c}\text { Ash } \\
\text { Content }\end{array}$ & $\begin{array}{c}\text { Toluene } \\
\text { Solubility }\end{array}$ & $\begin{array}{c}\text { NMP } \\
\text { Solubility } \\
\end{array}$ & $\begin{array}{c}\text { Softening } \\
\text { Point }\end{array}$ & \multirow{2}{*}{$\begin{array}{c}\text { Overall Coal } \\
\text { Conversion } \\
\text { coal-alone basis }\end{array}$} \\
\hline \multirow{5}{*}{$\begin{array}{c}\text { BCP- } 396 \\
\text { Hondo } \\
1500 \text { psig } \\
350^{\circ} \mathrm{C} \\
\end{array}$} & THF Insoluble & $75.00 \%$ & $70.70 \%$ & $10.80 \%$ & ND & & $*$ & \\
\hline & Heptane Insol & $25.50 \%$ & $48.50 \%$ & $0.26 \%$ & $77.4 \%$ Sol & & $>200^{\circ} \mathrm{C}$ & \multirow{4}{*}{$20.90 \%$} \\
\hline & Heptane Sol & $9.60 \%$ & $7.46 \%$ & $0.06 \%$ & ND & & $*$ & \\
\hline & Hept Ins/Tol Ins & $70.30 \%$ & $61.30 \%$ & $1.78 \%$ & $\sim 0 \%$ & & $*$ & \\
\hline & Hept Ins/Tol Sol & $46.70 \%$ & $50.70 \%$ & $0.14 \%$ & $\sim 100 \%$ & & $>200^{\circ} \mathrm{C}$ & \\
\hline \multirow{5}{*}{$\begin{array}{c}\text { BCP- } 397 \\
\text { V-1074 } \\
1000 \text { psig } \\
350{ }^{\circ} \mathrm{C} \\
\end{array}$} & THF Insoluble & $75.70 \%$ & $71.40 \%$ & $13.70 \%$ & $\mathrm{ND}$ & & $*$ & \multirow{5}{*}{$36.80 \%$} \\
\hline & Heptane Insol & $48.95 \%$ & $47.00 \%$ & $0.11 \%$ & $51.6 \%$ Sol & & $>200{ }^{\circ} \mathrm{C}$ & \\
\hline & Heptane Sol & $11.00 \%$ & $2.93 \%$ & $0.02 \%$ & ND & & $*$ & \\
\hline & Hept Ins/Tol Ins & $77.50 \%$ & $71.10 \%$ & $0.75 \%$ & $\sim 0 \%$ & & $*$ & \\
\hline & Hept Ins/Tol Sol & $46.40 \%$ & $38.20 \%$ & $0.03 \%$ & $\sim 100 \%$ & & $157.8^{\circ} \mathrm{C}$ & \\
\hline \multirow{7}{*}{$\begin{array}{c}\text { BCP- } 398 \\
\text { Hondo } \\
1000 \text { psig } \\
350^{\circ} \mathrm{C}\end{array}$} & THF Insoluble & $73.70 \%$ & $70.70 \%$ & $9.92 \%$ & ND & $78.00 \%$ & $*$ & \multirow{7}{*}{$14.10 \%$} \\
\hline & Heptane Insol & $38.75 \%$ & $48.90 \%$ & $0.29 \%$ & $97.3 \%$ Sol & ND & $>200{ }^{\circ} \mathrm{C}$ & \\
\hline & Heptane Sol & $11.20 \%$ & $9.05 \%$ & $0.03 \%$ & ND & ND & $*$ & \\
\hline & Hept Ins/Tol Ins & ND & $\mathrm{ND}$ & ND & $\sim 0 \%$ & ND & ND & \\
\hline & Hept Ins/Tol Sol & $42.30 \%$ & $52.40 \%$ & $0.19 \%$ & $\sim 100 \%$ & $\mathrm{ND}$ & $>200^{\circ} \mathrm{C}$ & \\
\hline & THF Ins/NMP Ins. & $78.80 \%$ & $79.00 \%$ & $11.70 \%$ & ND & $\sim 0 \%$ & $*$ & \\
\hline & THF Ins/NMP Sol & $52.30 \%$ & $47.40 \%$ & $0.65 \%$ & ND & $\sim 100 \%$ & $>200^{\circ} \mathrm{C}$ & \\
\hline \multirow{7}{*}{$\begin{array}{c}\text { BCP- } 399 \\
\text { V-1074 } \\
1000 \text { psig } \\
390^{\circ} \mathrm{C}\end{array}$} & THF Insoluble & $88.10 \%$ & $72.10 \%$ & $30.47 \%$ & ND & & $*$ & \multirow{7}{*}{$70.10 \%$} \\
\hline & Heptane Insol & $44.90 \%$ & $34.50 \%$ & $0.22 \%$ & $71.4 \%$ Sol & ND & $131.5^{\circ} \mathrm{C}$ & \\
\hline & Heptane Sol & $3.28 \%$ & $2.82 \%$ & $0.02 \%$ & ND & ND & $*$ & \\
\hline & Hept Ins/Tol Ins & $79.60 \%$ & $74.80 \%$ & $0.94 \%$ & $\sim 0 \%$ & ND & $*$ & \\
\hline & Hept Ins/Tol Sol & $38.10 \%$ & $31.50 \%$ & $0.07 \%$ & $\sim 100 \%$ & ND & $114.7^{\circ} \mathrm{C}$ & \\
\hline & THF Ins/NMP Ins. & $85.60 \%$ & $86.70 \%$ & $49.10 \%$ & ND & $\sim 0 \%$ & $*$ & \\
\hline & THF Ins/NMP Sol & $54.40 \%$ & $51.30 \%$ & $0.98 \%$ & ND & $\sim 100 \%$ & $<200^{\circ} \mathrm{C}$ & \\
\hline
\end{tabular}


Table C.1: Carbon Products from Coal Raw Data (cont.)

\begin{tabular}{|c|c|c|c|c|c|c|c|c|}
\hline Reactor & Sample & $\begin{array}{l}\text { Coking Value } \\
\text { WVU Method }\end{array}$ & $\begin{array}{c}\text { Coking Value } \\
\text { ASTM Method }\end{array}$ & $\begin{array}{c}\text { Ash } \\
\text { Content }\end{array}$ & $\begin{array}{c}\text { Toluene } \\
\text { Solubility }\end{array}$ & $\begin{array}{c}\text { NMP } \\
\text { Solubility } \\
\end{array}$ & $\begin{array}{c}\text { Softening } \\
\text { Point }\end{array}$ & $\begin{array}{l}\text { Overall Coal } \\
\text { Conversion }\end{array}$ \\
\hline \multirow{5}{*}{$\begin{array}{c}\text { BCP- } 400 \\
\text { V-1074 } \\
1000 \text { psig } \\
425^{\circ} \mathrm{C} \\
\end{array}$} & THF Insoluble & $91.60 \%$ & $86.90 \%$ & $27.15 \%$ & $\mathrm{ND}$ & & $*$ & coal-alone basis \\
\hline & Heptane Insol & $46.70 \%$ & $41.60 \%$ & $0.19 \%$ & $78.1 \%$ Sol & & $102.8^{\circ} \mathrm{C}$ & \multirow{4}{*}{$67.70 \%$} \\
\hline & Heptane Sol & $4.27 \%$ & $1.95 \%$ & $0.05 \%$ & ND & & $*$ & \\
\hline & Hept Ins/Tol Ins & $87.50 \%$ & $88.20 \%$ & $1.05 \%$ & $\sim 0 \%$ & & $*$ & \\
\hline & Hept Ins/Tol Sol & $44.40 \%$ & $38.30 \%$ & $0.02 \%$ & $\sim 100 \%$ & & $104.9^{\circ} \mathrm{C}$ & \\
\hline \multirow{5}{*}{$\begin{array}{c}\text { BCP- } 401 \\
\text { V-1074 } \\
1500 \text { psig } \\
425^{\circ} \mathrm{C} \\
\end{array}$} & THF Insoluble & $91.90 \%$ & $86.40 \%$ & $33.10 \%$ & ND & & $*$ & \multirow{5}{*}{$73.40 \%$} \\
\hline & Heptane Insol & $48.80 \%$ & $44.60 \%$ & $0.19 \%$ & $68.5 \%$ Sol & & $146.6^{\circ} \mathrm{C}$ & \\
\hline & Heptane Sol & $3.29 \%$ & $1.78 \%$ & $0.36 \%$ & ND & & $*$ & \\
\hline & Hept Ins/Tol Ins & $84.20 \%$ & $82.40 \%$ & $1.46 \%$ & $\sim 0 \%$ & & $*$ & \\
\hline & Hept Ins/Tol Sol & $49.40 \%$ & $42.60 \%$ & $0.02 \%$ & $\sim 100 \%$ & & $139.5^{\circ} \mathrm{C}$ & \\
\hline \multirow{6}{*}{ Solvent } & V-1074 & $4.71 \%$ & $1.55 \%$ & $0.05 \%$ & $91.8 \%$ Sol & & $*$ & \multirow{3}{*}{ N/A } \\
\hline & Toluene Insoluble & ND & ND & ND & $\sim 0 \%$ & & $*$ & \\
\hline & Toluene Soluble & $8.43 \%$ & $4.76 \%$ & $0.01 \%$ & $\sim 100 \%$ & & $*$ & \\
\hline & Hondo & $19.60 \%$ & $16.70 \%$ & $0.09 \%$ & $96.7 \%$ Sol & & $*$ & \multirow{3}{*}{ N/A } \\
\hline & Toluene Insoluble & ND & ND & ND & $\sim 0 \%$ & & $*$ & \\
\hline & Toluene Soluble & $21.40 \%$ & $19.10 \%$ & $0.15 \%$ & $\sim 100 \%$ & & $*$ & \\
\hline \multirow{5}{*}{$\begin{array}{c}\text { BCP-403 } \\
\text { V-1074 } \\
1000 \mathrm{psig} \\
425^{\circ} \mathrm{C} \\
\end{array}$} & THF Insoluble & $89.70 \%$ & $85.00 \%$ & $27.70 \%$ & $\mathrm{ND}$ & & $*$ & \multirow{5}{*}{$69.40 \%$} \\
\hline & Heptane Insol & $43.40 \%$ & $38.30 \%$ & $0.06 \%$ & $75.4 \%$ Sol & & $121.2^{\circ} \mathrm{C}$ & \\
\hline & Heptane Sol & $4.99 \%$ & $1.93 \%$ & $5.21 \%$ & ND & & $*$ & \\
\hline & Hept Ins/Tol Ins & $81.90 \%$ & $83.00 \%$ & $4.39 \%$ & $\sim 0 \%$ & & $*$ & \\
\hline & Hept Ins/Tol Sol & $52.40 \%$ & $50.40 \%$ & $0.02 \%$ & $\sim 100 \%$ & & $142.3^{\circ} \mathrm{C}$ & \\
\hline \multirow{5}{*}{$\begin{array}{c}\text { BCP- } 404 \\
\text { V-1074 } \\
500 \text { psig } \\
425^{\circ} \mathrm{C} \\
\end{array}$} & THF Insoluble & $86.20 \%$ & $83.80 \%$ & $17.90 \%$ & ND & & $*$ & \multirow{5}{*}{$58.70 \%$} \\
\hline & Heptane Insol & $47.45 \%$ & $43.00 \%$ & $0.07 \%$ & $72.2 \%$ Sol & & $121.9^{\circ} \mathrm{C}$ & \\
\hline & Heptane Sol & $3.99 \%$ & $2.82 \%$ & $0.07 \%$ & ND & & * & \\
\hline & Hept Ins/Tol Ins & $88.00 \%$ & $81.30 \%$ & $0.64 \%$ & $\sim 0 \%$ & & $*$ & \\
\hline & Hept Ins/Tol Sol & $47.30 \%$ & $52.80 \%$ & $0.05 \%$ & $\sim 100 \%$ & & $139.4^{\circ} \mathrm{C}$ & \\
\hline
\end{tabular}


Table C.1: Carbon Products from Coal Raw Data (cont)

\begin{tabular}{|c|c|c|c|c|c|c|c|c|}
\hline Reactor & Sample & $\begin{array}{l}\text { Coking Value } \\
\text { WVU Method }\end{array}$ & $\begin{array}{l}\text { Coking Value } \\
\text { ASTM Method }\end{array}$ & $\begin{array}{c}\text { Ash } \\
\text { Content } \\
\end{array}$ & $\begin{array}{c}\text { Toluene } \\
\text { Solubility }\end{array}$ & $\begin{array}{c}\text { NMP } \\
\text { Solubility } \\
\end{array}$ & $\begin{array}{c}\text { Softening } \\
\text { Point }\end{array}$ & $\begin{array}{l}\text { Overall Coal } \\
\text { Conversion }\end{array}$ \\
\hline \multirow{5}{*}{$\begin{array}{l}\text { BCP- } 405 \\
\text { Hondo } \\
1500 \mathrm{psig} \\
425^{\circ} \mathrm{C} \\
\end{array}$} & THF Insoluble & $86.95 \%$ & $87.70 \%$ & $10.20 \%$ & ND & & $*$ & coal-alone basis \\
\hline & Heptane Insol & $61.45 \%$ & $64.10 \%$ & $0.09 \%$ & $73.4 \%$ Sol & & $>200^{\circ} \mathrm{C}$ & \multirow{4}{*}{$18.40 \%$} \\
\hline & Heptane Sol & $6.21 \%$ & $4.78 \%$ & $0.08 \%$ & ND & & $*$ & \\
\hline & Hept Ins/Tol Ins & $87.20 \%$ & $90.20 \%$ & $1.15 \%$ & $\sim 0 \%$ & & $*$ & \\
\hline & Hept Ins/Tol Sol & $36.10 \%$ & $65.10 \%$ & $0.04 \%$ & $\sim 100 \%$ & & $195.9^{\circ} \mathrm{C}$ & \\
\hline \multirow{5}{*}{$\begin{array}{c}\text { BCP-406 } \\
\text { V-1074 } \\
1500 \text { psig } \\
390{ }^{\circ} \mathrm{C} \\
3 \% \mathrm{H}_{2} \mathrm{~S} \\
\end{array}$} & THF Insoluble & $92.00 \%$ & $83.30 \%$ & $33.40 \%$ & ND & & $*$ & \multirow{5}{*}{$71.80 \%$} \\
\hline & Heptane Insol & $46.60 \%$ & $42.60 \%$ & $0.11 \%$ & $57.5 \% \mathrm{Sol}$ & & $163.3^{\circ} \mathrm{C}$ & \\
\hline & Heptane Sol & $2.89 \%$ & $1.64 \%$ & $0.22 \%$ & ND & & $*$ & \\
\hline & Hept Ins/Tol Ins & $83.20 \%$ & $81.60 \%$ & $0.52 \%$ & $\sim 0 \%$ & & $*$ & \\
\hline & Hept Ins/Tol Sol & $49.90 \%$ & $41.20 \%$ & $0.03 \%$ & $\sim 100 \%$ & & @ & \\
\hline \multirow{5}{*}{$\begin{array}{c}\text { BCP- } 407 \\
\text { V-1074 } \\
1500 \text { psig } \\
410{ }^{\circ} \mathrm{C} \\
3 \% \mathrm{H}_{2} \mathrm{~S} \\
\end{array}$} & THF Insoluble & $95.20 \%$ & $92.40 \%$ & $40.60 \%$ & ND & & $*$ & \multirow{5}{*}{$76.00 \%$} \\
\hline & Heptane Insol & $50.70 \%$ & $45.00 \%$ & $0.11 \%$ & $61.8 \%$ Sol & & $144.4^{\circ} \mathrm{C}$ & \\
\hline & Heptane Sol & $3.18 \%$ & $1.96 \%$ & $0.07 \%$ & ND & & $*$ & \\
\hline & Hept Ins/Tol Ins & $81.90 \%$ & $80.30 \%$ & $1.52 \%$ & $\sim 0 \%$ & & ND & \\
\hline & Hept Ins/Tol Sol & $51.00 \%$ & $46.90 \%$ & $0.01 \%$ & $\sim 100 \%$ & & $152.5^{\circ} \mathrm{C}$ & \\
\hline \multirow{5}{*}{$\begin{array}{c}\text { BCP- } 408 \\
\text { V-1074 } \\
1000 \text { psig } \\
410^{\circ} \mathrm{C} \\
3 \% \mathrm{H}_{2} \mathrm{~S} \\
\end{array}$} & THF Insoluble & $93.90 \%$ & $88.20 \%$ & $30.80 \%$ & ND & & $*$ & \multirow{5}{*}{$86.80 \%$} \\
\hline & Heptane Insol & $48.60 \%$ & $37.70 \%$ & $0.10 \%$ & $68.2 \% \mathrm{Sol}$ & & $140.5^{\circ} \mathrm{C}$ & \\
\hline & Heptane Sol & $2.28 \%$ & $1.31 \%$ & $0.05 \%$ & ND & & $*$ & \\
\hline & Hept Ins/Tol Ins & $77.20 \%$ & $75.30 \%$ & $0.51 \%$ & $\sim 0 \%$ & & $*$ & \\
\hline & Hept Ins/Tol Sol & $46.70 \%$ & $43.40 \%$ & $0.03 \%$ & $\sim 100 \%$ & & $144.2^{\circ} \mathrm{C}$ & \\
\hline \multirow{5}{*}{$\begin{array}{c}\text { BCP- } 409 \\
\text { V-1074 } \\
500 \text { psig } \\
410{ }^{\circ} \mathrm{C} \\
3 \% \mathrm{H}_{2} \mathrm{~S} \\
\end{array}$} & THF Insoluble & $92.40 \%$ & $89.20 \%$ & $27.80 \%$ & ND & & * & \multirow{5}{*}{$68.50 \%$} \\
\hline & Heptane Insol & $44.30 \%$ & $40.20 \%$ & $0.03 \%$ & $71.7 \%$ Sol & & $111.2^{\circ} \mathrm{C}$ & \\
\hline & Heptane Sol & $3.82 \%$ & $2.15 \%$ & $0.01 \%$ & ND & & * & \\
\hline & Hept Ins/Tol Ins & $80.50 \%$ & $80.80 \%$ & $2.10 \%$ & $\sim 0 \%$ & & $*$ & \\
\hline & Hept Ins/Tol Sol & $50.20 \%$ & $40.80 \%$ & $0.01 \%$ & $\sim 100 \%$ & & $@$ & \\
\hline
\end{tabular}


Table C.1: Carbon Products from Coal Raw Data (cont)

\begin{tabular}{|c|c|c|c|c|c|c|c|c|}
\hline Reactor & Sample & $\begin{array}{l}\text { Coking Value } \\
\text { WVU Method }\end{array}$ & $\begin{array}{c}\text { Coking Value } \\
\text { ASTM Method }\end{array}$ & $\begin{array}{c}\text { Ash } \\
\text { Content } \\
\end{array}$ & $\begin{array}{c}\text { Toluene } \\
\text { Solubility }\end{array}$ & $\begin{array}{c}\text { NMP } \\
\text { Solubility } \\
\end{array}$ & $\begin{array}{c}\text { Softening } \\
\text { Point }\end{array}$ & \multirow{2}{*}{$\begin{array}{c}\text { Overall Coal } \\
\text { Conversion } \\
\text { coal-alone basis }\end{array}$} \\
\hline \multirow{5}{*}{$\begin{array}{c}\text { BCP- } 410 \\
\text { V-1074 } \\
1000 \text { psig } \\
390{ }^{\circ} \mathrm{C} \\
3 \% \mathrm{H}_{2} \mathrm{~S}\end{array}$} & THF Insoluble & $89.40 \%$ & $76.60 \%$ & $36.60 \%$ & ND & & $*$ & \\
\hline & Heptane Insol & $52.80 \%$ & $47.00 \%$ & $0.20 \%$ & $64.6 \%$ Sol & & $179.7^{\circ} \mathrm{C}$ & \multirow{4}{*}{$69.00 \%$} \\
\hline & Heptane Sol & $2.22 \%$ & $1.20 \%$ & $0.02 \%$ & ND & & $*$ & \\
\hline & Hept Ins/Tol Ins & $81.40 \%$ & $78.50 \%$ & $0.82 \%$ & $\sim 0 \%$ & & $*$ & \\
\hline & Hept Ins/Tol Sol & $45.40 \%$ & $36.10 \%$ & $0.02 \%$ & $\sim 100 \%$ & & ${ }^{\circ} \mathrm{C}$ & \\
\hline \multirow{5}{*}{$\begin{array}{c}\text { BCP- } 411 \\
\text { V-1074 Only } \\
1000 \text { psig } \\
410{ }^{\circ} \mathrm{C} \\
3 \% \mathrm{H}_{2} \mathrm{~S}\end{array}$} & THF Insoluble & $83.60 \%$ & $80.60 \%$ & $42.50 \%$ & ND & & $*$ & \multirow{5}{*}{ N/A } \\
\hline & Heptane Insol & $32.50 \%$ & $20.20 \%$ & $0.18 \%$ & $85.8 \%$ Sol & & $78.4^{\circ} \mathrm{C}$ & \\
\hline & Heptane Sol & $1.05 \%$ & $0.55 \%$ & $0.01 \%$ & ND & & $*$ & \\
\hline & Hept Ins/Tol Ins & $84.70 \%$ & $75.10 \%$ & $9.23 \%$ & $\sim 0 \%$ & & $*$ & \\
\hline & Hept Ins/Tol Sol & $37.40 \%$ & $22.30 \%$ & $0.07 \%$ & $\sim 100 \%$ & & ${ }^{\circ} \mathrm{C}$ & \\
\hline
\end{tabular}




\section{Appendix D.}

\section{Gas Products}

The data presented here was obtained from DOE/NETL raw data. The amount of gas present was calculated from the gas analysis preformed for each run through gas chromatography $(\mathrm{GC})$. The $\mathrm{GC}$ results were presented in volumetric percent which for gases equals mole percent. These were then converted into fractions (i.e, 0.5) and each species was multiplied by the total moles presented in each run. The total moles were calculated from the flow rate of each run which was $\sim 3-4$ SCFH. Since the reactions were performed in one hour the volume of the total gases was $~ 3-4$ SCF.

The total moles for the tail gas was converted to moles using the ideal gas law at the STP conditions, while for the flash gas it was calculated using the reactor volume and reaction temperature and pressure. These gave us then the total moles of each species, which multiplied by its molecular weight, gave us the amount of each species present in grams. 
Table D.1: Gas Products Present in Reaction Runs

\begin{tabular}{|c|c|c|c|}
\hline Reactor & Species & $\begin{array}{c}\text { Gas Product }(\mathrm{g}) \\
\text { Tail Gas }\end{array}$ & $\begin{array}{l}\text { Gas Product }(\mathrm{g}) \\
\text { Flash Gas }\end{array}$ \\
\hline \multirow{9}{*}{$\begin{array}{c}\text { BCP-393 } \\
\text { Run } 1\end{array}$} & $\mathrm{He}$ & 0.0317 & 0.0109 \\
\hline & $\mathrm{H} 2$ & 9.8132 & 3.6886 \\
\hline & $\mathrm{N} 2$ & 0.8310 & 1.5074 \\
\hline & $\mathrm{CH} 4$ & 0.2947 & 0.1531 \\
\hline & $\mathrm{CO} 2$ & 0.2251 & 0.6603 \\
\hline & $\mathrm{C} 2 \mathrm{H} 6$ & 0.2303 & 0.1125 \\
\hline & $\mathrm{H} 2 \mathrm{~S}$ & 0.1914 & 0.0000 \\
\hline & C3H8 & 0.1576 & 0.0825 \\
\hline & $\mathrm{O} 2$ & 0.0000 & 0.0300 \\
\hline \multirow{10}{*}{$\begin{array}{c}\text { BCP-394 } \\
\text { Run } 2\end{array}$} & $\mathrm{He}$ & 0.0246 & 0.0060 \\
\hline & $\mathrm{H} 2$ & 8.7379 & 3.6132 \\
\hline & $\mathrm{O} 2$ & 0.1814 & 0.0120 \\
\hline & $\mathrm{N} 2$ & 7.9341 & 0.6723 \\
\hline & $\mathrm{CH} 4$ & 0.3249 & 0.2491 \\
\hline & $\mathrm{CO} 2$ & 0.2078 & 0.0495 \\
\hline & $\mathrm{C} 2 \mathrm{H} 6$ & 0.2267 & 0.1688 \\
\hline & $\mathrm{H} 2 \mathrm{~S}$ & 0.6583 & 0.5931 \\
\hline & C3H8 & 0.2494 & 0.1321 \\
\hline & NC4H10 & 0.0000 & 0.0326 \\
\hline \multirow{5}{*}{$\begin{array}{c}\text { BCP-395 } \\
\text { Run } 3\end{array}$} & $\mathrm{H} 2$ & 9.4515 & 3.8419 \\
\hline & $\mathrm{O} 2$ & 0.1770 & 0.0447 \\
\hline & $\mathrm{N} 2$ & 8.0817 & 2.0457 \\
\hline & $\overline{\mathrm{CO} 2}$ & 0.1106 & 0.0351 \\
\hline & $\mathrm{H} 2 \mathrm{~S}$ & 0.1881 & 0.0000 \\
\hline \multirow{5}{*}{$\begin{array}{c}\text { BCP-396 } \\
\text { Run } 4\end{array}$} & $\mathrm{H} 2$ & 9.9664 & 3.0550 \\
\hline & $\mathrm{O} 2$ & 0.0000 & 0.0319 \\
\hline & $\mathrm{N} 2$ & 0.9997 & 13.0289 \\
\hline & $\overline{\mathrm{CO} 2}$ & 0.0664 & 0.0264 \\
\hline & $\mathrm{H} 2 \mathrm{~S}$ & 0.2735 & 0.0611 \\
\hline \multirow{3}{*}{$\begin{array}{c}\text { BCP-397 } \\
\text { Run } 5\end{array}$} & $\mathrm{H} 2$ & 6.1601 & 2.5432 \\
\hline & $\mathrm{O} 2$ & 0.2807 & 0.3790 \\
\hline & $\mathrm{N} 2$ & 1.2458 & 1.3303 \\
\hline \multirow{5}{*}{$\begin{array}{c}\text { BCP-398 } \\
\text { Run } 6\end{array}$} & $\overline{\mathrm{H} 2}$ & 5.7118 & Not Available \\
\hline & $\mathrm{O} 2$ & 1.6309 & Not Available \\
\hline & $\mathrm{N} 2$ & 5.8225 & Not Available \\
\hline & $\mathrm{CO} 2$ & 0.7752 & Not Available \\
\hline & $\mathrm{H} 2 \mathrm{~S}$ & 0.4599 & Not Available \\
\hline
\end{tabular}


Table D.1: Gas Products Present in Reaction Runs (cont.)

\begin{tabular}{|c|c|c|c|}
\hline Reactor & Species & $\begin{array}{c}\text { Gas Product }(\mathrm{g}) \\
\text { Tail Gas }\end{array}$ & $\begin{array}{l}\text { Gas Product }(\mathrm{g}) \\
\text { Flash Gas }\end{array}$ \\
\hline \multirow{7}{*}{$\begin{array}{c}\text { BCP-399 } \\
\text { Run } 7\end{array}$} & $\mathrm{H} 2$ & 8.2701 & 2.3483 \\
\hline & $\mathrm{O} 2$ & 5.3312 & 0.3682 \\
\hline & $\mathrm{N} 2$ & 18.2262 & 1.3831 \\
\hline & $\mathrm{CH} 4$ & 0.2873 & 0.1361 \\
\hline & $\mathrm{CO} 2$ & 0.3292 & 0.0825 \\
\hline & $\mathrm{C} 2 \mathrm{H} 6$ & 0.2095 & 0.1013 \\
\hline & $\mathrm{C} 2 \mathrm{H} 8$ & 0.1536 & 0.0715 \\
\hline \multirow{10}{*}{$\begin{array}{c}\text { BCP-400 } \\
\text { Run } 8\end{array}$} & $\mathrm{H} 2$ & 8.3961 & 1.5737 \\
\hline & $\mathrm{O} 2$ & 4.4296 & 2.4023 \\
\hline & N2 & 15.6766 & 8.1353 \\
\hline & $\mathrm{CH} 4$ & 2.2230 & 0.3079 \\
\hline & $\mathrm{CO} 2$ & 0.3396 & 0.0784 \\
\hline & $\mathrm{C} 2 \mathrm{H} 6$ & 1.5901 & 0.2281 \\
\hline & $\mathrm{H} 2 \mathrm{~S}$ & 0.1575 & 0.0283 \\
\hline & C3H8 & 1.4038 & 0.2038 \\
\hline & IC4H10 & 0.1194 & 0.0000 \\
\hline & NC4H10 & 0.6566 & 0.0758 \\
\hline \multirow{10}{*}{$\begin{array}{c}\text { BCP-401 } \\
\text { Run } 9\end{array}$} & $\mathrm{He}$ & 0.0177 & 0.0093 \\
\hline & $\mathrm{H} 2$ & 9.1569 & 3.3608 \\
\hline & $\mathrm{O} 2$ & 1.2713 & 0.0000 \\
\hline & $\mathrm{N} 2$ & 5.1773 & 0.3542 \\
\hline & $\mathrm{CH} 4$ & 0.8161 & 0.7783 \\
\hline & $\overline{\mathrm{CO} 2}$ & 0.3453 & 0.1490 \\
\hline & $\mathrm{C} 2 \mathrm{H} 6$ & 0.5886 & 0.5345 \\
\hline & $\mathrm{H} 2 \mathrm{~S}$ & 0.2335 & 0.0969 \\
\hline & C3H8 & 0.5179 & 0.4625 \\
\hline & NC4H10 & 0.0000 & 0.1860 \\
\hline \multirow{10}{*}{$\begin{array}{c}\text { BCP-403 } \\
\text { Run } 10\end{array}$} & $\mathrm{He}$ & 0.0162 & 0.0233 \\
\hline & $\overline{\mathrm{H} 2}$ & 9.0239 & 2.0683 \\
\hline & $\mathrm{O} 2$ & 1.8802 & 0.0000 \\
\hline & $\mathrm{N} 2$ & 8.5377 & 3.1065 \\
\hline & $\mathrm{CH} 4$ & 1.5965 & 0.3345 \\
\hline & $\mathrm{CO} 2$ & 0.4012 & 0.0470 \\
\hline & $\mathrm{C} 2 \mathrm{H} 6$ & 1.1548 & 0.2352 \\
\hline & $\mathrm{H} 2 \mathrm{~S}$ & 0.2928 & 0.0323 \\
\hline & $\mathrm{C} 3 \mathrm{H} 8$ & 0.9583 & 0.2038 \\
\hline & NC4H10 & 0.4407 & 0.0896 \\
\hline
\end{tabular}


Table D.1: Gas Products Present in Reaction Runs (cont.)

\begin{tabular}{|c|c|c|c|}
\hline Reactor & Species & $\begin{array}{c}\text { Gas Product }(\mathrm{g}) \\
\text { Tail Gas } \\
\end{array}$ & $\begin{array}{l}\text { Gas Product }(\mathrm{g}) \\
\text { Flash Gas }\end{array}$ \\
\hline \multirow{11}{*}{$\begin{array}{c}\text { BCP-404 } \\
\text { Run } 11\end{array}$} & $\mathrm{He}$ & 0.0704 & 0.0416 \\
\hline & $\mathrm{H} 2$ & 9.4033 & 1.0795 \\
\hline & $\mathrm{O} 2$ & 2.5275 & 0.0494 \\
\hline & $\mathrm{N} 2$ & 9.2347 & 0.4640 \\
\hline & $\mathrm{CH} 4$ & 1.7761 & 0.2300 \\
\hline & $\mathrm{CO} 2$ & 0.2583 & 0.0183 \\
\hline & $\mathrm{C} 2 \mathrm{H} 6$ & 1.3609 & 0.1657 \\
\hline & $\mathrm{H} 2 \mathrm{~S}$ & 0.2177 & 0.0141 \\
\hline & C3H6 & 0.0672 & 0.0075 \\
\hline & $\mathrm{C} 3 \mathrm{H} 8$ & 1.1976 & 0.1463 \\
\hline & NC4H10 & 0.6500 & 0.0792 \\
\hline \multirow{11}{*}{$\begin{array}{c}\text { BCP-405 } \\
\text { Run } 12\end{array}$} & $\mathrm{H} 2$ & 9.5616 & 3.1751 \\
\hline & $\mathrm{O} 2$ & 0.0000 & 0.1825 \\
\hline & $\mathrm{N} 2$ & 1.4055 & 0.8232 \\
\hline & $\overline{\mathrm{CH} 4}$ & 1.8111 & 1.2173 \\
\hline & $\mathrm{CO} 2$ & 0.4057 & 0.1490 \\
\hline & $\mathrm{C} 2 \mathrm{H} 6$ & 1.1832 & 0.8499 \\
\hline & $\mathrm{H} 2 \mathrm{~S}$ & 3.3436 & 1.0177 \\
\hline & $\mathrm{C} 3 \mathrm{H} 6$ & 0.0645 & 0.0000 \\
\hline & $\mathrm{C} 3 \mathrm{H} 8$ & 1.0141 & 0.6193 \\
\hline & IC4H10 & 0.0891 & 0.1550 \\
\hline & NC4H10 & 0.6239 & 0.0241 \\
\hline \multirow{10}{*}{$\begin{array}{c}\text { BCP-406 } \\
\text { Run } 13\end{array}$} & $\mathrm{H} 2$ & 8.6558 & 3.4248 \\
\hline & $\mathrm{O} 2$ & 0.8718 & 0.3061 \\
\hline & N2 & 4.5100 & 2.1219 \\
\hline & $\mathrm{CH} 4$ & 0.2753 & 0.1261 \\
\hline & $\mathrm{CO} 2$ & 0.2313 & 0.0495 \\
\hline & $\mathrm{C} 2 \mathrm{H} 6$ & 0.2007 & 0.0957 \\
\hline & $\mathrm{H} 2 \mathrm{~S}$ & 7.6702 & 2.1174 \\
\hline & C3H6 & 0.0602 & 0.0000 \\
\hline & $\mathrm{C} 3 \mathrm{H} 8$ & 0.3155 & 0.1486 \\
\hline & NC4H10 & 0.0000 & 0.0218 \\
\hline \multirow{8}{*}{$\begin{array}{c}\text { BCP-407 } \\
\text { Run } 14\end{array}$} & $\mathrm{H} 2$ & 0.2059 & Not Available \\
\hline & $\mathrm{O} 2$ & 29.9520 & Not Available \\
\hline & N2 & 102.9870 & Not Available \\
\hline & $\mathrm{CH} 4$ & 0.1539 & Not Available \\
\hline & $\mathrm{CO} 2$ & 0.1481 & Not Available \\
\hline & $\mathrm{C} 2 \mathrm{H} 6$ & 0.1010 & Not Available \\
\hline & $\mathrm{H} 2 \mathrm{~S}$ & 2.5021 & Not Available \\
\hline & $\mathrm{C} 3 \mathrm{H} 8$ & 0.1058 & Not Available \\
\hline
\end{tabular}


Table D.1: Gas Products Present in Reaction Runs (cont.)

\begin{tabular}{|c|c|c|c|}
\hline Reactor & Species & $\begin{array}{l}\text { Gas Product (g) } \\
\text { Tail Gas }\end{array}$ & $\begin{array}{c}\text { Gas Product (g) } \\
\text { Flash Gas }\end{array}$ \\
\hline \multirow{8}{*}{$\begin{array}{c}\text { BCP-408 } \\
\text { Run } 15\end{array}$} & $\mathrm{H} 2$ & 0.0019 & 0.5890 \\
\hline & $\mathrm{O} 2$ & 31.3888 & 6.0599 \\
\hline & $\mathrm{N} 2$ & 104.7151 & 18.8882 \\
\hline & $\mathrm{CH} 4$ & 0.0764 & 0.1554 \\
\hline & $\mathrm{CO} 2$ & 0.1260 & 0.0427 \\
\hline & $\mathrm{C} 2 \mathrm{H} 6$ & 0.1289 & 0.1165 \\
\hline & $\mathrm{H} 2 \mathrm{~S}$ & 1.2172 & 1.3042 \\
\hline & $\mathrm{C} 3 \mathrm{H} 8$ & 0.1680 & 0.1068 \\
\hline \multirow{11}{*}{$\begin{array}{c}\text { BCP-409 } \\
\text { Run } 16\end{array}$} & $\mathrm{H} 2$ & 8.0106 & 0.4343 \\
\hline & $\mathrm{O} 2$ & 1.8531 & 2.6609 \\
\hline & $\mathrm{N} 2$ & 9.6483 & 7.5798 \\
\hline & $\mathrm{CH} 4$ & 1.0337 & 0.1321 \\
\hline & $\mathrm{CO}$ & 0.2010 & 0.0000 \\
\hline & $\mathrm{CO} 2$ & 0.2527 & 0.0214 \\
\hline & $\mathrm{C} 2 \mathrm{H} 6$ & 0.8184 & 0.1020 \\
\hline & $\mathrm{H} 2 \mathrm{~S}$ & 8.5753 & 0.7223 \\
\hline & $\mathrm{C} 3 \mathrm{H} 6$ & 0.0603 & 0.0000 \\
\hline & $\mathrm{C} 3 \mathrm{H} 8$ & 0.7160 & 0.0881 \\
\hline & NC4H10 & 0.2498 & 0.0317 \\
\hline \multirow{9}{*}{$\begin{array}{c}\text { BCP-410 } \\
\text { Run } 17\end{array}$} & $\mathrm{H} 2$ & 8.3329 & 2.0706 \\
\hline & $\mathrm{O} 2$ & 1.6435 & 0.6443 \\
\hline & $\mathrm{N} 2$ & 8.6148 & 3.1759 \\
\hline & $\mathrm{CH} 4$ & 0.2946 & 0.1341 \\
\hline & $\mathrm{CO} 2$ & 0.2132 & 0.0440 \\
\hline & $\mathrm{C} 2 \mathrm{H} 6$ & 0.2326 & 0.1050 \\
\hline & $\mathrm{H} 2 \mathrm{~S}$ & 9.6701 & 2.2577 \\
\hline & $\mathrm{C} 3 \mathrm{H} 8$ & 0.2132 & 0.0880 \\
\hline & NC4H10 & 0.0000 & 0.0218 \\
\hline \multirow{10}{*}{$\begin{array}{c}\text { BCP-411 } \\
\text { Run } 18\end{array}$} & $\mathrm{He}$ & 0.0101 & 0.0083 \\
\hline & $\mathrm{H} 2$ & 8.7743 & 1.9573 \\
\hline & $\mathrm{O} 2$ & 1.4515 & 0.1204 \\
\hline & $\mathrm{N} 2$ & 8.0577 & 4.3133 \\
\hline & $\mathrm{CH} 4$ & 0.2338 & 0.0816 \\
\hline & $\mathrm{C} 2 \mathrm{H} 6$ & 0.1663 & 0.0656 \\
\hline & $\mathrm{H} 2 \mathrm{~S}$ & 9.9042 & 2.2205 \\
\hline & $\mathrm{C} 3 \mathrm{H} 6$ & 0.0635 & 0.0204 \\
\hline & $\mathrm{C} 3 \mathrm{H} 8$ & 0.1774 & 0.0801 \\
\hline & NC4H10 & 0.0000 & 0.0282 \\
\hline
\end{tabular}




\section{Appendix E.}

\section{NMR Results}

The results presented herein are the ones obtained from the Western Research Institute in Laramie, WY. These results are presented as received with curve fit and the calculations performed by the scientist. The legend for the samples is as follows

\begin{tabular}{|c|c|c|c|c|}
\hline Reactor & $\begin{array}{c}\text { Reaction } \\
\text { Temperature }\end{array}$ & $\begin{array}{c}\text { Reaction } \\
\text { Pressure }\end{array}$ & Solvent & Gas Phase \\
\hline $\mathrm{BCP}-397$ & $350^{\circ} \mathrm{C}$ & $1000 \mathrm{psig}$ & $\mathrm{V}-1074$ & $\mathrm{H}_{2}$ \\
\hline $\mathrm{BCP}-399$ & $390^{\circ} \mathrm{C}$ & $1000 \mathrm{psig}$ & $\mathrm{V}-1074$ & $\mathrm{H}_{2}$ \\
\hline $\mathrm{BCP}-400$ & $425^{\circ} \mathrm{C}$ & $1000 \mathrm{psig}$ & $\mathrm{V}-1074$ & $\mathrm{H}_{2}$ \\
\hline
\end{tabular}


Sample: BCP397

integralion of ${ }^{14} \mathrm{C}$ CF Spectrum

A.99 $\quad 177.7000$

Ato.24 $\quad 562.5000$

$A_{41024} \quad 00000$

$A_{1501159} \quad 32.60000$

A

$A_{1.5-150} \quad 40.5000$

A.25 $\quad 68.0000$

$A_{50}$ of

$A_{0000}$

${ }^{2}$ C Spectrum Dipolar Dephasing

$\mathrm{M}_{0}^{\mathrm{CH}} \quad 0.3349$

$M^{C} \quad 0.6651$

$T_{\nu: 4^{0}}$

$\mathrm{T}_{\mathrm{w}}{ }^{\mathrm{L}}$

Elemental Analysis

श्र

\% $\mathrm{H}$

MW

$(H / C)_{T} \quad$ \#VALUE!
Date:

\begin{tabular}{|c|c|}
\hline$f_{\mathrm{rg}}$ & 0.7599 \\
\hline$f_{31}$ & 0.5401 \\
\hline $\mathrm{l}_{\mathrm{Ar}}{ }^{1}$ & 0.7590 \\
\hline too & 0.0000 \\
\hline $\mathrm{r}_{\mathrm{yr}}{ }^{\circ}$ & 0.0440 \\
\hline$i_{a r}{ }^{5}$ & 0.0547 \\
\hline $\mathrm{f}_{\mathrm{al}}^{\mathrm{MHOCOA}}$ & 0.0919 \\
\hline$f_{31}^{L{ }^{L} H C H 2}$ & 0.1482 \\
\hline$f_{3 i}^{6}$ & 0.0000 \\
\hline$f_{B r}$ & 0.3349 \\
\hline & 0.6651 \\
\hline$I_{H}$ & 0.2545 \\
\hline $\mathrm{I}_{71}{ }^{\mathrm{C}}$ & 0.5054 \\
\hline$f_{3} x^{y}$ & [0. 4057 \\
\hline $\mathrm{IJr}^{38}$ & 0.1500 \\
\hline $\mathrm{x}_{\mathrm{b}}$ & 0.5351 \\
\hline$X_{\mathrm{u}}^{\prime}$ & 0.3929 \\
\hline$x_{6} "$ & 0.5 .373 \\
\hline
\end{tabular}

Structural Parameters;

28.023

$\mathrm{C}_{\mathrm{al}} \quad$ HVALUE!

sigma+1 3.642

$P_{\mathrm{n}} \quad 0.0690$

BL $\quad 0.254$

SC $\quad 3389$

MW HVALUE!

Camments Brad Backrath sample ECP397, Deconvoluled spectre, $T$ peaks

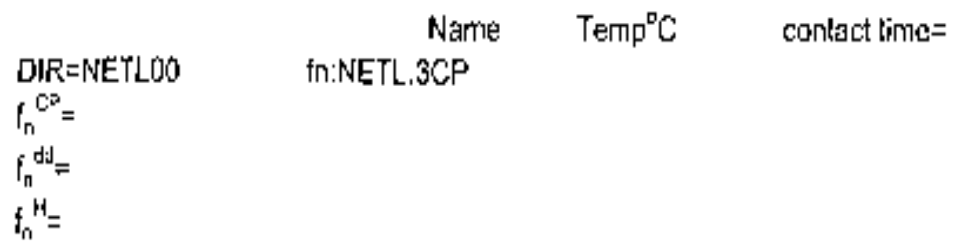


Sample: BCFag7

Integration of 'de CP Spectrum

409180.5000

A $240 \quad 571.2000$

A $165240 \quad 0.0 \$ 00$

$A_{150.185} 20.4000$

Ago IES 579.2000

$A_{115.150} \quad 96.7000$

A.7: $\quad 80.4000$

$A_{\text {Man }}$

A.r.:s

${ }^{14}$ C Spectrum Dipolar Dephasing

H. $^{\text {वा }} \quad 0.3349$

$M_{0}{ }^{C} \quad 0.6651$

$T_{\mathrm{dg}}^{\mathrm{d}}$

$T_{\text {dd }}{ }^{L}$

Elemental Analysis

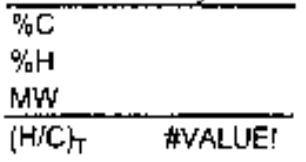

Date: 320.00

\begin{tabular}{|c|c|}
\hline$f_{7 r}$ & 0.7509 \\
\hline$f_{31}$ & 0.2491 \\
\hline$f_{A r}$ & 0.7509 \\
\hline$f_{\infty}$ & 0.0000 \\
\hline $\mathrm{r}_{\mathrm{s}}$ & 0.0268 \\
\hline & 0.1271 \\
\hline $\int_{3}\left[\begin{array}{ll}1300+3 \\
3\end{array}\right.$ & 0.1162 \\
\hline$\Gamma_{31}^{014012}$ & 0.1329 \\
\hline$f_{11}=0$ & 0.0000 \\
\hline$\because \mathrm{H}$ & 0.3349 \\
\hline & 0.6651 \\
\hline $\mathrm{LH}$ & 0.2515 \\
\hline $\mathrm{P}_{\mathrm{gr}}^{\mathrm{C}}$ & 0.4994 \\
\hline$f{ }^{r}$ & 0.3455 \\
\hline$r_{\mathrm{ar}} g$ & 0.2050 \\
\hline$x_{b}$ & 0.4601 \\
\hline$K_{1}^{\prime}$ & 0.3657 \\
\hline$x_{b} "$ & $0461 B$ \\
\hline
\end{tabular}

\section{Structural Parameters:}

$\begin{array}{lc}\mathrm{C}_{\sharp} & 22.330 \\ \mathrm{C}_{\text {al }} & \text { HW/ALLEI } \\ \text { sigma+1 } & 4.579 \\ \mathrm{P}_{\square} & 0.2451 \\ \mathrm{BL} & 1.127 \\ 5 \mathrm{C} & \mathbf{3 . 4 5 6} \\ \text { WW } & \text { \#WALLE! }\end{array}$

Cortituents Brad Bockath sariple BCP397, Deponwoluted spectra, B peaks $50 \%$ Gaussian

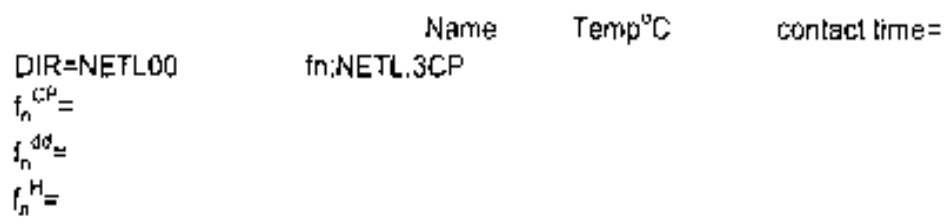


Sample: BCP399

Integration of '"CCP Spectum

$A_{1 \rightarrow 00} \quad 215.7000$

$A_{00270} \quad 541,6060$

$A_{105-2+10} \quad 0.0000$

A 180180000

A $54-105 \quad 541.6000$

$A_{130-180} \quad 56.7000$

A.9.5 $\quad 109.2000$

$A_{60+00}$

A

${ }^{13} \mathrm{C}$ Spectiom Dopolar Dephoshg

$\mathrm{H}_{0}{ }^{\mathrm{CP}} \quad \mathbf{0 . 5 3 4 2}$

$M^{\mathrm{C}} \quad 0.4658$

$T_{\phi 0}{ }^{0}$

$T_{\text {tut }}{ }^{\mathrm{L}}$

Elemental Aratsh

\begin{tabular}{|c|c|}
\hline Ale: & 3.28 .90 \\
\hline & 0.7152 \\
\hline & 0,2848 \\
\hline & 0.7152 \\
\hline & 0.0000 \\
\hline & 0.0248 \\
\hline & 0.0736 \\
\hline OCHA & 0.1442 \\
\hline & 0.1408 \\
\hline & 0.0000 \\
\hline & 0.5342 \\
\hline & 0.4658 \\
\hline & 0.3620 \\
\hline & 0.3931 \\
\hline & 0.2348 \\
\hline & 0.1376 \\
\hline & $0.32 \mathrm{Ag} 2$ \\
\hline & 0.3141 \\
\hline & 0.3000 \\
\hline
\end{tabular}

$\mathbf{~ \$ C}$

\$ي

MW

(HC)T WALUE!

Structural Paramaters:

C. 16.140

C. WALUE!

sigmat1 2.220

$P_{\mathrm{a}} \quad-0.4658$

BL. $\quad-1.034$

SC $\quad 3.254$

MW WVLUEI

Conments: Erad Boxdoath samplo BCP399, deconnoluted spectra, 7 peaks $50 \%$ Gglegsan

Hame Temp"C conbet tmo=

$I_{f}^{C P}=$

$f_{n+2}^{*}$

$r_{n}=$ AT:NETL.2CP 
Sample: 8CP399

Integration of ${ }^{13} \mathrm{C}$ CP Speetrum

A 217.00000

A 02000528.5000

A 10524000000

A 150 15: 15000

$A_{00165} \quad 528.5000$

$A_{136-150} \quad 106.6000$

A 0.25 .101 .1000

A

A

${ }^{34} \mathrm{C}$ Spectum Dipolar Dephasing

$\mathrm{M}_{0}^{\mathrm{CH}} \quad \mathbf{0 . 5 3 4 2}$

$M_{0}{ }^{C} \quad 0.4656$

$T_{\text {dit }}{ }^{3}$

$T_{a}{ }^{L}$

Elmantantal Andjols

\section{\%O}

$\% \mathrm{H}$

$M W$

(H/C)T WALUE!
Date: $\quad 3.28 .00$

\begin{tabular}{|c|c|}
\hline F & 0.7099 \\
\hline 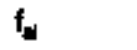 & 0.2911 \\
\hline$y$ & 0.7089 \\
\hline 400 & 0.0000 \\
\hline & 0.0205 \\
\hline & $\phi .1430$ \\
\hline & 0.1350 \\
\hline & 0.1555 \\
\hline $\mathrm{f}_{\boldsymbol{4}}^{\mathrm{C}}$ & 0.0000 \\
\hline & 0.5342 \\
\hline & 0.4658 \\
\hline & 0.3787 \\
\hline & 0.3302 \\
\hline & 0.1667 \\
\hline & 0.2307 \\
\hline & 0.2351 \\
\hline$x_{6}$ & 0.2335 \\
\hline$x_{4}^{\prime \prime}$ & 0.2699 \\
\hline
\end{tabular}

\section{Structural Parameters:}

$\begin{array}{lc}C_{y} & 11.257 \\ C_{d} & \text { \#VAUEI } \\ \text { sigma+1 } & 2.596 \\ \text { Po }_{0} & 0.1706 \\ \text { BL } & 0.443 \\ \text { SC } & 2.153 \\ \text { HW } & \text { NALUEI }\end{array}$

Comments: Bred Bockagth sample BCP399, decorwoluted spectre, 8 peaks $50 \%$ Gaussian

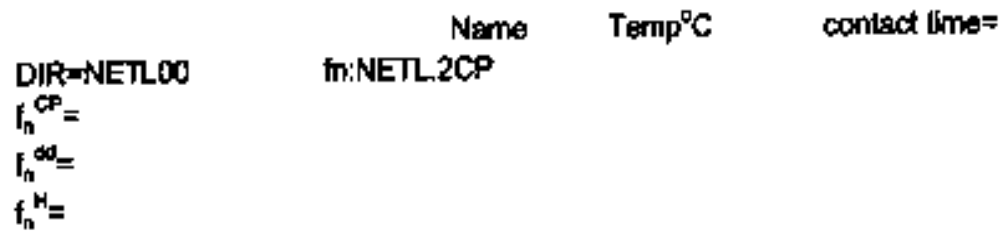


Sample: BCP400

Integratlon of "C CP Specirum

$A_{000} \quad 148.1000$

Ans:20 554.5000

$A_{180-400} \quad 0.0000$

$A_{190-195} \quad 13.9000$

A 0 - 554.5000

$A_{135} \quad 46.5000$

$A_{0,25} \quad 69.2000$

Angon

A tarka

${ }^{14} \mathrm{C}$ Spectrum Dipolar Dephasing

$\begin{array}{ll}M_{0}{ }^{2+} & 0.5040 \\ M_{0}{ }^{C} & 0.4960 \\ T_{d 0}{ }^{6} & \\ T_{d o}{ }^{L} & \end{array}$

Elementel Analysh

\section{FC}

钻H

$m$

(WC) T WALUE!
Date: $\quad 32600$

\begin{tabular}{|c|c|}
\hline I & 0.7802 \\
\hline$f_{0 u}$ & 0.2100 \\
\hline & 0.7692 \\
\hline & 0.0000 \\
\hline & 0.01988 \\
\hline & 0.0662 \\
\hline & 0.0985 \\
\hline & 0.1123 \\
\hline$f_{-\infty}^{\infty}$ & 0.0000 \\
\hline & 0.5040 \\
\hline & 0.4960 \\
\hline & 0.9978 \\
\hline & 0.3914 \\
\hline & 0.3055 \\
\hline & 0.9089 \\
\hline$x_{4}$ & 0.3871 \\
\hline$x_{t^{\prime}}^{\prime}$ & 0.3418 \\
\hline$x_{\phi}{ }^{\prime}$ & 0.4374 \\
\hline
\end{tabular}

Structural Parameters:

C. 18958

C. WALUE!

algma+1 2.065

$P_{0} \quad-0.1457$

BL $\quad-0.901$

SC $\quad 2366$

WHe WVLLUEI

Cominents: Brad Bockurath sample BCP400, deconwoluted spectra, 7 peaks 50 \% Geussian

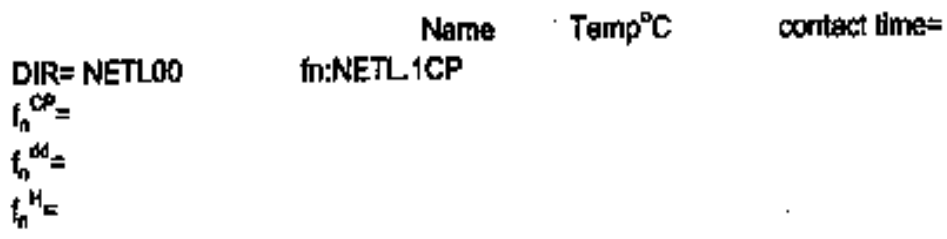


Sample: BCP400

Integration of ${ }^{13} \mathrm{C}$ CP Spectnum

A $0-8 \quad 152.6000$

$A_{00-240} \quad 5 \$ 0.7000$

$A_{15-200} \quad 0,0000$

$A_{150165} \quad 10.8000$

A $50-1650.7000$

$\mathrm{A}_{135-190} \quad 96.5000$

A $0.25 \quad$ 72,6000

$A_{\operatorname{mix} \rightarrow 0}$

A

${ }^{7} \mathrm{C}$ Spectrum Dipoler Dephasing

$\mathrm{M}_{0}{ }^{\text {LF }} \quad 0.5040$

$\mathrm{M}_{0}^{\mathrm{C}} \quad 0.4960$

$T^{\circ}$

$T_{\infty x}$

Elempanal Anglyods

XC

$\% \mathrm{H}$

MW

$\overline{\text { WICh }}$ WVAUEI

Structural Parameters:

C. $\quad 14,620$

C. WALUEI

Egma+1 2, 849

$P_{0} \quad 0.3234$

BL $\quad 0.921$

SC $\quad$ : 927

NW FALUEl

Comments Erad Bockrath sampla BCP400, deconroluted spectra, 8 peaks 50 \% Gauselari

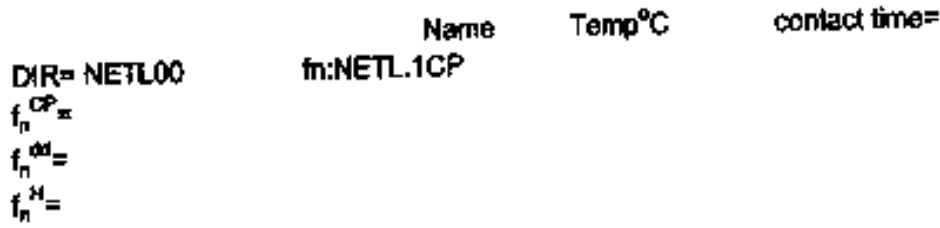

Date: $\quad 3.26 .00$

\begin{tabular}{|c|c|}
\hline$f_{\text {rr }}$ & 0.7830 \\
\hline$t_{\mathbf{z}}$ & 0.2170 \\
\hline & 0.7630 \\
\hline$f_{c o}$ & 0.0000 \\
\hline & 0.0154 \\
\hline & 0.1372 \\
\hline $\mathrm{H}_{\mathrm{A}}^{\mathrm{CH}}$ & 0.1032 \\
\hline$t_{\mathrm{d}}^{\mathrm{OHCH}}$ & 0.1137 \\
\hline$f_{0}$ & 0,0000 \\
\hline & 0.5040 \\
\hline & 0.4960 \\
\hline & 0.3946 \\
\hline & 0.3984 \\
\hline & 0.2358 \\
\hline 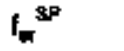 & 0.1948 \\
\hline$x_{4}$ & 0.3012 \\
\hline$x_{t}^{\prime}$ & 0.2946 \\
\hline$x_{b}{ }^{*}$ & 0.3594 \\
\hline
\end{tabular}


Summary of NMR Aromaticities of NETL Samples

Sample Solid-State Results Liquid-State Results

$\begin{array}{lccccc} & \mathrm{CP} & \mathrm{SP}^{\mathrm{b}} & \mathrm{C} & \mathrm{H} & \\ \text { BCP-397 } & 0.73 & 0.74 & 0.700 & 0.361 & 28.3 \% \text { insolubles } \\ \text { BCP-399 } & 0.69 & 0.70 & 0.609 & 0.297 & 12.8 \% \text { minglubles } \\ \text { BCP-400 } & 0.78 & 0.75 & 0.712 & 0.409 & 18.8 \% \text { insolubles } \\ \text { V1074 } & & & 0.374 & 0.165 & \text { Completaly soluble }\end{array}$

- Cross Polarizasion, ' Single Pulse 
Tahle 3. Definition of Parameters for Dipolar Dephasing and Cross Polarization NMR Techniques

Definition of Parameter Measured and Calculated

Total intensiry of aromatic carbors

at dephasing time, $\tau$

$M(t)=M_{0}{ }^{0} \exp \left(-0.5\left(t T_{26}\right)^{2}+M_{L}{ }^{4} \exp \left(-1 / T_{\mathfrak{L}}\right)\right.$

Intensity of protonated anomatic carbons at $\tau=0$

$\mathrm{H}_{0}{ }^{\mathrm{O}}$

Intensity of non-protonatod momatic carbons at $t=0$

$\mathrm{M}_{\mathbf{L}}^{0}$

Gálssian component of dipoler dephasing relaxation time constunt

$T_{\text {4 }}$

Loreutzimin component of dipolar dephasing relexxition time constmat

$\mathrm{T}_{\mathbf{1}}$

Dephasing time

$$
1
$$

Aliphatic carben tintegrated are from 0-90 ppu

$A^{0.90}$

Carbonyl cabon integrated area from $165-240 \mathrm{ppm}$

$A^{165-201}$

Aronatic and carbonyl carbon integrated area from 90-240 ppm

$$
\mathbf{A}^{\mathbf{4 0 4 0}}
$$

Phenolic carbon integrated arta fom 150-165 Ppm

$$
\mathrm{A}^{\text {150165 }}
$$

Alky] gubstitinted aromic cubon imtegrated ares from $135-150 \mathrm{ppm}$

$$
A^{131-106}
$$

Aromatic catoons integated area

$$
\text { from } 90-165 \mathrm{ppm}
$$

$A^{90-165}$

Aliphatic cerbons bonded to oxygen integnted aroa

$$
\text { from 50-90 pim }
$$

$$
A^{51-90}
$$

Metboxy carbon integrated arta from $50-60 \mathrm{ppm}$

$$
A^{5060}
$$

Methyl caboo intogroted area from 0-25 ppm

$$
A^{\text {an-3 }}
$$


Table 4. Calculation of Structural and Lattice Pammeters

Defintitiou

Formula

Stractural Parameters

-t. Fraction of total sp' carbon (f)

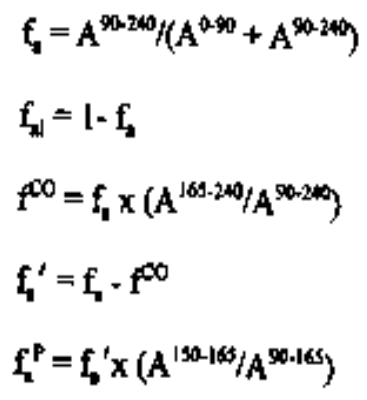

-2. Fraction of total $\mathrm{sp}^{\mathrm{j}}$ cation (f,

3. Fraction of cabonyl carbous (for)

i4. Fraction of aromatic carbons (f ${ }^{\prime}$ )

5. Fraction of phenolic ertane (f.,

6. Fraction of alkyl sabstituted surontate carbons ( $f^{5}$ )

$f^{3}=f^{\prime} x\left(A^{\left.155 \cdot 150 / A^{90-166}\right)}\right.$

7. Fraction of methyl and methory carton( $\left.f_{1}\right)$

$f_{1}^{*}=f_{1 \mid}\left\{\left(A^{0-25}+A^{5060}\right) / A^{0.90}\right\}$

8. Fraction of methine and mothylene carbon $\left(\mathrm{f}_{\mathrm{J}}{ }^{\mathrm{H}}\right)$

$f_{d^{\prime}}^{H}=f_{l}-f_{i}^{*}$

9. Fraction of aliphatic carbons bonded to oxygen ( $f_{1}$ )

$f_{1}=f_{1}\left(A^{30-9 / A^{0-30}}\right)$

10. Fraction of quatemary ammatic artons ( $f$, )

$f^{Q}=M_{L}{ }^{p} /\left(M_{L}{ }^{0}+M_{G}{ }^{0}\right)$

11. Fraction of Tertiary aromatic corbons $\left(f_{2}^{\top}\right)$

$\mathrm{f}^{\mathrm{T}}=\mathbf{l}-\mathrm{f}^{\mathrm{Q}}$

12. Fraction of protonated aromatic carbons norrtalized to total cortbens (f

$f_{1}^{H}=E_{1}^{\prime} \times f_{1}^{T}$

13. Fraction of quatertary arom tic carbens Jonualized to total carbous ( $\mathrm{f}^{\prime \prime}$ )

$f_{1}^{H}=t_{1} \times f_{1}^{\circ}$

14. Fraction of aromatic bridgehead carbons $\left(\mathrm{f}^{\mathrm{B}}\right.$ )

$\mathrm{f}^{\mathrm{B}}=\mathrm{f}^{\mathrm{C}^{2}}-\mathrm{f}_{1}^{\prime}-\mathrm{f}^{\mathrm{s}}$

\section{Lattice Parameters}

15. Mole fraction of bridgehead cubona $\left(X_{n}\right)$

$x_{b}=f^{\mathrm{B}} / \mathrm{f}_{\mathrm{i}}$

16. Mole fraction of tridgelped carbons

for linear catenation cluster $\left(\mathbf{X}_{k}\right)$

$\chi_{b^{\prime}}=(1 / 2)-\left(3 / C_{k}\right)$

17. Mole fraction of bridgehead cutrons for circular catenaticn clugter $\left(\alpha_{b}\right)$

$X_{t^{*}}=1-(6 / \mathrm{Car})^{1 / 2}$ 
Table 4. Calculetion of Structural and Latties Parameters, Cont

\section{Definition Fómula}

18. Number of anchatic cerbons per cluster ( $\left.\mathrm{C}_{\mathrm{w}}\right)$

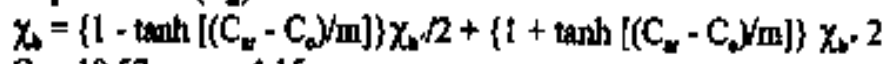

$\mathrm{C}_{\mathrm{g}}=19.57 \mathrm{~m}=4.15$

19. Number of attachments per cluster $(0+1)$

$$
0+1=\left(f^{s}+f_{j}\right) C_{m} / f^{\prime}
$$

20. Fraction of intact bridges per lottice $\left(\mathrm{P}_{2}\right)$

$$
P_{0}=\left(f_{1}^{4}+f_{1}^{P}-f_{1}\right)\left(f_{1}^{5}+f_{i}{ }^{T}\right)
$$

21. Number of bridges and loops per tluster (B.L.)

$$
\text { B.L. }=(0+1) \text {, }
$$

22. Number of side chains per cluster ( $(\mathrm{S}, \mathrm{C}$ )

$$
\text { S.C. }=(\sigma+1)-B . L .
$$

23. Molecular wejght of cluster (Mw)

$$
\mathrm{MW}_{\mathrm{c}}=\left(12 \mathrm{C}_{-}\right) / \mathrm{f}_{\mathrm{f}}^{\prime}(\% \mathrm{C} / 100)
$$

24. Molecular weight per attzchmout

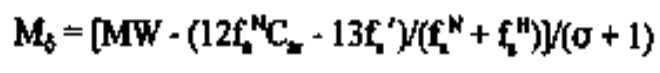


MaI ITR Center

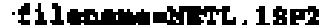

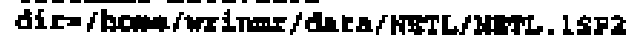

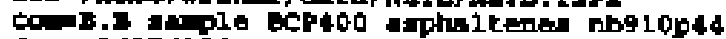

ancestrof $17 / 100$

timaro:07:26

\section{-}

pptin-1pdn

act' $[x+1=300$

by chind

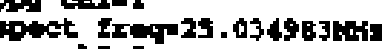

og ehtr.7

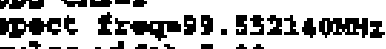

Dite Hathes. Dou

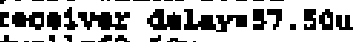

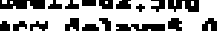

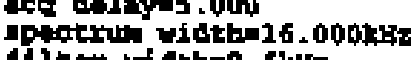

filter Hatb 9 . Skyt

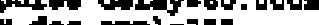

H apo nicis:

rope phaston, 0

Aca lingth-512

Gunpy pulatent

ativ 1erith 10

ect trac32.001m

rocelver Thine16.00

crarst Dityat 0620

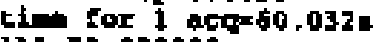

$131=0.00000$

triho1 53,000000

tra1100.00000

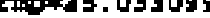

YI-17, 210000

Gurrant atsocios

$y=0410=970,335022$
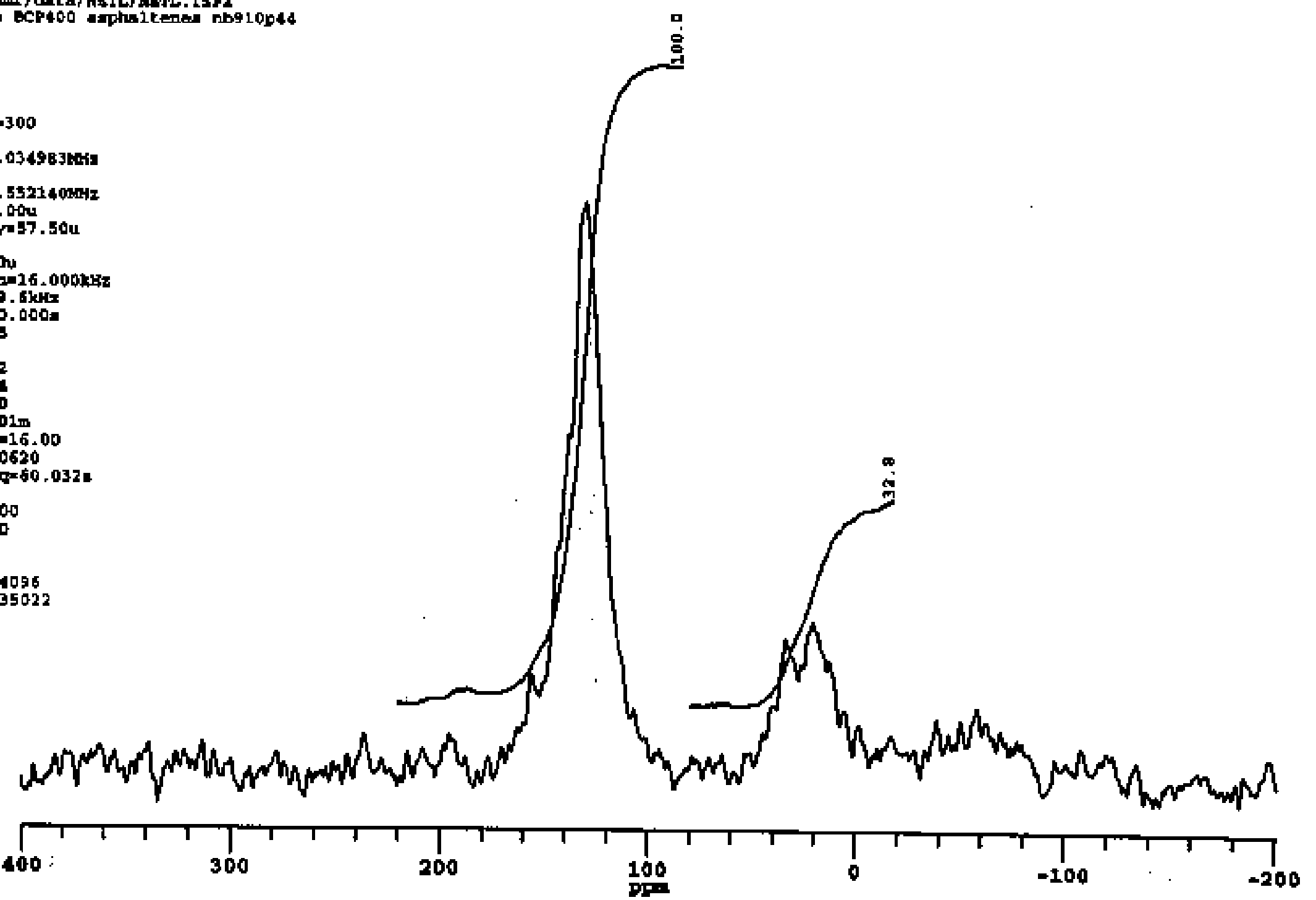
Ar Hor Center

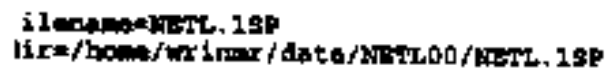

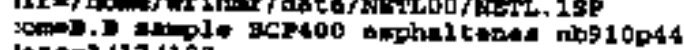

LActas/17/10

:icuag 59 : 24

1c-3600

Iplanjpde.

$7 \cos (x+y+3600$

xp enting

200 th- 2

pules vitth=5, $00 \mathrm{u}$

coceiver tolay=57.50u

s.til=6. Sou

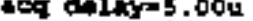

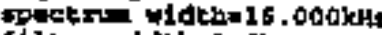

C11ter wdrheg . 6hdr

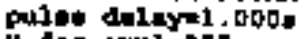

4 ang topers

rec phinto.

act 1 rothrsi2

$\operatorname{tin}_{3}$ thethe

act $t+1-37+601 m$

=16. 0

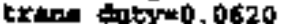

$t$ Lor 1 ectr=2.032:

161050 ; 000000

tpho1-73,000000

tphina +000000

The 25,031099

curxant M1zon 4096

Y ache 271,69395
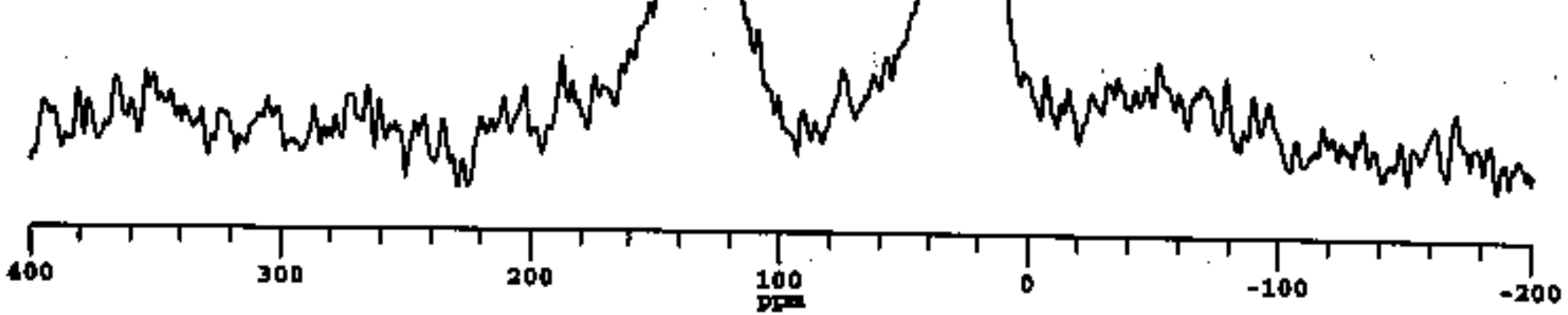
IRr Ha centex

\section{t1 1.}

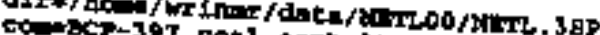

the

timens a 0.100

\section{ac=103}

pptrolpds.

40x' [x 410300

pos chl一e1

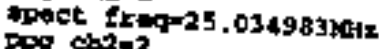

1.

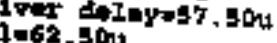

met delays . pou

Pecrat Nidth-16.000kot

pulde deldtheg . 6xth

Hot Apl=255

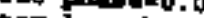

cox longthat 12

dits pulente

dito linth=10

agd 51,-12,001n

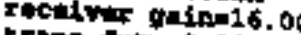

cantomo.0620

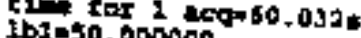

$t$

gtos 54000000

r...-75

2.17. 39099

cturent

Y_enl-757+6724s
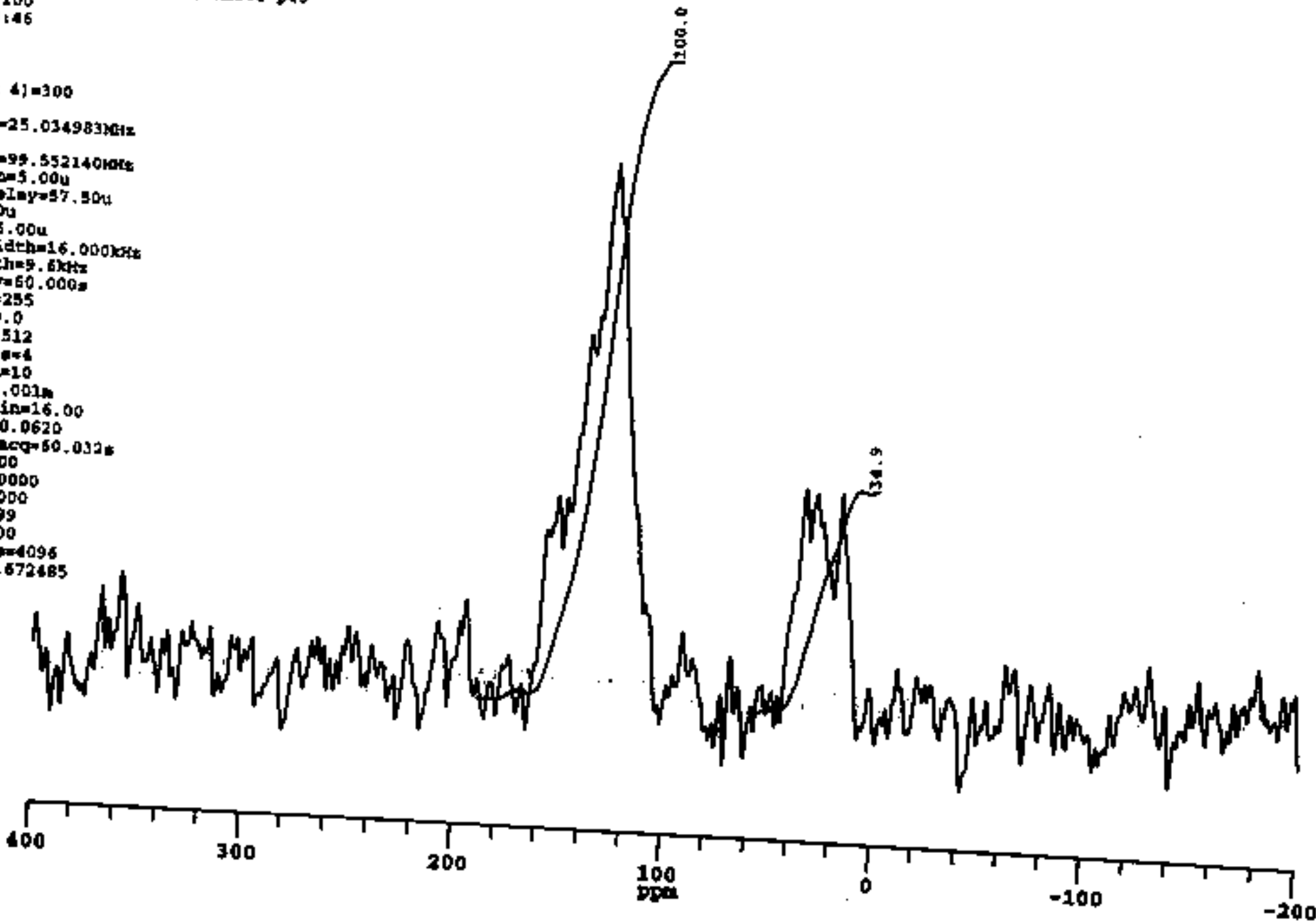
MRI LIR conter

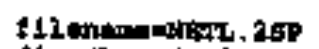

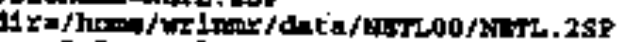

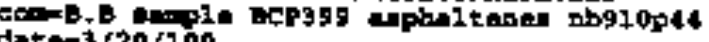

th

no=190

potaripan

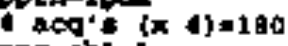

opp ehl一1

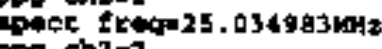

and chr

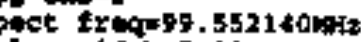

DH1E wachos. bou

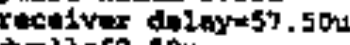

d-11-62 + 50t

rovere widthe 16,000kH

Elit

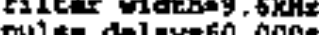

pule daldy

to to

ato 1 ingther

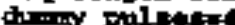

dim 1 rath-10

(5)

Iester vor Tat

res

c1me tor 1 acoso

1.1-50 00000

tph1 1-77 000

FP=25, 033099

\pm IIV-17, 11000

Eurrent ti 10006

4 .
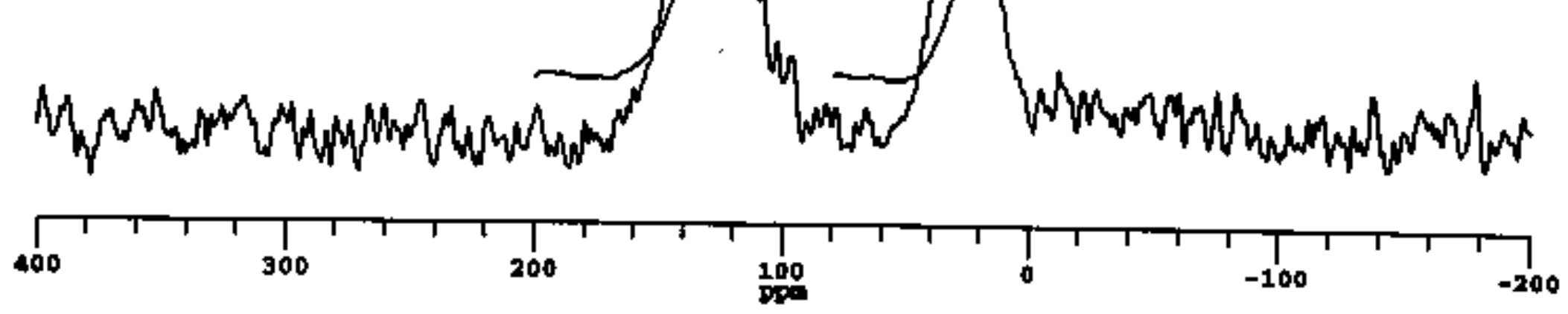
RI na contor

ilemanamiritit. 100

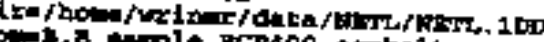

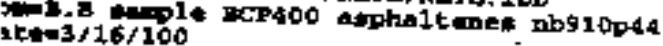

$\ln -15,39: 31$

$=3600$

ifr-intriptofor

1 co 0360

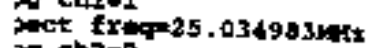

pect Frop-99.55411200s

20 , óononom

satere thand obo

Moitis timel, oth

Falfor deley=57. 50hu

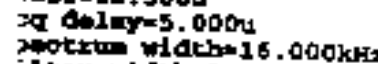

ileter whas

1.e dime1

90 pownes

co porme-75s

detpl powere25s

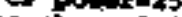

ce phite-0.0

a. 10.thesi.

ir punger

10

4 trit

190.000.00

hot -134 , 00000

h1I=6. 000000

prezs. 93570

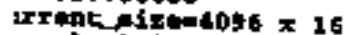

$=01+10000 \times 16$

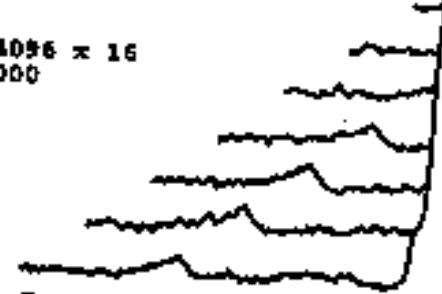

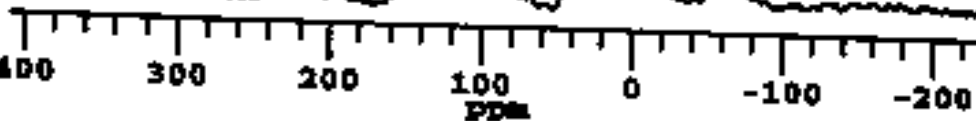




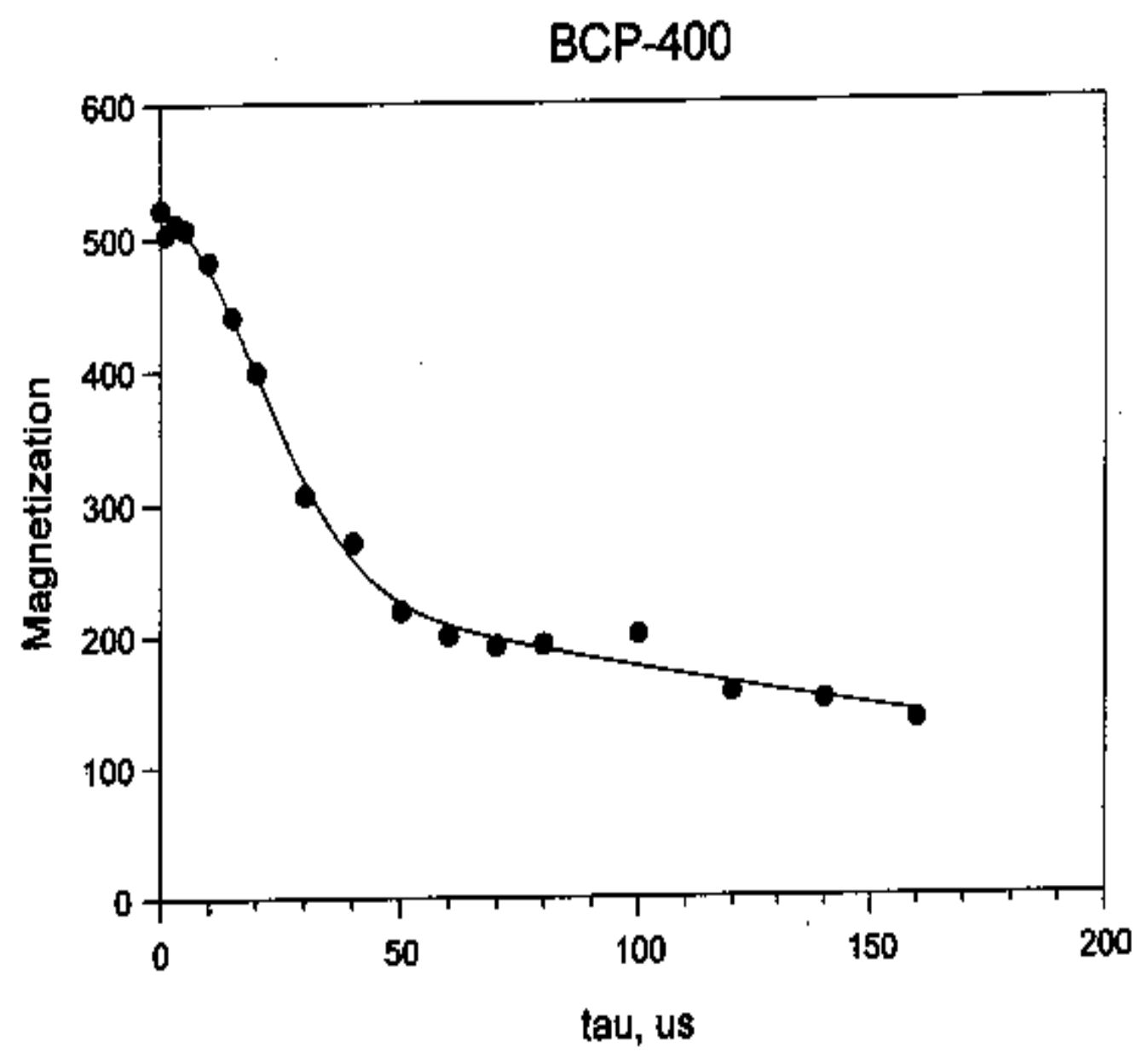


RI rin conter

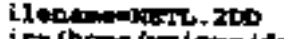

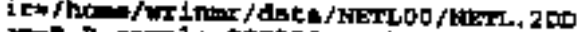

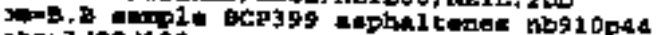

$150=3 / 20 / 100$
$10+16: 22599$

$=0600$

=13600

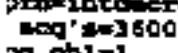

peni=1

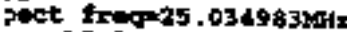

po ahto

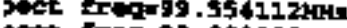

pret 4 .

mot sighes.

roction

-oetrar colays? $500 \mathrm{w}$

Mil-6.500u

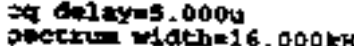

pectum Fathe16 - 000k

11 EF MAtEht9, 6kF:

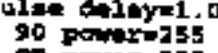

Cr. pamartas

atpl nothes

CF ponteras

ex pingo.a

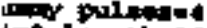

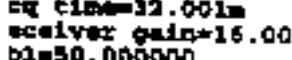

1010-132,000.000

pht1 $=0$. 000000

Den - 23.79

-

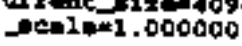
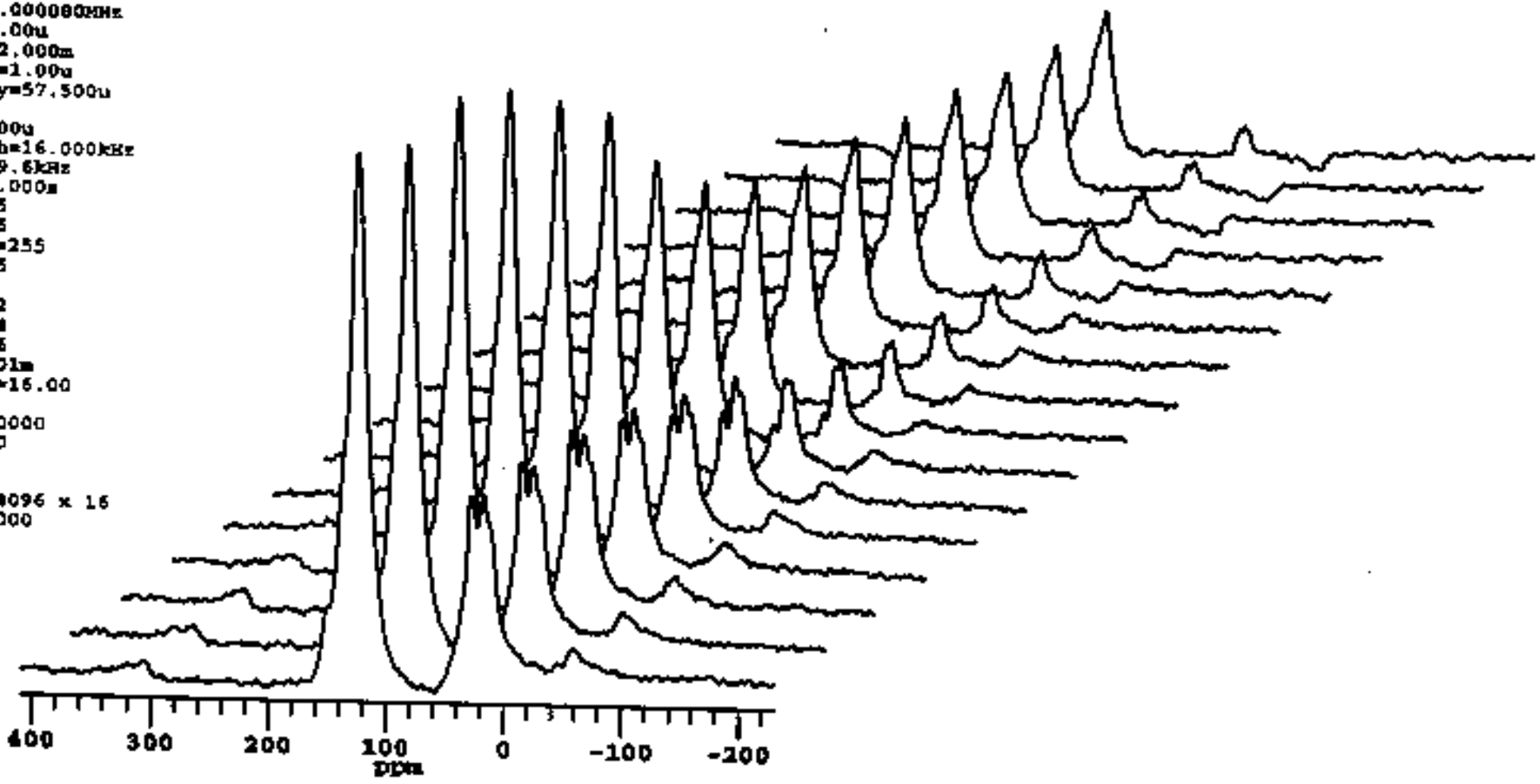


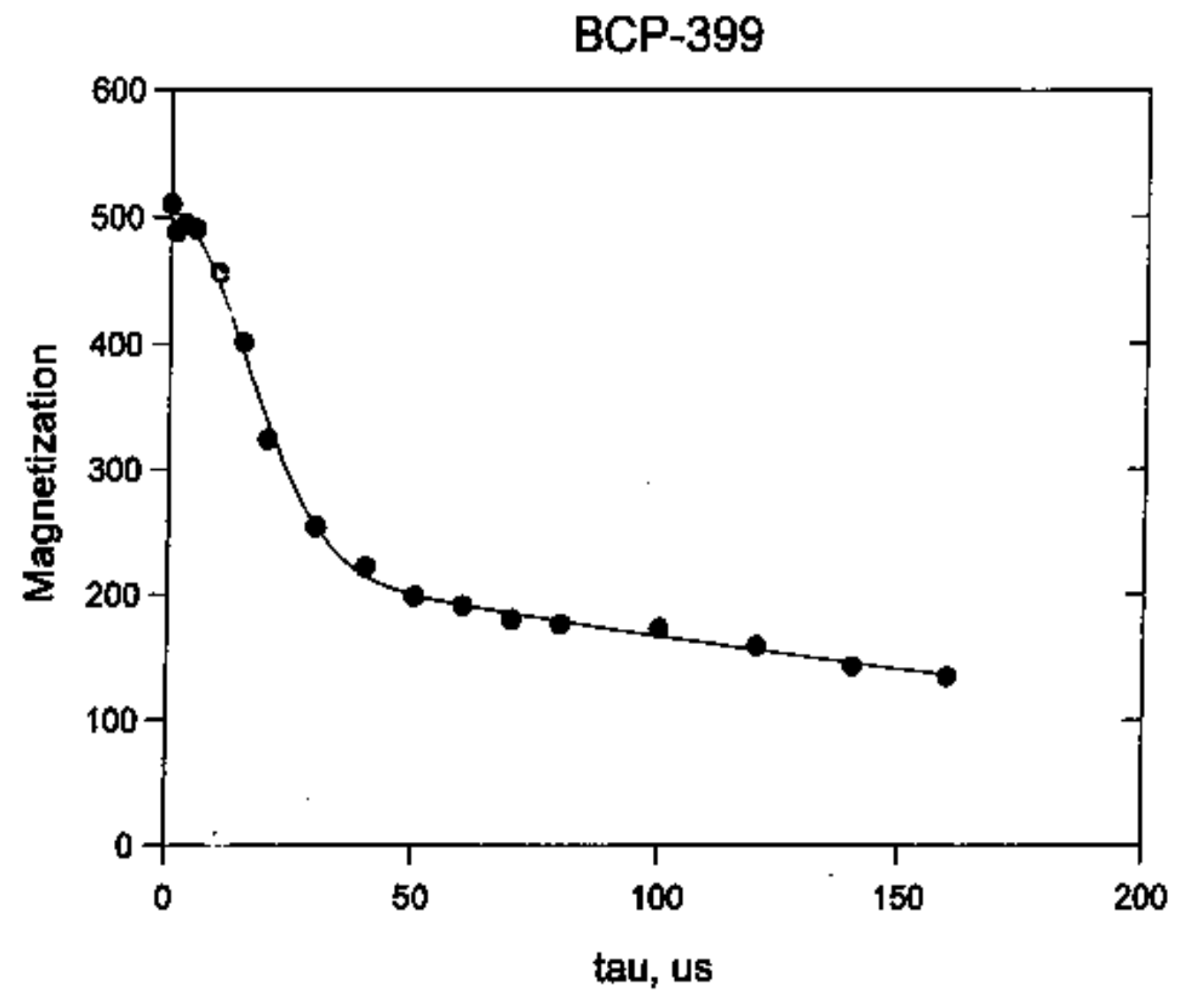




\section{IRI LuR Center}

\section{1 end}

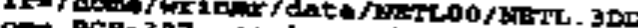

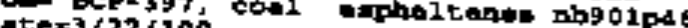

Imens = $5,5: 24$

\section{com 3500}

pte*1ntdecretion

Acrice 500

Peet Extop-25, 034963ritz

Dot cha 2

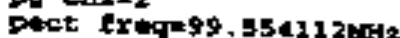

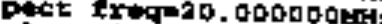

ald wathes, oo

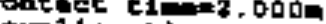

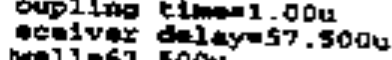

ect delers $000 u$

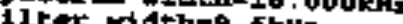

ni. a date 1 .

190 powatem.

t GP penme-75s

incol poukrez5s

Cet ponatas

of pharefo.0

icq 14moth=5:

ing Diliaterd

co tom the 16

tor.

hi=0.

ch11094 00004

He25.037570

$4 \$-33$. 700000

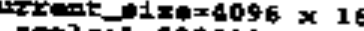

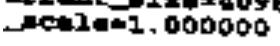

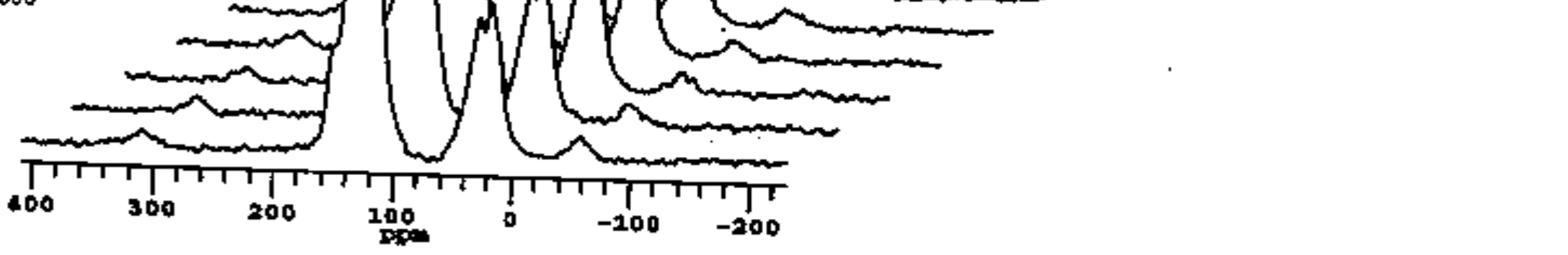




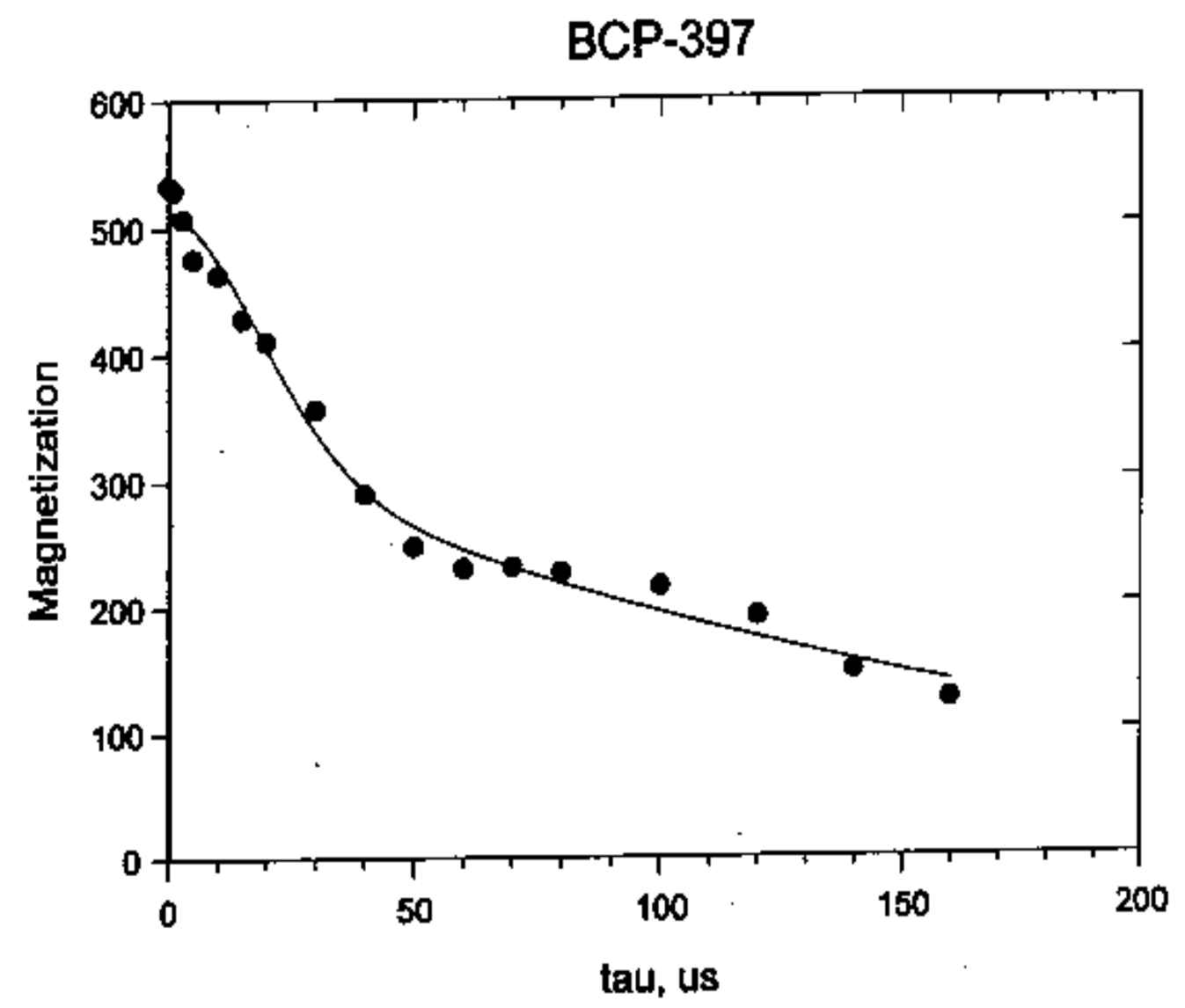




\section{PRT DiR Contor}

\section{Elinnmestert 1}

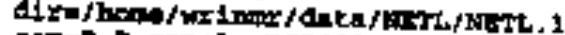

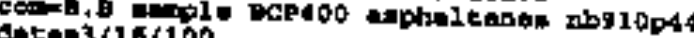

\section{$\cos 3600$}

Fitincos

- Act'ir [x $4+3600$

Fog thi=1

pitet Erect=25 , 034963try For che?

put 1req699.5571404저

pulte with 5 . obs

contace elmor. $2.000 \%$

rectiva delayes - $50 u$

mot.

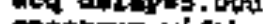

pHerey Hath-15.00dut

Titer Hdebs . Ettr

p on das=1.000a

4 dis portirazs

40p1. potrits \pm 255

and po

a ingth-si2

ding pulpeter

ding

sed cime 31.001 .

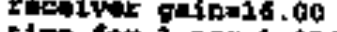

Cis far 1 becte1.034

1hin ary 0.0670

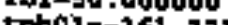

4h1 -161 +213099

$r$ ch

17. 17.71000

curx ant afretos 6

Y_achlogets6.49604

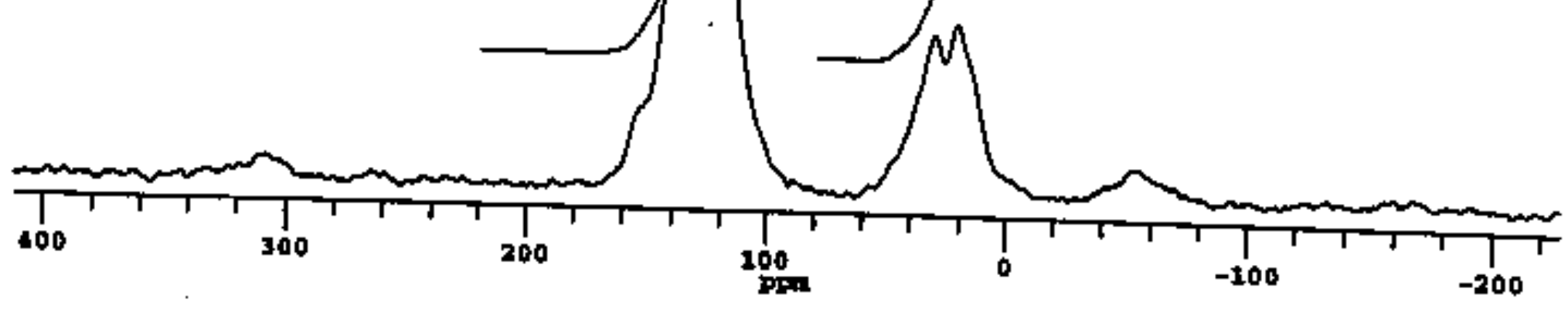




$$
h
$$




\section{IRI H:R Center}

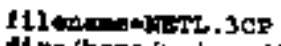

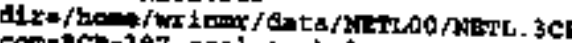

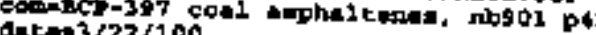

IImeng 40

\section{$\cos 30$ \\ pofring}

1.tex $4 x$ \& $1=3600$

Dos chil =

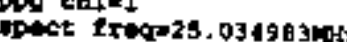

boj eh? 2

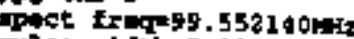

pulet rdebes. Q001

centerat timed. opon

rochut de19y=57.5 du

4611-61. S004

oted blows.00u

tilen wiathos, 5 dot

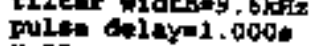

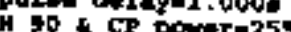

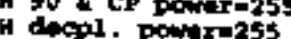

ces phatiano 0

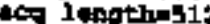

nowit.

dif 1 inothe10

ans $=1-1932.001$

rocelvar on 1 nEl6.00

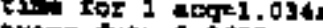

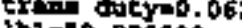

ibicop. 090000

thoie-1so.00000

tonis.

rep=2.033099

(a)

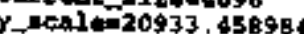

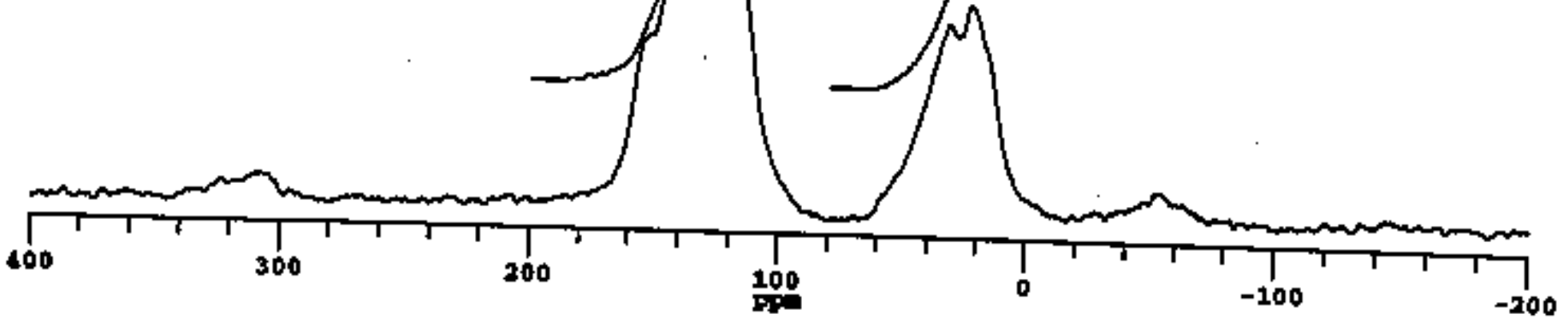




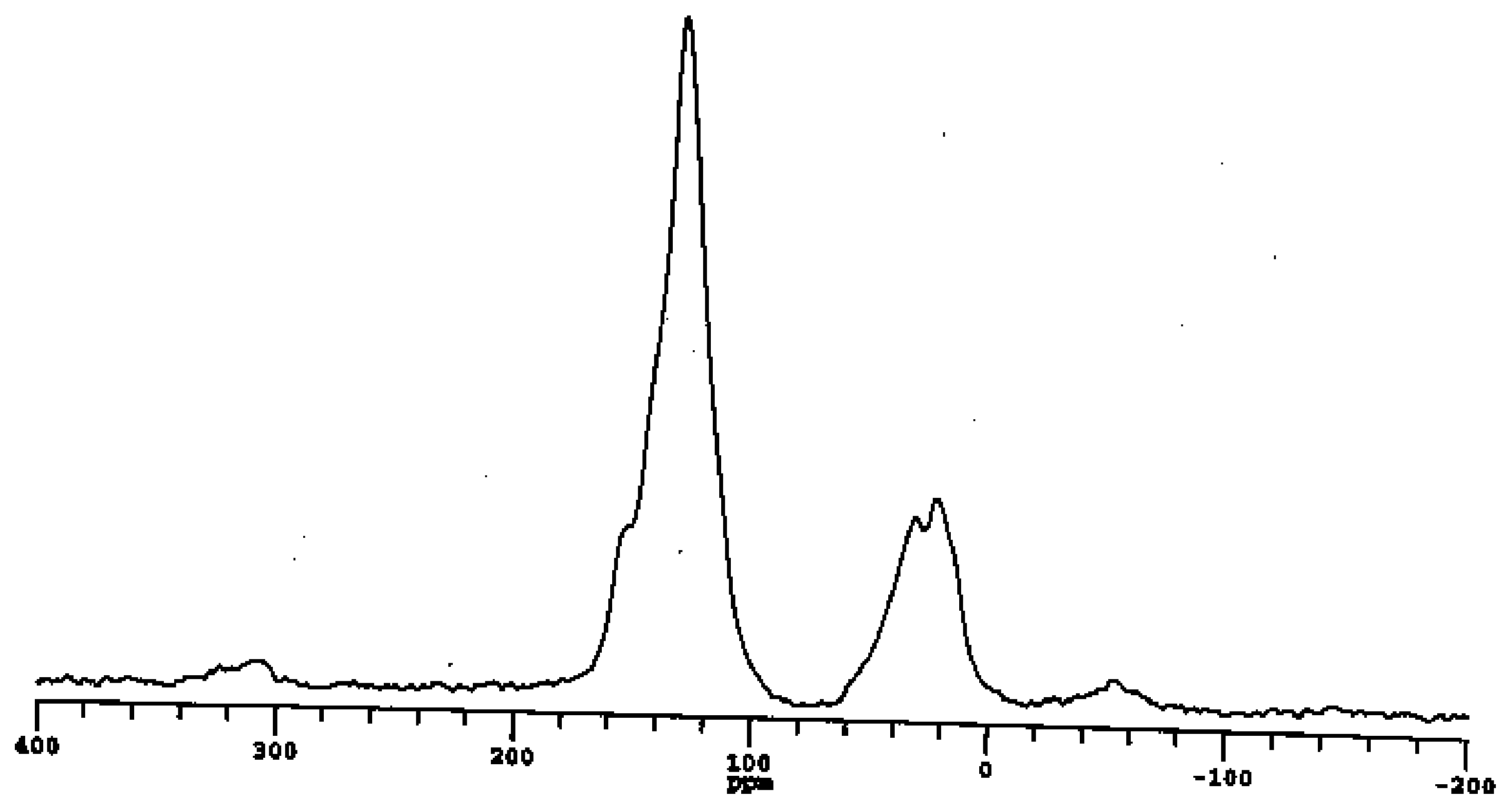


Mr in cante

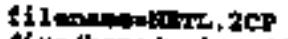

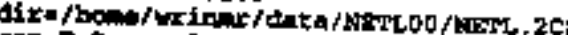

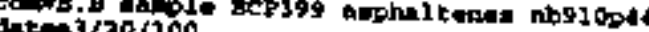
teto-10:4:20

\section{acastopo}

cptancos $\{x$ \& $1=\$ 600$

25.0300000

por traqt25, 03496324x

Wet traq-99, 5521 cowts

pula thathes, 00u

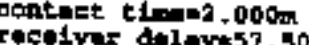

rocelvar doleyt5? . .

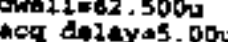

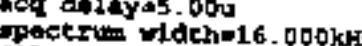

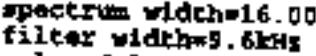

gulfe atay-1.000

$90<$ CP DOHWr-255

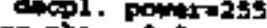

and

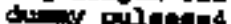

$4 \rightarrow_{1} \rightarrow 0$

ect the $32,001 \mathrm{~m}$

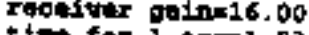

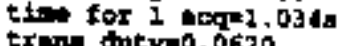

Ibic50.00000

Gino1 172.000000

toh1 1=131.000000

Lipi-25.033099

rTh-77,210000

currobt_e1xard 096

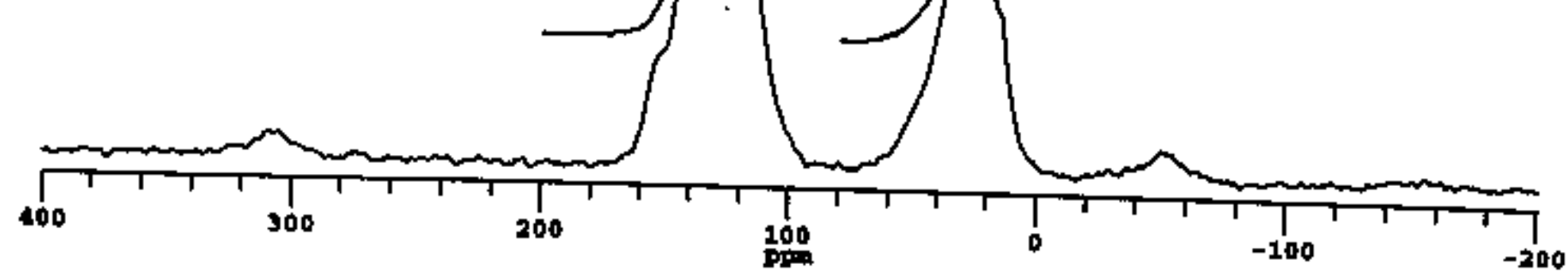




\title{
VITA
}

\author{
Lizbeth Laureano Pérez \\ 1547 Spartan Village Apt. B \\ East Lansing, MI, 48823 \\ $\mathrm{Ph}:$ (517) 355-3065 \\ lizbethlp@hotmail.com
}

\author{
EDUCATION: \\ August 1998 - December 2000 \\ August 1992 - December 1997
}

WORK EXPERIENCE:

February 1998 - May 1998

August 1997 - December 1997

August 1997 - December 1997

January 1997 - July 1997

August 1996 - December 1996

May 1996 - August 1996
WEST VIRGINIA UNIVERSITY, Morgantown Campus $\mathrm{MS}$ in Chemical Engineering

UNIVERSITY OF PUERTO RICO, Mayagüez Campus

BS in Chemical Engineering

\section{RESEARCH ASSISTANT}

Pharmacia \& Upjohn Caribe, Inc., Barceloneta, P.R.

I worked in the development of the Rosenmund filter protocol for its utilization in the Clindamycin Phosphate Process. I also developed documentation relevant for the release of the Clindamycin Phosphate final product.

Supervised by: Carmen Gracia and Mario Rojas

\section{CHEMICAL ENGINEER ASSISTANT}

Chemical Engineering Department, University of P. R., Mayagüez Campus I helped on the analysis, installation, and operation of a digital control system for the automated operation of a distillation column. Supervised by: Dr. Saliceti.

\section{SENIOR PROJECT DESIGN ASSISTANT}

Sponsored by: ERM-Panzardi \& Associates, Cayey, P. R. I worked on the design analysis of an anaerobic digestion / fuel cell system of industrial water treatment plant, to minimize waste load and produce $200 \mathrm{~kW}$ for energy purposes.

Supervised by: Dr. José Colucci (Chemical Engineering Department Director).

\section{CHEMICAL ENGINEER ASSISTANT}

Pharmacia \& Upjohn Caribe, Inc., Barceloneta, P.R.

I worked with the Methylene Chloride air emissions reduction in the Clindamycin $\mathrm{HCl}$ Process. I performed lab scale reductions for future plant scale production. I developed emissions calculations for the Chemical Synthesis Area,and Title V Air Permit. Under the supervision of: Sigfrido García and Aurea Pedraza (Environmental \& Safety Leader).

\section{LABORATORY ASSISTANT}

Chemistry Department, University of P. R., Mayagüez Campus

I assisted the professor in the Physical Chemistry laboratory and performed modifications to experiments under the supervision of Dr. Ismael Scott. I analyzed and tested the program Orbital Interactions Theory for further application in the course.

\section{FELLOW STUDENT}

National Institute of Standards and Technology, Maryland, U. S.

I worked in the Production, Purification, and Characterization of Iodine Endofullerenes for Potential Use in Medical Imaging with the Ionizing Radiation Division. I learned and used several analytical separation techniques. Research Advisors: Dr. Lisa Karam and Dr. Michael Mitch. 
13th International Conference on Chemical Education, InterAmerican University, $P R$. I assisted presenters and participants from the Chemistry and Chemical Engineering fields, in the Registration committee, computer centers, conferences and lectures, laboratories, and the Poster areas. Directed by: Dr. Shiva Sharma.

SKILL AREAS:

- Operating Systems: MS DOS 6.2, MS Windows 3.1, 95

- Programming Language : FORTRAN 77

- Computer Software: MS Word 97, MS PowerPoint 97, Word Perfect 6.0, QUATTRO PRO, MS Excel 97, Lotus 1-2-3, Millenium, Slide Write

- Simulation Program: Heat Exchanger Networks, and PRO/II, Emission Master, TANKS, and VOC.

- Seminars: Oral Presentation and Abstract Preparation; Workgroups development

- Languages: English, Spanish, and a basic knowledge of French.

\section{HONORS:}

Dean's list of the University of Puerto Rico

Magna Cum Laude from University of Puerto Rico, Mayaguez Campus

MEMBERSHIPS:

Tau Beta Pi National Engineering Honor Society, IIQPR, and AICHE. Chemical Engineering Graduate Students Organization, Vice President 